Uma arquitetura de personalização de conteúdo baseada em anotações do usuário 



\title{
Uma arquitetura de personalização de conteúdo baseada em anotações do usuário
}

\author{
Marcelo Garcia Manzato
}

Orientador: Prof. Dr. Rudinei Goularte

Tese apresentada ao Instituto de Ciências Matemáticas e de Computação - ICMC-USP, como parte dos requisitos para obtenção do título de Doutor em Ciências - Ciências de Computação e Matemática Computacional. VERSÃO REVISADA. 
Ficha catalográfica elaborada pela Biblioteca Prof. Achille Bassi e Seção Técnica de Informática, ICMC/USP, com os dados fornecidos pelo(a) autor(a)

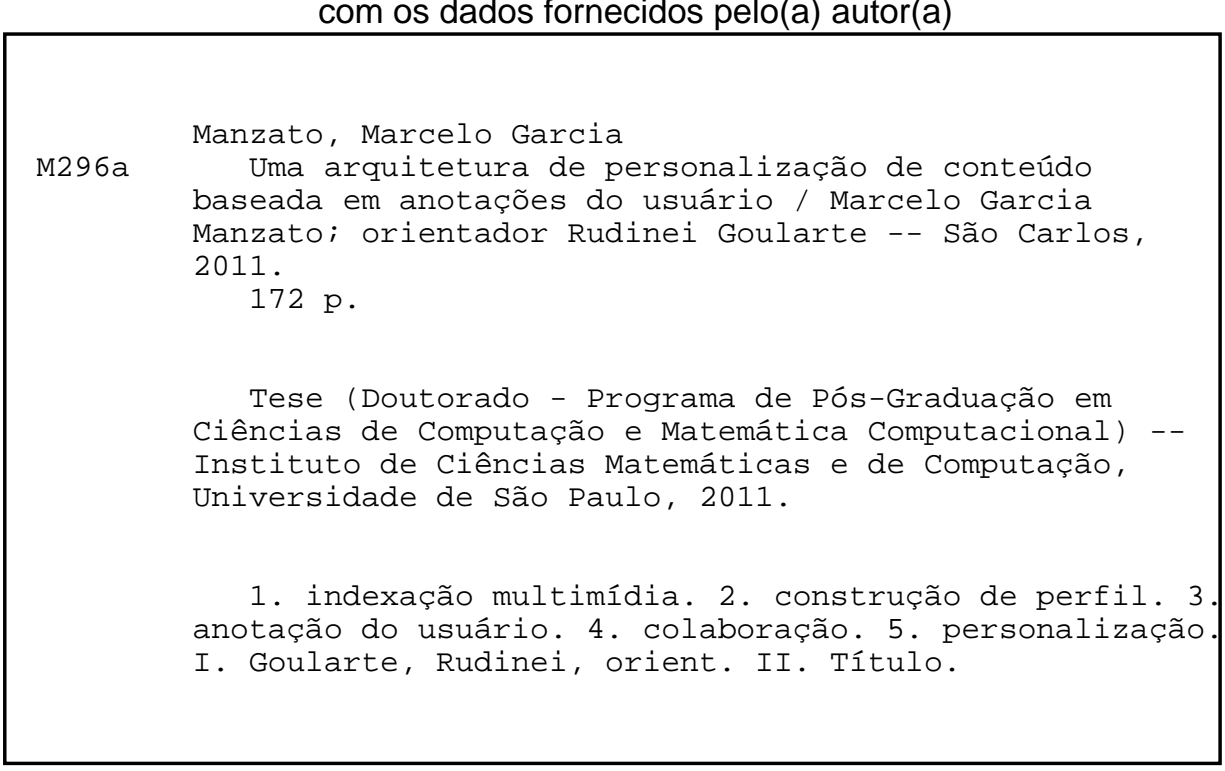


"Pedras no caminho? Guardo todas, um dia vou construir um castelo..."

Fernando Pessoa 



\section{Dedicatória}

Aos meus pais, Lucia e Valdomiro, pelo amor incondicional. Aos meus irmãos, Gustavo e Daniel, pela valiosa amizade. 


\section{Agradecimentos}

Inicialmente, agradeço a Deus por mais esta oportunidade de crescimento em minha vida. São inúmeros os motivos de felicidade, mas alegro-me principalmente com os momentos de dificuldade superados ao longo desta jornada.

Agradeço aos meus queridos pais, Lucia e Valdomiro, pelo apoio recebido em mais esta importante conquista. Eles que guiaram com muito amor meus primeiros passos na vida, e com eles aprendi o verdadeiro sentido das palavras integridade, honestidade e confiança.

Agradeço aos meus inestimáveis irmãos, Gustavo e Daniel, por serem verdadeiros amigos em todas as horas. Sem a companhia deles, os momentos de alegria, conquista e prazer teriam sido menos agradáveis, e os momentos de tristeza, sofrimento e decepção teriam sido mais dolorosos.

Agradeço à minha querida tia Josefa, pelo apoio, dedicação e por sempre ter uma palavra de consolo nas horas difíceis; aos meus avós, Maria (em memória) e Henrique, pelo amor sempre presente; aos meus avós em memória, Gema e José, pelas boas lembranças de minha infância; aos meus padrinhos, Elvira e Hipólito (em memória), pelas agradáveis conversas e simpatia que sempre tivemos; e às minhas irmãs de coração, Maira, Maísa e Cida, pelo carinho de sempre.

Agradeço à minha companheira Carol, que esteve vibrando e sofrendo comigo em todas as fases deste trabalho. Sou grato a ela pelo seu amor, incentivo, confiança e carinho depositados ao longo desta jornada. Teria sido mais difícil sem nossos momentos de lazer, companheirismo e amizade.

Agradeço, em especial, ao meu orientador, Prof. Rudinei Goularte, pelo incontável auxílio e, também, pela amizade e confiança construídas. Grande parte de minha formação profissional eu devo a ele que, ao longo destes sete anos de mestrado e doutorado, contribuiu para o meu aprendizado através de seus incentivos, atendimentos, cobranças e orientações. 
Agradeço à equipe do Centrum Wiskunde \& Informatica (CWI), pelo acolhimento durante o estágio-sanduíche em Amsterdã, na Holanda. Agradeço, em especial, aos pesquisadores Pablo Cesar, Dick Bulterman, Jack Jansen e Rodrigo Laiola, pelas críticas construtivas, aprendizado, momentos de descontração e oportunidades de crescimento profissional e pessoal.

Agradeço ao meu amigo e irmão Michell Macedo, pela confiança, amizade e por ter iluminado meu caminho a serviço do bem. Aos amigos do Posto de Assistência Irmão Áureo, em especial, à Dona Eva, Sr. Donizetti, Cida, Grazi, Hugo e Felipe, pelos momentos de auxílio mútuo tão importantes para minha vida. Agradeço também aos amigos das Associações Espíritas Francisco Thiesen e Obreiros do Bem, pela calorosa simpatia sempre presente.

Agradeço a todos os colegas do ICMC-USP e Laboratório Intermídia, pela receptividade e momentos de lazer; aos professores que me auxiliaram durante o doutorado; e aos funcionários do ICMC-USP, pela prestimosidade nos serviços.

Agradeço aos colegas do CPA Wernher von Braun. O convivio com eles me deu forças para conciliar o tempo dedicado ao trabalho e às pesquisas do doutorado.

Agradeço a todos os companheiros de escalada e ciclismo, por sempre proporcionarem descontração e divertimento, tão importantes nesta fase difícil.

Agradeço ao UOL pelo apoio financeiro concedido durante dois anos do doutorado (programa UOL Bolsa Pesquisa, números de processos: 20080129100700 e 20090205103800).

Agradeço, por fim, a todas as pessoas que, direta ou indiretamente, contribuiram para que este trabalho se realizasse. Obrigado! 


\section{Resumo}

A extração de metadados semânticos de vídeos digitais para uso em serviços de personalização é importante, já que o conteúdo é adaptado segundo as preferências de cada usuário. Entretanto, apesar de serem encontradas várias propostas na literatura, as técnicas de indexação automática são capazes de gerar informações semânticas apenas quando o domínio do conteúdo é restrito. Alternativamente, existem técnicas para a criação manual dessas informações por profissionais, contudo, são dispendiosas e suscetíveis a erros. Uma possível solução seria explorar anotações colaborativas dos usuários, mas tal estratégia provoca a perda de individualidade dos dados, impedindo a extração de preferências do indivíduo a partir da interação. Este trabalho tem como objetivo propor uma arquitetura de personalização que permite a indexação multimídia de modo irrestrito e barato, utilizando anotações colaborativas, mas mantendo-se a individualidade dos dados para complementar o perfil de interesses do usuário com conceitos relevantes. A multimodalidade de metadados e de preferências também é explorada na presente tese, fornecendo maior robustez na extração dessas informações, e obtendo-se uma maior carga semântica que traz benefícios às aplicações. Como prova de conceito, este trabalho apresenta dois serviços de personalização que exploram a arquitetura proposta, avaliando os resultados por meio de comparações com abordagens previamente propostas na literatura.

Palavras-chave: indexação multimídia, construção de perfil, anotação do usuário, colaboração, seleção de conteúdo, recomendação, personalização. 


\section{Abstract}

The extraction of semantic information from digital video is important to be used on personalization services because the content is adapted according to each user's preferences. However, although it is possible to find several approaches in the literature, automatic indexing techniques are able to generate semantic metadata only when the content's domain is restricted. Alternatively, this information can be created manually by professionals, but this activity is time-consuming and error-prone. A possible solution would be to explore collaborative users' annotations, but such approach has the disadvantage of lacking the individuality of annotations, hampering the extraction of user's preferences from the interaction. This work has the objective of proposing a generic personalization architecture that allows multimedia indexing procedures to be accomplished in a cheap and unrestricted way. Such architecture uses collaborative annotations, but keeps the individuality of the data in order to augment the user's profile with relevant concepts. The multimodality of metadata and user's preferences is also explored in this work, which provides robustness during the extraction of semantic information, bringing benefits to applications. This work also presents two personalization services that explore the proposed architecture, along with evaluations that compare the obtained results with previously proposed approaches.

Keywords: multimedia indexing, profile construction, user's annotation, collaboration, content selection, recommendation, personalization. 


\section{Sumário}

Lista de Figuras $\quad$ xiii

Lista de Tabelas $\quad$ xv

Lista de Siglas $\quad$ xvii

1 Introdução 1

1.1 Motivação . . . . . . . . . . . . . . . . . . . 4

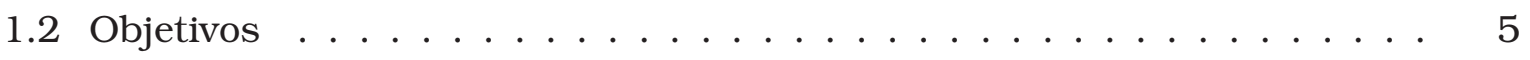

1.3 Organização da Tese . . . . . . . . . . . . . . . . 7

2 Personalização e Adaptação de Conteúdo 9

2.1 Adaptação Direcionada a Dispositivos e Rede . . . . . . . . . . . . . . . . 11

2.1.1 Mídia Escalável . . . . . . . . . . . . . . . . . . . . . . . . . 12

2.1 .2 Recodificação . . . . . . . . . . . . . . . . . . . . 12

2.1.3 Conversão de Modalidade . . . . . . . . . . . . . . . . . . . . 13

2.2 Adaptação Direcionada à Percepção . . . . . . . . . . . . . . . . . . . . . . 14

2.2.1 Baseada em Sensações . . . . . . . . . . . . . . . . . 15

2.2 .2 Assistência a Limitações . . . . . . . . . . . . . . . . . . . . 16

2.2 .3 Meio Ambiente . . . . . . . . . . . . . . . . . . . . 17

2.3 Adaptação Direcionada à Semântica . . . . . . . . . . . . . . . . . 17

2.3.1 Sumarização Espacial . . . . . . . . . . . . . . . . . . . . 18

2.3.2 Sumarização Temporal . . . . . . . . . . . . . . . . 20

2.4 Seleção e Recomendação . . . . . . . . . . . . . . . . . . . . . . . . . . . . . . . . . . 22

2.4.1 Filtragem Baseada em Conteúdo . . . . . . . . . . . . . . . 23

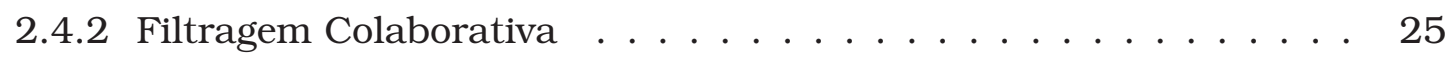

2.4 .3 Filtragem Híbrida . . . . . . . . . . . . . . . . 28

2.5 Considerações Finais . . . . . . . . . . . . . . . 30 
3 Indexação Multimídia $\quad 33$

3.1 Segmentação de Vídeo . . . . . . . . . . . . . . . . . . . 36

3.1 .1 Reconhecimento de Padrões . . . . . . . . . . . . . . . 36

3.1 .2 Reconstrução de Layout . . . . . . . . . . . . . . . . . . . . . . . . . . . . . . . . . . . . . . . . .

3.1 .3 Segmentação de Conteúdo . . . . . . . . . . . . . . . . . . . . . . . . . . . . . 48

3.2 Análise Multimodal . . . . . . . . . . . . . . . . . . 41

3.2 .1 Conversão . . . . . . . . . . . . . . . . . . 42

3.2 .2 Integração . . . . . . . . . . . . . . . . . . . 42

3.3 Indexação Semântica . . . . . . . . . . . . . . . . . . 43

3.3.1 Gênero . . . . . . . . . . . . . . . . . 45

3.3 .2 Subgênero . . . . . . . . . . . . . . . . . . . 45

3.3 .3 Unidades Lógicas . . . . . . . . . . . . . . . . . . . . . 46

3.3 .4 Eventos Nomeados . . . . . . . . . . . . . . . . . . 47

3.4 Considerações Finais . . . . . . . . . . . . . . . . . . 47

4 Anotações e Perfil do Usuário 49

4.1 A Web $2.0 \ldots \ldots \ldots \ldots \ldots \ldots \ldots$

4.1 .1 Sistemas de Etiquetação . . . . . . . . . . . . . . . 52

4.1 .2 Folksonomias . . . . . . . . . . . . . . . . . 54

4.2 Anotações Multimídia . . . . . . . . . . . . . . . . 57

4.2 .1 Descrição Hierárquica . . . . . . . . . . . . . . . . 57

4.2 .2 Enriquecimento de Conteúdo . . . . . . . . . . . . . . . . . . . . . . . . . . 59

4.2 .3 Representação de Anotações . . . . . . . . . . . . . . . . . . . 61

4.2 .4 Exemplos de Aplicações . . . . . . . . . . . . . . . . . . . . . . . . . . . . . . . 62

4.2 .5 A Ferramenta M4Note . . . . . . . . . . . . . . . . . . 65

4.3 Construção de Perfis . . . . . . . . . . . . . . . . . 67

4.3.1 Coleta de Informações . . . . . . . . . . . . . . . . 68

4.3 .2 Representação de Perfil . . . . . . . . . . . . . . . 70

4.4 Considerações Finais . . . . . . . . . . . . . . . . . . 73

5 Arquitetura de Personalização $\quad 77$

5.1 Visão Geral . . . . . . . . . . . . . . . . . . . . . 78

5.2 Anotações do Usuário . . . . . . . . . . . . . . . . . 81

5.3 Indexação Multimídia . . . . . . . . . . . . . . . . . . . . . . . . . . . . . . . . .

5.4 Criação e Enriquecimento de Perfil . . . . . . . . . . . . . . . . 89

5.4 .1 Notação . . . . . . . . . . . . . . . . . . 91

5.4 .2 Nuvem de Palavras-chave . . . . . . . . . . . . . . . . 91

5.4 .3 Nuvem de Gêneros . . . . . . . . . . . . . . . . . . . . . . . . . . . . . . 92

5.4 .4 Nuvem de Etiquetas . . . . . . . . . . . . . . . . . . . 92

5.4 .5 Nuvem de Faces . . . . . . . . . . . . . . . . 93 
5.4 .6 Similaridade entre Usuários . . . . . . . . . . . . . . . . . 93

5.4 .7 Representação . . . . . . . . . . . . . . . . . . . 94

5.5 Considerações Finais . . . . . . . . . . . . . . . . . . 96

6 Aplicações e Análises $\quad 99$

6.1 Sistema de Seleção de Conteúdo . . . . . . . . . . . . . . . . . 101

6.1 .1 Seleção de Conteúdo Baseada em Imagens . . . . . . . . . . . . . . 103

6.1 .2 Seleção de Conteúdo Baseada em Tópicos . . . . . . . . . . . . . . 105

6.1.3 Seleção de Conteúdo Baseada em Faces . . . . . . . . . . . . . . . 107

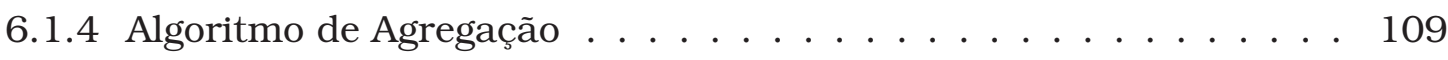

6.1 .5 Avaliação . . . . . . . . . . . . . . . . . . 111

6.2 Sistema de Recomendação . . . . . . . . . . . . . . . . . . . . 117

6.2.1 Recomendação Baseada em Conteúdo . . . . . . . . . . . . . 118

6.2 .2 Recomendação Colaborativa . . . . . . . . . . . . . . . . . 119

6.2 .3 Recomendação Híbrida . . . . . . . . . . . . . . . . . . . . 120

6.2.4 Recomendação Baseada em Anotações . . . . . . . . . . . . . . . 120

6.2 .5 Avaliação . . . . . . . . . . . . . . . . . . . . 122

6.3 Sistema de Sumarização Temporal: Discussão . . . . . . . . . . . . . 126

6.4 Considerações Finais . . . . . . . . . . . . . . . . . . . 128

7 Conclusão 131

7.1 Contribuições . . . . . . . . . . . . . . . . . . . . . . . . . . . . . . . . . . . . . . . . . . .

7.2 Limitações . . . . . . . . . . . . . . . . . . . . . . . . 134

7.3 Trabalhos Decorrentes desta Pesquisa . . . . . . . . . . . . . . . . . . . . . . . . . . .

7.4 Trabalhos Futuros . . . . . . . . . . . . . . . . . 135

$\begin{array}{ll}\text { Referências Bibliográficas } & 137\end{array}$

$\begin{array}{ll}\text { Apêndice A: Publicações } & 159\end{array}$

$\begin{array}{ll}\text { Glossário } & 165\end{array}$ 


\section{Lista de Figuras}

2.1 Classificação do modelo de personalização e adaptação de conteúdo. . 11

2.2 Exemplo de duas imagens iguais mas com diferentes temperaturas. . . . 15

2.3 Exemplo de sumarização espacial. . . . . . . . . . . . . . . . . . 19

2.4 Sumarização temporal de conteúdo segmentado. . . . . . . . . . . . . 21

3.1 Esquema para indexação multimodal de vídeo. . . . . . . . . . . . . . 35

3.2 Hierarquia para indexação semântica. . . . . . . . . . . . . . . . . . 44

4.1 Anotações no YouTube. . . . . . . . . . . . . . . . . . . . 63

4.2 Anotações no Orkut. . . . . . . . . . . . . . . . . . . . 64

4.3 Anotações no Flickr. . . . . . . . . . . . . . . . . . . . 65

4.4 A ferramenta M4Note. . . . . . . . . . . . . . . . . . 66

4.5 Esquema para construção de perfil do usuário. . . . . . . . . . . . . . 68

5.1 Arquitetura de personalização. . . . . . . . . . . . . . . . . 79

5.2 M4Note estendido. . . . . . . . . . . . . . . . . . . 82

5.3 Esquema para descrição hierárquica. . . . . . . . . . . . . . 85

5.4 Perfil do usuário contendo diferentes tipos de metadados. . . . . . . . . . 90

6.1 Esquema geral para o sistema de seleção de conteúdo. . . . . . . . . . . 102

6.2 Experimento 1 para seleção de conteúdo. . . . . . . . . . . . . . . 114

6.3 Resultados para experimento $1 \ldots \ldots \ldots \ldots$. . . . . . . . 115

6.4 Experimento 2 para seleção de conteúdo. . . . . . . . . . . . . . 116

6.5 Resultados para experimento $2 \ldots \ldots \ldots \ldots$. . . . . . . . 116

6.6 Experimento 3 para seleção de conteúdo. . . . . . . . . . . . . . . 117

6.7 Resultados para experimento 3. . . . . . . . . . . . . . . . 118

6.8 Resultados para todos os algoritmos de recomendação. . . . . . . . . . . 124

6.9 Sumarização baseada em anotações de usuários. . . . . . . . . . . . . . 127 


\section{Lista de Tabelas}

4.1 Relacionamento de etiquetas baseado em suas co-ocorrências. . . . . . . 56

6.1 Estrutura de noticiários e metadados. . . . . . . . . . . . . . . 112 


\section{Lista de Siglas}

$\begin{array}{ll}\text { AG } & \text { Algoritmo Genético. } \\ \text { CRT } & \text { Tubo de Raios Catódicos (Cathode Ray Tube). } \\ \text { DCT } & \text { Transformada Discreta do Cosseno (Discrete Cossine Transform). } \\ \text { FAINT } & \text { API em Java para Interface de Anotação de Face (Face Annotation } \\ & \text { Interface Java API). } \\ \text { GPS } & \text { Sistema de Posicionamento Global (Global Positioning System). } \\ \text { HMM } & \text { Modelo Escondido de Markov (Hidden Markov Model). } \\ \text { HTML } & \text { Linguagem de Marcação de Hipertexto (HyperText Markup Language). } \\ \text { IMDB } & \text { Banco de Dados de Filmes da Internet (Internet Movies Database). } \\ \text { LPC } & \text { Coeficiente de Predição Linear (Linear Prediction Coefficient). } \\ \text { LSI } & \text { Indexação Semântica Latente (Latent Semantic Indexing). } \\ \text { LSU } & \text { Unidade Lógica de Cena (Logical Story Unit). } \\ \text { MAP } & \text { Maximum-a-Posteriori. } \\ \text { MFCC } & \text { Coeficiente Cepstral nas Frequências de Mel (Mel-Frequency Cepstral } \\ & \text { Coefficient). } \\ \text { MLE } & \text { Estimativa de Máxima Verossimilhança (Maximum-Likelihood Estimation). } \\ \text { NCL } & \text { Linguagem de Contexto Aninhado (Nested Context Language). } \\ \text { OCR } & \text { Reconhecimento Ótico de Símbolos (Optical Character Recognition). } \\ \text { ODP } & \text { Projeto de Diretório Aberto (Open Directory Project). } \\ \text { P2P } & \text { Ponto-a-ponto (Peer-to-Peer). } \\ \text { P\&A } & \text { Personalização e Adaptação de Conteúdo. } \\ \text { PMX } & \text { Crossover Mapeado Parcialmente (Partially Mapped Crossover). } \\ \text { PNN } & \text { Rede Neural Probabilística (Probabilistic Neural Network). } \\ \text { RGB } & \text { Vermelho-Verde-Azul (Red-Green-Blue). } \\ \text { RMSE } & \text { Raiz do Erro Quadrático Médio (Root Mean Squared Error). } \\ \text { ROI } & \text { Região de Interesse (Region of Interest). }\end{array}$ 
SMIL Linguagem de Integração Multimídia Sincronizada (Synchronized Multimedia Integration Language).

SNR Razão Sinal-Ruído (Signal-to-Noise Ratio).

SRT SubRip (formato de legenda).

SVD Decomposição de Valor Singular (Singular Value Decomposition).

SVM Máquina de Vetor de Suporte (Support Vector Machine).

TDM Matriz Termo-Documento (Term-Document Matrix).

$\mathrm{TF} \times \mathrm{IDF}$ Frequência de Termos $\times$ Frequência Inversa de Documentos (Term Frequency $\times$ Inverse Document Frequency).

URI Identificador de Recurso Uniforme (Uniform Resource Identifier).

URL Localizador Padrão de Recursos (Uniform Resource Locator).

WaC Assistir e Comentar (Watch-and-comment).

XML Linguagem de Marcação Extensivel (eXtensible Markup Language).

ZCR Taxa de Cruzamento Zero (Zero-Crossing Rate). 


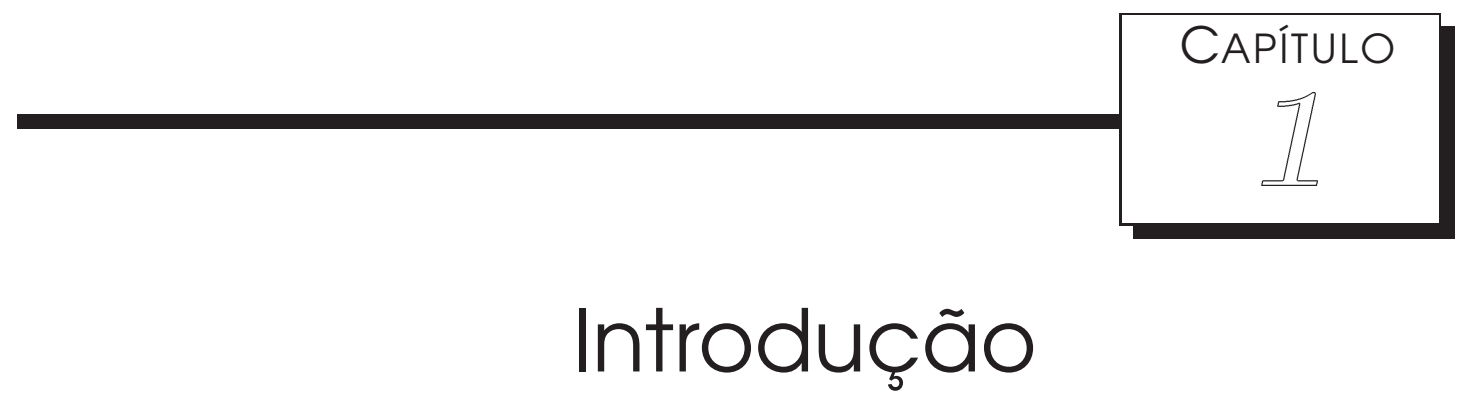

$\mathrm{N}$ as últimas décadas, a era digital trouxe novas possibilidades de manipulação multimídia. A interação entre conteúdo e usuário, em especial, é uma importante característica desse cenário, considerando os grandes avanços da Web, cuja principal peculiaridade é a capacidade de os usuários interativamente escolherem diferentes caminhos de navegação explorando variadas informações disponíveis, inclusive multimídia.

Em paralelo ao desenvolvimento de serviços interativos, surgiram novas tecnologias relacionadas a dispositivos e redes que revolucionaram o modo em que os dados são acessados. Primeiramente, o consumo pode ser realizado utilizando diferentes tipos de pontos de acesso, incluindo celulares e computadores portáteis, independentemente da localidade. Adicionalmente, tais avanços mudaram o paradigma conhecido em que usuários apenas acessam conteúdo já existente, permitindo a autoria e a disponibilização dos dados na rede por qualquer indivíduo. Como resultado dessa tendência, o novo modelo de manipulação multimídia está ocasionando um aumento de conteúdo existente, tornando mais evidente certas barreiras para o usuário em sua atividade comum de acesso a dados audiovisuais. Um primeiro problema está relacionado ao uso de dispositivos portáteis: dados em alta resolução poderão não ser visualizados corretamente em aparelhos eletrônicos com capacidades restritas, tais como tela com pequena área de visualização ou restrições de processamento, memória e/ou banda para transmissão. Outro problema refere-se à quantidade de vídeos, áudios, imagens e documentos que são gerados constantemente, causando uma sobrecarga de informações e, consequentemente, dificultando a recuperação pelo usuário de itens multimídia específicos. 
Tais desafios vêm sendo estudados por uma área recente chamada personalização e adaptação de conteúdo (P\&A) [Magalhães \& Pereira, 2004]. Um sistema de adaptação procura decidir a versão de conteúdo ideal para apresentação e a melhor estratégia para gerar essa versão [Lum \& Lau, 2002]. A personalização, por sua vez, conforme argumentam Barrios et al. [2005], é vista como um caso particular da adaptação, quando os dados são adaptados para um único usuário. Na prática, a adaptação procura disponibilizar meios de se acessar conteúdo multimídia a partir de diferentes condições de dispositivos, rede e ambiente computacional. Já a personalização, conforme o próprio nome sugere, estuda meios de se customizar e/ou filtrar os dados segundo as preferências, interesses e necessidades de um usuário específico.

Há alguns anos, a adaptação era o principal enfoque de pesquisadores na cadeia de consumo multimídia, devido às necessidades de infraestrutura que não agregavam capacidades suficientes para processamento dos dados. Apesar de tais esforços ainda serem importantes, atualmente estudiosos têm se dedicado também a investigar a experiência do usuário, procurando maximizar sua satisfação com os serviços disponíveis. Destarte, trabalhos recentes estão direcionados à personalização multimídia, disponibilizando diferentes serviços cujo objetivo em comum é customizar o conteúdo com base nas preferências de cada indivíduo. Serviços que exploram essa funcionalidade podem ser categorizados em seleção de conteúdo, sistemas de recomendação e sistemas de sumarização [Adomavicius \& Tuzhilin, 2005].

A seleção de conteúdo trata de serviços que oferecem busca de itens multimídia a partir de critérios que são definidos pelo usuário. Esses critérios, por sua vez, podem ser baseados em anotações criadas durante o enriquecimento do conteúdo, sendo que tal atividade é vista como uma customização ou personalização dos dados audiovisuais originais. Assim, são inseridas informações adicionais por meio de mecanismos avançados de interação, como tinta/caneta eletrônica, comentários por texto ou voz, avaliações por meio de notas, entre outros.

A recomendação, ao contrário da seleção por meio de critérios definidos manualmente pelo usuário, consiste em selecionar automaticamente (ou sugerir) os itens de interesse, a partir de um perfil de preferências para cada indivíduo. Geralmente, o perfil é um documento textual que especifica dados pessoais e diferentes níveis de interesse do usuário para uma variedade de tópicos e assuntos relevantes. A extração dessas informações pode ser realizada explicitamente, com intervenção do usuário, ou implicitamente pelo sistema de maneira automática, baseando-se no histórico de interações do indivíduo com itens visitados anteriormente. Salienta-se que quanto mais informações resultantes da interação do usuário forem consideradas pelas técnicas, mais preciso será o perfil de preferências do mesmo [Teevan et al., 2005]. Adicionalmente, representações baseadas em conhecimento, ou seja, que 
organizam os dados semanticamente, podem oferecer informações mais relacionadas aos tópicos de interesse de cada indivíduo [Adomavicius \& Tuzhilin, 2005; Burke, 2000].

Já a sumarização procura produzir uma versão modificada do conteúdo, com base em uma agregação de informações que são selecionadas a partir de critérios definidos pelo usuário e de seu perfil de interesses. Como exemplo, um noticiário pode ser personalizado no sentido de conter apenas notícias sobre saúde e educação, sendo que tais categorias são consideradas relevantes no perfil do usuário. Assim, pode-se criar um sumário contendo apenas informações relevantes, eliminando dados espaciais (objetos segmentados ou componentes intraquadro) ou temporais (cenas de um vídeo).

Sistemas de personalização, em geral, apresentam uma necessidade em comum, que é o conhecimento das informações agregadas ao conteúdo. Esses metadados descrevem a mídia em si, como formato, tipo de compressão e tamanho de arquivo, como também disponibilizam dados informativos sobre o conteúdo sendo apresentado. Nesse último caso, as descrições podem variar em granularidade ou detalhamento, assim como em nível semântico de representação [Snoek \& Worring, 2005]. Uma informação com baixo nível semântico poderia ser o vetor de histograma de uma imagem, a média de cores dos blocos que compõem um quadro de um vídeo, a quantidade de movimento existente em uma cena, entre outras. Esses dados, de modo geral, podem ser facilmente extraídos ou calculados do fluxo audiovisual a partir de ferramentas conhecidas. Já descrições com alto nível semântico observam características conceituais do conteúdo, como objetos reconhecidos, existência e identificação de pessoas, localidade de uma cena, entre outras. Para disponibilizar essas informações, é necessário o desenvolvimento de técnicas complexas que extraiam esses metadados a partir de uma análise do fluxo de dados. Alternativamente, conta-se com o auxílio de profissionais especializados em tal tarefa de anotação, que criam descrições sobre o conteúdo de maneira manual.

Informações semânticas têm potencial para promover uma melhoria nos serviços de personalização, uma vez que podem formar um elo entre a representação computacional de um conteúdo e a interpretação dos dados por um determinado usuário. A falta dessa ligação entre a informação em si e a interpretação do usuário é chamada de lacuna semântica [Smeulders et al., 2000], e pesquisadores vêm centrando esforços no desenvolvimento de técnicas capazes de criar o referido elo entre ambas as partes. Entretanto, apesar dos esforços sendo realizados, a literatura ainda reporta problemas na obtenção desses metadados - chamada indexação multimídia - que dificultam sobremaneira o desenvolvimento de aplicações de P\&A. Tais problemas aparecem tanto na indexação automática quanto na manual. No caso da indexação automática, a principal dificuldade é a necessidade de se restringir o domínio em que 
os dados serão analisados. Por exemplo, é comum confinar técnicas de indexação de vídeo para operarem apenas no domínio de noticiários, ou então no de esportes. Isso se deve às diferentes propriedades que são inerentes a cada gênero multimídia, fazendo com que a extração de informações semânticas seja difícil de ser realizada sem considerar um modelo visual e auditivo bem definido [Brezeale \& Cook, 2007].

No caso da indexação manual, o problema da restrição do domínio de dados inexiste, já que o processo de interpretação do conteúdo é realizado pelo próprio especialista. Contudo, além de tal abordagem resultar em um trabalho cansativo, caro e propenso a erros, outro problema existente é que a indexação pode explorar diferentes aspectos do conteúdo. Normalmente, profissionais irão criar metadados relacionados a certas características vistas subjetivamente como as mais importantes em uma apresentação. Um produtor, por exemplo, poderá achar que o local onde um carro está estacionado é mais importante que o modelo do carro, que, por sua vez, poderá ser visto como a informação prioritária por outra pessoa.

\subsection{Motivação}

Conforme mencionado anteriormente, a mudança de paradigma no acesso aos dados tem possibilitado a usuários atuarem como produtores de conteúdo. Serviços que exploram esse mecanismo, como YouTube ${ }^{1}$, Flickr $^{2}$, Facebook $^{3}$, entre outros, estão relacionados à Web 2.0, que é um termo criado em 2004 por Tim O'Reilly para designar uma segunda geração de comunidades e serviços, tendo como conceito básico a "Web como plataforma" [Governor et al., 2009]. Nesse sentido, espera-se que aplicações sejam desenvolvidas aproveitando as possibilidades da rede de usuários, de modo a melhorarem seus serviços à medida que sejam utilizados por mais indivíduos.

Partindo desse princípio, alguns conceitos relacionados com a Web 2.0 inspiraram novos direcionamentos de pesquisa para solucionar o problema da lacuna semântica. Em particular, a inteligência coletiva ou participação colaborativa é um termo criado para referenciar o agrupamento dinâmico de participantes de uma comunidade, que fazem reuso de conteúdo, atualizações fracionárias e contribuições para trabalhos coletivos. Nesse cenário, anotações produzidas colaborativamente pelos usuários podem ser exploradas para se produzir metadados sobre o conteúdo, eliminando alguns dos problemas da criação automática e manual de metadados. Desse modo, as descrições tornam-se independentes ao domínio de dados por serem criadas manualmente, porém sem despender consideráveis recursos e tempo durante a

\footnotetext{
${ }^{1}$ http://www.youtube.com, último acesso em 10 de Novembro de 2010.

${ }^{2}$ http://www.flickr.com, último acesso em 10 de Novembro de 2010.

${ }^{3}$ http://www.facebook.com, último acesso em 10 de Novembro de 2010.
} 
anotação, uma vez que são colaborativas.

Apesar da participação colaborativa ser capaz de prover metadados semânticos sobre o conteúdo, sua utilização direta em sistemas de personalização gera outro problema, já que perde-se a individualidade das anotações produzidas por cada usuário. Assim, informações valiosas que poderiam indicar as preferências do indivíduo não são consideradas no processo de anotação, sendo que tais dados poderiam enriquecer seu perfil com termos, conceitos e/ou assuntos de seu interesse.

Verificando a necessidade de individualização das anotações em serviços de personalização, uma alternativa, que até o momento não foi explorada, é analisar a atividade de enriquecimento de conteúdo [Bulterman, 2004; Goularte et al., 2004b], tais como a adição de texto explicativo a fotos ou vídeos, o ato de circular um determinado objeto com caneta/tinta eletrônica, a inserção de mídias relacionadas ao conteúdo sendo apresentado, entre outras. Essa abordagem é interessante pois tais anotações de enriquecimento apresentam considerável carga semântica a respeito dos interesses do indivíduo. Além disso, podem ser representadas de maneira multimodal [Goularte et al., 2004a], o que aumenta o elo semântico entre as informações agregadas e a interpretação do usuário.

Destarte, a utilização de dados provenientes da atividade de enriquecimento de conteúdo realizada por um usuário pode fornecer metadados significativos a respeito de suas preferências. Adicionalmente, conforme mencionado anteriormente, a ação colaborativa de anotações produzidas por vários usuários pode contribuir para reduzir os problemas da indexação automática e manual de conteúdo.

Entretanto, considerando o cenário apresentado em que se explora as anotações (colaborativas e de enriquecimento) para obter as informações necessárias para o provimento de serviços de personalização, alguns desafios precisam ser analisados de modo a viabilizar tais benefícios para as aplicações. Um desses desafios é a multiplicidade de meios disponibilizados ao indivíduo para interagir com o conteúdo e/ou criar anotações de enriquecimento. Tal característica destaca-se ainda mais se for considerada a liberdade fornecida aos usuários para se expressarem, não seguindo um vocabulário pré-definido. Nesse contexto, o foco deste trabalho é o desenvolvimento de técnicas multimodais apropriadas para analisar dados provenientes da atividade interativa, fornecendo informações relevantes sobre o usuário e conteúdo que possam ser representadas de maneira controlada, permitindo, assim, a sua utilização durante a personalização.

\subsection{Objetivos}

Esta tese tem como objetivo propor uma arquitetura que utilize anotações dos usuários para promover personalização de conteúdo independentemente do domínio 
de dados. Para isso, a arquitetura provê um mecanismo de indexação multimídia irrestrito e barato ${ }^{4}$, utilizando anotações colaborativas, mas mantendo-se a individualidade dos dados para complementar o perfil de interesses do indivíduo com conceitos relevantes.

Tal estratégia tem como finalidade auxiliar o processo de descrição do conteúdo, delegando parte da tarefa de criação de metadados aos usuários do sistema. Além disso, a abordagem possibilita a construção do perfil de maneira mais precisa, já que são extraídos tópicos semânticos de interesse a partir das anotações multimodais produzidas pelo próprio indivíduo. Os metadados extraídos, por sua vez, irão atuar como subsídios significativos para aplicações diversas situadas no contexto da personalização multimídia, como a seleção de conteúdo e a recomendação.

Desse modo, para atingir esse objetivo, esta tese adota a seguinte abordagem:

- a definição e o desenvolvimento de um mecanismo colaborativo de descrição de conteúdo, de modo a auxiliar profissionais especializados e técnicas automáticas de indexação durante o processo de criação de metadados;

- o desenvolvimento de um processo de aquisição de tópicos de interesse a partir da atividade de enriquecimento do usuário, criando um perfil multimodal composto por termos relacionados semanticamente que carregam informações relevantes para os serviços de personalização;

- o desenvolvimento de serviços de personalização que explorem a arquitetura proposta, avaliando os resultados por meio de comparações com abordagens previamente propostas na literatura.

Assim, a arquitetura proposta nesta tese contribui para a redução da lacuna semântica em serviços de personalização, provendo metadados sobre conteúdo multimídia e preferências do usuário de maneira barata e irrestrita ao domínio de dados. Desse modo, os resultados deste trabalho podem ser aplicados no desenvolvimento de serviços de personalização para ambientes diversos, como Web (personalização de buscas no YouTube, por exemplo) e Televisão Digital Interativa (recomendação de conteúdo de interesse para usuários, por exemplo).

\footnotetext{
${ }^{4}$ O termo "irrestrito", nesta tese, indica que a arquitetura não depende do domínio de dados para obtenção de informações semânticas sobre o conteúdo, assim como acontece com as abordagens de indexação automática mencionadas anteriormente. O termo "barato", por sua vez, indica que a arquitetura não necessita de grandes esforços de profissionais para a indexação multimídia, ao contrário das abordagens manuais relatadas na literatura.
} 


\subsection{Organização da Tese}

Os demais capítulos desta tese estão estruturados como segue. O Capítulo 2 apresenta uma contextualização dos trabalhos existentes na literatura sobre personalização e adaptação de conteúdo, organizados segundo a taxonomia proposta por Magalhães \& Pereira [2004]. Priorizam-se aplicações em personalização, sendo que tal estudo inicial ajuda a entender a quais aspectos o presente trabalho está relacionado, e em quais situações os resultados obtidos podem contribuir para melhoria das abordagens existentes.

O Capítulo 3 apresenta uma contextualização dos trabalhos sobre indexação multimídia automática, organizados segundo o esquema multimodal proposto por Snoek \& Worring [2005]. O objetivo é descrever as principais abordagens para obtenção automática de metadados, discutindo o estado da arte e as limitações encontradas nas técnicas atuais. Essa descrição é importante pois oferece um suporte para uma das contribuições da presente tese, que é a indexação baseada em anotações colaborativas dos usuários.

O Capítulo 4 descreve os processos de indexação manual, criação de anotações e construção do perfil do usuário. A partir do cenário atual da Web 2.0, que permite a criação e enriquecimento de conteúdo por usuários comuns, o estado da arte relacionado aos trabalhos de customização, compartilhamento e representação de anotações é discutido. Também com base na interação do usuário, são expostas as abordagens existentes para captura e representação das preferências e interesses do indivíduo, de modo a auxiliar o processo de personalização de conteúdo. Essa contextualização do estado da arte fornece a argumentação necessária para as contribuições desta tese.

O Capítulo 5 apresenta a arquitetura de personalização proposta neste trabalho, que é baseada nas atividades do usuário de interação, anotação e enriquecimento de conteúdo. Descrevem-se sua visão geral, os trabalhos realizados para descrição de vídeos em diferentes domínios de dados e as ferramentas usadas para autoria, enriquecimento e anotação pelos usuários. Adicionalmente, são descritas as técnicas desenvolvidas para criar e enriquecer o perfil de interesses.

O Capítulo 6 apresenta duas aplicações da arquitetura de personalização proposta neste trabalho: a seleção de conteúdo com base em múltiplos critérios, e o sistema de recomendação que explora anotações produzidas pelos usuários. Ambos os sistemas são analisados a fim de se avaliar os resultados obtidos com a abordagem proposta. Além disso, também é apresentada uma discussão de como um sistema de sumarização poderia ser desenvolvido a partir da arquitetura proposta.

O Capítulo 7, por fim, sumariza o trabalho apresentado nesta tese ao descrever os resultados e contribuições alcançados. Além disso, discutem-se as limitações da 
abordagem proposta e apresentam-se as sugestões de trabalhos futuros visando a continuidade deste trabalho. 


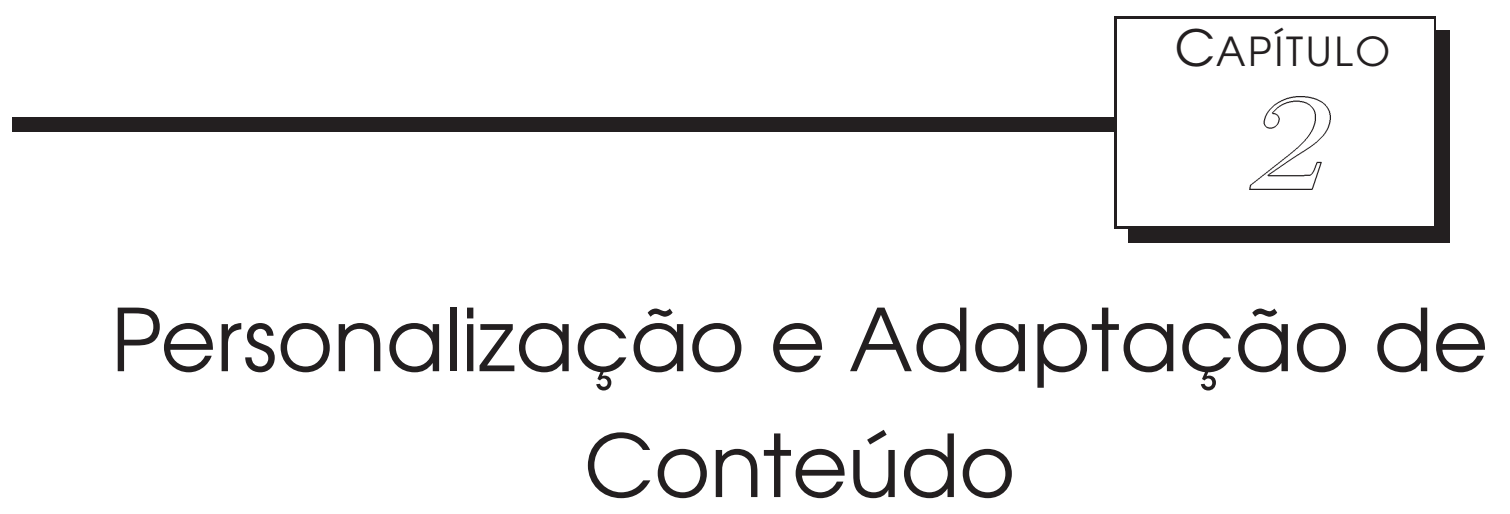

$\mathrm{C}$ onteúdo multimídia é definido como informações que podem ser apresentadas ao usuário de diferentes maneiras, explorando os canais sensoriais humanos, tais como visão e audição. Essa exploração é realizada, principalmente, por meio de texto, imagem, vídeo e áudio, que podem ser utilizados em conjunto ou isoladamente [Halsall, 2001].

A autoria de conteúdo multimídia, atualmente, está tendo um significativo aumento, visto que câmeras, scanners, gravadores e outros dispositivos de captura estão se tornando mais populares. Uma vez que os dados podem ser facilmente digitalizados por tais aparelhos, existe a possibilidade de criação e compartilhamento dessas informações entre diferentes usuários, seja por meio de redes interligando usuários amadores, como redes P2P (do Inglês, Peer-to-peer - Ponto-a-ponto), ou então utilizando serviços avançados de difusão, como a TV digital. Como resultado, uma quantidade crescente de dados audiovisuais está sendo disponibilizada, podendo ser acessada por consumidores que utilizam diferentes canais de comunicação.

Contribuindo também com a rápida expansão de aplicações multimídia, o desenvolvimento de dispositivos portáteis e/ou móveis, que podem, inclusive, ser interligados por rede, está permitindo que diferentes maneiras de acessar os dados sejam desenvolvidas. Tais maneiras podem englobar: outros mecanismos de interação com o conteúdo; acesso a partir de diferentes localizações, dispositivos e redes; distribuição do conteúdo de acordo com as preferências do usuário, entre outros. As preferências, em particular, têm um destaque importante no contexto da popula- 
rização de autoria multimídia, pois permitem que a grande quantidade de conteúdo disponível atualmente seja filtrada antes de sua distribuição, de modo a fornecer ao usuário apenas informações relacionadas aos seus interesses particulares.

Por outro lado, alguns desafios estão presentes nesse cenário, entre eles: a) as características dos terminais de acesso podem limitar a apresentação de uma mídia específica; b) a rede pode não disponibilizar largura de banda suficiente para transmitir dados a uma certa taxa de bits; e c) as atividades momentâneas de um usuário podem impedir que ele preste a devida atenção na apresentação em si.

Esses desafios vêm sendo estudados por uma área recente chamada personalização e adaptação de conteúdo (P\&A). Um sistema de adaptação procura decidir a versão de conteúdo ideal para apresentação e a melhor estratégia para gerar essa versão [Lum \& Lau, 2002]. A personalização, por sua vez, conforme argumentam Barrios et al. [2005], é vista como um caso particular da adaptação, quando os dados são adaptados conforme as necessidades de um usuário específico.

Diferentes estratégias de P\&A têm sido apresentadas na literatura, as quais podem ser organizadas segundo a taxonomia proposta por Magalhães \& Pereira [2004], apresentada na Figura 2.1. A classificação tem início com um termo genérico, Customização, que está representado pelo elemento raiz da Figura 2.1. A partir dele, as técnicas são divididas em dois grupos: Seleção ou Recomendação, onde o conteúdo multimídia não sofre nenhum tipo de processamento objetivando a modificação dos dados durante a apresentação; e Adaptação, que possibilita a geração de diferentes versões de um conteúdo original de acordo com as características dos dispositivos, rede, usuário e ambiente envolvidos na apresentação. A adaptação está direcionada a três aspectos relacionados ao acesso multimídia: usuário, conteúdo e infraestrutura, os quais estão representados na Figura 2.1, respectivamente, pelos elementos Percepção, Semântica e Dispositivos e Rede.

Apesar da taxonomia organizada, geralmente as técnicas de P\&A englobam diversos aspectos simultaneamente. Por exemplo, sistemas de recomendação podem fazer uso de informações sobre o conteúdo (semântica), ao mesmo tempo em que exploram características inerentes ao usuário (percepção).

O objetivo deste capítulo é prover uma contextualização dos trabalhos existentes sobre P\&A, priorizando aplicações em personalização. Este estudo inicial ajuda a entender a quais aspectos o presente trabalho está relacionado, e em quais situações os resultados obtidos podem contribuir para melhoria das abordagens existentes. Nas próximas seções, portanto, trabalhos relacionados a cada elemento da taxonomia proposta por Magalhães \& Pereira são apresentados. 


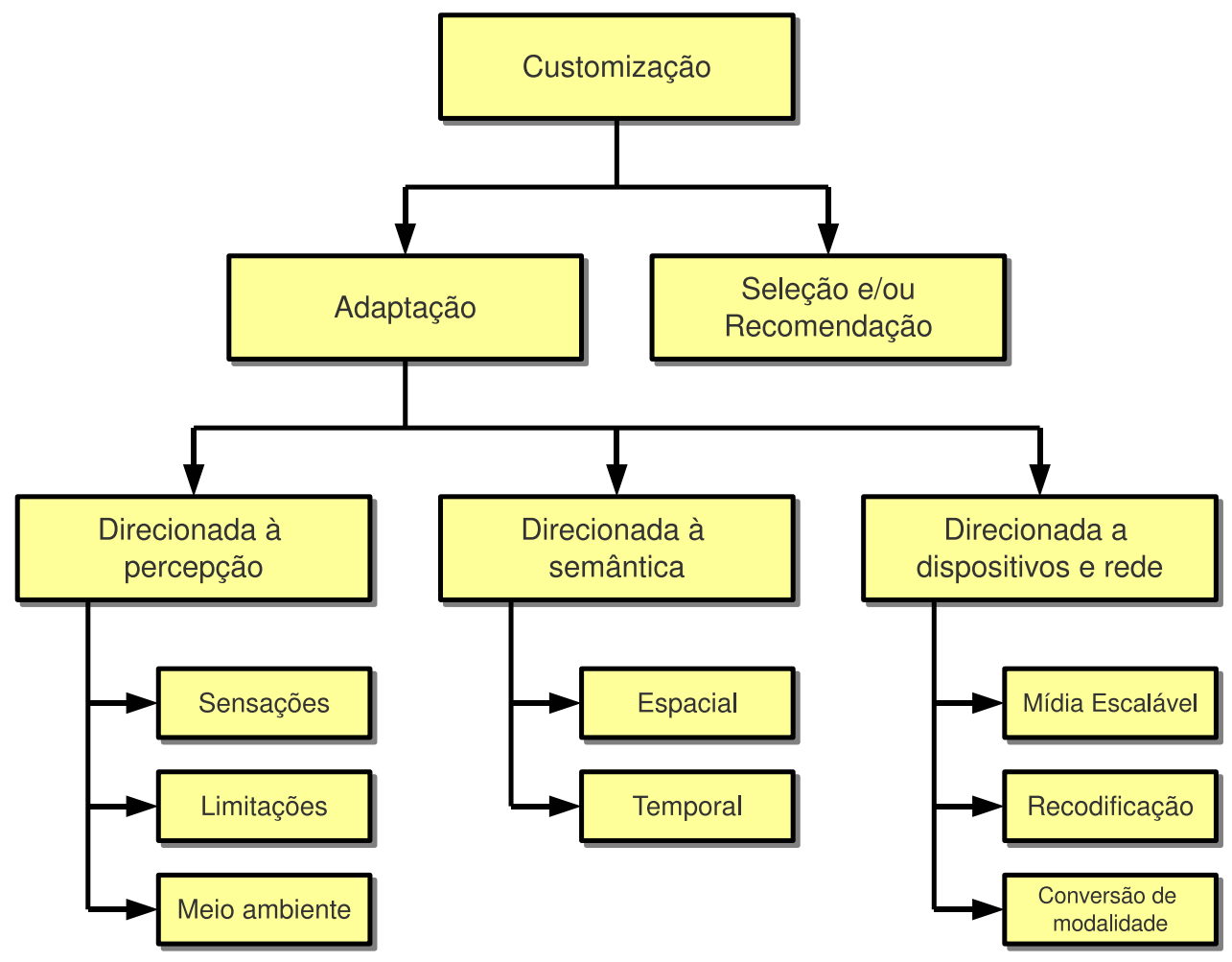

Figura 2.1: Classificação do modelo de personalização e adaptação de conteúdo [Magalhães \& Pereira, 2004].

\subsection{Adaptação Direcionada a Dispositivos e Rede}

Dispositivos e rede podem dificultar ou até mesmo impossibilitar a distribuição e consumo de conteúdo multimídia em diversas aplicações. Portanto, em certas situações, são necessários mecanismos de adaptação de acordo com as restrições dos terminais de acesso e das características da rede utilizada para transmissão dos dados.

Três modelos de adaptação direcionada a dispositivos e rede são utilizados atualmente: mídia escalável, que organiza o fluxo de bits em camadas de consumo, as quais podem ser truncadas para fornecer melhor qualidade, porém ao custo de serem necessários dispositivos com mais recursos; a recodificação, que pode trabalhar diretamente com os dados codificados, alterando algumas características, tais como resolução espacial e temporal; e a conversão de modalidade, que altera a natureza de uma mídia (por exemplo, vídeo para imagens) no caso em que o terminal de acesso é incapaz de processar o conteúdo em um formato específico, ou quando a diminuição da resolução ultrapassa um nível mínimo de qualidade. Nas próximas subseções, 
esses três modelos de adaptação serão descritos sucintamente.

\subsubsection{Mídia Escalável}

O modelo de mídia escalável consiste na codificação de dados multimídia por camadas, onde uma camada base contém as mínimas informações necessárias para apresentação, e camadas adicionais oferecem meios de se melhorar a qualidade do conteúdo aumentando a resolução e/ou as taxas de bits ou de quadros [Dogan et al., 2004]. O usuário, portanto, dependendo da situação do seu canal de comunicação com o servidor de conteúdo, recebe a camada base e possíveis camadas adicionais, de acordo com a largura de banda, a fim de acessar o conteúdo com a melhor qualidade possível.

A fim de fornecer vídeo com suporte à escalabilidade, o padrão MPEG-2 ${ }^{1}$ especificou quatro diferentes técnicas que podem ser aplicadas durante a codificação [Horn \& Girod, 1997; Conklin et al., 2001; Li, 2001]: escalabilidade espacial, particionamento de dados, escalabilidade SNR (do Inglês, Signal-to-Noise Ratio - Razão Sinal-Ruído) e escalabilidade temporal. Apesar dos inúmeros esforços, a utilização desse modelo gera alguns problemas. A entrega de vídeo personalizado pode ser limitada uma vez que funcionalidades de interação do usuário com o conteúdo são restritas às condições da rede e dos dispositivos. Outro problema é a interdependência entre as camadas, que requer o recebimento completo da camada adicional pelo usuário, para que ocorram melhorias na qualidade e serviços [Dogan et al., 2004].

\subsubsection{Recodificação}

Visando proporcionar uma solução mais flexível ao problema do acesso a conteúdo audiovisual em ambientes heterogêneos, diversos pesquisadores têm centrado esforços no modelo de recodificação. Recodificação é a operação de converter um conteúdo de um formato para outro, mudando algumas características, tais como taxa de bits, resolução espacial, resolução temporal, entre outras [Vetro et al., 2003a; Xin et al., 2005; Ahmad et al., 2005]. Por ser uma operação que é realizada no servidor, ou em algum proxy ou gateway entre servidor e cliente, funcionalidades de adaptação ou personalização de conteúdo podem ser eficientemente implementadas, com possibilidade de trabalharem de modo estático ou dinâmico [Dogan et al., 2004].

A recodificação estabelece uma série de conversões nas características de apresentação dos dados. Ahmad et al. [2005] classificam essas conversões em dois

\footnotetext{
${ }^{1}$ http://www.chiariglione.org/mpeg/standards/mpeg-2/mpeg-2.htm, último acesso em $10 \mathrm{de}$ Novembro de 2010.
} 
grupos: recodificação homogênea, caracterizada pela mudança de atributos, porém sem alterar o padrão de codificação (de MPEG-4 para MPEG-4, por exemplo); e recodificação heterogênea, definida também pela mudança de atributos, porém alterando-se o padrão de codificação (de MPEG-2 para MPEG-4, por exemplo).

Diferentemente do modelo de mídia escalável, a recodificação não requer nenhuma funcionalidade adicional do decodificador presente no dispositivo, uma vez que a operação de adaptação de conteúdo é realizada antes dos dados serem recebidos pelo usuário. Por outro lado, em certas situações, tais como quando vários usuários fazem requisições de diferentes níveis de qualidade de um mesmo conteúdo, a utilização do modelo de mídia escalável é melhor, pois exige menos processamento de dados [Xin et al., 2005].

\subsubsection{Conversão de Modalidade}

O termo "conversão de modalidade", neste trabalho, refere-se ao tipo de adaptação em que existe uma mudança da natureza do conteúdo; por exemplo, um vídeo é convertido em uma sequência de imagens, ou um áudio é convertido em texto. A necessidade de conversão de modalidade é influenciada, segundo Thang et al. [2005], por fatores como: i) a capacidade de um dispositivo de processar e apresentar um conteúdo em determinada modalidade; ii) as preferências do usuário por determinado tipo de apresentação; e iii) a semântica do conteúdo, que pode determinar o melhor formato para exibição de uma informação.

Devido à natureza intrínseca de cada modalidade, torna-se difícil, senão impossível, a conversão livre entre todos os formatos. Smith et al. [1998] descrevem algumas conversões que podem ser aplicadas de acordo com o conteúdo. Dentre essas conversões, alguns trabalhos relacionados foram selecionados:

- imagem para texto: Pesquisas no contexto de converter imagens ou quadros de vídeo em texto estão mais relacionadas à extração de texto por meio de técnicas de segmentação [Chen et al., 2004; Lienhart \& Wernicke, 2002; Kim et al., 2007]. Apesar das técnicas serem utilizadas principalmente para auxiliar aplicações multimídia baseadas em conteúdo, sua utilização para conversão de modalidade pode gerar problemas pela falta de informação, já que nem todo conteúdo é descrito nos textos que aparecem na imagem ou vídeo;

- vídeo para imagens: A conversão de vídeo para imagens normalmente é fundamentada na extração de quadros-chaves [Xiao et al., 2006; Papin \& Luo, 2007], pois esses tipos de quadros representam com melhor qualidade o conteúdo sendo apresentado. As técnicas para extração de quadros-chaves 
estão direcionadas para diferentes aplicações; assim, no contexto da conversão de modalidade, é necessário um estudo das heurísticas utilizadas durante a extração, com o objetivo de se selecionar quadros significativos de acordo com a semântica agregada ao vídeo sendo adaptado;

- texto para áudio: A maioria dos trabalhos que exploram a conversão de texto para áudio situa-se na utilização de síntese de fala. Tipicamente, esses trabalhos estão relacionados a algum idioma específico: Oliveira [1996], Pitrelli et al. [2006] e Mukhopadhyay et al. [2006], por exemplo, propuseram sistemas de síntese de fala, respectivamente, para as línguas Portuguesa, Inglesa e Indiana;

- áudio para texto: O reconhecimento de fala é utilizado durante a conversão automática de áudio para texto. Diversos trabalhos exploram essa área [Liu et al., 2006; de Wachter et al., 2007; Halavati et al., 2007]; no entanto, para que o reconhecimento de fala seja satisfatoriamente utilizado em conversão de modalidade, o áudio a ser convertido deverá ser caracterizado pela fala humana. Conteúdo contendo músicas instrumentais, por exemplo, não poderá ser convertido em texto da mesma maneira que é realizada com o reconhecimento de fala.

De acordo com os diferentes tipos de conversão, nota-se a necessidade de o sistema de adaptação ter um conhecimento semântico mínimo do tipo de conteúdo que será convertido. Tais informações conceituais podem ser obtidas usando uma série de técnicas descritas no Capítulo 3; alternativamente, pode-se utilizar a arquitetura de personalização proposta neste trabalho (vide Capítulo 5), que procura reduzir os problemas encontrados atualmente nas abordagens para indexação multimídia. Essas limitações serão discutidas no próximo capítulo desta tese.

\subsection{Adaptação Direcionada à Percepção}

A adaptação direcionada à percepção consiste em transformações no conteúdo de acordo com as preferências relacionadas às sensações do usuário, ou então, de acordo com limitações ou condições físicas, tais como dificuldades visuais ou auditivas. É importante salientar, nesse caso, que situações extremas, como a total impossibilidade visual, podem fazer com que a adaptação se enquadre na conversão de modalidade descrita anteriormente, como é o caso de vídeo, imagem ou texto convertidos em áudio.

De modo geral, essa classe de adaptação considera todos os tipos de transformação relacionados a alguma preferência, característica ou desvantagem perceptual 
humana. Magalhães \& Pereira [2004] dividiram a adaptação direcionada à percepção em três subclasses: baseada em sensações, assistência a limitações e meio ambiente. Nas próximas subseções, cada subclasse será apresentada resumidamente.

\subsubsection{Baseada em Sensações}

Sensações audiovisuais provocadas pelo conteúdo podem ser modificadas de acordo com as preferências do usuário. Como exemplo, a temperatura de cores de uma imagem pode ser alterada com o objetivo de gerar sensações frias ou quentes para o telespectador. Outro exemplo seria a mudança de gênero da voz do narrador de uma história [Magalhães \& Pereira, 2004].

A temperatura de cores, especificamente, é definida como aquela correlacionada à energia da iluminação na imagem, podendo variar o nível ótimo de acordo com as preferências de cada usuário [Nam et al., 2005]. Na Figura 2.2 [Magalhães \& Pereira, 2003] é possivel visualizar duas imagens iguais, mas com diferentes temperaturas. A Figura 2.2(a) transmite a sensação de uma imagem morna (tons alaranjados), fotografada durante o dia, enquanto a Figura 2.2(b) transmite a sensação de uma imagem fria (tons azulados), fotografada durante o crepúsculo.

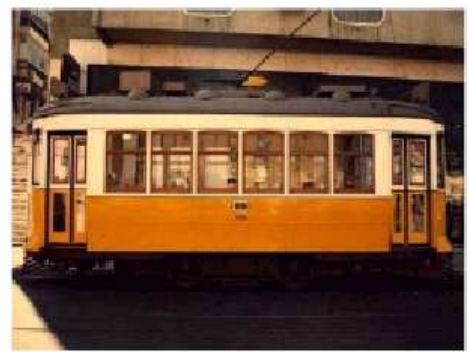

(a)

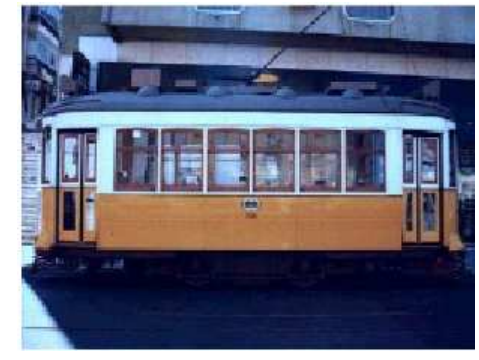

(b)

Figura 2.2: Exemplo de duas imagens iguais mas com diferentes temperaturas [Magalhães \& Pereira, 2003]. (a) apresenta cores quentes, de tonalidade alaranjada; e (b) apresenta cores frias, de tonalidade azulada.

Um exemplo de adaptação baseada em sensações é apresentado por Nam et al. [2005]. Eles desenvolveram um sistema de adaptação com suporte à alteração da temperatura de cores em imagens ou vídeos. O processo tem início com a obtenção das preferências do usuário relacionadas a essa característica. Tais preferências são extraídas por meio da escolha entre diferentes versões de uma imagem contendo diferentes temperaturas. Em seguida, estima-se a temperatura de cores da imagem original por meio de cálculos com a luminância dos pixels da imagem. Posteriormente, determina-se a temperatura de cores da imagem adaptada, aplicando-se uma função de mapeamento baseada nas preferências do usuário. Por fim, realiza-se uma 
transformação dos valores dos pixels da imagem original a fim de se obter a temperatura desejada.

Nesta subclasse de adaptação, é importante salientar a necessidade de se obter e representar as preferências de cada usuário. Geralmente, essas informações são armazenadas em um perfil de interesses, que é consultado pelas aplicações a fim de proverem serviços personalizados para o indivíduo. O Capítulo 4 descreve algumas abordagens existentes na literatura para construção de tais perfis; alternativamente, o Capítulo 5 apresenta uma das contribuições deste trabalho que é a obtenção das preferências do usuário com base nas anotações do mesmo com o conteúdo.

\subsubsection{Assistência a Limitações}

Algumas limitações físicas do usuário podem ser auxiliadas por certos tipos de adaptação de conteúdo, como transformações de cores do texto ou da imagem, aumento da fonte do texto, aumento da luminosidade da imagem devido a problemas visuais, entre outros [Magalhães \& Pereira, 2004].

Por haver diferentes níveis e tipos de limitações relacionados à deficiência visual, ela é a mais estudada por cientistas que procuram desenvolver sistemas multimídia com suporte à adaptação de acordo com as características dos problemas visuais explorados. Algumas deficiências na percepção de cores, tais como a dicromacia e a tricomacia anômala, são relevadas durante a adaptação do conteúdo, transformando cores com objetivo de compensar aqueles valores que não podem ser percebidos pelo usuário.

A dicromacia é caracterizada pela falta completa de um dos pigmentos dos cones do olho humano. Consequentemente, as cores do espectro visível são percebidas a partir de duas cores monocromáticas. A tricomacia anômala, por sua vez, também conhecida como Daltonismo, caracteriza-se pela modificação de uma das três classes de pigmentos dos cones do olho humano, resultando em distorções nas cores originais [Smith \& Pokorny, 1975].

Apesar de ser uma área que requer mais estudos para se resolver problemas ainda inexplorados, uma série de trabalhos tem sido reportada na literatura. Rigden [1999] e Brettel \& Vienot [2001], por exemplo, propuseram paletas de cores para simular a percepção de cores em pessoas com dicromacia. No trabalho de Kovacs et al. [2001], um filtro não linear obtido por meio de heurísticas foi usado para melhorar a representação de cores em monitores CRT (do Inglês, Cathode Ray Tube - Tubo de Raios Catódicos), objetivando a melhor percepção por telespectadores com tricomacia anômala. Os três trabalhos fornecem apenas soluções parciais: os dois primeiros não tratam da tricomacia anômala, enquanto o último é impraticável devido à insuficiência em propriedades específicas dos dispositivos de apresentação. 


\subsubsection{Meio Ambiente}

Além da adaptação baseada em sensações e do auxílio às limitações físicas dos usuários, o meio ambiente pode limitar as capacidades de percepção humana e, portanto, necessita ser considerado durante o consumo de conteúdo. Exemplos deste tipo de adaptação incluem: distância do telespectador à tela, exigindo um aumento da fonte do texto; ambientes muito claros, que necessitam de vídeo com alta luminosidade; se o usuário está dirigindo, então o conteúdo deverá ser baseado em áudio, entre outros [Magalhães \& Pereira, 2004].

$\mathrm{O}$ meio ambiente pode influenciar de inúmeras maneiras o modo em que o conteúdo multimídia é acessado. Considerando a localização, por exemplo, uma aplicação pode fornecer serviços interessantes ao usuário. A partir de um ponto qualquer em uma cidade desconhecida, uma pessoa poderia usar seu computador de bolso, equipado com GPS (do Inglês, Global Positioning System - Sistema de Posicionamento Global), para obter uma lista de restaurantes dentro de um raio de alguns quarteirões; ou então, usar uma aplicação em tempo real para encontrar percursos alternativos para chegar ao seu destino em dias de congestionamento.

Apesar de diversos trabalhos serem relatados na literatura, os quais estão direcionados a diferentes domínios de aplicação, tais como turismo [Boll et al., 2004; Cheverst et al., 2000], guias de exibição [Bieber \& Giersich, 2001], email [Ueda et al., 2000], compras [Fano, 1998] e informações para visitas [Chávez et al., 1999], ainda há desafios que precisam ser solucionados. Dentre eles, destaca-se a necessidade de desenvolvimento de meios mais eficientes para se obter a localização precisa do usuário. O GPS, em particular, pode fornecer a localização precisa em áreas abertas; porém, torna-se difícil sua utilização em ambientes fechados ou em cidades com muitos edifícios.

\subsection{Adaptação Direcionada à Semântica}

A adaptação de conteúdo sem conhecimento semântico (adaptação sintática) tem como característica a adaptação dos dados de maneira uniforme, contribuindo com um desperdício da largura de banda e recursos do dispositivo de acesso para transmissão e processamento de informações não importantes, como o plano de fundo de um vídeo. Do mesmo modo, a adaptação uniforme faz com que regiões de interesse possam ser codificadas com baixa qualidade, gerando insatisfação do usuário [Bertini et al., 2006].

Ao contrário da adaptação sintática, a adaptação semântica realiza alterações nas 
resoluções espacial e/ou temporal de acordo com a semântica do conteúdo sendo apresentado. Certos componentes são detectados e classificados em categorias com base em prioridades definidas de acordo com as preferências do usuário e/ou domínio de dados [Bertini et al., 2006].

Tendo em vista as vantagens oferecidas pela adaptação semântica, muitos pesquisadores têm centrado esforços na definição de novas abordagens para adaptação de dados multimídia baseada em conteúdo. Dois modos de adaptação podem ser considerados: em nível de objetos, também conhecida como sumarização espacial, e em nível de eventos, também chamada de sumarização temporal [Magalhães \& Pereira, 2004]. Ambos os tipos de adaptação semântica requerem a detecção de elementos relevantes no fluxo de dados, o que pode ser realizado por meio de técnicas de segmentação e a posterior anotação/indexação dos dados [Bertini et al., 2006].

A indexação multimídia é um pré-requisito para a eficiência da adaptação direcionada à semântica. Juntamente com técnicas de segmentação, métodos de reconhecimento de padrões podem ser empregados para detectar padrões visuais e auditivos específicos que identificam trechos de eventos relevantes ou regiões da imagem correspondentes a objetos significativos. Diversas técnicas são propostas na literatura, as quais exploram os dados codificados [Tseng et al., 2004; Lei \& Georganas, 2002] ou sem compressão [Cucchiara et al., 2003; Vetro et al., 2003b], derivando dados semânticos a partir de informações em baixo nível, tais como cor, textura, vetores de movimento, entre outras. O Capítulo 3 apresenta uma descrição das abordagens existentes para indexação multimídia baseada em técnicas automáticas. Por ora, nas próximas subseções deste capítulo, os tipos de adaptação semântica serão apresentados com mais detalhes, incluindo a descrição de alguns trabalhos relacionados.

\subsubsection{Sumarização Espacial}

A sumarização espacial consiste em processar elementos espaciais de um vídeo, podendo alterar a estrutura da cena, modificar o layout de uma apresentação e compor objetos semânticos a partir de análises baseadas em regras específicas [Cavallaro et al., 2005]. Este tipo de sumarização é mais utilizado em vídeos no formato MPEG-4, pois sua característica de codificar o conteúdo com base em objetos intra-quadros permite um nível de granularidade maior durante o processamento dos dados.

A sumarização de uma cena pode envolver a avaliação de cada elemento espacial individualmente, em termos de sua relevância semântica para o usuário. Em seguida, a adaptação é realizada por meio da remoção de alguns segmentos espaciais ou, utilizando algum tipo de processamento - como a recodificação -, alterando a resolução ou qualidade do segmento selecionado. A Figura 2.3 [Magalhães \& Pereira, 
2004] ilustra uma adaptação semântica por meio da sumarização espacial, onde vários segmentos espaciais foram removidos da cena, diminuindo a quantidade de informação a ser apresentada para o usuário.
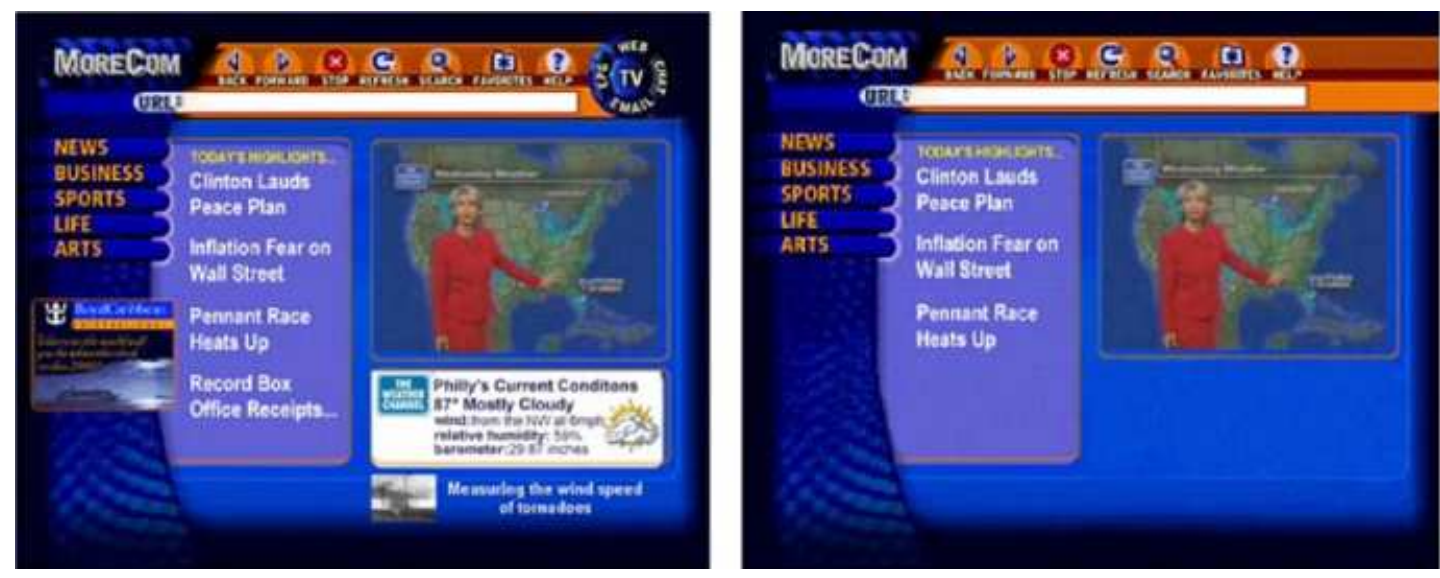

Figura 2.3: Exemplo de sumarização espacial [Magalhães \& Pereira, 2004].

A adaptação de layout, especificamente, é explorada por Zhang et al. [2005] com o objetivo de as mídias poderem ser acessadas utilizando dispositivos portáteis. Eles propuseram uma linguagem visual por meio de uma gramática de grafos para autoria e apresentação de dados multimídia adaptativos. Essa gramática é descrita de modo a mostrar como ela pode ser utilizada para especificar e suportar transformações e adaptações automáticas de apresentações multimídia. Uma ferramenta de autoria gráfica é gerada automaticamente a partir de um gerador de linguagem visual, sendo que essa ferramenta pode ser posteriormente utilizada por usuários sem conhecimentos em computação.

A literatura também reporta trabalhos que realizam a codificação com base em regiões de interesse do vídeo. Nesse caso, pode ser necessária a aplicação de técnicas de segmentação espacial nos quadros a fim de se definir as regiões de interesse. Essas técnicas são classificadas em semi-automáticas ou automáticas, e utilizam, em conjunto com rastreamento de objetos e vetores de movimento, alguns mecanismos explorados pela área de processamento de imagens, tais como watershed [Nguyen et al., 2003], detecção de bordas [Sappa \& Dornaika, 2006], campos randômicos de Markov [Zeng et al., 2005], entre outros.

Como exemplo de sumarização espacial, Cavallaro et al. [2005] propuseram um sistema de adaptação semântica de vídeo que procura analisar o conteúdo antes da codificação. São aplicadas técnicas de análise de vídeo a fim de extrair áreas relevantes e com significado semântico. Essas áreas são codificadas com um alto nível de qualidade, ou então são sumarizadas na forma textual. O objetivo desse processamento é fazer com que a mensagem do conteúdo apresentado não seja inibida 
por restrições na largura de banda ou capacidades do dispositivo. A análise semântica e sua correspondente anotação de conteúdo são utilizadas por codificadores baseados em objetos e em quadros, tais como o MPEG-4 e o MPEG- $1^{2}$, respectivamente, sendo que as anotações são representadas por descritores MPEG- $7^{3}$.

\subsubsection{Sumarização Temporal}

A sumarização temporal tem como objetivo criar um novo conteúdo a partir de algum já existente contendo apenas eventos relevantes para o usuário, os quais são selecionados automaticamente, por meio de algum critério semântico adotado. O novo conteúdo, portanto, terá um tempo menor de duração, que poderá também ser especificado pelo usuário, por exemplo: “crie um sumário com as cenas mais violentas de um filme, mas com tempo de duração menor do que 2 minutos" [Magalhães \& Pereira, 2004].

Normalmente, as técnicas de sumarização temporal trabalham com descritores de conteúdo (por exemplo, MPEG-7 ou TV-Anytime ${ }^{4}$ ), que indicam em quais momentos do fluxo de dados ocorrem mudanças de cenas, além de uma descrição semântica de cada segmento. Uma cena é composta por várias tomadas relacionadas semanticamente, sendo que o conceito de tomada é definido como uma unidade básica de vídeo representando uma ação contínua capturada por uma única câmera [Smeaton, 2007]. Assim, a detecção de mudança de cena inicia-se com a detecção dos limites de cada tomada, e o posterior agrupamento semântico de tomadas para compor uma cena [Manzato \& Goularte, 2007; Hanjalic, 2002; Joyce \& Bede, 2006; Lee et al., 2005; Kyperountas et al., 2007].

A Figura 2.4 [Magalhães \& Pereira, 2004] ilustra um esquema de sumarização temporal, onde um sumário é formado por um conjunto de cenas, que contém alguma semelhança semântica entre si, definida pelo usuário.

A utilização de quadros-chaves também pode ser verificada em técnicas de sumarização temporal, já que eles tipicamente representam com fidelidade o segmento de vídeo ao qual eles pertencem. Mundur et al. [2006], por exemplo, usam quadros-chaves como dados de entrada para uma técnica de agrupamento conhecida como Triangulação de Delaunay [Fortune, 1995]. Todo o sistema objetiva a detecção automática de quadros de interesse em fluxos de vídeo a fim de se realizar a sumarização. Primeiramente, uma amostragem de quadros de cada cena é obtida do fluxo original. Em seguida, quadros semelhantes são relacionados por meio do

\footnotetext{
${ }^{2}$ http://www.chiariglione.org/mpeg/standards/mpeg-1/mpeg-1.htm, último acesso em $10 \mathrm{de}$ Novembro de 2010.

${ }^{3} \mathrm{http}$ //www.chiariglione.org/mpeg/standards/mpeg-7/mpeg-7.htm, último acesso em $10 \mathrm{de}$ Novembro de 2010.

${ }^{4}$ http://www.tv-anytime.org, último acesso em 10 de Novembro de 2010.
} 


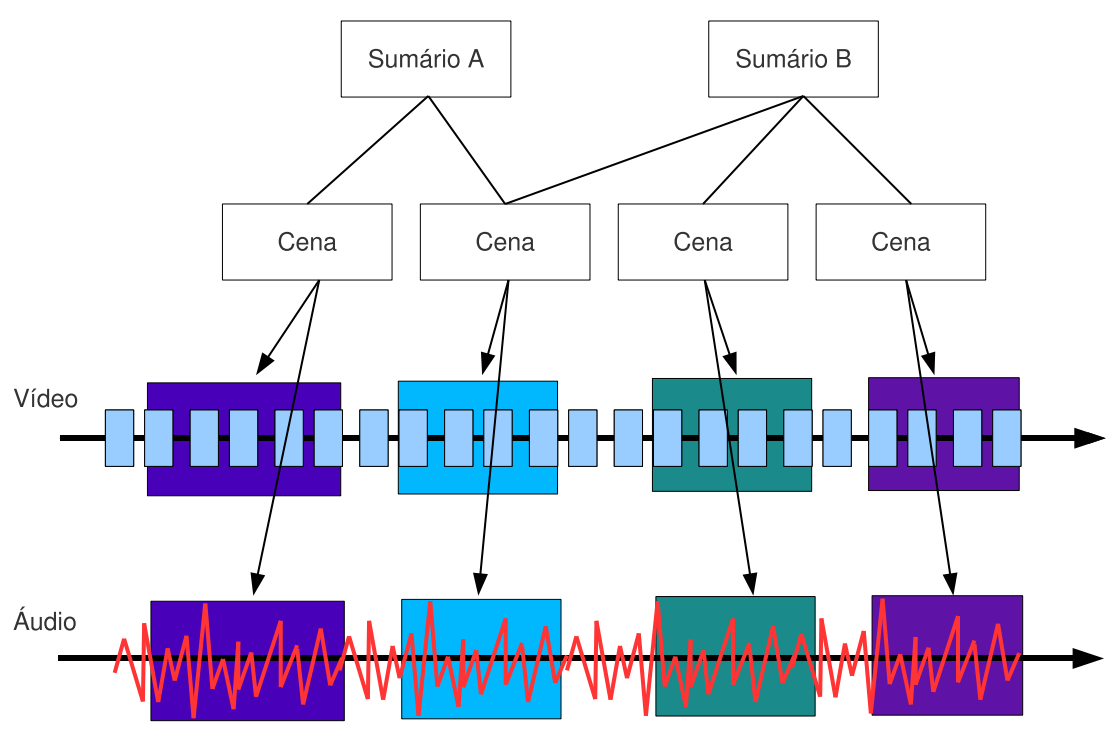

Figura 2.4: Sumarização temporal de conteúdo segmentado [Magalhães \& Pereira, 2004].

agrupamento de Delaunay, que utiliza histogramas de cores de cada imagem. Uma vez que quadros semelhantes estão agrupados, a sumarização é finalizada por meio da seleção do quadro mais próximo do centro de cada grupo, obtendo-se, assim, um conjunto de quadros representativos de todo o vídeo.

A extração de cenas importantes também pode ser considerada pertencente à sumarização temporal. Devido à necessidade de processamento em nível semântico do fluxo de vídeo, os trabalhos relacionados nessa área geralmente exploram um domínio de dados específico. Xiong [2006], por exemplo, utiliza modelos de Markov aplicados a rótulos de vídeo e áudio para extrair cenas importantes de esportes, em particular, futebol e golfe. Os rótulos de áudio são criados usando uma classificação baseada em modelos de mistura Gaussiana, e os rótulos de vídeo são criados pela quantização da média das magnitudes dos vetores de movimento. A extração de cenas importantes em jogos de baseball é realizada por Cheng \& Hsu [2006], que utilizam modelos de semelhança para criar categorias de áudio e movimento a fim de auxiliar o processo de extração. Outros domínios explorados na literatura incluem: filmes, notícias, reuniões, registros pessoais e tênis de mesa [Otsuka et al., 2006; Xiong et al., 2006; Zhang et al., 2007].

Em tempo, salienta-se que a necessidade de restrição de domínio de dados das técnicas supracitadas é reduzida pela arquitetura de personalização proposta neste trabalho, que utiliza anotações colaborativas dos usuários para criar metadados semânticos relacionados ao conteúdo. O Capítulo 5 apresenta em detalhes o esquema 
desenvolvido.

\subsection{Seleção e Recomendação}

Segundo a taxonomia proposta por Magalhães \& Pereira, ilustrada na Figura 2.1, as técnicas de P\&A são divididas em dois grupos: a Adaptação, que fornece mecanismos para modificar os dados originais de acordo com as necessidades do sistema e/ou preferências do usuário; e a Seleção ou Recomendação, que envolve apenas procedimentos de filtragem e/ou seleção de conteúdo sem alterar os dados originais [Magalhães \& Pereira, 2004]. Apesar dessa classificação expandir somente as técnicas de adaptação em três aspectos disjuntos (percepção, semântica e dispositivos/rede), verifica-se que os trabalhos sobre seleção e recomendação também podem explorar informações sobre usuários, conteúdo e infraestrutura.

No contexto de infraestrutura, pode-se utilizar a seleção ${ }^{5}$ para se distribuir conteúdo audiovisual aos usuários com diferentes restrições de rede e de dispositivos. Produz-se um número de cópias dos dados codificados com uma variedade de parâmetros, tais como taxas de bits, resoluções e formatos de apresentação. Tais cópias são disponibilizadas para acesso por clientes com velocidades de rede variadas e dispositivos com características limitadas [Dogan et al., 2004]. Um exemplo dessa estratégia é o sistema RealSystem G2, proposto pela RealNetworks ${ }^{6}$ [Lippman, 1999], que implementa um codificador capaz de produzir múltiplas representações (ou fluxos) do conteúdo original, otimizadas de acordo com as características de diferentes canais de comunicação. Os fluxos codificados são armazenados em arquivos específicos, facilitando sua recuperação pelo servidor. Durante uma sessão de streaming, um cliente monitora a largura de banda atual e as estatísticas de perda de dados da conexão, e instrui o servidor para enviar um determinado fluxo de dados, específico para as atuais condições, a fim de reduzir possíveis problemas de transmissão e distorções na reconstrução do sinal [Conklin et al., 2001].

No contexto de usuários e conteúdo, a seleção consiste em fornecer conteúdo multimídia com base em critérios pré-definidos, e nas preferências ou características de cada indivíduo. Propagandas de produtos, lojas ou serviços, por exemplo, podem ser selecionadas de acordo com a região em que o usuário se encontra, ou então relacionando-as com as intenções atuais do mesmo [Magalhães \& Pereira, 2004]. Adicionalmente, sistemas de seleção podem oferecer filtragens de vídeos, imagens, músicas e documentos ao usuário a partir de um pré-processamento de suas preferências, de modo a maximizar a probabilidade de tal indivíduo se interessar

\footnotetext{
${ }^{5}$ Neste caso, a seleção também é chamada de modelo de distribuição por difusão simultânea.

${ }^{6}$ http://www.realnetworks.com, último acesso em 10 de Novembro de 2010.
} 
pelo conteúdo fornecido [Adomavicius \& Tuzhilin, 2005].

Os sistemas de recomendação, por sua vez, vêm se tornando um importante nicho de pesquisa nos últimos anos. O interesse é devido a uma série de problemas multi-disciplinares que precisam ser estudados, além de possibilidades de desenvolvimento de aplicações que podem auxiliar usuários a gerenciar a grande quantidade de conteúdo multimídia disponível atualmente [Adomavicius \& Tuzhilin, 2005]. Normalmente, as técnicas de recomendação são classificadas em três categorias distintas: filtragem baseada em conteúdo, filtragem colaborativa e filtragem híbrida. Nas próximas subseções, cada estratégia é descrita em detalhes.

\subsubsection{Filtragem Baseada em Conteúdo}

A recomendação baseada em conteúdo consiste em prover uma filtragem de dados audiovisuais a partir de itens aprovados anteriormente pelo usuário [Gauch et al., 2007]. Analisando os metadados do conteúdo previamente apreciado pelo indivíduo, o sistema seleciona novos vídeos, músicas, imagens e documentos cuja descrição se assemelha com aqueles metadados considerados. Como exemplo, em um sistema de recomendação de filmes, a filtragem é realizada a partir de uma série de informações sobre o vídeo, tais como atores, gêneros, palavras-chave e título, que têm pesos agregados indicando a importância de tais metadados para o usuário. Informações com alto grau de interesse são usadas para se recuperar filmes relacionados que não foram ainda visitados pelo indivíduo.

A fim de manter o controle das preferências de cada cliente cadastrado no sistema, as técnicas de recomendação baseada em conteúdo mantêm um perfil de interesses para cada usuário. Normalmente, esse perfil contém dados textuais capturados dos metadados do conteúdo, juntamente com pesos indicando a importância daquelas informações. Esses pesos são calculados com base em uma avaliação do usuário sobre o conteúdo visitado, podendo ser realizada de diversas maneiras, como notas, questionários, tempo de visitação, comentários e anotações [Adomavicius \& Tuzhilin, 2005]. No Capítulo 4 as técnicas de obtenção e representação de preferências são descritas com mais detalhes.

Após a construção do perfil de interesses, sistemas de recomendação geralmente utilizam métodos provenientes da área de recuperação de informações para buscar conteúdo relacionado às preferências do usuário. Como exemplo, a equação $T F \times I D F$ (do Inglês, Term Frequency $\times$ Inverse Document Frequency - Frequência de Termos $\times$ Frequência Inversa de Documentos), definida por Salton [1989], pode ser usada para criar vetores de pesos de palavras-chave agregadas ao conteúdo. A frequência 
normalizada $T F_{i, j}$ da palavra-chave $k_{i}$ presente no documento ${ }^{7} d_{j}$ é definida como:

$$
T F_{i, j}=\frac{n_{i, j}}{\sum_{z} n_{z, j}}
$$

onde $n_{i, j}$ é o número de ocorrências da palavra-chave $k_{i}$ no documento $d_{j}$; e o denominador é a soma do número de ocorrências de todas as palavras-chave $k_{z}$ no documento $d_{j}$. A frequência inversa $I D F_{i}$ da palavra-chave $k_{i}$ é definida como:

$$
I D F_{i}=\log \frac{|D|}{\left|\left\{d: k_{i} \in d\right\}\right|}
$$

onde $|D|$ é o número total de documentos; e $\left|\left\{d: k_{i} \in d\right\}\right|$ representa o número de documentos em que a palavra-chave $k_{i}$ aparece. Portanto, o peso $w_{i, j}$ de uma palavra-chave $k_{i}$ no documento $d_{j}$ é definido como:

$$
w_{i, j}=T F_{i, j} \times I D F_{i}
$$

Assim, considera-se o item $s$ passivel de ser recomendado ao usuário $u$. A descrição de $s$ é formada pelo conjunto de pesos $w_{i, s}$ (Equação 2.3); e o perfil de $u$ é formado pelo conjunto de pesos $w_{i, u}$ (calculados com base na avaliação do usuário). Com base nessas informações, cria-se um ranking dos itens disponíveis usando uma função de correlação, como a medida de similaridade por cosseno [Baeza-Yates \& Ribeiro-Neto, 1999; Salton, 1989]:

$$
\cos (u, s)=\frac{\sum_{i=1}^{K} w_{i, u} w_{i, s}}{\sqrt{\sum_{i=1}^{K} w_{i, u}^{2}} \sqrt{\sum_{i=1}^{K} w_{i, s}^{2}}},
$$

onde $K$ é o número total de palavras-chave no sistema.

Outros modelos de recomendação exploram informações estatísticas e técnicas de aprendizado de máquina, tais como classificadores Bayesianos [Mooney et al., 1998], agrupamentos, árvores de decisão e redes neurais artificiais [Pazzani \& Billsus, 1997]. Porém, de modo geral, a filtragem baseada em conteúdo apresenta diversas limitações, que são descritas a seguir.

\footnotetext{
${ }^{7}$ O termo 'documento', neste caso, representa o conjunto de metadados textuais que descrevem um item multimídia apto a ser recomendado.
} 


\section{Análise Limitada de Conteúdo}

Um problema existente com a filtragem baseada em conteúdo é a necessidade de se ter disponíveis metadados representativos sobre os itens a serem recomendados. Essas informações, quando textuais, podem ser eficientemente processadas por técnicas de recuperação de informações; no entanto, quando não-textuais, requerem métodos complexos de extração de características, pois é necessário analisar dados provenientes de imagens, vídeo e áudio, a fim de se obter informações capazes de descrever o conteúdo semanticamente. Por outro lado, a extração pode ser realizada manualmente, como uma descrição. Contudo, tal tarefa é suscetivel a erros e dispendiosa, à medida que mais conteúdo multimídia é criado diariamente [Shardanand \& Maes, 1995]. Um estudo de algumas técnicas de extração de características em conteúdo audiovisual é apresentado no Capítulo 3.

\section{Sobre-Especialização}

A sobre-especialização (do Inglês, overspecialization) é um problema gerado quando o sistema é incapaz de recomendar itens diferentes do perfil do usuário, resultando em uma limitação do fornecimento de conteúdo, pois apenas itens parecidos com aqueles já vistos serão selecionados pelo sistema. Algumas estratégias foram propostas na literatura para reduzir esse problema, como o uso de algoritmos genéticos [Sheth \& Maes, 1993], a não recomendação de itens muito similares [Billsus \& Pazzani, 2000], e o uso de medidas de redundância para avaliar se um item parecido contém informações adicionais [Zhang et al., 2002]. Em suma, a diversidade de recomendações deve ser considerada, de modo a fornecer diferentes opções ao usuário, ao invés da seleção de apenas um conjunto de itens homogêneos [Adomavicius \& Tuzhilin, 2005].

\section{Problema do Novo Usuário}

Na filtragem baseada em conteúdo, é necessário que um novo usuário forneça inicialmente um conjunto de avaliações para que o sistema seja capaz de entender suas preferências. Assim, somente aqueles usuários que já proveram informações sobre seus interesses é que serão beneficiados com recomendações eficazes [Adomavicius \& Tuzhilin, 2005].

\subsubsection{Filtragem Colaborativa}

Sistemas de recomendação colaborativos procuram encontrar itens de interesse para o usuário a partir de avaliações feitas por outras pessoas. Define-se um conjunto 
de indivíduos cujos interesses são similares, e recomendam-se itens apreciados por esses indivíduos ao usuário em questão. Como exemplo, em um sistema de recomendação de filmes, a fim de se recomendar filmes ao usuário $u$, o sistema procura outros usuários que são "pares" de $u$, ou seja, com preferências parecidas. Assim, somente aqueles filmes que obtiveram avaliações positivas pelos pares de $u$ são selecionados.

Pode-se também realizar a filtragem colaborativa com base na similaridade de conteúdo. As avaliações de um vídeo, por exemplo, que são provenientes de diversos clientes, são usadas para encontrar vídeos que se assemelham entre si. Desse modo, realiza-se a recomendação desses dados, que são parecidos com o conteúdo já avaliado positivamente pelo usuário.

Muitos trabalhos em filtragem colaborativa são encontrados na literatura. Essa abordagem tornou-se especialmente conhecida durante o Prêmio Netflix ${ }^{8}$, que contribuiu com o surgimento de duas direções para pesquisa: o uso de decomposição de valor singular (do Inglês, Singular Value Decomposition - SVD) a fim de agrupar itens e usuários parecidos usando uma série de fatores latentes semânticos [Koren et al., 2009], e a combinação de múltiplos algoritmos de recomendação para melhorar o desempenho [Bell \& Koren, 2007]. Além desses esforços, é possível encontrar filtragem colaborativa em sistemas conhecidos, como Amazon ${ }^{9}$, GroupLens [Konstan et al., 1997], Video Recommender [Hill et al., 1995], Ringo [Shardanand \& Maes, 1995], PHOAKS [Terveen et al., 1997] e Jester [Goldberg et al., 2001].

A função de similaridade entre usuários (ou entre itens) é baseada em avaliações criadas anteriormente. Em geral, utiliza-se como método de avaliação um conjunto de notas passiveis de serem escolhidas para cada item. Considera-se uma nota $r$ sendo que $r \in\{0.5,1,1.5, \ldots, 5\} \equiv R$. Um conjunto de itens avaliados pelo usuário $u$ é representado por $S_{u}$; e com base nesse conjunto, define-se uma função de avaliação para esse usuário como sendo: $\delta_{u}: s \in S_{u} \mapsto \delta_{u}(s) \in R$. Adicionalmente, define-se $S_{u v}$ para indicar o conjunto de todos os itens avaliados pelos usuários $u$ e $v$, ou seja, $S_{u v}=\left\{s \in S \mid \delta_{u}(s) \neq \varnothing \quad \& \quad \delta_{v}(s) \neq \varnothing\right\}$. A função de similaridade $\operatorname{sim}(u, v)$ pode ser definida por meio de uma correlação de Pearson [Resnick et al., 1994]:

$$
\operatorname{sim}(u, v)=\frac{\sum_{s \in S_{u v}}\left(\delta_{u}(s)-\bar{\delta}_{u}\right)\left(\delta_{v}(s)-\bar{\delta}_{v}\right)}{\sqrt{\sum_{s \in S_{u v}}\left(\delta_{u}(s)-\bar{\delta}_{u}\right)^{2} \sum_{s \in S_{u v}}\left(\delta_{v}(s)-\bar{\delta}_{v}\right)^{2}}},
$$

onde $\bar{\delta}_{u}$ é a média de todas as notas atribuídas pelo usuário $u$, e $\bar{\delta}_{v}$ o mesmo para o usuário $v$. De modo alternativo, pode-se definir a mesma função usando a medida de

\footnotetext{
${ }^{8}$ http://www.netflixprize.com, último acesso em 10 de Novembro de 2010.

${ }^{9}$ http://www.amazon.com, último acesso em 10 de Novembro de 2010.
} 
similaridade por cosseno [Breese et al., 1998], ou seja:

$$
\operatorname{sim}(u, v)=\frac{\sum_{s \in S_{u v}} \delta_{u}(s) \delta_{v}(s)}{\sqrt{\sum_{s \in S_{u v}} \delta_{u}(s)^{2}} \sqrt{\sum_{s \in S_{u v}} \delta_{v}(s)^{2}}} .
$$

A correlação de Pearson apresenta uma vantagem sobre a similaridade por cosseno porque ela considera a possibilidade de usuários adotarem diferentes escalas de notas. Assim, ao invés de se usar valores absolutos, a Equação 2.5 utiliza os desvios da média de notas de cada usuário [Adomavicius \& Tuzhilin, 2005].

Após definida a função de similaridade, utilizam-se os $N$ usuários mais parecidos com $u$ para formar o conjunto de indivíduos $\hat{U}$. A partir dele, pode-se calcular de diferentes maneiras a nota $\delta_{u}\left(s^{\prime}\right)$ do novo item $s^{\prime}$ passivel de ser recomendado a $u$. Alguns exemplos são [Adomavicius \& Tuzhilin, 2005]:

$$
\begin{aligned}
& \text { (1) } \delta_{u}\left(s^{\prime}\right)=\frac{1}{N} \sum_{v \in \hat{U}} \delta_{v}\left(s^{\prime}\right), \\
& \text { (2) } \delta_{u}\left(s^{\prime}\right)=k \sum_{v \in \hat{U}} \operatorname{sim}(u, v) \times \delta_{v}\left(s^{\prime}\right), \\
& \text { (3) } \delta_{u}\left(s^{\prime}\right)=\bar{\delta}_{u}+k \sum_{v \in \hat{U}} \operatorname{sim}(u, v) \times\left(\delta_{v}\left(s^{\prime}\right)-\bar{\delta}_{v}\right),
\end{aligned}
$$

onde $k$ é um fator de normalização definido como $k=1 / \sum_{v \in \hat{U}}|\operatorname{sim}(u, v)|$.

A filtragem colaborativa é capaz de reduzir o problema da sobre-especialização existente na abordagem baseada em conteúdo. Isso acontece porque o sistema não tem conhecimento sobre os metadados de cada item, explorando apenas as avaliações atribuídas anteriormente pelos usuários. No entanto, outras limitações podem ser encontradas, as quais são descritas a seguir.

\section{Problema do Novo Usuário}

O problema do novo usuário também está presente na filtragem colaborativa, pois o sistema não consegue definir indivíduos similares sem ter o conhecimento de um número mínimo de avaliações realizadas pelo usuário em questão. Por outro lado, a filtragem híbrida, descrita na próxima subseção, é capaz de reduzir este problema, já que combina técnicas de recomendação baseada em conteúdo e colaborativa [Adomavicius \& Tuzhilin, 2005]. Outros trabalhos reportados na literatura propõem soluções plausíveis, tais como a exploração de popularidade e entropia de itens, personalização do usuário, e a combinação dessas estratégias [Rashid et al., 2002; Yu et al., 2004]. 


\section{Problema do Novo Conteúdo}

Um efeito negativo gerado pelo fato de a filtragem colaborativa não considerar metadados acontece quando novos itens são adicionados no sistema. Torna-se necessário que eles tenham sido visitados e avaliados por um número mínimo de usuários, a fim de serem selecionados. A abordagem híbrida, descrita na próxima subseção, é capaz de reduzir este problema, já que os metadados são considerados pelo processo de recomendação [Adomavicius \& Tuzhilin, 2005].

\section{Esparsidade}

A esparsidade ocorre quando o sistema tem poucas avaliações dos itens, fazendo com que eles não sejam recomendados mesmo que tais avaliações existentes sejam positivas. Adicionalmente, existe esparsidade quando alguns usuários possuem interesses diferentes da grande maioria, não sendo possível definir um número suficiente de usuários similares para o bom desempenho da filtragem colaborativa. Uma maneira de resolver este problema é a utilização de dados demográficos sobre usuários, tais como sexo, idade, nível de escolaridade, entre outras. Consequentemente, a similaridade é definida não apenas com base nas avaliações, mas também nessas informações adicionais [Pazzani, 1999]. Pode-se também utilizar técnicas de redução de dimensionalidade ao lidar com matrizes esparsas de notas, assim como é feito por Billsus \& Pazzani [1998] e Sarwar et al. [2000], que adotam a técnica de decomposição de valor singular (SVD).

\subsubsection{Filtragem Híbrida}

Sistemas de recomendação híbridos realizam uma combinação das abordagens descritas anteriormente, ou seja, utilizam tanto informações sobre o conteúdo (metadados), como também agrupam usuários e/ou itens similares. A partir desta abordagem, é possivel reduzir alguns problemas existentes na filtragem baseada em conteúdo e na colaborativa, como a sobre-especialização, os problemas dos novos usuários e itens e esparsidade. Quatro maneiras de se agrupar ambas estratégias são verificadas na literatura:

1. implementação isolada dos métodos e posterior combinação dos resultados;

2. incorporação de algumas características da filtragem baseada em conteúdo em um sistema de recomendação colaborativo;

3. incorporação de algumas características da filtragem colaborativa em um sistema de recomendação baseado em conteúdo; 
4. construção de um modelo genérico e único que incorpora características de ambas abordagens.

No primeiro caso, pode-se usar uma combinação linear para se agrupar os resultados obtidos por cada técnica [Claypool et al., 1999]. Alternativamente, é possível analisar algumas informações sobre o conteúdo e sobre o usuário com o objetivo de se definir qual método será utilizado por vez [Billsus \& Pazzani, 2000]. Exemplos de tais informações são: quantidade de notas atribuídas a cada item, quantidade e qualidade de metadados relacionados ao conteúdo, número de avaliações feitas pelo usuário, entre outros. A principal vantagem dessa abordagem é a facilidade de implementação, podendo-se utilizar algoritmos isolados de recomendação colaborativa e baseada em conteúdo para construir uma técnica híbrida [Adomavicius \& Tuzhilin, 2005].

No segundo caso, um sistema de recomendação colaborativo incorpora algumas características da filtragem baseada em conteúdo. Balabanovic \& Shoham [1997] e Pavlov \& Pennock [2002], por exemplo, calculam a similaridade de usuários com base não apenas nas avaliações criadas anteriormente, mas também utilizando o perfil de cada indivíduo. A principal vantagem dessa estratégia é a redução do problema de esparsidade, pois é possivel criar relacionamentos entre usuários mesmo que eles não tenham avaliado os mesmos itens. Além disso, a esparsidade é reduzida uma vez que é considerado o perfil de cada indivíduo para realizar recomendações [Adomavicius \& Tuzhilin, 2005].

No terceiro caso, utilizam-se algumas características da filtragem colaborativa para melhorar o desempenho de um sistema de recomendação baseado em conteúdo. Técnicas de redução de dimensionalidade são aplicadas em um grupo de perfis a fim de se criar uma visão colaborativa de uma coleção de usuários. Tais perfis são então representados por vetores enriquecidos de termos, gerando melhores resultados do que uma abordagem baseada simplesmente em conteúdo [Soboroff \& Nicholas, 1999; Adomavicius \& Tuzhilin, 2005].

No quarto caso, desenvolve-se um modelo que incorpora características da filtragem baseada em conteúdo e da colaborativa. Esse modelo pode ser criado usando métodos probabilísticos [Popescul et al., 2001; Schein et al., 2002; Hofmann, 1999], ou regressão Bayesiana para estimativa de parâmetros [Condliff et al., 1999; Ansari et al., 2000].

Além dessas diferentes maneiras para se criar um sistema híbrido, é possível também utilizar técnicas baseadas em conhecimento para reduzir algumas limitações dos sistemas tradicionais de recomendação (como os problemas dos novos usuários e itens). Como ilustração, o sistema Entrée [Burke, 2000] utiliza dados semânticos sobre restaurantes e culinária (por exemplo, "frutos do mar" não é "comida vegetariana”) com o objetivo de fornecer uma seleção de restaurantes para seus usuários. 
Geralmente, sistemas de filtragem baseados em conhecimento são desenvolvidos para domínios de dados onde essas informações de alto-nível estão disponíveis em uma forma estruturada para análise computacional, como em uma ontologia. Apesar de tal estrutura de conhecimento ser difícil de ser implementada por profissionais sem restrição de domínio, a viabilidade desses dados semânticos é o ponto-chave para o funcionamento eficaz de tal abordagem [Adomavicius \& Tuzhilin, 2005].

\subsection{Considerações Finais}

Este capítulo apresentou uma contextualização dos trabalhos existentes sobre P\&A, organizados segundo a taxonomia proposta por Magalhães \& Pereira [2004]. Observa-se um conjunto de esforços atuando na área de adaptação de conteúdo, de modo a fornecer dados multimídia modificados de acordo com a infraestrutura do ambiente computacional, tais como dispositivos e redes. Notam-se também trabalhos que procuram fornecer adaptação e personalização de conteúdo com base na percepção do usuário, considerando suas sensações, limitações físicas e localização. Verificam-se ainda técnicas que atuam diretamente com o significado do conteúdo (como serviços de sumarização temporal e espacial), sendo necessário procedimentos para extrair informações semânticas dos dados a partir de suas características de baixo-nível (como níveis de cores, histogramas, entre outras). Por fim, observam-se inúmeros trabalhos que propõem técnicas de seleção e recomendação com o objetivo de fornecer ao usuário uma filtragem dos dados de acordo com suas preferências.

Conforme pode ser observado neste capítulo, as técnicas de P\&A necessitam de dois tipos de informações para proverem seus serviços: i) informações sobre o usuário, incluindo seus interesses particulares, limitações, dispositivos utilizados e meio ambiente no qual está inserido; e ii) metadados sobre o conteúdo, que descrevem os dados semanticamente, e estruturados de modo a permitir a análise computacional pelo sistema.

Ambos os tipos de informações podem ser representados por metadados criados na indexação multimídia (automática ou manual). As descrições criadas durante a indexação podem ser informações de baixo nível sobre o conteúdo, como formato, tipo de codificação e histograma de cores, ou então podem considerar metadados semânticos a respeito do item multimídia, tais como os atores presentes em uma cena, local de gravação do conteúdo, assuntos discutidos, entre outros.

No caso de informações semânticas, em particular, tais dados contribuem de diversas maneiras para a área de $\mathrm{P} \& \mathrm{~A}$, seja atuando no processo de indexação de conteúdo, ou então na construção do perfil do usuário. Ao longo deste capítulo, foram citados vários exemplos em que os serviços podem ser aperfeiçoados com 
o uso de metadados semânticos. Na conversão de modalidade, por exemplo, o conhecimento do conteúdo pode oferecer subsídios na definição da melhor estratégia de adaptação; na sumarização, as informações semânticas podem ser exploradas para se decidir quais elementos espaciais e temporais serão eliminados do fluxo de acordo com os interesses do indivíduo. Na recomendação, em especial, alguns problemas podem ser reduzidos: a análise limitada de conteúdo, uma vez que serão fornecidas descrições conceituais sobre os dados; e os problemas da sobre-especialização e do novo usuário, já que um perfil mais rico semanticamente será usado para representar as preferências do indivíduo.

Atualmente, entretanto, os serviços de P\&A com suporte à semântica apresentam limitações devido ao problema da indexação. Conforme será discutido no próximo capítulo, as técnicas automáticas para descrição semântica de conteúdo são restritas a um domínio de dados específico, sendo difícil sua utilização em situações reais. Por outro lado, a descrição manual, conforme será argumentado no Capítulo 4, é uma atividade dispendiosa e propensa a erros.

No caso da representação das preferências do usuário, o perfil de interesses, segundo mencionado na Subseção 2.4.3, pode oferecer uma melhor descrição se for baseado em conhecimento; contudo, a representação desse conhecimento em estruturas conhecidas, como ontologias, sem restrição de domínio, é uma tarefa difícil de ser realizada por profissionais. Adicionalmente, o Capítulo 4, Subseção 4.3.1 argumenta que quanto mais informações sobre o usuário forem capturados, mais preciso será seu perfil de interesses [Teevan et al., 2005].

Tais problemas são investigados pela presente tese por meio de uma abordagem alternativa para se extrair essas informações. Propõe-se uma arquitetura de personalização que utiliza anotações colaborativas dos usuários para auxiliar o processo de indexação multimídia. Além disso, a arquitetura considera a atividade de enriquecimento de conteúdo pelo usuário, mantendo a individualidade das anotações produzidas, para que essas informações possam ser complementares ao perfil de preferências do mesmo. Como resultado, disponibiliza-se um processo de indexação mutlimídia irrestrito ao domínio de dados e barato ${ }^{10}$; simultaneamente, obtém-se uma representação multimodal e semanticamente estruturada dos interesses pessoais do usuário.

Assim, como um modo de aprofundar essa discussão, o Capítulo 3 descreve alguns trabalhos relevantes relacionados à indexação automática de conteúdo audiovisual. Posteriormente, o Capítulo 4 discute várias abordagens manuais de anotação multimídia e enriquecimento de conteúdo, juntamente com estratégias existentes na

\footnotetext{
${ }^{10}$ O termo "barato", neste tese, indica que a arquitetura não necessita de grandes esforços de profissionais para a indexação multimídia, ao contrário das abordagens manuais discutidas no Capítulo 4, Subseção 4.2.1.
} 
literatura para se construir as preferências de cada usuário. Por fim, os Capítulos 5 e 6 apresentam, respectivamente, a arquitetura de personalização proposta e algumas aplicações desenvolvidas baseadas na nova abordagem. 


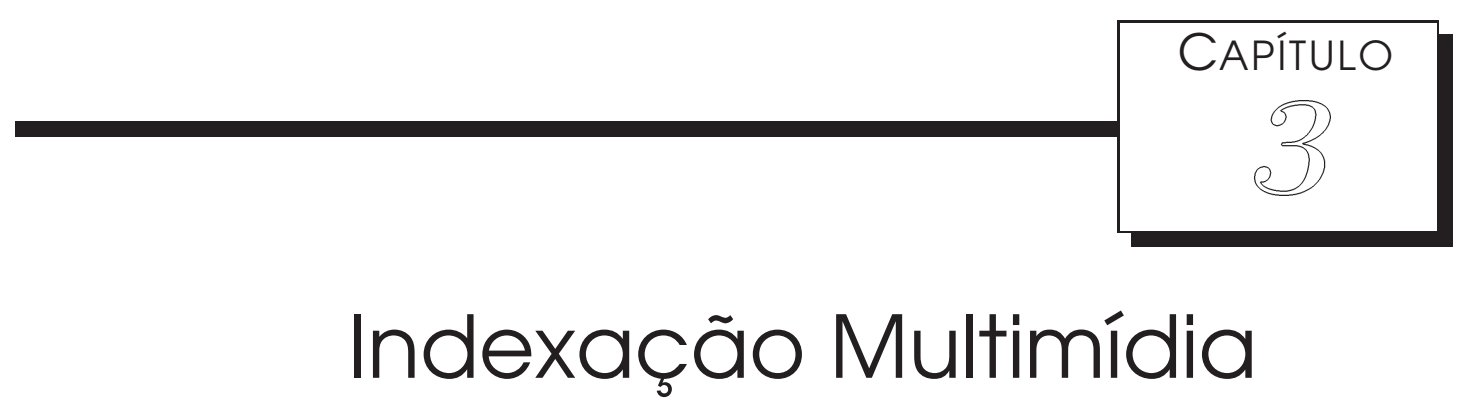

$\mathrm{S}$ erviços de personalização requerem um conhecimento sobre o conteúdo, de modo a proverem dados audiovisuais de acordo com as preferências de cada usuário. Esse conhecimento é representado por descrições contendo rótulos textuais, índices e marcações temporais e espaciais a respeito do conteúdo multimídia. A criação dessas informações é chamada de indexação multimídia [Hampapur et al., 1995], e é normalmente realizada por especialistas para posterior disponibilização em provedores de conteúdo.

Marcações podem ser construídas manualmente ou automaticamente. No primeiro caso, profissionais atribuem um número limitado de metadados ao conteúdo. Devido à natureza especialista do trabalho de indexação, a descrição manual torna essa tarefa um processo demorado, caro e propenso a erros, requerendo grandes esforços para se anotar uma quantidade crescente de dados audiovisuais [Snoek \& Worring, 2005]. A descrição automática, por sua vez, pode reduzir esse problema, pois metadados são definidos pelo sistema, sem intervenção humana, a partir de análises do fluxo de dados. No entanto, a complexidade das técnicas de indexação tende a aumentar à medida que mais dados semânticos são requisitados pelas aplicações.

O propósito deste capítulo é apresentar as principais abordagens para obtenção automática de metadados, discutindo o estado da arte e limitações existentes nas técnicas atuais. Esta descrição é importante pois irá fomentar uma das contribuições da presente tese, que é um mecanismo de indexação multimídia capaz de agregar semântica aos dados por ser baseado em anotações do usuário. Salienta-se que uma discussão dos métodos manuais de indexação multimídia pode ser encontrada no 
Capítulo 4, Seção 4.2, juntamente com técnicas que auxiliam a criação de anotações de enriquecimento pelos usuários.

De acordo com a definição de conteúdo multimídia apresentada no Capítulo 2, os dados são representados por três modalidades distintas: visual, auditiva e textual ${ }^{1}$. A partir desses tipos, técnicas automáticas de indexação podem seguir uma abordagem monomodal [Mohan \& Yegnanarayana, 2010; Das \& Geetha, 2010; Lee et al., 2009], ou seja, explora-se apenas uma modalidade por vez; ou multimodal, que combina dados de múltiplas fontes para se obter uma melhor descrição do conteúdo [Fendri et al., 2010; Yan et al., 2007; Montagnuolo \& Messina, 2009].

Snoek \& Worring [2005] propuseram um esquema unificado para indexação multimodal de vídeo, que pode ser utilizado para representar eficientemente uma classificação das técnicas de indexação existentes na literatura. Com base em tal esquema, é possível verificar como os trabalhos relacionados à descrição automática de conteúdo multimídia estão organizados. A Figura 3.1 ilustra o esquema proposto, que segue uma perspectiva do autor do conteúdo.

Na Indexação Semântica, descrevem-se em diferentes niveis de granularidade as informações significativas do conteúdo. A modelagem desses níveis de detalhamento é caracterizada na Figura 3.1 dividindo-se a indexação semântica em 5 segmentos hierarquizados [Snoek \& Worring, 2005]. No topo da hierarquia, o Propósito refere-se a um conjunto de vídeos que compartilham um mesmo propósito ou intenção; como exemplo, entretenimento, informação ou comunicação [Jain \& Hampapur, 1994]. Logo abaixo, o Gênero indica um conjunto de vídeos classificados com um mesmo gênero ou estilo, como filmes, comerciais ou notícias. Em um nível inferior, o Subgênero representa um subconjunto de um gênero onde o conteúdo compartilha informações similares; como exemplo, filmes de comédia, biografias, jogos de tênis, entre outros. Em Unidades Lógicas, a descrição está relacionada a um grupo de eventos nomeados ou outras unidades lógicas que, quando combinados, têm um significado semântico; um exemplo pode ser uma cena de roubo a banco em um filme de ação, ou o primeiro tempo de um jogo de basquete. No último nível, Eventos Nomeados caracterizam segmentos cujo significado não muda com o tempo: um beijo em um filme de romance, um gol em um jogo de futebol ou a visualização da previsão do tempo em uma notícia sobre o clima.

No aspecto Conteúdo, relacionam-se segmentos aos elementos utilizados pelo autor para criar um vídeo. Em Configurações (letra C na Figura 3.1), envolve-se o tempo e o lugar onde a história sendo contada no vídeo está situada, podendo também representar a fotografia, atmosfera ou estado de espírito. Em Objetos (letra $\bigcirc$

\footnotetext{
${ }^{1}$ Apesar de a definição de multimídia referenciar as modalidades de acordo com os canais sensoriais humanos (visão, audição, tato e paladar), por conveniência, assume-se neste trabalho que modalidade está relacionada à maneira em que os dados são representados (áudio, vídeo, texto e imagem)
} 


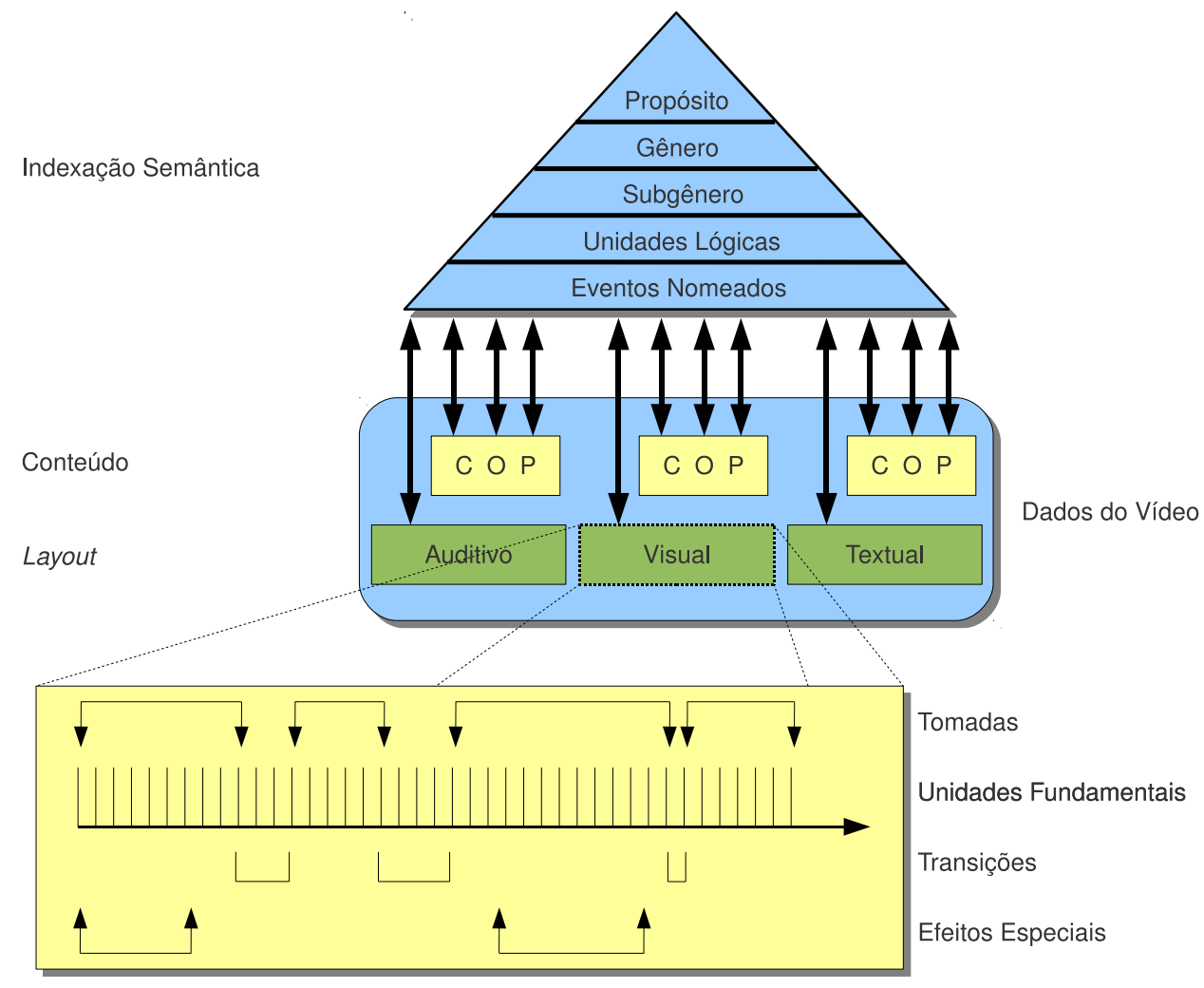

Figura 3.1: Esquema unificado para indexação multimodal de vídeo [Snoek \& Worring, 2005]. As letras C, O e P indicam, respectivamente, os conceitos configurações, objetos e pessoas.

na Figura 3.1), descrevem-se entidades estáticas ou dinâmicas em destaque no vídeo. Em Pessoas (letra P na Figura 3.1), consideram-se seres humanos sendo filmados [Snoek \& Worring, 2005].

O Layout define a estrutura sintática que um autor utiliza durante a edição do vídeo. Basicamente, essa estrutura é formada por uma sequência temporal de Unidades Fundamentais, que variam de acordo com as diferentes modalidades existentes. Na modalidade visual, a unidade fundamental é um quadro; na auditiva, um conjunto de amostras obtido em um instante específico; e na textual, uma simples letra do alfabeto ou símbolo qualquer. A partir da agregação dessas unidades fundamentais, define-se o conceito de Tomadas, que, de acordo com as modalidades visual e auditiva, representam, respectivamente, uma gravação contínua ou não-interrupta de uma câmera ou microfone. No caso da modalidade textual, uma tomada é definida como uma expressão textual contínua ou ininterrupta, que pode estar em um nível de palavras ou sentenças [Snoek \& Worring, 2005].

As tomadas podem ser concatenadas usando Transições, que inferem relacionamentos entre as tomadas, de modo a guiar o pensamento e as respostas emocionais 
do telespectador. No caso da modalidade visual, definem-se transições abruptas, como um corte repentino de um quadro a outro, ou transições graduais, como wipes, fades e dissolução. No caso de transições auditivas, pode-se utilizar melodias ou volume para oferecer uma mudança suave, ou silêncio para representar uma transição abrupta. Na modalidade textual, é comum encontrar sequências de símbolos específicos para indicar uma transição, principalmente em closed-caption, onde a sequência ">>> é usada para indicar uma mudança de tomada [Snoek \& Worring, 2005].

Por fim, Efeitos Especiais podem ser criados para melhorar o impacto de uma informação, ou para adicionar novos significados [Snoek \& Worring, 2005]. Exemplos de efeitos especiais são legendas, efeitos sonoros e edições visuais em 3 dimensões.

Nas próximas seções deste capítulo, descrevem-se os trabalhos existentes em diversos aspectos ilustrados no esquema de indexação multimodal proposto por Snoek \& Worring [2005]. Tal discussão tem como objetivo fornecer uma visão detalhada das técnicas automáticas de indexação multimídia.

\subsection{Segmentação de Vídeo}

A segmentação de vídeo consiste em identificar os elementos que compõem os aspectos layout e conteúdo ilustrados na Figura 3.1. A partir de dados audiovisuais de um vídeo, obtêm-se informações sobre a configuração, objetos e pessoas (segmentação espacial); e adicionalmente, obtêm-se informações sobre tomadas, unidades fundamentais, transições e efeitos especiais (segmentação temporal). Na próxima subseção, descrevem-se abordagens que exploram conceitos relacionados ao reconhecimento de padrões. Em seguida, são apresentados nas próximas subseções trabalhos que lidam com a reconstrução de layout e detecção de configurações, objetos e pessoas.

\subsubsection{Reconhecimento de Padrões}

O reconhecimento e análise de certos padrões no fluxo de dados são necessários para que sejam viáveis os processos de segmentação espacial e temporal. Exemplos de padrões de interesse que podem ser explorados são: regiões importantes de uma imagem, amostras significativas e características derivadas dos elementos de layout e conteúdo [Snoek \& Worring, 2005]. Segundo Jain et al. [2000], as abordagens para reconhecimento de padrões que geram melhores resultados são:

- Equivalência de Modelos (do Inglês, Template Matching): o padrão a ser reconhecido é comparado a um modelo pré-definido, sendo possível seu ajuste em relação à posição espacial e escala; 
- Classificação Estatística: o padrão a ser reconhecido é classificado com base na distribuição de padrões no espaço baseada em valores dos parâmetros considerados;

- Equivalência Sintática e Estrutural (do Inglês, Syntactic or Structural Matching): o padrão a ser reconhecido é comparado com um conjunto pequeno de primitivas analisadas e regras gramaticais para combinação de tais primitivas;

- Redes Neurais: o padrão a ser reconhecido é aplicado a uma rede artificial de neurônios que é previamente treinada a partir de amostras conhecidas.

A equivalência de modelos funciona como um mapeamento entre conceitos em alto nível e funcionalidades visuais em baixo nível. Normalmente, define-se um modelo como uma funcionalidade representativa de um conceito, calculada a partir de uma coleção de amostras [Zhuang et al., 1999]. Um modelo visual pode ser composto por um conjunto de ícones ou objetos/cenas-exemplo, denotando uma visão personalizada de conceitos, tais como encontros, pôr-do-sol, entre outros. Essa técnica tem como desvantagem a necessidade da interação com o usuário de modo que o resultado possa ser convergido para um conjunto pequeno de amostras com alta similaridade ao modelo fornecido [Chang et al., 1998].

A classificação estatística pode ser realizada com base em diferentes técnicas, tais como máquinas de vetor de suporte (do Inglês, Support Vector Machines SVM), classificadores Bayesianos, árvores de decisão, modelos escondidos de Markov (do Inglês, Hidden Markov Models - HMM), entre outras. SVMs e classificadores Bayesianos são computacionalmente caros, uma vez que grandes quantidades de dados são necessários para treinamento. Além disso, a obtenção de amostras para a fase de treinamento é uma tarefa exaustiva, podendo gerar erros de classificação. Árvores de decisão, por sua vez, quando utilizadas com conceitos em alto nível, podem gerar problemas de falta de modularidade [Liu et al., 2007].

Ainda entre os trabalhos de classificação estatística, a teoria Bayes para classificação por probabilidade está entre as ferramentas de clusterização mais poderosas. Juntamente com o classificador maximum-a-posteriori (MAP) e sua variação Estimativa de Máxima Verossimilhança (do Inglês, Maximum-Likelihood Estimation - MLE), os trabalhos relacionados [Vasconselos, 2003; 2004] têm mostrado ótimos resultados, principalmente em recuperação de imagens baseada em conteúdo. No entanto, é difícil utilizar os classificadores na prática devido à complexidade da função de similaridade [Liu et al., 2007]. 


\subsubsection{Reconstrução de Layout}

A reconstrução de layout, ou segmentação temporal, consiste em detectar automaticamente mudanças de tomadas, identificando os tipos de transição utilizados pelo autor durante a criação do vídeo. Índices e marcações dessa natureza são importantes, pois além de facilitarem a busca por momentos específicos do vídeo, oferecem ainda sugestões sobre a mensagem do conteúdo sendo passada pelo autor.

Na modalidade visual, diversos trabalhos podem ser encontrados sobre detecção de mudança de tomadas (do Inglês, shot boundary detection). Cortes abruptos são identificados a partir de comparações entre quadros sucessivos, usando limiares estáticos ou dinâmicos relacionados à diferença entre pixels, arestas, blocos ou quadros. Vetores de movimento também são explorados, principalmente quando se utiliza vídeos previamente codificados. Transições graduais, por sua vez, são mais difíceis de serem detectadas, necessitando de estratégias mais complexas. Pesquisas nessa área, incluindo uma revisão da literatura, podem ser encontradas nos trabalhos de Manzato \& Goularte [2007], Cernekova et al. [2006] e Koprinska \& Carrato [2001].

Na modalidade auditiva, a detecção de mudança de tomada é feita a partir da identificação de silêncio, ou pontos de transição, ou seja, momentos no fluxo de áudio em que o sinal altera seu comportamento. Nesse sentido, encontram-se trabalhos na literatura que exploram a energia do sinal para detecção de ausência de som [Patel \& Sethi, 1996; Li, 2001]; e taxa de cruzamento zero (do Inglês, zero-crossing rate - ZCR) para distinguir música de fala, silêncio e sons ambientais [Ghosal et al., 2009].

$\mathrm{Na}$ modalidade textual, geralmente o primeiro passo é o processo de divisão do texto em unidades representadas por letras ou palavras. Tomadas textuais podem ser detectadas de várias maneiras, que dependem do nível de granularidade utilizado. Espaço em branco ou ponto-final, por exemplo, podem indicar, respectivamente, mudança de tomada nos níveis de palavras ou frases [Manning \& Schütze, 1999]. Transições, por sua vez, são tipicamente encontradas utilizando padrões pré-definidos [Snoek \& Worring, 2005; Cesario et al., 2008; Cour et al., 2008].

\subsubsection{Segmentação de Conteúdo}

A segmentação de conteúdo, ou espacial, consiste em identificar automaticamente elementos presentes no conteúdo, como pessoas, objetos ou configurações (por exemplo, plano de fundo). Nas próximas subseções, descrevem-se algumas técnicas para segmentar cada um desses elementos utilizando diferentes modalidades.

\section{Detecção de Pessoas}

Na modalidade visual, uma pessoa pode ser detectada a partir de sua face [Yang et al., 2002; Abate et al., 2007], ou outras partes do corpo [Kohli et al., 2008; Bi 
et al., 2008]. No caso de faces, as técnicas necessitam considerar fatores que podem influenciar os resultados, como o posicionamento da face de diferentes maneiras no espaço tridimensional, além de diferentes configurações de luz, expressões faciais, presença de óculos e/ou maquiagem e oclusão parcial. Uma vez detectada a face, o algoritmo retorna a posição e escala em que ela foi encontrada, podendo, posteriormente, ser identificada por meio de técnicas de reconhecimento, que fazem uso de conceitos como Eigenfaces [Pentland et al., 1994] e Fisherfaces [Peter N. Belhumeur, 1997]. Problemas existentes no reconhecimento de faces incluem a necessidade de um conjunto de treinamento extenso para cada indivíduo e a falta de robustez das técnicas em relação à variação de parâmetros, como luminosidade, posição, entre outros.

Na modalidade auditiva, a presença de fala no fluxo de áudio pode indicar que uma pessoa está em destaque no vídeo. Zhang \& Kuo [1999] analisam certas características do sinal de áudio para distinguir a fala de outros tipos de som. Essas informações dizem respeito à relação entre as amplitudes da ZCR com curvas de energia, o formato, variância e intervalo da ZCR e a frequência fundamental do áudio. Li et al. [2001], por sua vez, propuseram uma técnica que é capaz de identificar a fala juntamente com ruído e/ou música, atingindo melhores resultados por meio da utilização de coeficientes cepstrais nas frequências de Mel (do Inglês, Mel-frequency cepstral coefficients - MFCC) e coeficientes de predição linear (do Inglês, linear prediction coefficients - LPC). Após a detecção, o reconhecimento de fala pode ser realizado por meio de uma análise da dicção de cada indivíduo [Heigold et al., 2009; Gales \& Young, 2008].

$\mathrm{Na}$ modalidade textual, nomes próprios podem sugerir a presença de certas pessoas. No trabalho de Satoh et al. [1999], técnicas de linguagem natural, combinadas com um dicionário e enciclopédia são capazes de localizar nomes próprios em transcrições. O reconhecimento de entidades nomeadas, que é um campo estudado pela área de linguística computacional, é explorado por Bikel et al. [1999], que procura classificar cada palavra de um documento em uma das oito categorias: pessoa, lugar, organização, data, hora, porcentagem, valor monetário, ou nenhuma das anteriores. Nesse trabalho, os autores utilizam HMM para reconhecer nomes próprios, e os resultados são considerados significativos [Snoek \& Worring, 2005].

De modo geral, as abordagens para detecção e reconhecimento de pessoas podem variar conforme a modalidade escolhida, mas cada uma apresenta limitações que ainda são objetos de pesquisa na atualidade. Na modalidade visual, a variação de luminosidade e a presença de oclusão podem prejudicar o desempenho dos métodos; sons ambientes e ruído, por sua vez, podem interferir a detecção de pessoas com base no fluxo de áudio; e nomes próprios em texto, por fim, ainda precisam de uma análise aprofundada para melhorar os resultados [Snoek \& Worring, 2005]. Contudo, 
tais problemas são reduzidos com a arquitetura proposta nesta tese (vide Capítulo 5), uma vez que é disponibilizada a alternativa de identificação de faces pelas anotações dos usuários do sistema.

\section{Detecção de Objetos}

A detecção de objetos é vista como uma generalização do problema da detecção de pessoas. Abordagens na modalidade visual exploram a identificação de objetos específicos e conhecidos [Leibe et al., 2008; Gould et al., 2009], ou a difícil tarefa de segmentação de objetos gerais e desconhecidos [Yokoyama et al., 2009; Solana-Cipres et al., 2009]. Nesse último caso, a utilização de vetores de movimento fornece os melhores resultados, principalmente se forem considerados objetos rígidos [Snoek \& Worring, 2005]. Geralmente, as técnicas iniciam com a segmentação do primeiro quadro por meio da exploração dos vetores de movimento dos objetos. Posteriormente, as regiões que compartilham uma movimentação similar são agrupadas, resultando em uma detecção dos objetos em destaque.

O problema da detecção de objetos também é estudado na análise dos dados na modalidade auditiva. Após a classificação do áudio em sons ambientais, as técnicas são capazes de reconhecer padrões conhecidos de objetos específicos, como latidos, campainhas e diferentes instrumentos musicais [Zhang \& Kuo, 1999; Livshin \& Rodet, 2009].

O reconhecimento de objetos usando texto explora dados textuais presentes em vídeos, como legendas de filmes, closed-caption de noticiários, entre outros. Um dos processos estudados é chamado de rotulação de parte da fala (do Inglês, part-of-speech tagging] [Abney, 1996], que consiste em relacionar as palavras com momentos específicos do áudio [Toutanova \& Cherry, 2009] e vídeo [Zhang et al., 2009].

Geralmente, no contexto da detecção de objetos, as técnicas que apresentam resultados satisfatórios estão limitadas a exemplos específicos, com parâmetros controlados. A identificação robusta pode ser obtida por meio de uma análise multimodal [Snoek \& Worring, 2005], mas depende de ferramentas capazes de analisar os dados em diferentes modalidades. Por outro lado, o uso de anotações do usuário, como etiquetas (vide Capítulo 4, Subseção 4.1.1), pode fornecer indícios da presença de objetos, independentemente do domínio de dados considerado. A arquitetura proposta no Capítulo 5, portanto, investiga essa abordagem de modo a fornecer melhores ferramentas para indexação multimídia. 


\section{Detecção de Configurações}

A detecção de configurações tende a ser mais fácil de ser realizada uma vez que lida-se com planos visuais estáticos, ou com pouco movimento [Smeulders et al., 2000]. A rotulação, no entanto, requer análises mais complexas, que também exploram os diferentes tipos de modalidades existentes.

Na visual, Gupta et al. [2007] classificam cenas nas categorias indoor e outdoor usando uma rede neural probabilística (do Inglês, probabilistic neural network - PNN), a partir de dados segmentados pela técnica de clusterização por lógica difusa. No trabalho de Quattoni \& Torralba [2009], um método é desenvolvido para classificar cenas do tipo indoor em 67 subcategorias diferentes, que variam de lojas e interior doméstico até lugares públicos, de lazer e de trabalho.

Na modalidade auditiva, padrões específicos do ambiente são identificados. Como exemplo, uma técnica proposta por Wold et al. [1996] é capaz de simplificar o fluxo de áudio em um conjunto reduzido de parâmetros, como nível de barulho, brilho, harmoniosidade, entre outros. Usando processos estatísticos sobre o espaço de parâmetros, os autores realizam a classificação de vários padrões de som, incluindo riso, multidões e água.

Na modalidade textual, transcrições podem ser usadas para inferir lugares, assim como é feito no trabalho de Christel et al. [2000]. Eles usam um dicionário geográfico composto de aproximadamente 300 países, estados e entidades administrativas, e 17 mil cidades espalhadas pelo mundo. Após os processos de relacionamento entre termos e remoção de stopwords, o método identifica as coordenadas geográficas relacionadas ao vídeo em questão.

Em suma, configurações sobre o ambiente são melhores identificadas por meio de análises dos dados visuais e auditivos; a localização geográfica, por sua vez, pode ser mais precisamente encontrada a partir de análises textuais. Analogamente à detecção de objetos, uma abordagem multimodal pode fornecer metadados mais significativos sobre as configurações, sendo possível identificar o ambiente, localização e elementos que compõem o plano de fundo [Snoek \& Worring, 2005]. Porém, as técnicas de reconhecimento ainda são limitadas a objetos conhecidos e parâmetros controlados.

\subsection{Análise Multimodal}

Conforme pode ser visto na introdução deste capítulo, metadados mais significativos podem ser obtidos se forem usadas abordagens multimodais, ou seja, aquelas que exploram diferentes fontes de informações do vídeo a ser indexado. $\mathrm{Na}$ próxima subseção, são apresentadas algumas técnicas de conversão de dados para a modalidade textual, a fim de facilitar o processo de integração. Posteriormente, 
descrevem-se algumas abordagens para realizar essa integração, visando a melhoria da qualidade dos metadados extraídos.

\subsubsection{Conversão}

Algumas abordagens para conversão de modalidade foram apresentadas no Capítulo 2, Subseção 2.1.3. No contexto de indexação multimídia apresentado neste capítulo, são importantes as estratégias para conversão de áudio para texto e de imagem para texto; tais mecanismos são úteis pois dados na modalidade textual fornecem maiores possibilidades de descrição e aplicação.

No primeiro caso, o reconhecimento de fala é executado no fluxo de áudio, criando uma transcrição da fala presente no vídeo. As técnicas relacionadas a essa atividade geralmente apresentam resultados satisfatórios em casos onde apenas uma pessoa está falando em um ambiente sem ruídos externos, fazendo uso de um vocabulário limitado [Brunelli et al., 1999]. Além disso, é necessário que essa pessoa realize um procedimento de treinamento junto à técnica, a fim de que o algoritmo possa modelar a dicção apresentada pelo indivíduo.

No segundo caso, o reconhecimento ótico de símbolos (do Inglês, Optical Character Recognition - OCR) [Mori et al., 1999] pode ser aplicado sobre os quadros do vídeo a fim de se obter uma representação textual de legendas, frases e palavras que estão agregadas à imagem. A qualidade dos resultados das técnicas existentes pode variar dependendo do tipo de fonte utilizado, cores de fundo, estabilidade e resolução do vídeo [Snoek \& Worring, 2005].

\subsubsection{Integração}

A análise multimodal contribui com a melhoria da indexação em três aspectos principais: i) verificação; ii) compensação de erros; e iii) adição de novas informações [Snoek \& Worring, 2005]. Na integração, é indispensável a correta sincronização e alinhamento entre os diferentes tipos de mídias, e essas funcionalidades podem ser implementadas por meio de dados temporais do conteúdo, como timestamps.

Além da sincronização e alinhamento, o processo de combinação deve considerar certas decisões de projeto. Tais decisões referem-se a três aspectos principais: o ciclo de processamento, o método de classificação e o tipo de segmentação de conteúdo. No ciclo de processamento, a integração pode ser de modo iterativo, permitindo o uso incremental de contexto, ou não-iterativo. Na classificação, é possível escolher entre métodos baseados em conhecimento, ou estatísticos. Na segmentação, por fim, pode-se realizar a detecção de conteúdo de maneira ordenada (assimétrica) ou simultânea (simétrica). Uma seleção de trabalhos existentes em cada um desses aspectos pode ser encontrada em [Snoek \& Worring, 2005]. 
A maioria dos métodos presentes na literatura são simétricos e não-iterativos. Alguns seguem uma abordagem baseada em conhecimento para classificação dos dados em classes hierárquicas semânticas [Pfeiffer et al., 2001; Tsekeridou \& Pitas, 2001]; e outros adotam uma estratégia estatística, por meio do uso de HMMs e modelos probabilísticos [La Cascia et al., 1998; Wang et al., 1999]. Métodos assimétricos, por sua vez, geralmente adotam uma estratégia em várias fases, como é o caso da abordagem de Wang et al. [1999], que propõe um HMM em dois passos para extrair metadados com base nas modalidades visual e auditiva.

Por ser uma abordagem que gera metadados mais significativos [Snoek \& Worring, 2005], a multimodalidade também é explorada nesta tese. De um lado, texto e imagens combinados com anotações colaborativas dos usuários são explorados para se extrair descrições semânticas sobre o conteúdo, conforme será discutido no Capítulo 5, Seção 5.3. Por outro lado, utilizam-se diferentes tipos de informações, como faces, avaliações, imagens, etiquetas e palavras-chave para construir o perfil de preferências do indivíduo, como será apresentado Capítulo 5, Seção 5.4. A contribuição deste trabalho é a combinação de anotações multimodais tanto no processo de indexação multimídia, como também na obtenção dos interesses pessoais. Consequentemente, serviços de personalização podem gerar melhores resultados devido à exploração de informações semânticas.

\subsection{Indexação Semântica}

Métodos para indexação automática de vídeo tendem ser mais complexos à medida que mais informações semânticas sobre o conteúdo são requisitadas pelas aplicações. A necessidade desses dados conceituais vem sendo estudada em diversas áreas, como recuperação de informações em vídeo e imagens, navegação multimídia e personalização. De fato, esse problema é conhecido como lacuna semântica, e é definido, segundo Smeulders et al. [2000], como "a falta de coincidência entre as informações que se pode extrair do fluxo audiovisual e a interpretação que os mesmos dados geram para um determinado usuário em dada situação".

Conforme mencionado no início deste capítulo, a interpretação do fluxo audiovisual pode ser composta por diferentes níveis de granularidade, que são definidos de acordo com as características da aplicação. Em um sistema de sumarização, por exemplo, metadados sobre cada cena de um vídeo são importantes para que as técnicas possam selecionar os segmentos de acordo com as preferências do usuário. Já em um sistema de recomendação, interpretações sobre o gênero e subgênero de um filme são as informações mínimas necessárias para fornecer uma filtragem significativa do conteúdo.

Desse modo, os trabalhos apresentados na literatura normalmente atuam sobre 


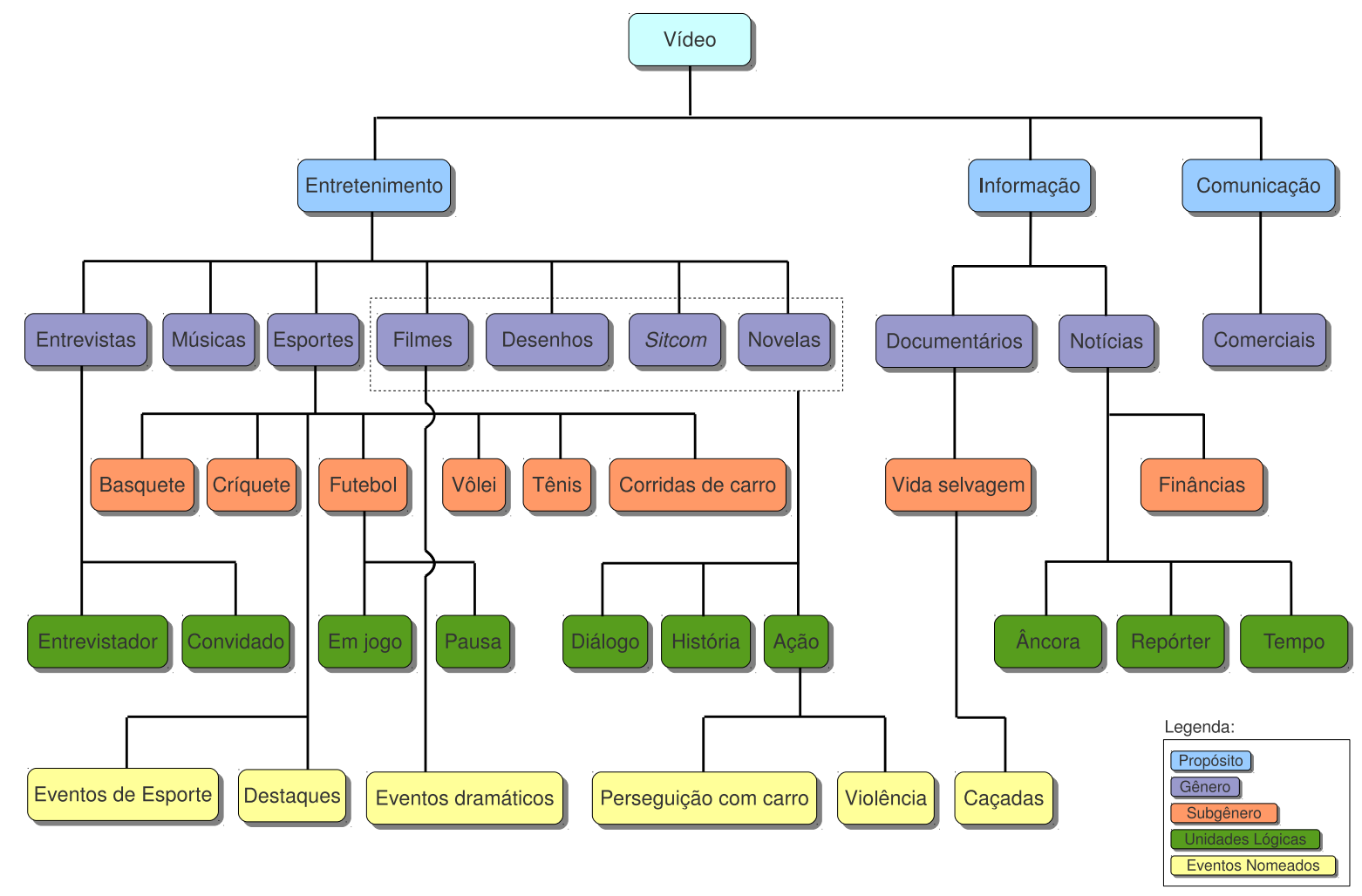

Figura 3.2: Hierarquia para indexação semântica [Snoek \& Worring, 2005].

níveis específicos de granularidade, bem como de acordo com restrições no domínio de dados dos vídeos considerados. A partir da divisão hierárquica feita por Snoek \& Worring [2005] no processo de indexação semântica (ilustrada na Figura 3.1 por meio dos níveis Propósito, Gênero, Subgênero, Unidades Lógicas e Eventos Nomeados), a Figura 3.2 [Snoek \& Worring, 2005] apresenta uma instanciação das hierarquias definidas, que está baseada nos trabalhos existentes sobre descrição semântica [Snoek \& Worring, 2005]. A lista de itens pertencentes a cada nível hierárquico não é exaustiva, sendo possivel encontrar técnicas cuja classificação está além dos elementos definidos na Figura 3.2.

Nas próximas subseções, apresentam-se alguns trabalhos relacionados a cada nível, com exceção de Propósito, que até o momento não foram encontrados esforços reportados sobre o tema. É importante ressaltar uma característica em comum das abordagens: a exploração de domínios de dados restritos por técnica, uma vez que elas exploram características visuais, auditivas e/ou textuais que são específicas para os eventos considerados. Tal limitação, entretanto, é explorada nos capítulos de contribuições deste trabalho, onde a arquitetura baseada em anotações dos usuários 
fornece o suporte necessário aos serviços de personalização em diferentes domínios, como filmes e telejornais.

\subsubsection{Gênero}

A identificação automática de gêneros pode ser realizada por meio de uma análise do layout do vídeo. O tempo médio de cada tomada, por exemplo, é explorado por Hauptmann \& Witbrock [1998] e Kuhmunch [1997] para determinar o ritmo da cena, sendo possível inferir instâncias de comerciais. Adicionalmente, a taxa de mudança de bordas, vetores de movimento, tipos de transições entre cenas e informações visuais são utilizados para a identificação de gêneros de notícias, musicais, desenhos e esportes nos trabalhos de Truong et al. [2000] e Das \& Geetha [2010].

Além de informações sobre o layout, padrões temporais e espaciais de faces e legendas também são utilizados para determinação de gêneros, como reportado por Dimitrova et al. [2000], que propuseram uma técnica capaz de identificar metadados relacionados a noticiários, esportes, filmes, programas de televisão e comerciais. Dentre esses metadados, destaca-se a anotação de pessoas, objetos, eventos nomeados, identificação de jogadores, créditos e legendas de filmes, nomes de produtos comerciais, entre outros.

A análise multimodal também é considerada, como é o caso de Montagnuolo \& Messina [2009], por exemplo, que agrupam características visuais (como cor, textura e movimento), informações de layout (como a duração e a distribuição de cenas e ritmo) e conteúdo (como posição, frequência e localização de faces), juntamente com texto e áudio para classificar vídeos nas categorias futebol, desenho, música, previsão do tempo, entrevista e comercial.

\subsubsection{Subgênero}

A indexação de subgêneros consiste em classificar instâncias de gêneros em subcategorias distintas. No caso de esportes, Mohan \& Yegnanarayana [2010] utilizam informações visuais, como direção e intensidade de histograma de bordas, para alimentar uma rede neural auto-associativa, que categoriza os vídeos esportivos em um conjunto de subgêneros, tais como críquete, futebol, tênis, basquete e vôlei. Os autores também experimentam a combinação dos resultados com outros processos classificatórios, como HMM e SVM, obtendo melhor desempenho da técnica.

No caso de músicas, Lee et al. [2009] propõem uma abordagem para classificação de subgêneros usando uma análise em longo prazo do espectro de modulação do áudio, juntamente com características cepstrais (MFCC). Essa análise resulta em um espectrograma que exibe informações rítmicas do sinal musical. Tais informações são decompostas em sub-bandas, que são posteriormente usadas por classificadores 
estatísticos para identificar os subgêneros musicais.

No caso de filmes, Brezeale [2006] utiliza marcações inerentes ao closed-caption agregado ao vídeo, em conjunto com dados visuais codificados, como coeficientes DCT (do Inglês, Discrete Cossine Transform - Transformada Discreta do Cosseno) para classificação automática de filmes em categorias como animação, ação, comédia, drama, entre outras.

\subsubsection{Unidades Lógicas}

O problema da detecção de unidades lógicas é estudado na literatura por meio de abordagens para identificação de cenas ou LSUs (do Inglês, Logical Story Units Unidades Lógicas de Cena). Uma cena é definida por Boggs \& Petrie [2000] como "um conjunto de tomadas que comunicam uma ação unificada em lugar e tempo em comum". Apesar de existirem trabalhos que abordam o tema [Vendrig \& Worring, 2002], no contexto da indexação é necessário também identificar o conteúdo presente em cada cena [Snoek \& Worring, 2005].

A maioria das técnicas para descrição automática de unidades lógicas depende do domínio de dados considerado. Em sitcoms e filmes, por exemplo, Brunelli et al. [1999] realizam uma análise do fluxo de áudio e características de faces para classificar uma determinada cena em rótulos como vinheta, transição ou diálogo. Em programas de TV e filmes, em geral, pode-se encontrar trabalhos que exploram as modalidades visual e auditiva para identificação de cenas violentas [Nam et al., 1998], e categorização em rótulos específicos como diálogo, história, ação e outros [Saraceno \& Leonardi, 1998].

No contexto de noticiários, abordagens baseadas em uma modelagem do vídeo fornecem bons resultados uma vez que a estrutura de um programa de notícias é bem definida. Assim, a identificação de cenas-âncora, por exemplo, pode ser facilmente realizada com base em informações temporais e espaciais [Shearer et al., 2000]. Um refinamento é proposto por Bertini et al. [2001], que classificam as cenas em âncora ou repórter, usando, em conjunto, informações textuais, reconhecimento de fala e análise da movimentação dos lábios. Ainda em noticiários, um número maior de rótulos é considerado por Eickeler \& Muller [1999], que usa um conjunto de 25 tipos de informações do fluxo de dados, incluindo vetores de movimento e áudio, para classificar as cenas em vinhetas, âncora, entrevista, repórter e previsão do tempo.

De maneira similar a noticiários, shows de entrevistas e de jogos também apresentam uma estrutura bem definida. Entrevistadores e/ou apresentadores podem ser diferenciados de convidados por meio da comparação de suas faces ao longo do vídeo. Geralmente, convidados aparecem apenas em determinados blocos do programa, e essa característica é explorada por Javed et al. [2001], que utilizam detecção de faces para rotular as cenas de acordo com a frequência de aparecimento de cada indivíduo. 
Em esportes, por fim, encontram-se esforços na classificação de cenas em vídeos de futebol [Xu et al., 2001; Yan et al., 2007], com anotações do tipo em jogo ou pausa.

\subsubsection{Eventos Nomeados}

$\mathrm{Na}$ indexação semântica, eventos nomeados correspondem ao nível de granularidade mais detalhado possível. Em documentários sobre vida selvagem, por exemplo, Haering et al. [2000] utilizam cores, texturas e vetores de movimento para detectar objetos moventes. Em seguida, uma rede neural é utilizada para verificar se tais objetos são de interesse ou não. Como último passo, as informações obtidas são exploradas por um processo de inferência dependente de domínio de dados para detectar eventos nomeados, como caçadas entre animais.

Sons do ambiente são explorados por Moncrieff et al. [2001] para identificar eventos de perseguição com carros ou cenas violentas. Informações de áudio características de motor, buzina, explosão ou tiro são automaticamente detectadas, sendo possível inferir eventos dessa natureza apenas com base na modalidade auditiva.

Truong \& Venkatesh [2001] argumentam que efeitos de iluminação são usados como artefato para intensificar eventos de drama em certas cenas. Desse modo, os autores exploram a luminância média de cada quadro, em conjunto com a área desse quadro que foi influenciada pela luminosidade. A partir dessa análise, a técnica é capaz de identificar cenas nas categorias sobrenatural, crise, terror, excitação e eventos genéricos de grande importância.

Na categoria esportes, as modalidades visual e textual são usadas por Fendri et al. [2010] para selecionar eventos de importância em jogos de futebol, e por Babaguchi et al. [2002] para detectar mudança de placar em jogos de futebol americano. Nos demais esportes, encontram-se técnicas que extraem eventos importantes em beisebol [Rui et al., 2000; Zhong \& Chang, 2001], basquete [Zhou et al., 2000] e tênis [Zhong \& Chang, 2001]. Tais técnicas baseiam-se, geralmente, em informações relacionadas a cores, bordas, movimentação de objetos e câmera, entre outras; a partir dessas informações, os métodos identificam os eventos por meio de classificadores baseados em conhecimento.

\subsection{Considerações Finais}

Este capítulo apresentou uma contextualização dos trabalhos existentes sobre indexação multimídia, organizados segundo o esquema multimodal proposto por Snoek \& Worring [2005]. Verifica-se uma grande variedade de abordagens para extração de metadados, que consideram três modalidades existentes: vídeo, áudio e texto. 
Particularmente no campo de vídeos digitais, grande parte das técnicas propostas na literatura explora poucos domínios de dados por vez. Tal fato ocorre devido às diferentes propriedades que são inerentes a cada gênero. Em shows de entrevista e noticiários, a estrutura do vídeo é bem definida, com a proeminência de monólogos, diálogos e visualização clara de faces. Clipes musicais e comerciais, por sua vez, mostram uma grande diversidade de configurações e duração de tomadas. Em vídeos esportivos, suas propriedades variam conforme o tipo de esporte considerado. Filmes, desenhos, sitcoms e novelas contêm pessoas ou personagens como informações relevantes, mas variam o ritmo da cena, juntamente com o uso de diferentes tipos de transições e efeitos especiais. Já documentários raramente fazem uso de efeitos, e apresentam voz narrando as cenas durante todo o vídeo [Snoek \& Worring, 2005].

Tais diferenças existentes entre gêneros e subgêneros dificultam o uso de técnicas automáticas que analisam dados audiovisuais para inferir metadados semânticos. Uma vez que os domínios de dados apresentam características distintas, as técnicas que exploram essas peculiaridades não conseguem ser genéricas o suficiente para permitir a irrestrição de domínio. Como exemplo, um método multimodal que explora histogramas, vetores de movimento, detecção de bordas e análise de áudio para identificação de cenas relevantes em vídeos de futebol ou beisebol não poderá ser usado para detectar cenas relevantes em filmes ou sitcoms, já que as características visuais e auditivas dos domínios de dados diferem entre si. Adicionalmente, descrições semânticas dependem do desenvolvimento de técnicas de análise nas três modalidades de dados. Atualmente, tais técnicas apresentam problemas sérios, como degradação dos resultados diante de ruídos, necessidade de amostras para treinamento, variação de fatores externos, dependência de domínio de dados, entre outros. Em consequência, a indexação multimídia usando abordagens automáticas necessita de mais pesquisa para que o problema da lacuna semântica seja resolvido [Brezeale \& Cook, 2007].

Alternativamente, conforme mencionado na introdução deste capítulo, pode-se indexar conteúdo audiovisual por meio da descrição manual. Tal abordagem será discutida no Capítulo 4 juntamente com uma análise dos trabalhos relacionados e limitações existentes. Além disso, o próximo capítulo apresenta ferramentas que auxiliam usuários no processo de enriquecimento de conteúdo, bem como descreve o estado da arte na área de construção e representação de perfis. Tais conceitos são explorados pela presente tese como possíveis alternativas para se melhorar os serviços de personalização, seja atuando na descrição semântica de conteúdo multimídia, ou na obtenção de interesses particulares de cada indivíduo. 


\section{- Anotações e Perfil do Usuário}

$\mathrm{N}$ os últimos anos, a interação entre usuário e conteúdo tem se adaptado a uma nova era de serviços e aplicações na Web. As atividades do usuário não se limitam mais à simples navegação de páginas ou consumo de conteúdo multimídia, mas envolvem também a produção de novos dados por indivíduos comuns, disponibilizando-os para serem acessados por outras pessoas. Serviços dessa natureza, tais como YouTube ${ }^{1}$, Flickr $^{2}$, Facebook $^{3}$, estão situados na chamada Web 2.0, que é um termo criado em 2004 por Tim O'Reilly para designar uma segunda geração de comunidades e serviços, tendo como conceito básico a "Web como plataforma" [Governor et al., 2009]. Nesse sentido, espera-se que aplicações sejam desenvolvidas aproveitando as possibilidades da rede, de modo a melhorarem seus serviços à medida que sejam utilizados por mais usuários.

No contexto de aplicações multimídia, a interação do usuário, conforme citado por alguns autores [Cesar et al., 2006; Aleem, 1998], pode ser classificada em quatro diferentes categorias: a) consumo de conteúdo, no qual o usuário é capaz apenas de assistir à apresentação; b) seleção de configuração, que permite configurar parâmetros como o volume, brilho ou o canal de um fluxo audiovisual; c) seleção/navegação, que viabiliza a possibilidade de se escolher diferentes fluxos multimídia, como exemplo, seleção de idioma, legenda, programação especial, entre outros; e d) autoria, que fornece ao indivíduo a capacidade de se criar ou enriquecer o conteúdo.

Geralmente, o processo de autoria ou anotações é realizado seguindo duas abordagens diferentes [Bulterman, 2004]: hierárquica ou de usuário. A primeira abordagem

\footnotetext{
${ }^{1}$ http://www.youtube.com, último acesso em 10 de Novembro de 2010.

${ }^{2}$ http://www.flickr.com, último acesso em 10 de Novembro de 2010.

${ }^{3}$ http://www.facebook.com, último acesso em 10 de Novembro de 2010.
} 
trata da criação de metadados que descrevem o conteúdo, sendo geralmente realizada manualmente por profissionais ou técnicas automáticas no provedor de conteúdo. Tal atividade produz informações adicionais a respeito da mídia com o objetivo de auxiliar ferramentas de busca. Como exemplo, os dados podem referenciar informações sobre um filme, tais como lista de atores, título, produtor, entre outras. Cesar et al. [2006] argumentam que esse tipo de metadado é essencial para a disponibilização de serviços de personalização. O Capítulo 3 apresentou uma descrição do estado da arte das técnicas usadas para se extrair automaticamente essas informações do fluxo audiovisual.

A segunda abordagem de autoria é chamada anotação de usuário e, ao contrário da primeira, as anotações são realizadas por qualquer pessoa. Envolve procedimentos de enriquecimento ou customização de conteúdo, tais como o ato de circular um determinado objeto com caneta/tinta eletrônica, ou a inserção de mídias relacionadas ao conteúdo sendo apresentado [Cesar et al., 2006]. Uma das características desse tipo de anotação é que ela não segue um vocabulário restrito, permitindo que exista plena liberdade de expressão do autor. Outra peculiaridade é a utilização de dispositivos portáteis para criá-las, o que requer, consequentemente, a aplicação de procedimentos de adaptação de conteúdo durante o acesso aos dados (vide Capítulo 2).

Esta tese tem como objetivo propor uma arquitetura que considera ambos os tipos de anotação para prover subsídios a serviços de personalização. Tais subsídios referem-se à disponibilização de informações semânticas a respeito do conteúdo e das preferências dos usuários. Anotações hierárquicas são complementadas com descrições colaborativas criadas pelos usuários, reduzindo os esforços de profissionais para criá-las; e anotações provenientes da atividade do usuário de enriquecimento de conteúdo são usadas para complementar seu perfil de interesses com dados significativos sobre suas preferências.

Desse modo, o propósito deste capítulo é descrever os trabalhos que têm sido feitos para fornecer capacidades avançadas de interação entre usuário e conteúdo, com suporte à autoria e anotação multimídia. Essa contextualização do estado da arte irá fornecer a argumentação necessária para as contribuições desta tese, já que atua-se diretamente no mecanismo atual de interação entre usuário e conteúdo, onde pessoas comuns são providas de possibilidades avançadas de anotação, autoria, enriquecimento e manipulação multimídia. Portanto, inicialmente neste capítulo, descrevem-se alguns conceitos da Web 2.0 que inspiraram a arquitetura proposta neste trabalho. Em seguida, apresentam-se os trabalhos que exploram as capacidades de anotação e enriquecimento de conteúdo, incluindo os esforços realizados para viabilizar a representação de anotações. Por fim, descrevem-se as abordagens relacionadas à construção e representação do perfil do usuário, que 
armazena suas preferências e interesses, obtidos do histórico de interações do mesmo com o conteúdo.

\subsection{A Web 2.0}

Apesar de ter sido apresentada uma definição para a Web 2.0 na introdução deste capítulo, argumenta-se que não existe na atualidade uma caracterização única e bem aceita do termo. Tal fato é explicado pela natureza dinâmica da Web, que modifica-se constantemente em níveis de serviços e infraestrutura pelas tendências trazidas pelas ações dos usuários. A definição de Tim O'Reilly, portanto, é a que melhor descreve a Web 2.0, já que ao contrário de se definir o conceito por meio de uma especificação ou arquitetura estática, explica-se o termo por meio de uma caracterização genérica, adicionando-se uma comparação de páginas Web, tecnologias e modelos do passado às novas perspectivas surgidas recentemente. Exemplos são: Britannica Online ${ }^{4}$ versus Wikipedia ${ }^{5}$, páginas pessoais versus blogs, diretórios/taxonomias versus etiquetação/folksonomias, entre outros [Governor et al., 2009].

Uma das principais peculiaridades da Web 2.0 é o paradigma de participação-colaboração, ou analogamente, inteligência coletiva. Os participantes das aplicações agrupam-se e organizam-se dinamicamente de maneira automática, fazendo reuso de conteúdo, atualizações fracionárias e contribuições para trabalhos coletivos. Como resultado, os serviços tornam-se mais valiosos e poderosos à medida que mais usuários participam ativamente das atividades [Governor et al., 2009].

Uma outra característica importante da Web 2.0 é a possibilidade de qualquer usuário etiquetar os recursos disponiveis por meio de termos, palavras-chave ou frases criados livremente sem o uso de um vocabulário de referência. Os sistemas del.icio.us ${ }^{6}$ e Flickr foram os pioneiros a implementar essa funcionalidade, facilitando a categorização e organização dos itens favoritos pelo próprio usuário. Quando as etiquetas obtidas de vários indivíduos são analisadas por meio de técnicas estatísticas, é possível criar relações semânticas entre termos, resultando em uma taxonomia (chamada de folksonomia) de baixo custo gerada apenas a partir de esforços colaborativos dos usuários.

São inúmeras as vantagens que podem ser obtidas a partir das atividades dos colaboradores com os sistemas categorizados na Web 2.0. Além da anotação colaborativa, exploram-se ainda, no contexto desta tese, os sistemas de etiquetação. Portanto, nas próximas subseções esse mecanismo será descrito em detalhes.

\footnotetext{
${ }^{4}$ http://www.britannica.com, último acesso em 10 de Novembro de 2010.

${ }^{5}$ http://www.wikipedia.com.br, último acesso em 10 de Novembro de 2010.

${ }^{6}$ http://delicious.com, último acesso em 10 de Novembro de 2010.
} 


\subsubsection{Sistemas de Etiquetação}

A etiquetação (do Inglês, tagging) é a prática de permitir a inserção de palavras-chave, termos ou etiquetas (do Inglês, tags) ao conteúdo pelos próprios usuários [Golder \& Huberman, 2005]. Sistemas que provêem tal funcionalidade são constituídos de três elementos principais: usuários, recursos e etiquetas. Além de estabelecerem um relacionamento entre um recurso e um conceito no parecer do usuário, as etiquetas podem também definir conexões implícitas entre os indivíduos (já que eles podem usar as mesmas etiquetas) e entre recursos (uma vez que os itens podem ser etiquetados com os mesmos termos) [Specia \& Motta, 2007].

Geralmente, as pessoas etiquetam conteúdo multimídia com um conjunto de termos com o objetivo de facilitar a busca de informações no futuro. Assim, embora essa funcionalidade não seja mandatória na maioria das aplicações, as anotações produzidas são importantes para melhorar a recuperação de dados pelos usuários. Diversos serviços na Web 2.0 disponibilizam ferramentas para que os clientes possam etiquetar seus itens favoritos: o sistema del.icio.us para marcação de páginas Web, Flickr para anotação de fotos, CiteULike $^{7}$ e Connotea $^{8}$ para classificação de referências bibliográficas, entre outros exemplos.

As funcionalidades dos sistemas de etiquetação permitem que usuários sejam aptos a executarem uma série de tarefas [Golder \& Huberman, 2005], entre elas:

- identificar o tópico de um recurso por meio da etiquetação usando termos e nomes próprios, tais como java, código e programação;

- classificar o tipo do recurso, por exemplo, livro, artigo, revisão e evento;

- denotar as qualidades e características do conteúdo (como engraçado, interessante e útil);

- organizar os próprios recursos por meio de etiquetas que referenciam o próprio autor, tais como meus favoritos, minhas músicas e meus dados;

- organizar as tarefas a serem executadas, usando etiquetas que denotam a atividade pendente (como ler depois, a imprimir e enviar para amigos).

Os sistemas de etiquetação tornaram-se populares devido a algumas peculiaridades inerentes ao processo de anotação. Wu et al. [2006] descrevem alguns desses atributos:

- baixo custo cognitivo e esforço adicional. A simplicidade de se atribuir etiquetas faz com que qualquer usuário seja capaz de classificar seus itens preferidos com termos não necessariamente pré-definidos em vocabulários;

\footnotetext{
${ }^{7}$ http://www.citeulike.org, último acesso em 10 de Novembro de 2010.

${ }^{8}$ http://www.connotea.org, último acesso em 10 de Novembro de 2010.
} 
- retorno instantâneo e comunicação. Em sistemas de etiquetação colaborativos, as sugestões de etiquetas para determinados itens atuam como uma comunicação implícita entre usuários para descrição do conteúdo;

- adaptação rápida para mudanças no vocabulário. A liberdade provida pela etiquetação permite respostas rápidas às mudanças no uso da linguagem e necessidades de novas palavras. Novos termos podem ser usados livremente sem precisar mudar esquemas pré-definidos;

- necessidades individuais e formação de organizações. Sistemas de etiquetação provêem uma maneira conveniente aos seus clientes para organizarem seus recursos favoritos. Além disso, em sistemas populares, os usuários podem encontrar outras pessoas que se interessam por tópicos similares.

Uma vez que as etiquetas são criadas individualmente e de forma livre, um problema importante encontrado é como identificar as etiquetas apropriadas, de modo a eliminar informações desnecessárias e ruído. Nesse sentido, um conjunto de critérios é definido por Yeung et al. [2007] com o objetivo de se criar um sistema de etiquetação eficiente. Dentre esses critérios, destacam-se:

- alta convergência de vários aspectos. Uma boa combinação de etiquetas deve incluir múltiplos aspectos dos objetos marcados. Quanto maior o número de aspectos, mais o usuário será capaz de lembrar do conteúdo anotado;

- alta popularidade. Se um conjunto de etiquetas é usado por um grande número de pessoas para anotar um objeto em particular, essas etiquetas irão identificar mais precisamente o conteúdo e provavelmente serão usadas por um novo usuário para descrever o mesmo objeto;

- menor esforço. O número de etiquetas para identificar um objeto deve ser minimizado, assim como o número de objetos identificados por uma combinação de etiquetas. Como resultado, o usuário pode recuperar qualquer objeto anotado em um pequeno número de interações durante a navegação por etiquetas;

- uniformidade. Usuários podem utilizar diferentes termos para representar um conceito. Uma etiqueta pode apresentar variância sintática, como Web 2.0 e web20, ou então duas palavras distintas podem significar um mesmo conceito, como carro e automóvel. Esse tipo de divergência pode melhorar o desempenho da busca, mas ao custo de introduzir ruído em alguns casos;

- exclusão de certos tipos de etiquetas. Algumas etiquetas de uso pessoal deveriam ser excluídas do uso público, já que são difíceis de serem usadas por 
outros usuários. A recomendação de etiquetas pode ajudar na convergência de termos, além de melhorar a usabilidade do sistema.

Uma outra questão importante dos sistemas de etiquetação é como eles operam. Marlow et al. [2006] descrevem algumas decisões de projeto que podem afetar o conteúdo e a usabilidade das etiquetas criadas. Essas decisões envolvem os direitos dos usuários em inserir marcações em certos itens, a maneira de criar os termos, a agregação de palavras semelhantes, os tipos dos itens envolvidos, as conectividades social e de recursos, entre outras.

No contexto da arquitetura proposta neste trabalho, a etiquetação agrega vantagens quando aplicada aos processos de indexação multimídia e obtenção de preferências. Inicialmente, termos criados colaborativamente para classificar recursos e identificar tópicos podem oferecer informações adicionais a respeito do conteúdo, sem necessitar de grandes esforços cognitivos individuais para descrição das mídias. Além disso, a interação em si realizada pelo usuário para associar os termos pode ser vista como um indicativo de que aquela mídia específica provocou percepções diferenciadas no indivíduo e, portanto, seus metadados podem ser agregados ao perfil de preferências do mesmo.

\subsubsection{Folksonomias}

O termo folksonomia foi inicialmente criado por Vander $\mathrm{Wal}^{9}$, em 2005, para definir um sistema de classificação distribuído que é criado quando grandes comunidades de indivíduos etiquetam colaborativamente seus recursos. Essas taxonomias geradas pelos usuários refletem uma visão popular dos atributos associados aos itens, formando uma categorização ascendente dos recursos disponíveis [Hammond et al., 2005]. Uma vez que os participantes de várias comunidades utilizam diferentes etiquetas, que normalmente refletem o grau de conhecimento desses usuários no domínio considerado, as folksonomias podem prover busca e navegação dos recursos de maneira altamente personalizada [Szomszor et al., 2007].

Uma característica importante de folksonomias é a possibilidade de extrair informações semânticas delas. Ferramentas inerentes aos campos de descoberta de conhecimento e aprendizado de ontologias promovem desafios devido à estrutura distinta das folksonomias. Relacionada a essas tarefas está o conceito de relacionalidade entre etiquetas. Métricas para criar tais relacionamentos podem ser definidas de várias maneiras. A maioria delas usa informações estatísticas sobre diferentes tipos de co-ocorrência entre etiquetas, recursos e usuários. Outras abordagens usam hipóteses de distribuição, que afirmam que palavras encontradas

\footnotetext{
2010.

${ }^{9}$ http://www.vanderwal.net/random/entrysel.php?blog=1750, último acesso em 10 de Novembro de
} 
em contextos similares tendem a se relacionar semanticamente. De fato, ambas famílias de métricas exploram a chamada relação sintagmática, que define relações entre palavras se elas ocorrem na mesma região do texto [Cattuto et al., 2008].

Formalmente, uma folksonomia $F$ é uma tupla $F=(U, E, R, A)$ onde $U$ é o conjunto de usuários, $E$ é o conjunto de etiquetas, $R$ é o conjunto de recursos ou itens multimídia e $A \subseteq U \times E \times R$ é o conjunto de anotações. Uma postagem é uma tripla $\left(u, E_{u r}, r\right)$ com $u \in U, r \in R$, e um conjunto não-vazio $E_{u r}:=\{e \in E \mid(u, e, r) \in A\}$ [Mika, 2007; Hotho et al., 2006]. Adicionalmente, uma folksonomia pode ser vista como um grafo tripartido e não-dirigido $G=(V, L)$ onde $V=U \cup E \cup R$ é o conjunto de vértices, e $L=\{\{u, e, r\} \mid(u, e, r) \in A\}$ é o conjunto de arestas [Cattuto et al., 2008]. A partir dessa definição, descrevem-se nas próximas subseções algumas métricas de relacionalidade entre etiquetas.

\section{Co-Ocorrência}

A métrica baseada em co-ocorrência de etiquetas é definida como um grafo ponderado não-dirigido, cujo conjunto de vértices é o conjunto de etiquetas $E$. Duas etiquetas $e_{1}$ e $e_{2}$ são conectadas por uma aresta se e somente se existe pelo menos uma postagem $\left(u, E_{u r}, r\right)$ com $e_{1}, e_{2} \in E_{u r}$. O peso dessa aresta é dado pelo número de postagens que contêm ambas etiquetas $e_{1}$ e $e_{2}$, ou seja:

$$
w\left(e_{1}, e_{2}\right):=\operatorname{card}\left\{(u, r) \in U \times R \mid e_{1}, e_{2} \in E_{u r}\right\} .
$$

A relacionalidade entre etiquetas é definida diretamente pelos pesos das arestas. Dada uma etiqueta $e \in E$, aquelas que mais se relacionam a $e$ são o conjunto formado por $e^{\prime} \in E \operatorname{com} e \neq e^{\prime}$ tal que $w\left(e, e^{\prime}\right)$ seja máximo [Cattuto et al., 2008].

\section{Medidas de Distribuição}

Cattuto et al. [2008] reportam três medidas de distribuição para relacionalidade entre etiquetas que são baseadas em três espaços vetoriais diferentes para representação dos termos. Sendo $X \in\{U, E, R\}$, eles consideram o espaço vetorial $\Re^{X}$, onde cada etiqueta $e$ é representada por um vetor $v_{e} \in \Re^{X}$ da seguinte maneira:

- Similaridade no Contexto de Etiquetas: Utiliza-se o espaço vetorial $\Re^{E}$, onde para a etiqueta $e$, os elementos do vetor $v_{e} \in \Re^{E}$ são definidos por $v_{e e^{\prime}}:=w\left(e, e^{\prime}\right)$ sendo $e \neq e^{\prime} \in E$. O valor do peso $w$ é definido pela Equação 4.1, e $v_{e e}=0$;

- Similaridade no Contexto de Recursos: Utiliza-se o espaço vetorial $\Re^{R}$, onde para a etiqueta $e$, os elementos do vetor $v_{e} \in \Re^{R}$ são definidos pela frequência de uso de uma etiqueta $e$ para anotar um certo recurso $r \in R: v_{e r}:=\operatorname{card}\{u \in$ $U \mid(u, e, r) \in A\}$ 
- Similaridade no Contexto de Usuários: Utiliza-se o espaço vetorial $\Re^{U}$, onde para a etiqueta $e$, os elementos do vetor $v_{e} \in \Re^{U}$ são definidos pela frequência de uso de uma etiqueta $e$ por um determinado usuário $u \in U: v_{e u}:=\operatorname{card}\{r \in$ $R \mid(u, e, r) \in A\}$.

Uma vez disponíveis os vetores nos espaços vetoriais correspondentes, pode-se utilizar alguma medida de similaridade vetorial a fim de se calcular a ortogonalidade entre vetores de uma mesma distribuição. Uma opção que é utilizada por Cattuto et al. [2008] é a medida de similaridade por cosseno, definida previamente no Capítulo 2, Equação 2.6.

Uma outra maneira de se calcular a relacionalidade entre etiquetas foi proposta por Hotho et al. [2006], que estenderam o tradicional algoritmo PageRank [Brin \& Page, 1998], que é utilizado para busca e recuperação de páginas Web. O princípio do algoritmo FolkRank é que um recurso marcado com etiquetas importantes por usuários relevantes tende a ser importante também, o que acontece, simetricamente, para etiquetas e usuários. Modificam-se os pesos de uma dada marcação em um vetor de navegação aleatória, resultando em um ranking de etiquetas relevantes.

Tabela 4.1: Relacionamento de etiquetas baseado em suas co-ocorrências.

\begin{tabular}{|c||c|c|c|c|c|}
\hline Etiqueta & $\mathbf{1}$ & $\mathbf{2}$ & $\mathbf{3}$ & $\mathbf{4}$ & $\mathbf{5}$ \\
\hline \hline superherói & comic book & marvel & super-herói & DC & Batman \\
\hline ópera & século 18 & Mozart & Oscar & bastidor & música \\
\hline holocáusto & segunda guerra & história verídica & nazista & nazi & Polônia \\
\hline amor & surreal & morte & livros & amizade & relacionamentos \\
\hline drogas & crime & violência & heroína & vício & crime organizado \\
\hline
\end{tabular}

Como ilustração ao procedimento de relacionalidade, a Tabela 4.1 lista cinco etiquetas que são apresentadas em conjunto com os cinco termos mais relacionados, calculados usando o algoritmo de co-ocorrência, definido na Equação 4.1. A utilização de outras métricas geram resultados parecidos, mas Cattuto et al. [2008] argumentam que as métricas de similaridade nos contextos de recursos e etiquetas são melhores para descoberta de sinônimos e expansão de termos de busca, e os algoritmos de co-ocorrência e FolkRank são mais apropriados para criação de hierarquias generalizadas de conceitos e recomendação de etiquetas.

No contexto da arquitetura proposta, folksonomias assumem um papel importante no processo de criação de perfis dos usuários. Conforme mencionado no Capítulo 2 , Subseção 2.4.3, uma representação das preferências com base em conhecimento pode fornecer uma descrição mais precisa dos interesses pessoais. Entretanto, a construção desse conhecimento utilizando estruturas semânticas conhecidas, com ontologias, sem restrição de domínio de dados, é uma tarefa difícil de ser realizada. Folksonomias, por outro lado, são construídas a partir de etiquetas criadas 
colaborativamente por comunidades de usuários. Como essas anotações independem do domínio considerado, o uso de folksonomias pode fornecer vantagens na descrição do perfil do usuário com suporte à semântica. Assim, a arquitetura proposta provê um processo de complementação de perfil com base em folksonomias para agregar à descrição de preferências termos relacionados semanticamente. Esse processo será melhor detalhado no Capítulo 5, Seção 5.4.

\subsection{Anotações Multimídia}

Conforme mencionado na introdução deste capítulo, anotações são classificadas como hierárquicas, referindo-se a metadados que podem ser usados como indexadores para localizar ou classificar itens multimídia, ou de usuário, caracterizando dados adicionais criados pelo usuário para enriquecer, customizar ou personalizar uma apresentação [Cesar et al., 2006; Bulterman, 2004].

As descrições hierárquicas podem ser criadas automaticamente por meio de técnicas que exploram as características visuais e auditivas dos dados. Alternativamente, pode-se descrever o conteúdo de maneira manual, onde especialistas são encarregados de criar metadados a partir de uma análise do conteúdo.

O enriquecimento, ou anotações de usuário, é realizado por indivíduos comuns (consumidores de conteúdo), que adicionam notas, comentários, mídias relacionadas, entre outros dados, a um conteúdo já existente, permitindo sua posterior reprodução sincronizada por meio de ferramentas propícias (como SMIL (do Inglês, Synchronized Multimedia Integration Language - Linguagem de Integração Multimídia Sincronizada) ou NCL (do Inglês, Nested Context Language - Linguagem de Contexto Aninhado)).

Esta seção apresenta em detalhes as peculiaridades, vantagens e desvantagens de cada abordagem relacionada ao processo de anotação. Tendo em vista que o Capítulo 3 descreveu as técnicas existentes de indexação automática, a Subseção 4.2.1 discute os mecanismos atuais para se criar metadados de maneira manual. A Subseção 4.2.2, por sua vez, trata das abordagens para enriquecer conteúdo por meio de anotações do usuário. Apresentam-se também alguns modelos e padrões disponiveis para representar os metadados (Subseção 4.2.3), uma variedade de aplicações situadas no cenário da Web 2.0 que provêem capacidades de anotação e enriquecimento (Subseção 4.2.4), e por fim, a aplicação M4Note, utilizada neste trabalho como ferramenta de enriquecimento pelos usuários (Subseção 4.2.5).

\subsubsection{Descrição Hierárquica}

Descrições hierárquicas criadas manualmente por profissionais podem ser baseadas em um vocabulário pré-definido, facilitando a posterior exploração dos metadados pelas aplicações. O Projeto Genoma de Música (do Inglês, Music Genome 
Project $)^{10}$, por exemplo, usa um conjunto de quase 400 atributos para que especialistas possam descrever músicas em diferentes gêneros musicais. No Banco de Dados de Filmes da Internet (do Inglês, Internet Movie Database - IMDB) ${ }^{11}$, por sua vez, são disponibilizados diferentes tipos de descrições, como lista de atores, título, nome de produtora, entre outros, para possibilitar a indexação hierárquica de programas e filmes.

Além da restrição de vocabulário, algumas ferramentas foram desenvolvidas para auxiliar o processo de anotação. Na área médica, a ferramenta CANNOT (do Inglês, Coyote Annotation Tool - Ferramenta de Anotação Coyote) [Santos \& Neto, 2004] é um ambiente para anotação, visualização e consulta de segmentos de vídeo em telemedicina. Sua arquitetura é baseada no framework CANNOT [Santos et al., 2005], que tem como principal objetivo auxiliar o desenvolvimento de aplicações relacionadas ao processo de anotação de vídeo, abstraindo-se problemas típicos, como associação, armazenamento, sincronização e exibição de anotações.

O Arquivo de Vídeos Familiares (do Inglês, Video Family Archive) (Abowd et al., 2003] é um exemplo em que se explora a criação semi-automática de metadados em arquivos de vídeo em ambientes domésticos. Embora as anotações adotem um modelo ad-hoc para se descrever as informações, o sistema permite aos usuários a autoria de marcações pessoais, o que maximiza a carga semântica. Por outro lado, um problema encontrado é a dificuldade de se localizar etiquetas específicas quando um número grande de termos já está cadastrado no sistema. Consequentemente, a probabilidade de o usuário escolher marcações erradas é grande, além da necessidade de tempo para se anotar os vídeos disponíveis.

Com o objetivo de fornecer uma maior liberdade ao produtor, algumas abordagens procuram não restringir o vocabulário utilizado. Em Ramos \& Balakrishnan [2003], por exemplo, anotações textuais livres podem ser criadas enquanto o vídeo é visualizado, contudo, tais dados não são representados hierarquicamente, o que dificulta a aplicação de operações de busca. Nesse sentido, Shevade \& Sundaram [2003] descrevem um sistema que usa construções empíricas para maximizar os resultados durante a recuperação de imagens. Entretanto, o processo de anotação é cansativo, requerendo esforços e tempo durante a indexação.

A maioria das técnicas de anotação manual apresentam o problema da necessidade de esforços humanos para descrever conteúdo audiovisual. Apesar de não ser necessária a restrição do domínio de dados, já que o processo de interpretação do conteúdo é realizado pelo próprio especialista, tal estratégia resulta em um trabalho cansativo, caro e propenso a erros. No caso do Projeto Genoma de Música, por exemplo, uma música leva de 20 a 30 minutos para ser analisada por cada

\footnotetext{
${ }^{10} \mathrm{http}$ ///www.pandora.com, último acesso em 10 de Novembro de 2010.

${ }^{11}$ http://www.imdb.com, último acesso em 10 de Novembro de 2010.
} 
profissional, sendo que vários músicos são encarregados de verificar as anotações de cada melodia a fim de se manter uma confiabilidade e conformidade na padronização dos metadados.

Além do problema da possibilidade de gerar erros, outra limitação da indexação manual é que diferentes usuários podem explorar vários aspectos do conteúdo. Normalmente, profissionais irão criar metadados relacionados a certas características vistas subjetivamente como as mais importantes em uma apresentação, o que pode ser diferente dependendo do indivíduo encarregado na tarefa de anotação.

Tendo em vista os problemas relacionados à indexação manual, uma possibilidade seria utilizar esforços colaborativos de usuários a fim de se obter descrições detalhadas sobre conteúdo. O IMDB é um exemplo em que vários usuários atuam na descrição de filmes e programas. Contudo, a individualidade das anotações é perdida uma vez que tais dados mesclam-se com descrições de outros indivíduos. Tal fato, por sua vez, prejudica os serviços de personalização, já que não é explorada a interação do usuário durante o processo de criação desses dados.

Portanto, a consideração isolada de anotações hierárquicas não é suficiente para fornecer subsídios às aplicações de P\&A. Em consequência, esta tese explora anotações produzidas por usuários para se obter os interesses detalhados do usuário a partir dos metadados criados pelo próprio indivíduo. Essa alternativa, que não foi explorada até o momento, é interessante pois tais informações agregam alta carga semântica a respeito das preferências do usuário. Logo, a próxima subseção apresenta em detalhes esse tipo de anotação.

\subsubsection{Enriquecimento de Conteúdo}

No cenário de interação descrito neste capítulo, onde usuários comuns são providos de capacidades avançadas de anotação multimídia, encontram-se ferramentas comerciais e propostas provenientes de pesquisa que exploram esse mecanismo de modo a fornecerem ao usuário uma melhor experiência de consumo de conteúdo audiovisual. Juntamente com a viabilidade de dispositivos móveis e/ou portáteis, que oferecem meios alternativos para se interagir com o conteúdo (por exemplo, caneta/tinta eletrônica, gestos, entre outros), as abordagens atuais procuram seguir o conceito de interfaces naturais, definido anteriormente por Abowd \& Mynatt [2000] como uma subárea da computação ubíqua [Weiser, 1991]. Desse modo, encontram-se vários trabalhos [Cattelan et al., 2008; Cesar et al., 2008; 2009; Goularte et al., 2004a] que simulam a ação do usuário de escrever manualmente em uma apresentação multimídia, usando, por exemplo, um TabletPC ou um dispositivo com tela sensível ao toque. Os vários tipos de anotações produzidas (traços em tinta eletrônica, comentários por voz, relacionamento de conteúdo, entre outros) são armazenados localmente, podendo-se criar apresentações multimídia personalizadas, passíveis de 
serem compartilhadas com outros usuários.

Uma abordagem é apresentada por Bulterman [2003], que propõe a ferramenta Ambulant Annotator para criar e visualizar anotações em fichas de pacientes. Trata-se de um ambiente de renderização de conteúdo multimídia em camadas, capaz de capturar anotações multimídia e reproduzir de modo sincronizado apresentações compostas pelo conteúdo original e as anotações criadas. É capaz de atender às necessidades de aplicações com suporte à criação de anotações baseadas em caneta eletrônica. Além disso, considera-se o processo de engenharia de documentos e da representação de anotações sobre a linguagem SMIL.

Uma proposta mais recente é fornecida com a ferramenta WacTool [Cattelan et al., 2008], que explora o paradigma watch-and-comment (WaC) [Pimentel et al., 2007], cuja premissa principal é que, enquanto o usuário assiste a um vídeo, qualquer interação natural entre ele e conteúdo (como um comentário de voz) pode ser capturada e reportada em um vídeo interativo criado a partir de uma linguagem declarativa. Desse modo, a ferramenta provê o suporte na criação de anotações em quadros ou segmentos de vídeo por meio da captura de tinta digital e comentários de voz. Como saída, a ferramenta cria um documento em NCL, que é a linguagem declarativa adotada pelo Sistema Brasileiro de TV Digital para sincronização de mídias e estruturação de programas interativos.

O sistema XLibris [Price et al., 1998] apresenta um documento textual ao usuário, permitindo a interação usando diferentes estilos de símbolos desenhados a partir de caneta/tinta eletrônica. Um exemplo típico é quando o indivíduo realça uma frase no texto por meio de sublinhado, fazendo com que o sistema transforme o texto destacado em dados de busca para recuperar documentos relacionados. Apesar de integrar capacidades de enriquecimento de conteúdo com funcionalidades de recuperação de informação, não é possível utilizar outros tipos de mídia. Adicionalmente, não é inferida nenhuma informação a respeito das preferências e/ou interesses do usuário.

Nesse sentido, outros trabalhos exploram certos tipos de informações com o objetivo de encontrar reações específicas do indivíduo. Yu et al. [2001], por exemplo, exploram a fala do usuário para inferir suas emoções de raiva, felicidade ou tristeza. Entretanto, tais trabalhos ainda requerem mais pesquisa para que o cenário interativo atual seja explorado em potencialidade. Em particular, diferentes tipos de anotações de enriquecimento podem ser usados, fazendo com que diferentes técnicas possam ser desenvolvidas para se inferir metadados relevantes sobre os interesses de cada usuário.

Portanto, no contexto da arquitetura proposta neste trabalho, dados provenientes das anotações e/ou enriquecimento do usuário assumem um papel importante no processo de personalização de conteúdo. Conforme será apresentado em mais 
detalhes no Capítulo 5, anotações de enriquecimento de conteúdo são usadas para complementar o perfil de preferências do indivíduo, uma vez que agregam alta carga semântica a respeito de seus interesses particulares. Ao contrário de anotações colaborativas, que apresentam a característica de serem imparciais, permitindo, assim, a sua utilização na descrição do conteúdo, os dados provenientes de enriquecimento são parciais e indicam a individualidade de cada usuário em relação ao conteúdo sendo acessado. Como resultado dessa estratégia, os serviços de personalização construídos com base na arquitetura proposta apresentam melhores resultados devido à semântica associada às anotações. Uma avaliação dos serviços desenvolvidos pode ser encontrada no Capítulo 6.

\subsubsection{Representação de Anotações}

A descrição de conteúdo multimídia é padronizada pelo padrão MPEG-7 ${ }^{12}$, que provê um framework contendo estruturas de descrições genéricas com associações semânticas. Os esquemas oferecidos podem ser utilizados por aplicações que necessitam de metadados relacionados ao conteúdo, mantendo a interoperabilidade por meio de especificações padronizadas. Uma vez que os domínios de aplicações são variados, o MPEG-7 foi projetado para ser flexível e extensível, permitindo aos desenvolvedores selecionar as estruturas de interesse, assim como estendê-las conforme a necessidade [Goularte et al., 2006]. Entretanto, apesar do poder e popularidade desse padrão, o uso direto dos esquemas de descrição MPEG-7 pode gerar documentos desnecessariamente complexos. Adicionalmente, o suporte a descrições contextuais em MPEG-7 é limitado a anotações textuais livres pobremente estruturadas.

A estruturação de programas de TV interativa, assim como a descrição de objetos de mídia, são funcionalidades que vêm sendo estudadas pelo padrão TV-Anytime ${ }^{13}$. A despeito de utilizar a especificação MPEG-7 durante a descrição de conteúdo, o padrão não provê suporte na representação de informações de contexto, tampouco na produção de documentos independentes para descrever programas e conteúdo, o que dificulta a reutilização de documentos. Além disso, o relacionamento entre diferentes programas é realizado pelo TV-Anytime por meio de uma URI (do Inglês, Uniform Resource Identifier - Identificador de Recurso Uniforme) que referencia um objeto geral e único representando o programa. O relacionamento é definido apenas pela inserção da URI em guias de programação, tornando lógica a segmentação do vídeo em cenas, tomadas e quadros. Portanto, o uso de fragmentos de um vídeo em serviços de personalização é prejudicado, uma vez que a separação lógica de objetos

\footnotetext{
${ }^{12} \mathrm{http}$ ///www.chiariglione.org/mpeg/standards/mpeg-7/mpeg-7.htm, último acesso em $10 \mathrm{de}$ Novembro de 2010.

${ }^{13}$ http://www.tv-anytime.org, último acesso em 10 de Novembro de 2010.
} 
dificulta a produção e distribuição de conteúdo personalizado [Goularte et al., 2006].

O modelo MediaObject [Goularte et al., 2006] fornece o suporte necessário para o desenvolvimento de aplicações e programas interativos e cientes de contexto. São providos mecanismos para representar conteúdo multimídia de maneira organizada, sucinta e estruturada, separando cada tipo de descrição multimídia (estrutura, composição, contexto e de ligação) em um conjunto de objetos MPEG-4 ${ }^{14}$ com esquemas MPEG-7 relacionados. Como argumentado pelos autores, o modelo pode ser facilmente estendido, a fim de satisfazer os requisitos de aplicações para novas descrições. É possível, por exemplo, criar novos descritores para um determinado tipo de anotação, de modo a reduzir o problema de vocabulário irrestrito presente em anotações de usuários [Manzato et al., 2009a].

\subsubsection{Exemplos de Aplicações}

Embora seja possivel encontrar outras contribuições no meio acadêmico que exploram a interação do usuário para criar ou enriquecer conteúdo multimídia, tais como o sistema proposto por Ursu et al. [2007] e a ferramenta NCL Composer [Costa et al., 2006], é importante destacar aplicações e serviços que já são bem conhecidos e aceitos pela população. Nesta subseção, foram selecionados três sistemas populares que fornecem mecanismos de anotação para que usuários comuns insiram novas informações relacionadas ao conteúdo existente: YouTube, Orkut ${ }^{15}$ e Flickr.

\section{Anotações no YouTube}

As possibilidades de anotações no YouTube permitem que usuários insiram notas com relacionamento temporal e espacial no vídeo. As anotações criadas são reproduzidas ao longo do vídeo, sendo possível o enriquecimento colaborativo, além do compartilhamento com outros usuários. A Figura 4.1 ilustra a interface de anotação do sistema. A região especificada pela Figura 4.1(a) indica a área de reprodução do vídeo personalizado. A Figura 4.1(b) lista todas as anotações produzidas pelo usuário, que podem ser ordenadas por ordem de exibição ou por autor. A Figura 4.1(c) apresenta quatro botões para inserção de diferentes tipos de anotações: balão de fala, nota textual, região de interesse e parada momentânea. A navegação do vídeo a partir das anotações produzidas pode ser realizada pelas funcionalidades exibidas na Figura 4.1(d). Na Figura 4.1(e) o usuário pode ajustar temporalmente a exibição das notas. Por fim, a Figura 4.1(f) apresenta um endereço que, quando acessado por outros usuários, permite que eles insiram anotações colaborativamente à apresentação existente.

\footnotetext{
${ }^{14} \mathrm{http}$ ///www.chiariglione.org/mpeg/standards/mpeg-4/mpeg-4.htm, último acesso em $10 \mathrm{de}$ Novembro de 2010.

${ }^{15}$ http://www.orkut.com, último acesso em 10 de Novembro de 2010.
} 


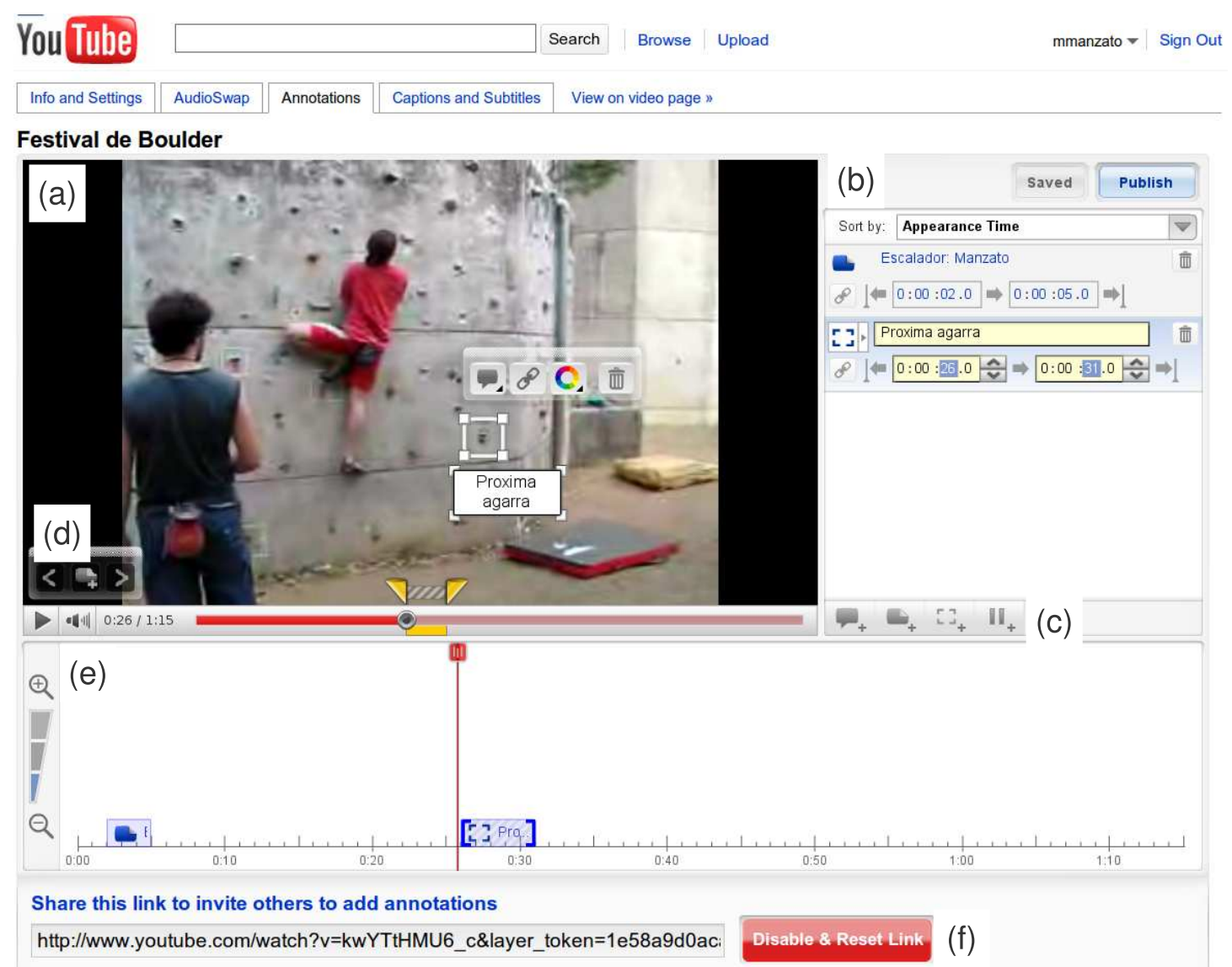

Figura 4.1: Anotações no YouTube. (a) indica a área de reprodução do vídeo personalizado; (b) lista todas as anotações produzidas pelo usuário; (c) apresenta quatro botões para inserção de diferentes tipos de anotações; (d) exibe as funcionalidades de navegação do vídeo a partir das anotações produzidas; (e) ilustra a funcionalidade de ajuste temporal da exibição das notas; e (f) apresenta um endereço que, quando acessado por outros usuários, permite que eles insiram anotações colaborativamente à apresentação existente.

\section{Anotações no Orkut}

O serviço de redes sociais Orkut permite relacionar pessoas conhecidas, facilitando a comunicação e troca de mensagens entre seus membros. Uma característica interessante desse sistema é a possibilidade de diferentes usuários identificarem e reconhecerem faces que aparecem em fotografias hospedadas nos álbuns pessoais dos usuários. A Figura 4.2 ilustra tal funcionalidade. Ao ser apresentada uma foto (Figura 4.2(a)), o sistema detecta automaticamente as faces presentes na imagem. O usuário também pode especificar manualmente as faces que não foram detectadas, como apresentado na Figura 4.2(b). Após um clique na face de interesse, o sistema apresenta uma janela em pop-up (Figura 4.2(c)), onde o usuário pode identificar a face, criando uma ligação com a página pessoal do indivíduo. As faces reconhecidas são 


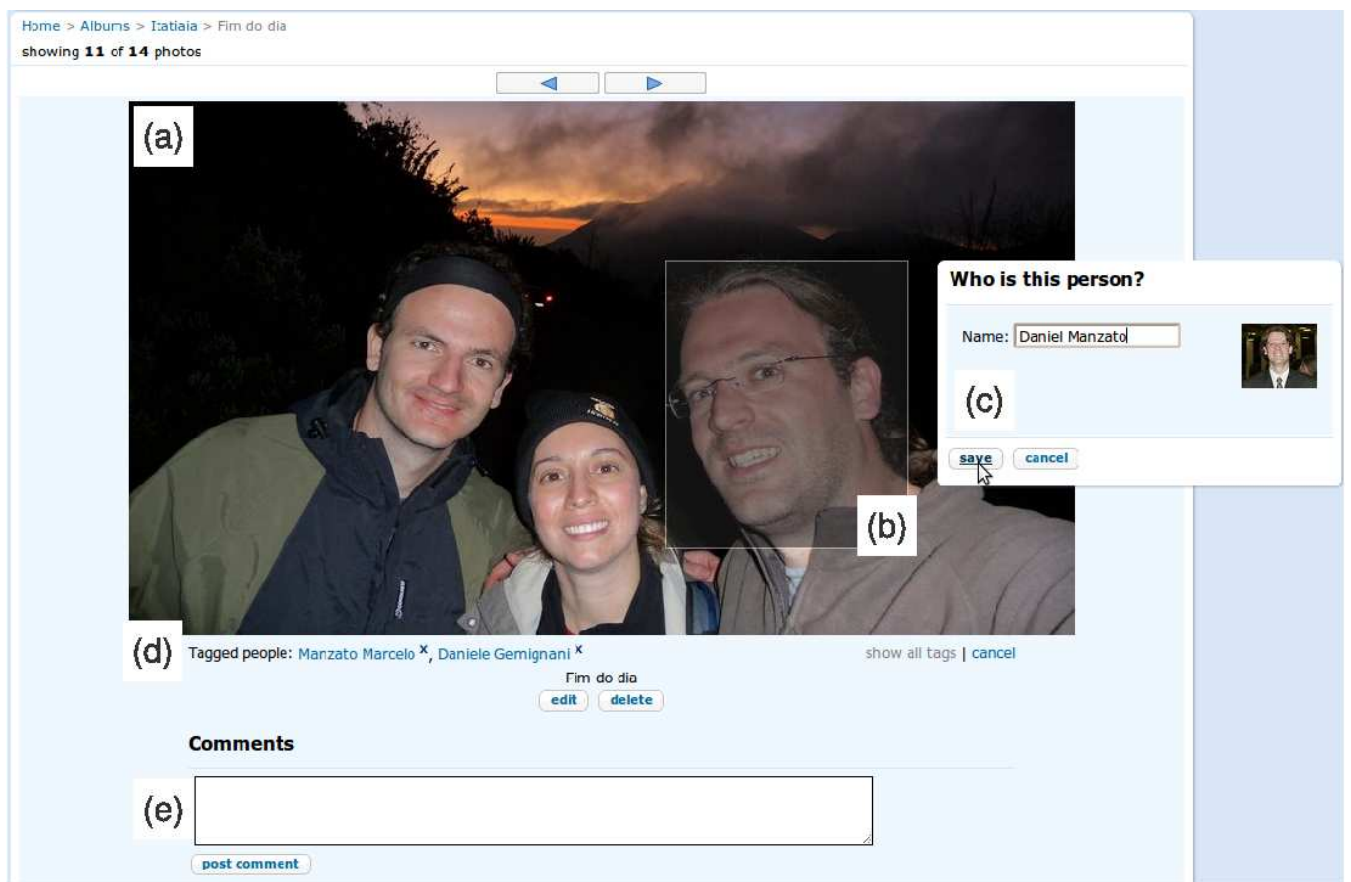

Figura 4.2: Anotações no Orkut. (a) indica a área de apresentação da foto; (b) apresenta a funcionalidade de especificar manualmente as faces não detectadas; (c) ilustra a janela de reconhecimento da face; (d) lista as faces reconhecidas da imagem; e (e) exibe a área de comentários.

listadas no rodapé da imagem (Figura 4.2(d)) e, logo abaixo, os comentários criados pelos usuários (Figura 4.2(e)).

\section{Anotações no Flickr}

O sistema de anotações do Flickr é composto por várias funcionalidades que estão relacionadas às fotografias postadas pelos usuários. Uma peculiaridade desse sistema é a possibilidade de inserção de etiquetas. A Figura 4.3 ilustra a interface de exibição e enriquecimento de fotos. A Figura 4.3(a) mostra um botão que, ao ser clicado, permite que o indivíduo compartilhe a foto com outros usuários, inserindo o email da pessoa na janela que se abre. Também é possivel especificar manualmente o local onde a foto foi registrada, como mostrado na Figura 4.3(b). A funcionalidade de identificar as pessoas presentes na imagem também está disponivel (Figura 4.3(c)), mas nesse caso, não é possível especificar espacialmente a face na imagem. As etiquetas podem ser inseridas livremente pelos usuários, como mostrado na Figura 4.3(d), e também é fornecida a capacidade de inserir comentários relacionados à fotografia (Figura 4.3(e)). 

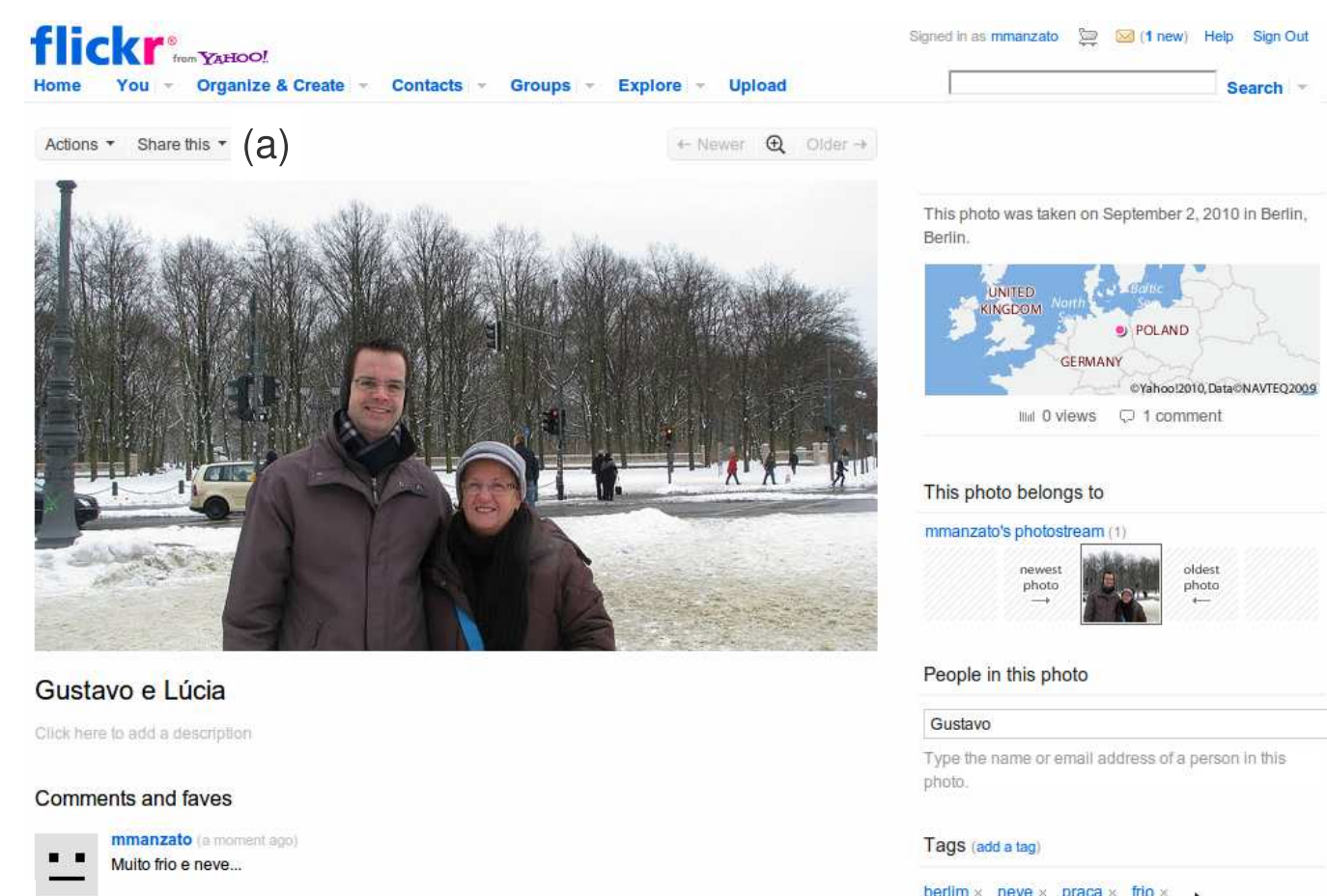

People in this photo

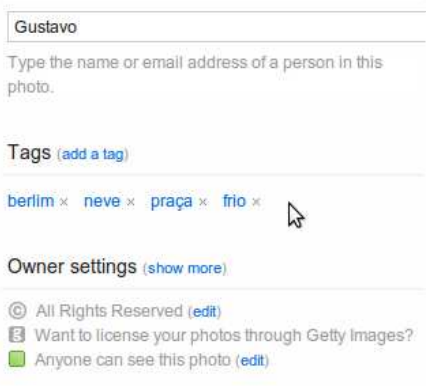

(e)

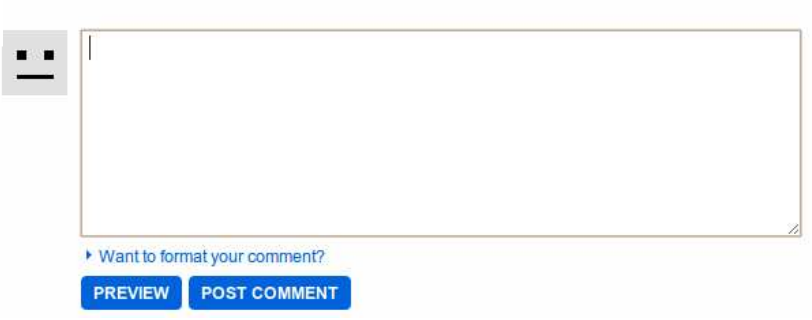

Figura 4.3: Anotações no Flickr. (a) mostra um botão para compartilhamento da foto com outros usuários; (b) permite a especificação manual do local onde a foto foi registrada; (c) ilustra a funcionalidade de identificar as pessoas presentes na imagem; (d) lista as etiquetas inseridas pelos usuários; e (e) apresenta a capacidade de inserir comentários relacionados à fotografia.

\subsubsection{A Ferramenta M4Note}

A ferramenta M4Note (do Inglês, Multimedia Multimodal Annotation - Anotação Multimodal Multimídia) [Goularte et al., 2004a] é composta por uma interface multimodal que permite a inserção de anotações enquanto o vídeo está sendo capturado ao vivo. As anotações podem ser feitas usando caneta/tinta eletrônica, ou por meio de voz que é convertida em texto a partir de um módulo de reconhecimento de fala. Em ambos os casos, os dados são transformados em texto, que é estruturado em documentos XML (do Inglês, eXtensible Markup Language - Linguagem de Marcação Extensível) que seguem o modelo MediaObject (descrito na Subseção 4.2.3). No final do processo de captura, além da descrição das mídias no formato MediaObject, 
cria-se uma apresentação reproduzível em SMIL, que é formada por diferentes mídias, como vídeo, áudio, imagens, slides, traços em tinta eletrônica e texto, as quais estão relacionadas temporalmente e espacialmente.

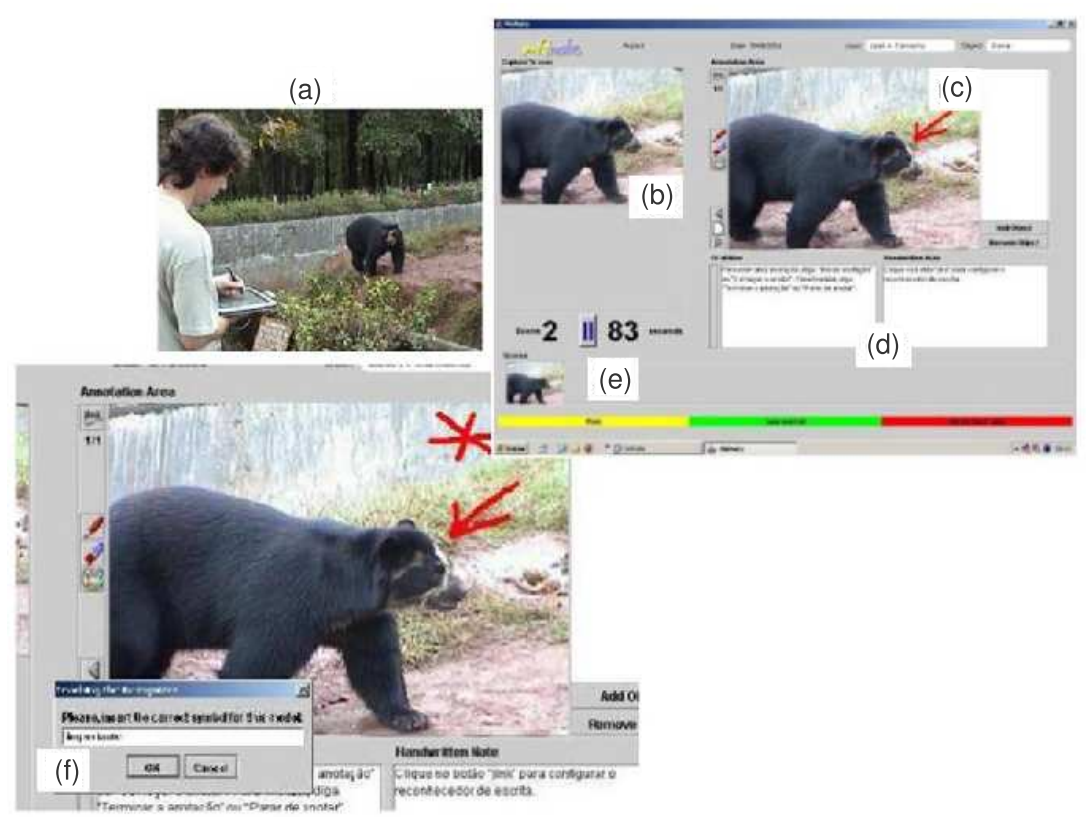

Figura 4.4: A ferramenta M4Note [Goularte et al., 2004a]. (a) ilustra uma sessão de captura de vídeo; (b) apresenta o vídeo sendo capturado na ferramenta; (c) exibe a área de anotação contendo o quadro capturado e enriquecido pelo usuário; (d) mostra as funcionalidades de reconhecimento de fala (esquerda) e inserção de palavras-chave (direita); (e) lista os thumbnails das imagens anotadas; e (f) apresenta uma janela para que o usuário informe o símbolo desenhado.

A Figura 4.4(a) [Goularte et al., 2004a] ilustra um usuário capturando o vídeo enquanto caminha em um zoológico. O vídeo capturado é apresentado em uma área de reprodução audiovisual na ferramenta (Figura 4.4(b)). O usuário extrai um quadro do vídeo por meio de um clique com a caneta na área de reprodução, fazendo com que a captura seja parada momentaneamente. Nesse instante, o quadro atual é transformado em uma imagem, que é utilizada como plano de fundo na região de anotações (Figura 4.4(c)). A partir dessa imagem, o usuário pode criar anotações usando tinta eletrônica, voz ou palavras-chave.

Na área de edição (Figura 4.4(c)), é possivel selecionar a cor da tinta e espessura dos traços, assim como inserir quadros em branco que estendem o conjunto de imagens capturadas do vídeo. A Figura 4.4(d) exibe o texto reconhecido da fala (esquerda), ou as palavras-chave inseridas manualmente pelo usuário (direita). No rodapé, são listados os thumbnails das imagens anotadas para facilitar a navegação (Figura 4.4(e)). 
A M4Note também é provida de um módulo de reconhecimento de símbolos, que são definidos e/ou personalizados pelo usuário. Quando o sistema se depara com um símbolo desconhecido, uma janela pop-up (Figura 4.4(f)) é exibida, pedindo para que o indivíduo informe manualmente o símbolo desenhado. Os novos símbolos são associados a instâncias do modelo MediaObject, permitindo que usuários enriqueçam o conteúdo criando hierarquias de objetos personalizados.

Ao finalizar uma sessão de anotação, um documento SMIL é gerado combinando todas as mídias capturadas: vídeo, imagens e texto convertido dos símbolos reconhecidos e fala. Tais elementos são armazenados com informações temporais, a fim de que seja possível a posterior reprodução sincronizada da sessão na ferramenta.

\subsection{Construção de Perfis}

A maioria dos serviços de personalização são baseados em algum tipo de perfil do usuário, que é uma instância de um modelo pré-definido de dados contendo informações sobre o indivíduo. Pode-se incluir dados demográficos, como nome, idade, origem e nível educacional, ou então representar interesses ou preferências sobre assuntos e tópicos variados [Gauch et al., 2007].

A construção de perfis requer a obtenção de informações pessoais sobre o usuário, que pode ser realizada explicitamente (com intervenção humana), ou implicitamente (de maneira automática pelo sistema). Embora os perfis geralmente contêm informações relevantes, alguns trabalhos [Hoashi et al., 2000] também incluem tópicos que não são do interesse do usuário, de modo a reforçar o processo de personalização. Adicionalmente, os perfis podem ser construídos estaticamente ou dinamicamente. No primeiro caso, as informações contidas no perfil não são alteradas ao longo do tempo. No segundo caso, os dados podem ser inseridos ou atualizados à medida que o usuário utiliza o sistema. Ainda em perfis dinâmicos, os tópicos de interesse podem ser classificados em curto-prazo ou longo-prazo. Tópicos de curto-prazo são temporariamente considerados relevantes. Um exemplo são informações de uma determinada localidade onde o indivíduo pretende passar as férias. Tópicos de longo-prazo, por sua vez, são dados pessoais que dificilmente serão modificados com o tempo, tais como informações sobre pintores, museus e obras artísticas listadas em um perfil de um admirador de artes [Gauch et al., 2007].

O processo de construção de perfil normalmente é dividido em três fases principais, conforme pode ser observado na Figura 4.5 [Gauch et al., 2007]. Inicialmente, a coleta de dados é executada para se obter informações pessoais sobre o usuário. Diferentes estratégias estão descritas na Subseção 4.3.1, as quais exploram a interação do usuário, obtendo os dados necessários de maneira implícita ou explícita. Após a coleta, o próximo passo é a construção do perfil, que consiste em agrupar 


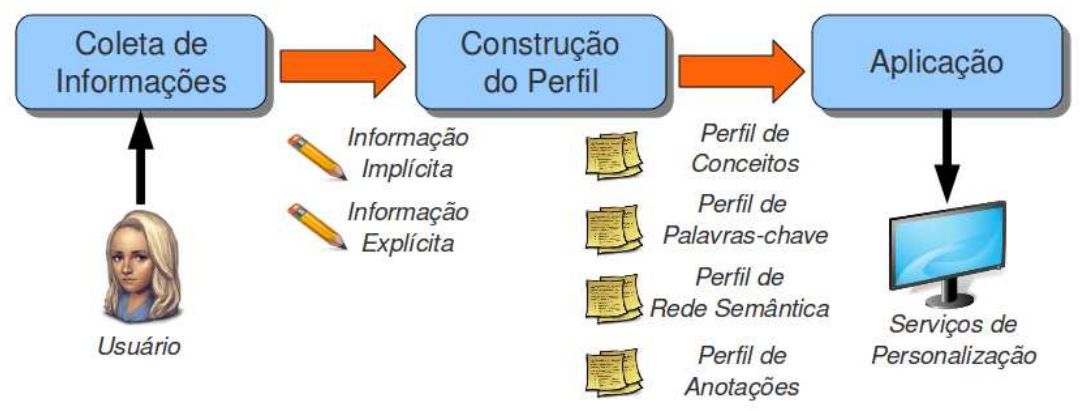

Figura 4.5: Esquema para construção de perfil do usuário.

e representar os conceitos de interesse seguindo um modelo pré-definido. A Subseção 4.3.2 apresenta algumas abordagens existentes para representar e construir o perfil do usuário. A última fase refere-se à aplicação, ou seja, o conjunto de serviços e técnicas de personalização que farão uso das informações pessoais disponiveis. O Capítulo 2 apresentou uma contextualização de tais técnicas encontradas na literatura.

\subsubsection{Coleta de Informações}

A coleta de informações inicia-se com a identificação do usuário, que pode ser realizada por meio de proxies, login, agentes de software, cookies e identificadores de sessão. Atualmente, os mecanismos mais utilizados são login e cookies, sendo a primeira opção mais confiável do que a segunda. Após a identificação, o perfil pode conter informações heterogêneas relacionadas a um indivíduo ou grupo de indivíduos que compartilham preferências e interesses similares. Geralmente, as técnicas são divididas de acordo com a maneira que os dados são obtidos do usuário: coleta explícita ou implícita.

\section{Coleta Explícita}

Na coleta explícita, o próprio usuário informa seus dados pessoais e interesses, normalmente por meio de formulários HTML (do Inglês, HyperText Markup Language - Linguagem de Marcação de Hipertexto). Pode-se solicitar informações demográficas, como nome, endereço, idade e sexo, ou então oferecer mecanismos de avaliação de itens visitados anteriormente, como notas e comentários [Pazzani et al., 1998].

Um problema existente com a coleta explícita é o esforço adicional imposto ao usuário. Devido a isso, ou mesmo por questões de privacidade, é possível que o indivíduo não utilize o sistema [Gauch et al., 2007]. Outro problema é que, em alguns casos, o usuário pode não fornecer as informações corretas sobre suas preferências; ou ainda, esses dados podem se tornar inconsistentes com novos interesses que 
surgem a longo-prazo. Por outro lado, algumas pessoas gostam de fornecer e/ou compartilhar suas preferências. Exemplos de sistemas que provêem mecanismos de coleta explícita são: NetFlix ${ }^{16}$, MyYahoo! ${ }^{17}$, MovieLens ${ }^{18}$ e YouTube.

\section{Coleta Implícita}

A coleta implícita tem como principal vantagem a não intervenção do usuário durante a obtenção de suas preferências. Kelly \& Teevan [2003] oferecem uma descrição detalhada dos principais métodos existentes para coleta de dados pessoais e as informações que podem ser extraídas com base no comportamento do usuário. As principais técnicas são:

- histórico de navegação: O histórico do usuário é uma fonte rica de informações pessoais que pode ser explorada por meio do compartilhamento da memória do navegador [Pretschner \& Gauch, 1999], ou então servidores proxy que atuam como gateways para a Internet, armazenando as páginas visitadas [Barrett et al., 1997]. A frequência e tempo gasto em cada tópico são suscetíveis de serem usados para se inferir o nível de interesse do indivíduo;

- agentes de software: Trata-se de uma aplicação que é instalada no computador do usuário, ou um plug-in ou add-on do próprio navegador. Esses agentes têm a função de coletar informações relacionadas à interatividade do indivíduo, enviando-as periodicamente ao servidor. Apesar de vários trabalhos serem encontrados [Chen \& Sycara, 1998; Marais \& Bharat, 1997], inclusive alguns comerciais na forma de barra de ferramentas [Dumais et al., 2003], essa abordagem necessita de instalação do software no sistema do cliente, implicando em alto custo para o desenvolvimento e manutenção da ferramenta, além da limitação do usuário para uso em outros dispositivos [Gauch et al., 2007];

- logs de navegação e de busca: O histórico de navegação pode também ser extraído no servidor da aplicação. Ao contrário das abordagens que utilizam um software instalado no cliente para obtenção da interação do usuário, nesse caso apenas a atividade do indivíduo com o sistema de personalização é armazenada no servidor. Além do log de navegação, é possível também obter o histórico das buscas realizadas pelo usuário no sistema. Dentre as informações úteis, destacam-se os URLs (do Inglês, Uniform Resource Locator - Localizador Padrão de Recursos) dos itens visitados e a data e hora da consulta. Como vantagens, o usuário não se limita ao uso de um dispositivo em particular, e não há

\footnotetext{
${ }^{16}$ http://www.netflix.com, último acesso em 10 de Novembro de 2010.

${ }^{17}$ http://my.yahoo.com, último acesso em 10 de Novembro de 2010.

${ }^{18}$ http://movielens.umn.edu, último acesso em 10 de Novembro de 2010.
} 
a necessidade de se instalar softwares adicionais. Como desvantagem, a quantidade de informações que serão extraídas é menor do que aquela obtida usando as abordagens anteriores [Liu et al., 2002; Speretta \& Gauch, 2005].

De modo geral, as coletas implícita e explícita de dados pessoais apresentam vantagens e desvantagens. Apesar de existirem estudos para indicar qual estratégia é melhor [Teevan et al., 2005; White et al., 2001; Guiroga \& Mostafa, 1999], não existe ainda uma resposta clara para o assunto, tendo em vista que os trabalhos reportados diferem nas conclusões. No entanto, uma descoberta importante feita por Teevan et al. [2005] refere-se à quantidade de informações disponíveis. Com base em seus experimentos, os autores argumentam que melhores resultados serão obtidos à medida que mais informações sobre o usuário forem extraídas. Assim, observa-se uma estratégia interessante para obtenção de preferências que é a combinação das técnicas de coleta implícita e explícita, assim como é reportado no trabalho de Quiroga \& Mostafa [1999].

\subsubsection{Representação de Perfil}

Geralmente, a representação de um perfil do usuário é realizada por meio de uma lista de palavras-chave com pesos associados; essa é a maneira mais simples para a descrição dos interesses pessoais. Entretanto, modelos mais complexos podem ser verificados, como é o caso daqueles baseados em níveis conceituais, redes semânticas ou anotações do usuário. A construção de tais perfis pode ser realizada automaticamente, por meio de análises do histórico e comportamento do indivíduo, ou manualmente, quando a inserção de informações é realizada pelos próprios usuários ou profissionais. No entanto, a segunda opção requer um esforço humano adicional, o que faz da abordagem uma barreira para a utilização dos serviços de personalização [Gauch et al., 2007].

\section{Perfil de Palavras-Chave}

A representação de perfis baseados em palavras-chave consiste em listar um conjunto de termos que representam os interesses do usuário. Os termos existentes no perfil são obtidos a partir de palavras-chave extraídas de documentos textuais, ou metadados referentes a itens multimídia visitados pelo usuário [Weiß et al., 2008]. Essas palavras geralmente são acompanhadas por pesos, que são representações numéricas do nivel de interesse para cada conceito. O peso associado a cada palavra-chave normalmente é calculado usando a equação $T F \times I D F$ [Salton, 1989] (vide Capítulo 2, Equação 2.3). Posteriormente, o conjunto de termos e respectivos pesos é comparado com os metadados dos itens disponíveis, de modo a se criar um ranking daqueles de maior interesse para o usuário. Essa comparação pode ser feita 
de várias formas, sendo as funções de correlação de Pearson [Resnick et al., 1994] e de cosseno [Baeza-Yates \& Ribeiro-Neto, 1999; Salton, 1989] as mais utilizadas (vide Capítulo 2, Equações 2.5 e 2.6, respectivamente). Uma das desvantagens do uso desse modelo é o fato que muitas palavras-chave têm múltiplos significados. Devido a essa característica, definida como polissemia, os termos podem conter ambiguidades, tornando o perfil impreciso [Gauch et al., 2007].

\section{Perfil de Rede Semântica}

O problema da polissemia é reduzido com o modelo de perfil baseado em rede semântica, já que os tópicos são agrupados formando uma rede de termos relacionados significativamente, obtidos dos metadados ou conteúdo. A proposta de Stefani \& Strappavara [1998], por exemplo, cria uma modelagem melhorada para discriminar o significado das palavras. Eles usaram informações do banco de dados léxico WordNet ${ }^{19}$ para agrupar os termos considerados sinônimos. Assim, cada nó da rede é composto por um conjunto de termos com significados parecidos, os arcos são os relacionamentos entre itens de cada conjunto e os pesos indicam o nível de interesse do usuário por cada conceito. As ligações entre termos ou conceitos, em especial, são uma vantagem desse modelo em relação ao de palavras-chave, uma vez que pode-se definir explicitamente os relacionamentos existentes, sobrepondo, consequentemente, os problemas de ambiguidades e sinônimos inerentes à linguagem natural. O mapeamento entre os termos, entretanto, é uma tarefa adicional que deve ser realizada por meio de consultas a bases de dados léxicos [Stefani \& Strappavara, 1998], mecanismos de aprendizagem [Gentili et al., 2003], ou manualmente [Micarelli \& Sciarrone, 2004].

\section{Perfil de Conceitos}

Apesar de similar ao modelo de rede semântica, o perfil de conceitos apresenta uma distinção, que é o fato de os nós representarem tópicos abstratos pré-existentes de interesse para o usuário, ao invés de um conjunto de palavras-chave extraídas dos metadados ou conteúdo. Os conceitos e relacionamentos podem ser obtidos com base em uma taxonomia de referência, como ontologias [Guarino et al., 1999; Wang et al., 2007] ou dicionário léxico [Labrou \& Finin, 1999; Daoud et al., 2010]. Adicionalmente, tais conceitos podem ser organizados hierarquicamente [Bloedorn et al., 1996; Kim \& Chan, 2008], sendo possível fazer generalizações; é possível ainda que a quantidade de níveis da hierarquia seja fixada [Trajkova \& Gauch, 2004], ou alterada dinamicamente de acordo com os interesses do usuário [Chen et al., 2001]. A utilização de ontologias, em particular, apresenta a vantagem de se permitir a

\footnotetext{
${ }^{19}$ http://wordnet.princeton.edu, último acesso em 10 de Novembro de 2010.
} 
definição ou distinção dos relacionamentos entre os conceitos. Taxonomias mais ricas nesse sentido fazem com que os resultados de busca personalizada sejam melhores [Guha et al., 2003; Zhu et al., 2002], mas ainda necessitam de estudos para reduzir problemas de escalabilidade durante a criação de ontologias extensas [Gauch et al., 2007].

\section{Perfil de Anotações}

Uma maneira alternativa de se construir perfis de interesses é por meio das anotações produzidas pelo usuário no passado. Atualmente, tais anotações referem-se principalmente às etiquetas produzidas pelo indivíduo, ou seja, não se encontram trabalhos que exploram outros mecanismos de anotações para obter as preferências do usuário. Liang et al. [2008] argumentam que sistemas de etiquetação, além de ajudar a organizar coleções pessoais de documentos ou itens multimídia, podem também ser usados para inferir uma opinião pessoal do indivíduo, sendo que o ato de inserir novos termos é considerado uma coleta implícita de dados pessoais [Liang et al., 2008].

Com base na definição de folksonomias, apresentada na Seção 4.1.2, é possivel obter um perfil de interesses a partir de uma personomia. Uma personomia $P_{u}$ de um usuário $u$ é uma parte de uma folksonomia $F$ relacionada a $u$, i.e., $P_{u}=\left(E_{u}, R_{u}, A_{u}\right)$, onde $A_{u}$ é o conjunto de todas as anotações de $u: A_{u}=\{(e, r) \mid(u, e, r) \in A\}, E_{u}$ é o conjunto de etiquetas de $u: E_{u}=\left\{e \mid(e, r) \in A_{u}\right\}$ e $R_{u}$ é o conjunto de documentos ou itens multimídia visitados por $u$ : $R_{u}=\left\{r \mid(e, r) \in A_{u}\right\}$ [Hotho et al., 2006]. O conjunto de todas as anotações (etiquetas) produzidas pelo usuário constitui sua personomia. O conjunto de todas as personomias forma uma folksonomia [Klasnja Milicevic et al., 2010].

Sen et al. [2009] desenvolveram um sistema de recomendação de filmes com base nas etiquetas criadas pelos usuários. Primeiramente, eles inferem as preferências de um usuário para um conjunto de etiquetas explorando a interação entre o indivíduo, as etiquetas utilizadas e os itens multimídia acessados. Em seguida, eles determinam os interesses por filmes baseando-se nas preferências para as etiquetas criadas anteriormente. Também são propostos mecanismos para calcular a qualidade das anotações existentes, já que muitos usuários podem criar termos livremente, os quais não apresentam nenhum conceito importante relacionado ao recurso anotado. Gemmis et al. [2008] propõem um método de recomendação baseado em conteúdo que explora folksonomias para inferir os interesses do usuário. Eles utilizam técnicas de aprendizado de máquina aplicadas às descrições hierárquicas, em conjunto com as etiquetas criadas pelo usuário.

No contexto de sistemas de recomendação colaborativos, Tso-Sutter et al. [2008] incorporam etiquetas nos algoritmos existentes, primeiro criando relacionamentos 
entre etiquetas, usuários e itens, e depois aplicando um método de fusão para re-associar essas correlações. Zanardi \& Capra [2008], por sua vez, criam rankings de itens multimídia com base na distância semântica inferida das palavras de busca do usuário, com relação às etiquetas associadas ao conteúdo. Tal distância é calculada com base em uma métrica de peso medida entre o usuário que realiza a busca e os usuários que criaram o conjunto de etiquetas correspondentes.

Em todos esses trabalhos, os autores assumem que quando um usuário atribui uma etiqueta a um item, essa atividade significa que aquele conteúdo pode trazer informações relevantes sobre suas preferências. No entanto, a maioria dos sistemas ainda necessita de pesquisa no sentido de descrever de maneira formal os perfis de interesses baseados em anotações. Além disso, não se encontram abordagens na literatura relacionadas à construção multimodal de perfis, o que poderia, por sua vez, representar de maneira mais precisa as preferências do usuário. Adicionalmente, descrições baseadas em conhecimento oferecem melhores serviços de personalização, mas enfrentam o problema da restrição de domínio de dados durante a representação usando estruturas semânticas, como ontologias.

Uma das contribuições desta tese, portanto, é o desenvolvimento de um perfil de preferências, que é complementado com termos relacionados semanticamente, provenientes de uma folksonomia criada colaborativamente pelos usuários. Apesar de utilizar anotações colaborativas, a proposta mantém a individualidade das anotações produzidas pelo indivíduo, de modo a explorar a atividade interativa do usuário, vista como um indício de que aquele conteúdo é relevante. O Capítulo 5 descreve a arquitetura de personalização desenvolvida, juntamente com o procedimento de criação de perfil.

\subsection{Considerações Finais}

Este capítulo apresentou alguns conceitos relacionados a anotações multimídia e construção de perfil do usuário. Relacionadas às anotações, foram expostas as abordagens de indexação manual de conteúdo, discutindo-se os problemas existentes em tal atividade. Argumentou-se que profissionais são submetidos à tarefa de anotação exaustiva, o que gera metadados semânticos a respeito do conteúdo, mas, como desvantagem, são necessários consideráveis esforços humanos e tempo, fazendo dessa atividade um processo caro, dispendioso e propenso a erros.

Por outro lado, se delegada parte da atividade de descrição a usuários comuns, a indexação pode ser realizada colaborativamente sem necessitar de esforços de especialistas. Essa alternativa vem sendo estudada nos últimos anos devido ao crescente desenvolvimento de aplicações e serviços situados no ambiente da Web 2.0 [Governor et al., 2009]. Alguns dos conceitos explorados por essa área, como a inteligência 
coletiva, sistemas de etiquetação e folksonomias, foram apresentados neste capítulo, uma vez que podem ser considerados no sentido de se obter metadados sobre o conteúdo produzidos colaborativamente. Assim, problemas existentes atualmente em indexação multimídia, e que foram mencionados ao longo dos Capítulos 3 e 4, podem ser reduzidos. A restrição de domínio de dados, por exemplo, inexiste nessa abordagem, já que usuários podem anotar as mídias sem depender das características do conteúdo. A descrição em si é um processo manual, mas torna-se uma atividade dinâmica que não requer grandes esforços, uma vez que vários usuários colaboram para indexação dos dados audiovisuais.

Contudo, a simples utilização de anotações colaborativas em sistemas de personalização gera outro problema, já que perde-se a individualidade dos dados produzidos por cada usuário. Consequentemente, informações valiosas que poderiam indicar as preferências do indivíduo não são consideradas no processo de anotação, sendo que tais dados poderiam enriquecer o perfil do usuário com termos, conceitos e/ou assuntos de seu interesse. Essas informações adicionais poderiam, ainda, contribuir com a redução de problemas existentes nas abordagens atuais de construção de perfis, tais como: i) a necessidade de obtenção de vários tipos de informações sobre o usuário; e ii) a representação baseada em conhecimento sem restrição no domínio de dados.

Verificando a necessidade de individualização das anotações em serviços de personalização, uma alternativa, que até o momento não foi explorada, é analisar dados provenientes da atividade de enriquecimento de conteúdo [Bulterman, 2004; Goularte et al., 2004b], sendo que trabalhos relacionados a tal atividade foram descritos na Subseção 4.2.2 deste capítulo. Essa abordagem é interessante pois essas informações apresentam considerável carga semântica a respeito dos interesses do indivíduo. Além disso, podem ser representadas de maneira multimodal [Goularte et al., 2004a], o que aumenta o elo semântico entre as informações agregadas e a interpretação do usuário.

Não obstante as anotações de usuários poder contribuir para reduzir os problemas relacionados, alguns desafios estão presentes nesse cenário. Um deles é que as anotações, em particular a atividade de enriquecimento, pode ser realizada de diferentes maneiras. Usuários podem criar anotações em manuscrito utilizando caneta/tinta eletrônica, delimitar regiões de interesse em uma imagem específica, adicionar comentários por texto ou voz, inserir mídias relacionadas semanticamente, entre outras. Todas essas atividades precisam ser analisadas individualmente por meio de técnicas específicas para que informações úteis possam ser extraídas e consideradas metadados ou relacionadas às preferências do indivíduo. Como exemplo, manuscritos precisam de métodos para reconhecer os símbolos desenhados, bem como procedimentos para analisar as regiões de interesse a fim de se detec- 
tar/reconhecer objetos conhecidos, como faces. Por outro lado, comentários por voz necessitam de um módulo de reconhecimento de fala, a fim de que o áudio possa ser convertido em texto, facilitando o processamento dos dados. Repara-se, portanto, que cada tipo de anotação requer procedimentos específicos para que informações úteis sejam extraídas e utilizadas na complementação de perfil e de descrições hierárquicas sobre o conteúdo.

Outro desafio é em relação à característica das anotações de usuários de não seguir um vocabulário restrito. Etiquetas e comentários (por voz ou texto), por exemplo, podem ser criados livremente, sem depender de termos especificados formalmente. O manuscrito, por sua vez, pode ser realizado independentemente de formas pré-determinadas, permitindo ao usuário desenhar traços ou marcações com plena liberdade de expressão. Dessa maneira, são necessários algoritmos para converter os dados extraídos da interação em um formato representativo que possa ser explorado pelo sistema de personalização. No caso de etiquetas e comentários, pode-se utilizar métodos estatísticos para que sejam encontradas representações em comum entre as anotações. Em manuscritos, o usuário pode especificar um conjunto de amostras para que símbolos sejam reconhecidos conforme sua caligrafia; e o sistema pode utilizar uma heurística pré-definida para determinar a região de interesse estabelecida.

Nesse contexto, o direcionamento deste trabalho é o desenvolvimento de técnicas multimodais apropriadas para analisar os dados provenientes da atividade interativa, encontrando informações relevantes que possam ser representadas de maneira controlada, permitindo, assim, a sua utilização durante a personalização. Desse modo, a arquitetura proposta nesta tese considera anotações hierárquicas e de usuários para melhorar os serviços agregados. Tal arquitetura é composta por técnicas multimodais que analisam as anotações produzidas pelos usuários, criando representações e informações utilizáveis pelas aplicações de personalização. Consideram-se anotações colaborativas para complementar as descrições hierárquicas do conteúdo, auxiliando profissionais e técnicas automáticas no processo de indexação multimídia. Além disso, a atividade de enriquecimento é explorada pelo sistema a fim de que a individualidade das anotações seja mantida, permitindo traçar um perfil mais preciso sobre as preferências do usuário. Ressalta-se aqui que: i) a individualidade dos dados está diretamente relacionada à semântica contida nos dados obtidos da interação do usuário; e ii) a utilização direta da anotação colaborativa, sem enriquecimento, provoca a perda da individualidade desses dados.

Considerando as questões expostas, o próximo capítulo descreve a arquitetura de personalização proposta neste trabalho. 


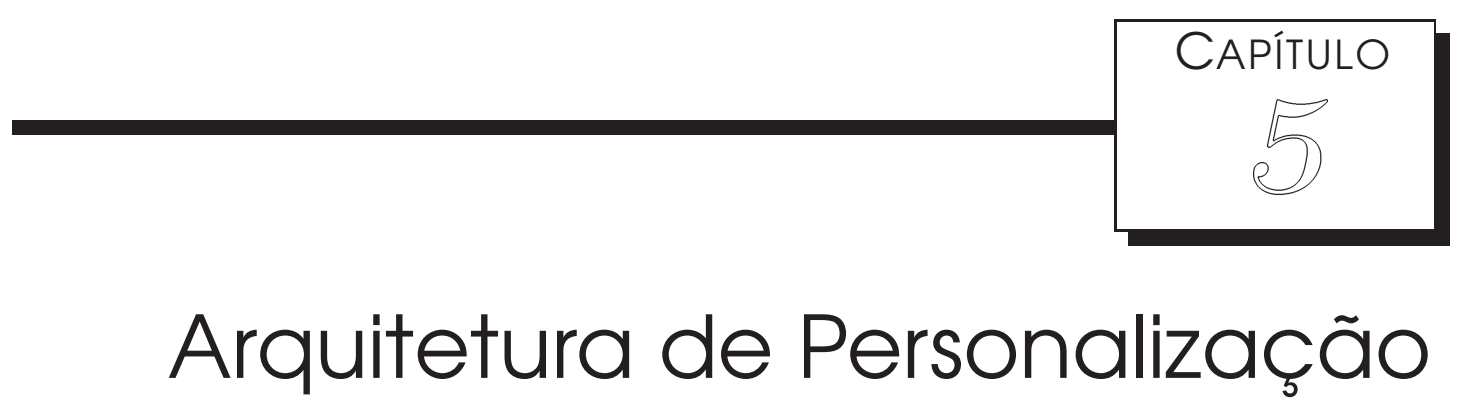

$\mathrm{E}$

ste trabalho tem como objetivo propor uma arquitetura de personalização que considera anotações dos usuários para prover informações semânticas a respeito do conteúdo e das preferências de cada indivíduo. A principal vantagem dessa abordagem, em relação às propostas existentes na literatura, é que além de se considerar dados semânticos para melhorar os resultados da personalização, a arquitetura também permite o desenvolvimento de novos serviços independente de domínio de dados. Tal funcionalidade atua no processo de extração de informações semânticas, e também na construção do perfil do usuário utilizando termos relacionados semanticamente para representação de preferências. No primeiro caso, a lacuna semântica relacionada às técnicas automáticas para indexação é preenchida por anotações multimodais criadas colaborativamente pelos usuários do sistema. Esse esforço colaborativo também reduz os problemas da indexação manual, que são a dispendiosidade e a suscetibilidade a erros da descrição por especialistas. No segundo caso, ou seja, na obtenção das preferências, a arquitetura provê um procedimento de complementação de perfil com conceitos relacionados semanticamente às anotações criadas pelo usuário durante a atividade de enriquecimento de conteúdo. Assim, ao contrário de se utilizar esquemas formais para representação de conhecimento, como ontologias, realiza-se uma estruturação semântica e multimodal do perfil utilizando folksonomias criadas dinamicamente pela comunidade de indivíduos do sistema.

As anotações dos usuários têm um papel de destaque na arquitetura proposta pois são responsáveis por agregar uma carga semântica adicional no conteúdo multimídia e também no perfil de preferências. Como resultado da exploração desses dados, obtêm-se informações que melhoram os serviços de personalização construídos a 
partir da arquitetura proposta (vide Capítulo 6).

Tendo em vista a descrição nos capítulos anteriores dos fundamentos, desafios e trabalhos relacionados à área de personalização e adaptação de conteúdo, neste capítulo apresenta-se a arquitetura de personalização proposta. Inicialmente, a Seção 5.1 descreve sua visão geral, definindo-se os módulos envolvidos no sistema. Em seguida, cada componente da arquitetura é discutido em detalhes, envolvendo os processos de anotações do usuário, indexação multimídia e criação de perfil. Na Seção 5.2 propõe-se uma nova versão da ferramenta M4Note, que foi estendida para satisfazer os requisitos deste projeto para anotação e enriquecimento de conteúdo. $\mathrm{Na}$ Seção 5.3, apresentam-se os trabalhos que foram feitos para descrever conteúdo em diferentes domínios de dados, como filmes e telejornais. Na Seção 5.4, descrevem-se as técnicas desenvolvidas para enriquecer o perfil do usuário com metadados semânticos.

\subsection{Visão Geral}

Esta seção apresenta uma visão geral da arquitetura de personalização baseada em anotações do usuário. A Figura 5.1 ilustra o esquema proposto, sendo que os retângulos destacados em cinza representam os módulos desenvolvidos neste trabalho.

Usuários utilizam diferentes dispositivos para acessar e interagir com conteúdo multimídia. Essa interação pode envolver atividades de anotação e/ou enriquecimento de conteúdo (Figura 5.1(a)), tais como a atribuição de notas de avaliação aos itens visitados, associação de etiquetas para organização local dos dados, manuscritos utilizando dispositivos baseados em caneta/tinta eletrônica para marcação, destaque e/ou delimitação de regiões de interesse, inserção de comentários escritos e/ou por voz, entre outros. Neste trabalho, estendeu-se a ferramenta M4Note (apresentada no Capítulo 4, Subseção 4.2.5), de modo a fornecer aos usuários a infraestrutura de interação necessária para anotação dos dados multimídia. A Seção 5.2 descreve em mais detalhes as funcionalidades desse módulo da arquitetura.

A partir das anotações colaborativas dos usuários, técnicas são agregadas à arquitetura para analisar essas informações, procurando transformá-las em metadados relacionados ao conteúdo (Figura 5.1(b)). Essas técnicas referem-se a procedimentos de extração de regiões de interesse, reconhecimento de símbolos em manuscritos, detecção e reconhecimento de faces, conversão de comentários por voz em texto, e recuperação de metadados de fontes externas (Figura 5.1(c)). Nesse último caso, considera-se neste trabalho o Banco de Dados de Filmes da Internet, que armazena e distribui diferentes informações sobre os mais variados tipos de conteúdo, incluindo metadados sobre filmes, como lista de atores, palavras-chave, gêneros, lista de 
(c)

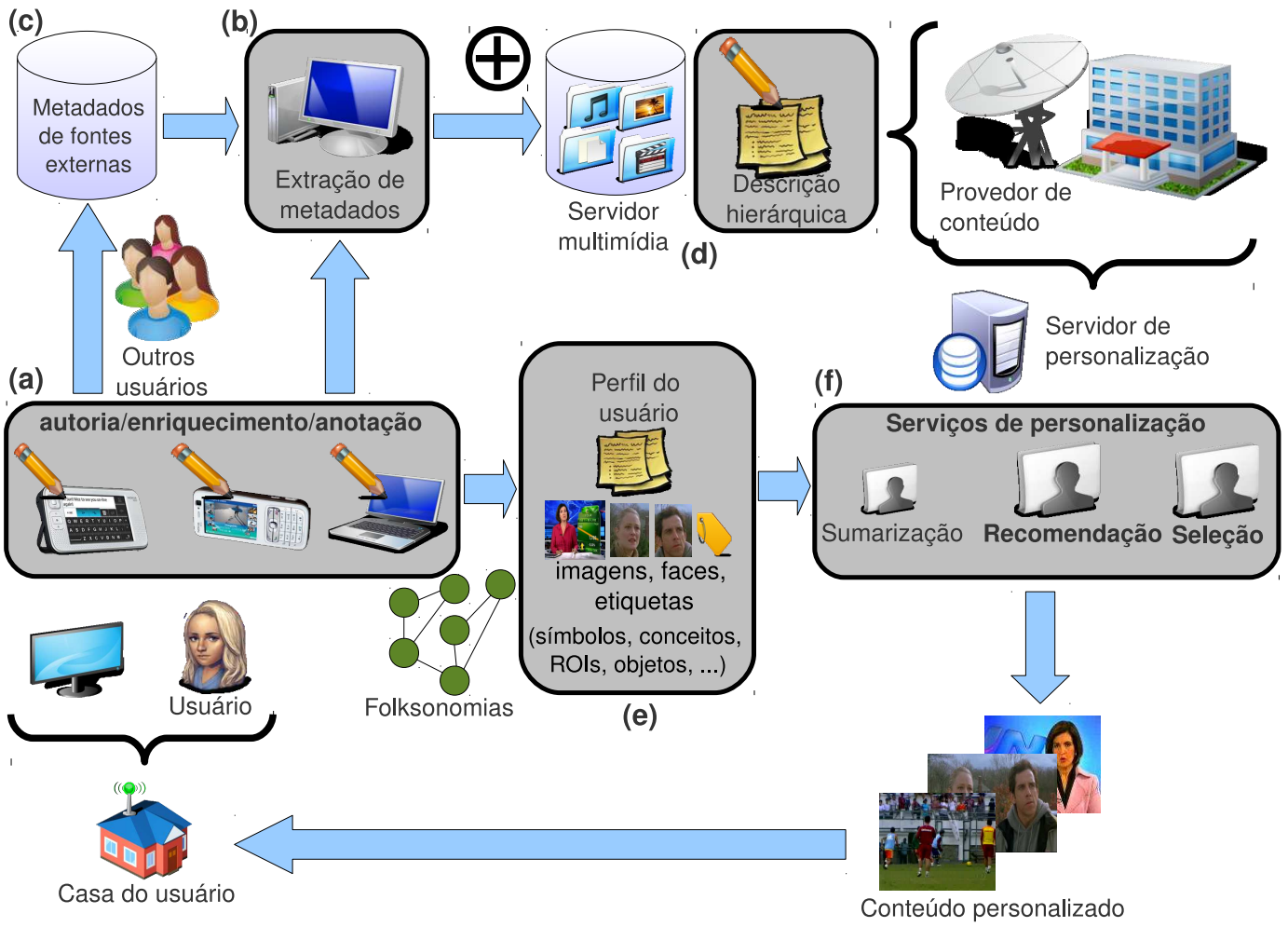

Figura 5.1: Arquitetura de personalização. (a) é o módulo para anotação e enriquecimento pelo usuário; (b) é o módulo contendo um conjunto de ferramentas multimodais para extração de metadados; (c) é uma base de dados contendo metadados colaborativos; (d) é o módulo de indexação multimídia realizada no provedor de conteúdo; (e) é o módulo de criação e enriquecimento de perfil; e (f) é o módulo de personalização.

diretores e produtores, entre outros. Uma característica importante dessa fonte de metadados é que as descrições fornecidas são organizadas (hierarquizadas) e, ao mesmo tempo, são inseridas colaborativamente pelos usuários por meio do cadastro de novos itens na base de dados.

Dessa maneira, a principal vantagem do módulo responsável pela extração de metadados (Figura 5.1(b)) é que ele explora a atividade interativa do usuário, que é realizada de diferentes formas. Assim, várias técnicas estão disponíveis para extrair informações úteis das anotações, as quais são somadas aos metadados do conteúdo, complementando-os com dados semânticos para melhoria dos serviços de personalização. Uma descrição detalhada desse módulo da arquitetura é apresentada na Seção 5.3.

Do lado do provedor de conteúdo ${ }^{1}$, dados em diferentes domínios (filmes, noti-

\footnotetext{
${ }^{1} \mathrm{O}$ provedor de conteúdo, neste trabalho, é simulado por um servidor de dados local.
} 
ciários, músicas, fotos, entre outros) são armazenados em um servidor multimídia (Figura 5.1(d)). Juntamente com eles, disponibilizam-se descrições hierárquicas sobre o conteúdo, que na arquitetura proposta, são geradas de modo automático e manual. A extração automática refere-se à obtenção de closed-caption de programas, legendas de filmes, detecção de faces, extração de quadros-chave e classificação de notícias. A indexação manual, por sua vez, envolve esforços de profissionais para segmentação do conteúdo em cenas. Essa atividade, em particular, será substituída em trabalhos futuros por uma técnica automática de segmentação utilizando os conceitos apresentados no Capítulo 3, Seção 3.1.

Além dos procedimentos de indexação automática e manual para descrição hierárquica (Figura 5.1(d)), a arquitetura implementa um processo de complementação de metadados utilizando as anotações criadas pelos usuários. Após as técnicas de extração de metadados terem refinado as anotações (Figura 5.1(b)), essas informações recém-geradas são agregadas às descrições hierárquicas, enriquecendo os dados com informações semânticas criadas colaborativamente pelos usuários. Apesar de se ter disponíveis diferentes técnicas de análise de anotações (situadas no módulo especificado pela Figura 5.1(b)), na versão atual do sistema utilizam-se apenas as faces identificadas pelos usuários, além dos metadados criados colaborativamente e disponibilizados na base IMDB (Figura 5.1(c)).

O processo de complementação de descrições apresenta a vantagem de se manter a estrutura inicial e organizada das descrições hierárquicas, reduzindo o problema das anotações de usuários de não seguir um vocabulário restrito. Dessa maneira, o conteúdo é representado por documentos declarativos que seguem o modelo MediaObject [Goularte et al., 2006], apresentado no Capítulo 4, Subseção 4.2.3, contendo informações criadas por três fontes distintas: i) técnicas automáticas de indexação; ii) procedimentos de descrição manual por especialistas; e iii) metadados provenientes das anotações dos usuários. Neste trabalho, adotou-se o modelo MediaObject devido à sua facilidade de utilização, à sua compatibilidade com a ferramenta M4Note e à sua característica de ser extensível para acoplar novos tipos de informações.

As anotações do usuário também contribuem para a criação de seu perfil de preferências (Figura 5.1(e)). A arquitetura considera que, quando o indivíduo decide interagir com o conteúdo, criando anotações ou enriquecendo os dados com avaliações, notas, comentários ou manuscritos, essa atividade indica que as informações contidas naquela mídia específica provocaram uma sensação diferenciada no usuário. Assim, o perfil é construído aproveitando esses dados, melhorando a carga semântica associada às preferências do indivíduo e, consequentemente, provendo melhores serviços de personalização.

As seguintes informações são usadas para construir o perfil: avaliação de 
itens por meio de notas, gêneros e categorias relacionados ao conteúdo ou parte dele, palavras-chave associadas anteriormente, faces detectadas e reconhecidas, e etiquetas atribuídas dinamicamente pelos usuários. Analogamente ao que é feito com descrições hierárquicas, a arquitetura também provê um procedimento de complementação de perfil, que agrega à descrição de interesses termos e nomes próprios relacionados semanticamente com etiquetas e faces produzidas pelo indivíduo. Desse modo, a representação das preferências é estruturada semanticamente por meio de folksonomias, que exploram a co-ocorrência de termos e nomes próprios para definir ligações semânticas entre as informações. Como resultado, o perfil é composto por: i) anotações individualizadas e multimodais, produzidas pelo próprio indivíduo; ii) termos e faces relacionados semanticamente com os dados produzidos, obtidos por meio de consultas a folksonomias criadas dinamicamente pelos outros usuários; e iii) uma representação estruturada composta por conceitos relacionados semanticamente sem restrição de domínio de dados. O procedimento de construção e enriquecimento de perfil é apresentado na Seção 5.4.

Com base na descrição enriquecida de conteúdo disponível no provedor, juntamente com o perfil de interesses do usuário complementado por anotações individualizadas, melhores serviços de personalização podem ser projetados e desenvolvidos, provendo conteúdo customizado de acordo com as preferências do indivíduo (Figura 5.1(f)). Nesta tese, exploram-se os seguintes tipos de personalização: recomendação de filmes e seleção de cenas em telejornais. No entanto, outros serviços irrestritos ao domínio de dados podem ser implementados com base nas informações disponíveis, como sistemas de sumarização de conteúdo. Exemplos de tais serviços, desenvolvidos com base na arquitetura proposta, serão apresentados no Capítulo 6.

\subsection{Anotações do Usuário}

Esta seção apresenta o ambiente de interação desenvolvido neste trabalho que permite a anotação e enriquecimento de conteúdo pelos usuários finais. Tais atividades estão relacionadas ao módulo autoria/enriquecimento/anotação da Figura 5.1(a) e são suportadas por diferentes paradigmas de interação. Um usuário pode capturar um quadro e fazer anotações manuais nas imagens selecionadas usando caneta/tinta eletrônica. Também é possível criar avaliações para o vídeo, inserir etiquetas e comentários por voz. Adicionalmente, durante o enriquecimento, o usuário pode requisitar personalização a um possível provedor munido de serviços especiais, como sumarização, seleção e recomendação. A seleção, por exemplo, pode auxiliar o indivíduo no sentido de recuperar vídeos relacionados ao assunto atual, de modo a facilitar a autoria de apresentações com mídias interligadas semanticamente. $\mathrm{O}$ Capítulo 6 descreve a implementação de alguns desses serviços. 


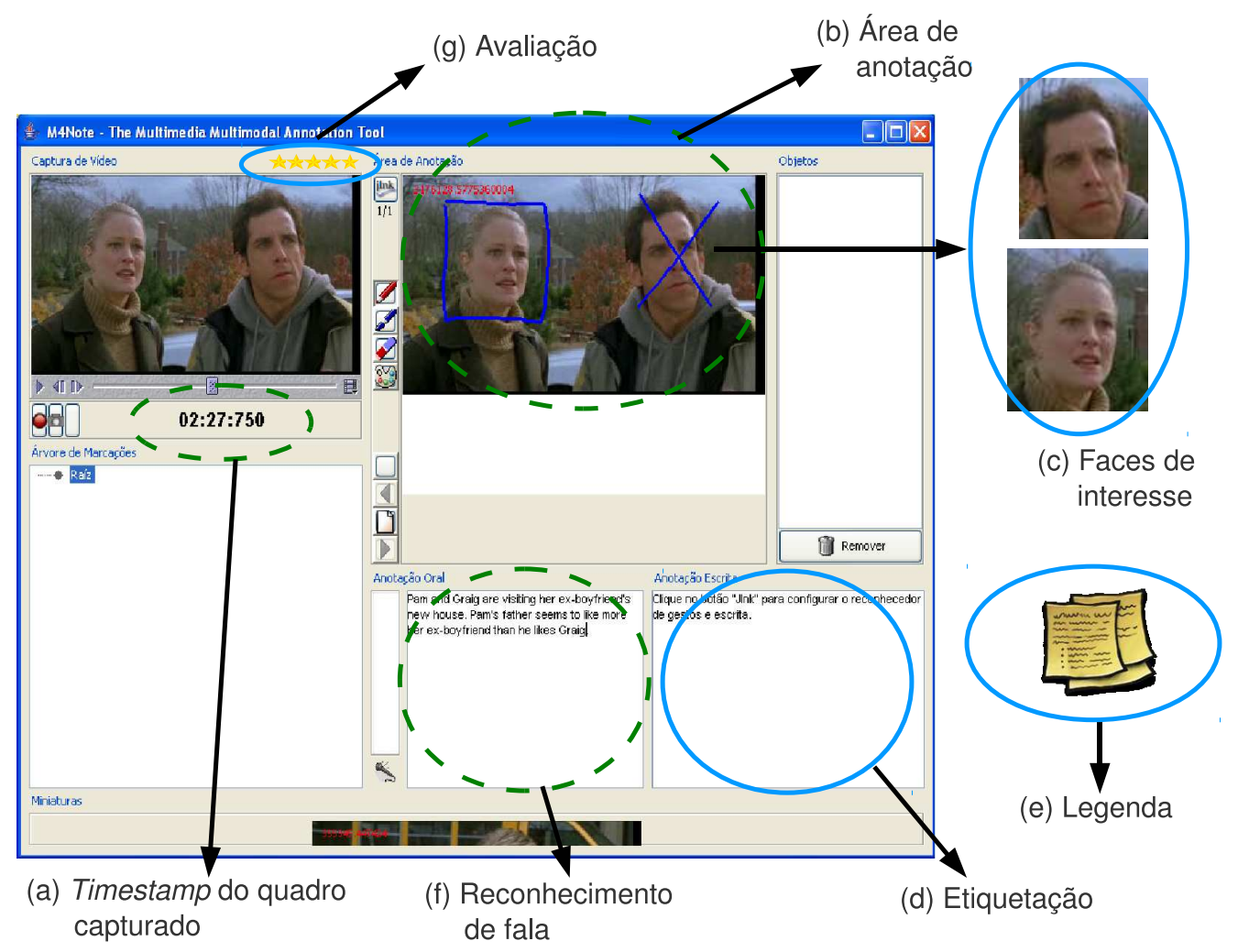

Figura 5.2: M4Note estendido. As elipses tracejadas (em verde) indicam as funcionalidades que já estavam disponíveis na ferramenta; e as elipses contínuas (em azul) indicam as funcionalidades implementadas neste trabalho. (a) indica o instante de captura de um quadro; (b) ilustra a área de anotação; (c) apresenta as faces de interesse detectadas; (d) exibe a área de etiquetação; (e) representa o closed-caption ou legenda utilizado para seleção textual de conteúdo; (f) ilustra a área de reconhecimento de fala; e (g) indica a funcionalidade de avaliação pelo usuário.

A Figura 5.2 apresenta a ferramenta M4Note [Goularte et al., 2004a], descrita anteriormente no Capítulo 4, Subseção 4.2.5. Neste trabalho, ela foi estendida para acessar fluxos audiovisuais pré-gravados fornecidos por provedores de conteúdo. As funcionalidades de anotação supracitadas foram implementadas na ferramenta (em adição a um conjunto previamente desenvolvido conforme apresentado na Subseção 4.2.5), além da possibilidade de se especificar diferentes critérios para selecionar conteúdo. Tais funcionalidades estão representadas na Figura 5.2 por elipses tracejadas (implementadas anteriormente), elipses contínuas (desenvolvidas neste trabalho) e legendas correspondentes. A Figura 5.2(a) referencia as informações temporais dos quadros capturados, usadas pelo sistema para delimitar um período de closed-caption que será usado como dados de busca para a seleção de conteúdo com base em dados textuais.

A Figura 5.2(b) representa a área de anotação, que pode ser preenchida com 
quadros capturados como plano de fundo, ou pode ser usada como área de desenho e anotações manuais usando caneta/tinta eletrônica. A área de anotação é suportada por um módulo de reconhecimento de escrita, que é capaz de receber como dados de entrada um conjunto de pontos, e gerar como saída texto ou símbolos reconhecidos.

Os traços são também usados para criar regiões de interesse: definem-se tais regiões como as coordenadas horizontal e vertical máximas e mínimas das notas desenhadas pelo usuário. Quando uma região de interesse é definida, o sistema executa um método de detecção de face na região extraída para verificar se o usuário criou uma anotação relacionada a uma pessoa na cena. Em caso afirmativo, apresenta-se ao usuário uma janela para que seja especificado o nome da pessoa, fazendo com que, posteriormente, a região seja classificada pelo sistema como uma face de interesse (Figura 5.2(c)). O nome e a face da pessoa presente na cena são enviados ao provedor de conteúdo para enriquecerem a descrição hierárquica do vídeo, conforme apresentado na Seção 5.3. A detecção em si é realizada automaticamente por meio da biblioteca Java em código-aberto FAINT (do Inglês, Face Annotation Interface Java API - API em Java para Interface de Anotação de Face) ${ }^{2}$.

Os módulos referenciados pela Figura 5.2(d), (e) e (f) representam as informações textuais que podem ser inseridas pelo usuário. É possivel associar um conjunto de etiquetas ao vídeo (Figura 5.2(d)), e/ou fazer comentários por voz sobre os quadros capturados, que são automaticamente convertidos em texto por meio de um reconhecedor de fala (Figura 5.2(f)). A partir do instante de captura de um quadro, o sistema pode delimitar um período de closed-caption da cena (Figura 5.2(e)) para ser utilizado pelo sistema de personalização em casos onde o usuário não insere nenhuma informação textual. Define-se, portanto, uma janela de 10 segundos a partir do instante de captura, sendo que o closed-caption referente a esse período é extraído e utilizado pela técnica de seleção de cenas.

Por fim, a ferramenta permite ainda que o usuário insira avaliações para o vídeo sendo assistido (Figura 5.2(g)). Tais avaliações são representadas por notas que variam de 0,5 (não gostou) até 5 (gostou), com 0,5 de incremento.

Neste trabalho, os seguintes tipos de anotações de usuários são considerados: avaliações, faces de interesse, etiquetas, manuscritos, captura de quadros e comentários por voz. Tais tipos de anotações foram escolhidos devido à disponibilidade de técnicas para converter esses dados em metadados significativos. Algumas dessas técnicas já estavam acopladas à ferramenta M4Note, como os módulos de captura de quadros, manuscrito e reconhecimento de fala e escrita [Goularte et al., 2004a]. Outras foram implementadas com este trabalho, tais como a inserção de notas de avaliação, a detecção/reconhecimento de faces e a associação de etiquetas.

Conforme a aplicação de personalização (vide Capítulo 6), diferentes informações

\footnotetext{
${ }^{2}$ http://faint.sourceforge.net, último acesso em 10 de Novembro de 2010.
} 
serão usadas para prover conteúdo personalizado. Nesse contexto, é importante ressaltar o mecanismo utilizado pela arquitetura proposta para explorar os dados obtidos a partir da interação entre usuário e conteúdo. Verifica-se que algumas informações são utilizadas para complementar descrições hierárquicas (como faces reconhecidas e metadados provenientes do IMDB), e outras são usadas para complementar o perfil de interesses do indivíduo com informações semânticas, conforme será apresentado na Seção 5.4.

\subsection{Indexação Multimídia}

Esta seção apresenta o processo de indexação adotado neste trabalho para extrair e representar metadados sobre conteúdo audiovisual. O método desenvolvido atua nos módulos autoria/enriquecimento/anotação (Figura 5.1(a)), extração de metadados (Figura 5.1(b)), metadados de fontes externas (Figura 5.1(c)) e descrição hierárquica (Figura 5.1(d))) da arquitetura desenvolvida. Ao contrário de delegar todo o processo de descrição a profissionais e técnicas automáticas de indexação no provedor de conteúdo, a abordagem proposta considera dados provenientes da interação entre usuários e conteúdo a fim de complementar os metadados com informações semânticas a partir de anotações colaborativas produzidas ao longo do tempo. Tal procedimento visa reduzir os problemas da indexação manual, como a dispendiosidade e a suscetibilidade a erros, e também possibilitar a extração de informações semânticas sem necessitar restringir o domínio do conteúdo, como acontece nas técnicas atuais de indexação automática. Em tempo, este trabalho, de modo geral, considera dois domínios de dados distintos: telejornais e filmes. Apesar de o Capítulo 6 descrever serviços de personalização em ambos os domínios, a arquitetura proposta pode ser estendida a tipos de conteúdo diversos, como esportes, novelas, reportagens, entre outros, bem como a diferentes modalidades, como documentos, imagens e áudio.

A Figura 5.3 ilustra o procedimento de descrição de vídeo adotado neste trabalho [Manzato et al., 2011; Manzato \& Goularte, 2010; 2009]. O processo inicia-se com a reconstrução de layout ou segmentação temporal (Figura 5.3(a)), que consiste em definir os limiares de cada cena. Como tratado no Capítulo 3, o conceito de cena depende do domínio de dados considerado: no caso de telejornais, por exemplo, assume-se que uma cena é uma notícia sendo apresentada, uma vez que ela trata de um mesmo assunto; na descrição de filmes, uma cena é formada por vários eventos que, quando combinados, apresentam um significado semântico, como um roubo a banco ou uma perseguição policial. No procedimento descrito neste trabalho, define-se manualmente o início e fim de cada cena, de modo a possibilitar que a arquitetura de personalização proposta seja aplicada a diferentes domínios de dados. 
(a)

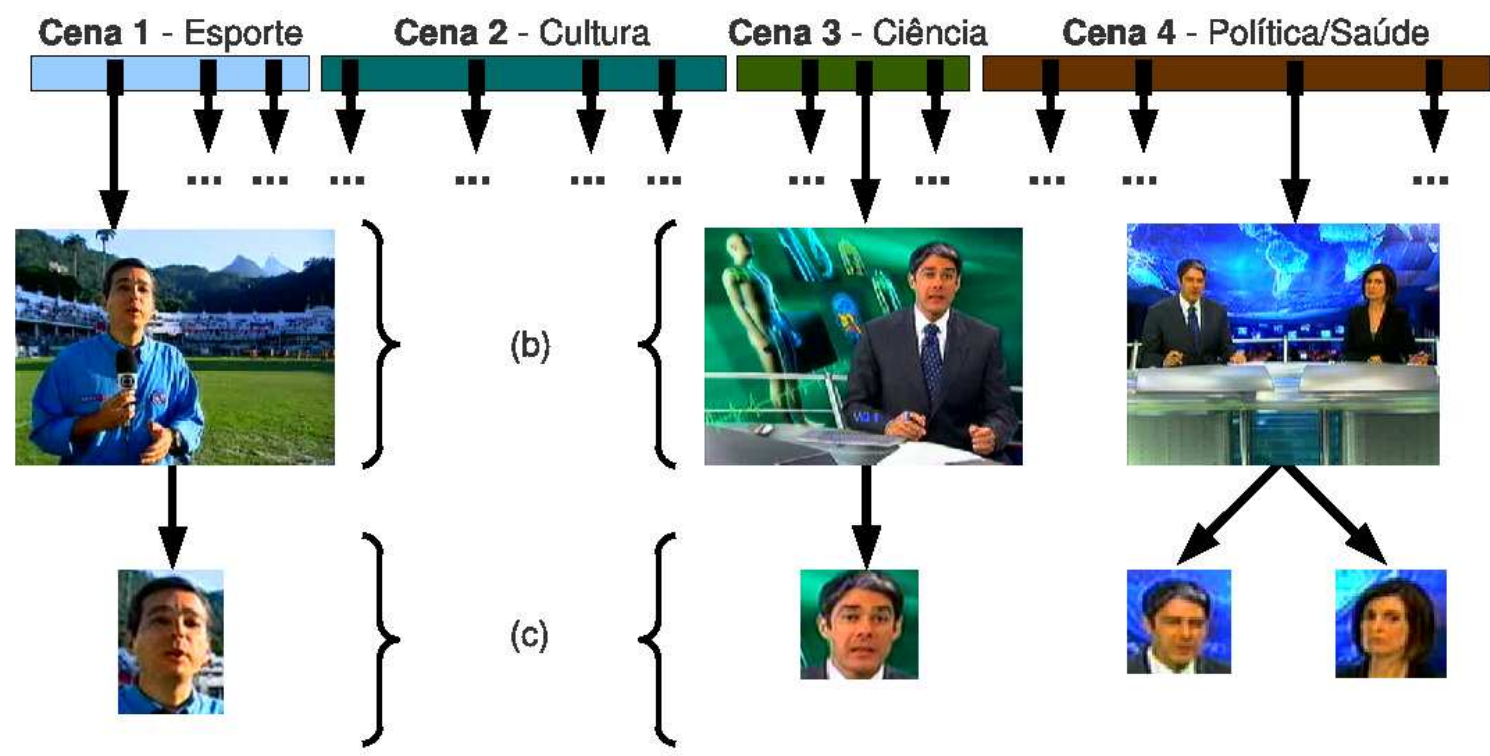

Figura 5.3: Esquema para descrição hierárquica. (a) representa o processo de segmentação temporal; (b) ilustra os quadros-chave extraídos; e (c) apresenta as faces detectadas.

Em trabalhos futuros, pretende-se desenvolver uma técnica automática de segmentação temporal, utilizando informações semânticas provenientes das anotações dos usuários, a fim de que o processo de detecção de mudança de cenas seja aplicado a diferentes domínios.

Após a segmentação temporal, o próximo passo é a extração de informações textuais de cada cena. Em noticiários (e programas televisivos de modo geral), utiliza-se a ferramenta em código-aberto CCExtractor ${ }^{3}$ para gerar um conjunto de arquivos de legenda no formato SubRip (SRT). Essa ferramenta extrai informações textuais a partir de dados binários de closed-caption capturados com o editor de gráficos Microsoft GraphEdit ${ }^{4}$, que é utilizado em conjunto com uma placa de captura de vídeo analógico. No caso de filmes, obtém-se de fontes externas o próprio arquivo de legendas do filme no idioma de origem. Utilizando as informações temporais provenientes da segmentação temporal, são gerados vários arquivos textuais que correspondem à legenda de cada cena.

Em seguida, um processo de classificação é realizado de modo a rotular noticiários ou filmes em categorias distintas. Em telejornais, essa classificação é realizada em nível de cenas, por meio de uma técnica proposta em [Manzato et al., 2009b; Manzato

\footnotetext{
${ }^{3}$ http://ccextractor.sourceforge.net, último acesso em 10 de Novembro de 2010.

${ }^{4}$ http://msdn.microsoft.com/en-us/library/dd390950(VS.85).aspx, último acesso em 10 de Novembro de 2010 .
} 
\& Goularte, 2008]. Essa técnica de categorização é baseada em algoritmos genéticos, e utiliza o closed-caption do programa para classificar as cenas em categorias como violência, esporte, clima, política, entre outras. Na descrição de filmes, por sua vez, a classificação é realizada de modo geral, para todo o vídeo. Obtêm-se os gêneros de cada filme (como romance, comédia, suspense, entre outros) por meio de uma consulta ao IMDB.

Além da classificação, vários quadros-chave são selecionados de cada cena (Figura 5.3(b)), com a ajuda de ferramentas em código-aberto (VirtualDub ${ }^{5}$ e Irfan$\left.V{ }^{2} w^{6}\right)$, a fim de se criar um banco de imagens para cada cena. A heurística adotada para extrair esses quadros-chave é: i) inicialmente, a extração de um quadro a cada dois segundos de vídeo, e ii) posteriormente, a seleção manual do primeiro quadro de cada tomada [Nascimento et al., 2010].

O último passo para a descrição de filmes e telejornais é a aplicação de um algoritmo de detecção e reconhecimento de face nos quadros selecionados (Figura 5.3(c)). Tal procedimento tem como finalidade verificar se há pessoas presentes na cena. A fase de detecção é realizada automaticamente utilizando a biblioteca FAINT, que extrai e armazena as faces detectadas em um banco de dados como miniaturas. A fase de reconhecimento, por sua vez, é realizada de uma das seguintes maneiras: i) automaticamente, quando um número suficiente de amostras de face daquele indivíduo está disponível no banco de dados para suportar a técnica de reconhecimento automático; e ii) manualmente, de modo interativo com o usuário, relacionando a face em questão com o nome do indivíduo apresentado.

No caso do reconhecimento manual, quando o usuário captura um quadro, cria uma anotação relacionada a uma face e informa o nome da pessoa anotada ${ }^{7}$, essas informações são enviadas ao servidor multimídia, de modo a enriquecer a descrição hierárquica do vídeo acessado. Para isso, no entanto, é necessário identificar em qual quadro-chave (que foi extraído anteriormente pelo procedimento de indexação multimídia) deve-se associar as anotações criadas. Na versão atual deste trabalho, essa associação é realizada por meio das informações temporais do quadro capturado pelo usuário e dos quadros-chave extraídos. Consequentemente, uma vez encontrado o quadro-chave mais próximo àquele capturado, as informações da face identificada pelo usuário são adicionadas à descrição hierárquica correspondente. Adicionalmente a esse processo de enriquecimento de metadados, as miniaturas e nomes enviados ao servidor são utilizados para se incrementar as amostras daquela pessoa, a fim de que futuros reconhecimentos possam ser realizados de maneira automática.

É importante salientar que parte do processo de descrição apresentado nesta

\footnotetext{
${ }^{5}$ http://www.virtualdub.org, último acesso em 10 de Novembro de 2010.

${ }^{6}$ http://www.irfanview.com, último acesso em 10 de Novembro de 2010.

${ }^{7}$ Tais atividades são realizadas com o uso da ferramenta de anotação M4Note, conforme apresentado na Seção 5.2
} 
seção está situado no módulo descrição hierárquica, ilustrado na Figura 5.1(d), e parte relaciona-se com os módulos autoria/enriquecimento/anotação (Figura 5.1(a)) e extração de metadados (Figura 5.1(b)). Na prática, tem-se que: i) os procedimentos de segmentação temporal, extração de legendas, classificação de notícias, extração de quadros-chave e detecção/reconhecimento de faces são realizados por profissionais ou técnicas automáticas no provedor de conteúdo (descrição hierárquica); ii) os procedimentos de classificação de filmes e associação de palavras-chave são realizados com anotações colaborativas provenientes do IMDB; e iii) a associação de etiquetas e o reconhecimento de faces são suportados pelas anotações ou enriquecimento dos usuários (anotações de usuários).

Como resultado do processo de descrição, um documento em XML é gerado, seguindo o modelo MediaObject [Goularte et al., 2006], para representar de maneira estruturada e organizada os metadados relacionados ao vídeo. Adotou-se o MediaObject devido à sua facilidade de utilização, à sua compatibilidade com a ferramenta M4Note e à sua característica de ser extensivel para acoplar novos tipos de informações. Uma vez que alguns tipos usados neste trabalho não estavam disponiveis, foi necessário estendê-lo por meio da criação de novos elementos e tipos em sua especificação em XML Schema ${ }^{8}$. Desse modo, os seguintes elementos foram criados: ClosedCaption, Statement, KeyFrames, KeyFrame, Faces e Face. A descrição de como o modelo pode ser estendido é encontrada no trabalho de Goularte et al. [2006].

A Listagem 5.1 apresenta um trecho de código da descrição criada. Uma cena ou notícia está listada nas linhas 14-27; o closed-caption correspondente a essa cena está representado nas linhas 28-36; e as sequências de quadros-chave e faces detectadas/reconhecidas estão descritas nas linhas 37-49. O bloco definido pelo elemento ObjectHierarchy (linhas 50-57) cria a hierarquia dos objetos declarados.

Listagem 5.1: Descrição de um telejornal usando o modelo MediaObject.

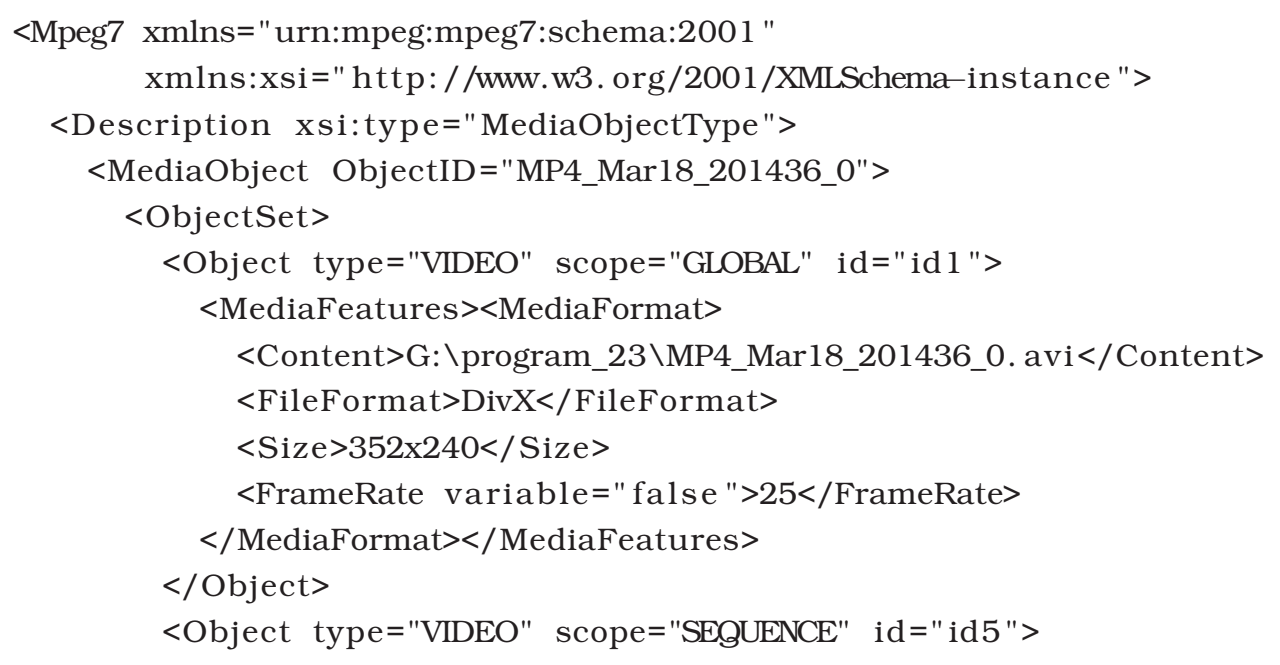

${ }^{8}$ http://www.w3.org/XML/Schema, último acesso em 10 de Novembro de 2010. 


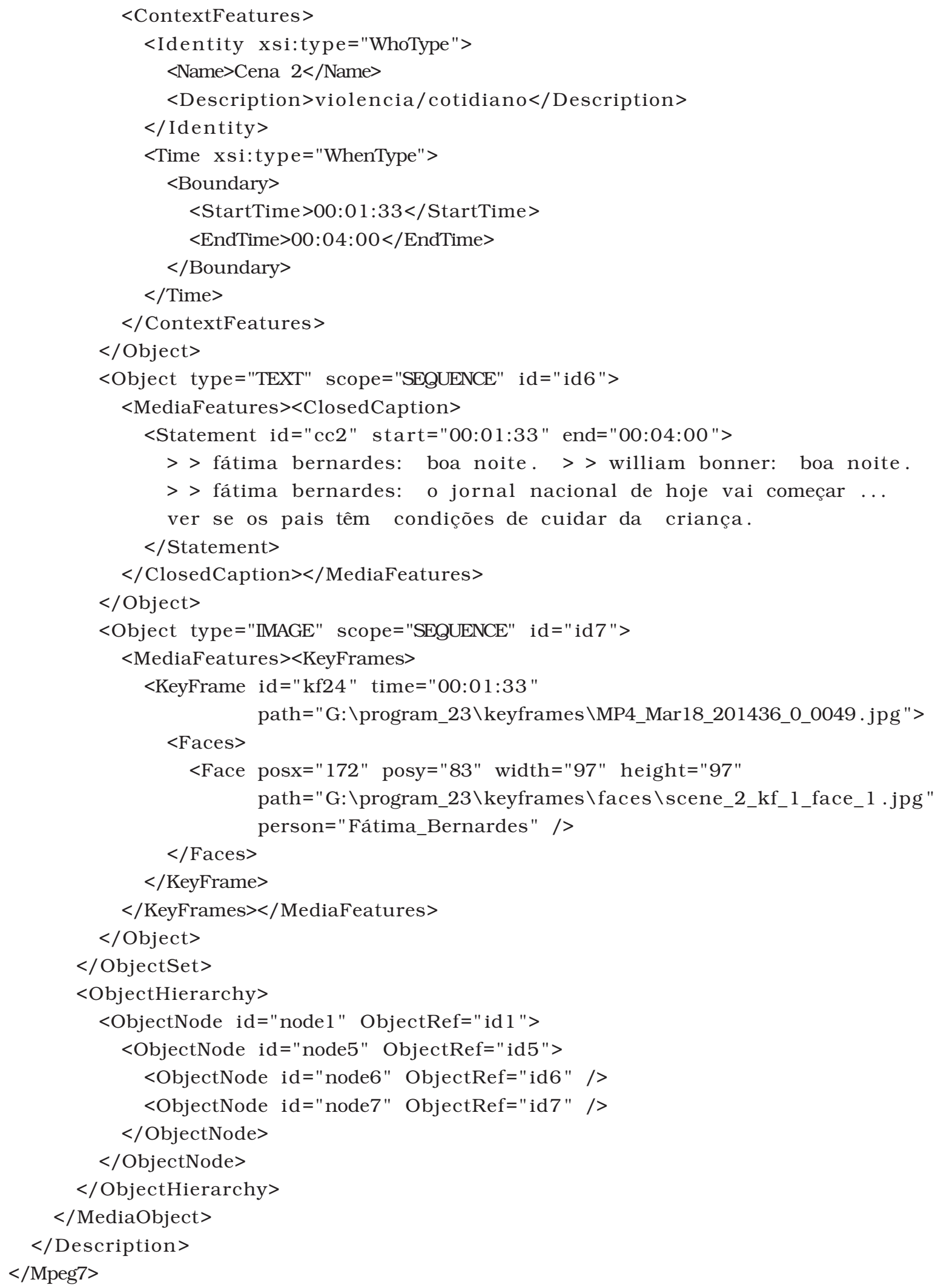




\subsection{Criação e Enriquecimento de Perfil}

Esta seção apresenta em detalhes o módulo de obtenção e representação de interesses pessoais delimitado pela Figura 5.1(e). A construção de perfis consiste em armazenar metadados provenientes de itens multimídia que foram apreciados pelo usuário. Junto aos metadados, define-se um peso que indica o nível de interesse do indivíduo por aquele conteúdo. As preferências podem ser extraídas e organizadas de várias formas; alguns trabalhos nesse sentido foram descritos no Capítulo 4, Seção 4.3. Entretanto, autores argumentam que melhores serviços de personalização são obtidos se mais informações sobre o usuário forem consideradas [Teevan et al., 2005]. Além disso, uma descrição multimodal e com suporte a informações semânticas pode prover uma representação mais precisa das preferências de cada indivíduo [Adomavicius \& Tuzhilin, 2005]. Contudo, a utilização de estruturas semânticas, como ontologias, para representar esse conhecimento, sem restrição do domínio de dados, é uma tarefa difícil de ser realizada por especialistas.

Desse modo, a arquitetura proposta nesta tese propõe uma abordagem de construção de perfil que explora os requisitos supracitados. Inicialmente, uma abordagem multimodal para representação das preferências é desenvolvida, utilizando diferentes tipos de informações para estruturar as preferências do usuário em um documento declarativo. Além disso, a estratégia proposta considera um procedimento de complementação de perfil, que utiliza anotações colaborativas de usuários para agregar dados semânticos à descrição de interesses. Consequentemente, o perfil é estruturado semanticamente por meio de folksonomias, que exploram a co-ocorrência de anotações para formar ligações semânticas entre as informações, resultando em uma representação rica, precisa e independente de domínio de dados.

A abordagem de criação de perfis adotada neste trabalho explora o conceito de nuvens de $\operatorname{dados}^{9}$ e interconexões entre usuários com gostos similares [Manzato \& Goularte, 2010]. Nuvens de dados agrupam uma variedade de tipos de informações obtidas a partir de diferentes paradigmas de interação entre usuários e conteúdo. A Figura 5.4 ilustra uma representação de um perfil, onde quatro tipos de nuvens de dados são anexados ao usuário principal (“Usuário a” na Figura 5.4): nuvem de palavras-chave, gêneros, etiquetas e faces. A fase de complementação automática de perfil é aplicada nos dois últimos tipos de nuvens de dados, ou seja, etiquetas e faces. Além de se definir relações semânticas entre os conceitos, tal procedimento tem como vantagem a redução do problema da falta de dados em casos onde um subconjunto de usuários não cria muitas anotações.

\footnotetext{
${ }^{9}$ Apesar de o termo "nuvem de dados" ser similar ao termo "computação em nuvem", cujo conceito é definido como a utilização de recursos computacionais distribuídos e situados na Web, a nuvem de dados é apenas uma metáfora para a representação estruturada e organizada de dados multimodais que são de interesse para o usuário.
} 


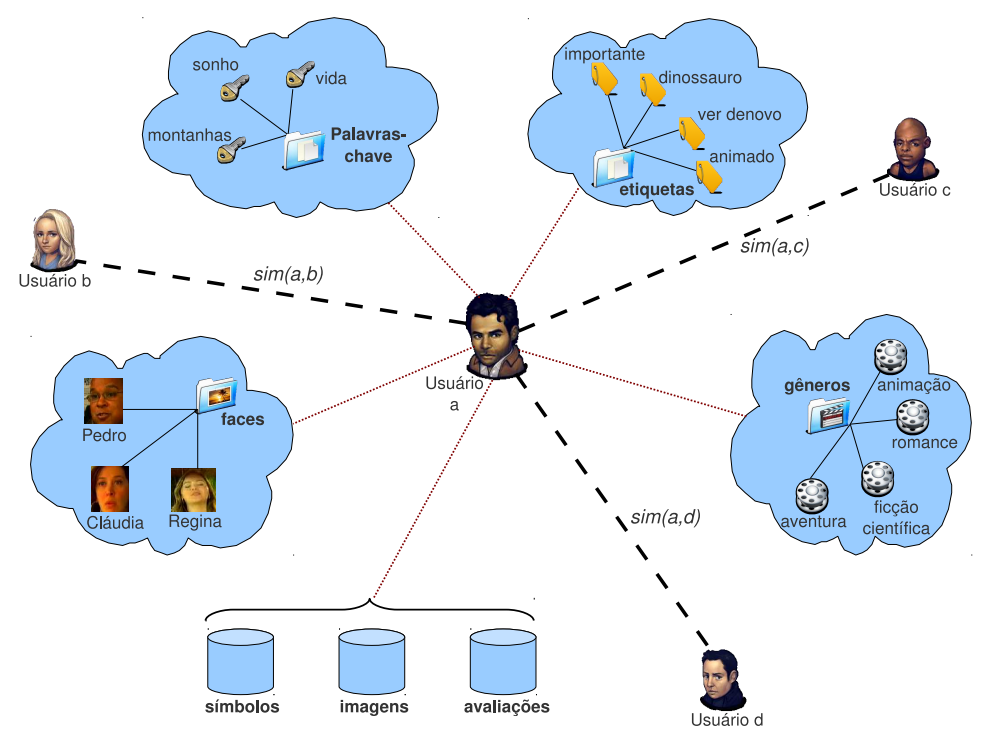

Figura 5.4: Perfil do usuário contendo diferentes tipos de metadados: etiquetas, gêneros e/ou categorias, faces de interesse, palavras-chave, símbolos, imagens, avaliações e relações com outros usuários.

Além das nuvens de dados, o perfil também contém uma lista de outros usuários que apresentam interesses similares ao atual. As interconexões são criadas com base nos valores de avaliações produzidas por eles em itens multimídia em comum. Tais relacionamentos são usados em algoritmos de recomendação colaborativa, com a vantagem de se reduzir problemas de sobre-especialização, descritos anteriormente no Capítulo 2, Subseção 2.4.1. Outras informações extraídas da interação do usuário também estão disponíveis no perfil, como lista de quadros capturados, lista de vídeos avaliados e símbolos criados e reconhecidos [Manzato et al., 2009a]. Tais informações são úteis para o desenvolvimento de serviços de personalização; a seleção de conteúdo, por exemplo, utiliza os quadros capturados e as regiões especificadas pelos símbolos para recuperar itens similares visualmente à imagem de busca, e o sistema de recomendação utiliza a lista de vídeos avaliados para identificar relações entre usuários. Esses serviços serão descritos em mais detalhes no Capítulo 6.

As próximas subseções apresentam a definição formal de cada nuvem de dados; inicialmente, porém, descreve-se a notação adotada nesta seção para criação e enriquecimento de perfil [Szomszor et al., 2007]. As duas últimas subseções, respectivamente, definem a função de similaridade e o modelo de representação adotados neste trabalho. 


\subsubsection{Notação}

Denota-se um dado usuário por $u \in U$, onde $U$ é o conjunto de todos os usuários; um vídeo, cena ou item multimídia por $s \in S$, onde $S$ é o conjunto de todos os itens disponíveis; e uma avaliação por $r \in\{0.5,1,1.5, \ldots, 5\} \equiv R$. O conjunto de todos os itens avaliados pelo usuário $u$ é representado por $S_{u}$; e com base nesse conjunto, define-se a função de avaliação para o usuário $u$ como $\delta_{u}: s \in S_{u} \mapsto \delta_{u}(s) \in R$.

Associadas às nuvens de dados, consideram-se também as seguintes notações:

- denota-se por $K$ o conjunto global de palavras-chave, $K_{s}$ o conjunto de palavras-chave associadas ao item $s$, e $N_{k}$ a frequência global de ocorrência da palavra-chave $k$ em todos os itens multimídia;

- analogamente, denota-se por $G$ o conjunto global de gêneros ou categorias, $G_{s}$ o conjunto de gêneros associados ao item $s$, e $N_{g}$ a frequência global de ocorrência do gênero $g$ em todos os itens;

- com relação às etiquetas, denota-se por $E$ o conjunto global de etiquetas, $E_{s} \mathrm{O}$ conjunto de etiquetas associadas ao item $s, E_{u}$ o conjunto de etiquetas criadas pelo usuário $u, E_{u s}$ o conjunto de etiquetas que o usuário $u$ associou ao item $s$, e $N_{e}$ a frequência global de ocorrência da etiqueta $e$ em todos os itens;

- da mesma maneira para faces, $F$ é o conjunto global de faces reconhecidas, $F_{s}$ é o conjunto de faces reconhecidas do item $s, F_{u}$ é o conjunto de faces anotadas e reconhecidas pelo usuário $u, F_{u s}$ é o conjunto de faces que o usuário $u$ anotou e reconheceu do item $s$, e $N_{f}$ é a frequência global de ocorrência da face $f$ em todos os itens.

A partir da notação adotada, descreve-se formalmente nas próximas subseções cada nuvem de dados considerada; a última subseção, em especial, apresenta a função de similaridade entre usuários utilizada neste trabalho.

\subsubsection{Nuvem de Palavras-chave}

Corresponde ao conjunto de palavras-chave que descrevem o conteúdo, obtidas de anotações colaborativas, como a base de dados IMDB. Ao contrário de etiquetas, que podem ser qualquer palavra ou frase criada pelo usuário, palavras-chave geralmente têm um conteúdo significativo e provêem metadados sobre o conteúdo sem denotar parcialidade.

Define-se $\operatorname{cloud}_{k}(u, r)$ como a nuvem de palavras-chave para um dado usuário $u$ e nota $r$, contendo o conjunto de pares $\left(k, n_{k, u, r}\right)$, onde $k \in K$ é uma palavra-chave e $n_{k, u, r}=\left|\left\{s \in S_{u} \mid k \in K_{s} \quad \& \quad \delta_{u}(s)=r\right\}\right|$. Portanto, $n_{k, u, r}$ contém a frequência de ocorrência da palavra-chave $k$ para todos os itens que o usuário $u$ associou à nota $r$. 


\subsubsection{Nuvem de Gêneros}

Corresponde ao conjunto de gêneros preferidos pelo usuário. São providos por descrições hierárquicas, podendo ser definidos colaborativamente (como a base de dados IMDB), ou automaticamente (por meio de ferramentas de classificação [Manzato et al., 2009b; Manzato \& Goularte, 2008]).

Define-se $\operatorname{cloud}_{g}(u, r)$ como a nuvem de gêneros para um dado usuário $u$ e nota $r$, contendo o conjunto de pares $\left(g, n_{g, u, r}\right)$, onde $g \in G$ é um gênero e $n_{g, u, r}=\mid\left\{s \in S_{u} \mid g \in\right.$ $\left.G_{s} \& \delta_{u}(s)=r\right\} \mid$. Portanto, $n_{g, u, r}$ contém a frequência de ocorrência do gênero $g$ para todos os itens que o usuário $u$ associou à nota $r$.

\subsubsection{Nuvem de Etiquetas}

Corresponde a todas as etiquetas que um usuário criou para itens visitados anteriormente, e seus significados para que seja inferido o grau de interesse do indivíduo em relação a um conjunto de conceitos.

Define-se cloud $_{e}(u, r)$ como a nuvem de etiquetas para um dado usuário $u$ e nota $r$, contendo o conjunto de pares $\left(e_{u}, n_{e_{u}, u, r}\right)$, onde $e_{u} \in E$ é uma etiqueta criada pelo usuário $u$ e $n_{e_{u}, u, r}=\left|\left\{s \in S_{u} \mid e_{u} \in E_{u s} \quad \& \quad \delta_{u}(s)=r\right\}\right|$. Portanto, $n_{e_{u}, u, r}$ contém a frequência de ocorrência da etiqueta $e_{u}$ para todos os itens que o usuário $u$ associou à nota $r$.

Além das etiquetas criadas e associadas pelo usuário, realiza-se um procedimento de complementação ou enriquecimento da nuvem de etiquetas, considerando a individualidade dos termos criados pelo indivíduo, juntamente com aqueles termos criados por outros usuários para o mesmo item multimídia. Esse processo tem a função de construir um perfil do usuário com informações semânticas e, também, reduzir a falta de dados em casos onde o usuário não adota uma postura ativa em relação à criação de anotações.

A complementação da nuvem de etiquetas é baseada na medida de similaridade descrita por Cattuto et al. [2008], que cria uma folksonomia com base na co-ocorrência de etiquetas. Tal medida foi apresentada no Capítulo 4, Subseção 4.1.2, Equação 4.1, e um exemplo de etiquetas com seus respectivos relacionamentos foi apresentado na Tabela 4.1. A escolha dessa medida de similaridade está fundamentada, além de sua simplicidade de implementação, na argumentação de Cattuto et al. [2008], cujo estudo apresenta melhores resultados no uso da co-ocorrência para criação de hierarquias generalizadas.

Portanto, a nuvem $\operatorname{cloud}_{e}(u, r)$ é estendida por meio da incorporação de uma folksonomia que é criada com base nas $P$ etiquetas mais relacionadas a $e_{u}$. Simultaneamente, mantém-se a nota original $r$ para as etiquetas relacionadas. Como exemplo, se o usuário $u$ associou uma etiqueta a um item $s \operatorname{com} e_{u s}=$ 'superherói', e 
avaliou $s$ com $r=3.5$, sua nuvem enriquecida de etiquetas $\operatorname{cloud}_{e}^{*}(u, r)$ terá os termos superherói, comic book, marvel, super-herói, DC e Batman associados à mesma nota $r=3.5$ (assumindo que $P=5$ ).

\subsubsection{Nuvem de Faces}

Corresponde às faces detectadas e reconhecidas que são de interesse do usuário. Por meio de uma anotação manual com tinta eletrônica ao redor da face de uma pessoa sendo apresentada na cena, é possível inferir que aquele personagem capturou a atenção do usuário naquele momento. O processo de reconhecimento, por sua vez, pode ser realizado pelo próprio usuário que está anotando, conforme apresentado na Seção 5.2 .

Define-se $\operatorname{cloud}_{f}(u, r)$ como a nuvem de faces para um dado usuário $u$ e nota $r$, contendo o conjunto de pares $\left(f_{u}, n_{f_{u}, u, r}\right)$, onde $f_{u} \in F$ é uma face anotada e/ou reconhecida pelo usuário $u$ e $n_{f_{u}, u, r}=\left|\left\{s \in S_{u} \mid f_{u} \in F_{u s} \quad \& \quad \delta_{u}(s)=r\right\}\right|$. Portanto, $n_{f_{u}, u, r}$ contém a frequência de ocorrência da face $f_{u}$ para todos os itens que o usuário $u$ associou à nota $r$.

Analogamente à nuvem de etiquetas, realiza-se um procedimento de enriquecimento da nuvem de faces definida anteriormente. Uma outra folksonomia é criada, mas nesse caso, cada vértice do grafo é um nome próprio utilizado pelo usuário para identificar uma face. Portanto, se o usuário anotou/reconheceu $f_{1}=$ 'Ben Stiller' e $f_{2}=$ 'Teri Polo' em um mesmo filme $s$, então ambos atores serão conectados com uma aresta, e seu peso $w\left(f_{1}, f_{2}\right)$ será o número de vezes que $f_{1}$ e $f_{2}$ co-ocorreram em $S$. Como resultado, a folksonomia conterá uma lista de nomes de indivíduos e suas relações, que podem ditar o quanto dois personagens estão ligados entre si.

Cria-se a nuvem enriquecida de faces $\operatorname{cloud}_{f}^{*}(u, r)$ da mesma maneira que foi feito com a nuvem de etiquetas. A vantagem de tal extensão é que o perfil de um usuário que anotou/reconheceu poucos atores poderá ser tão rico quanto o perfil de outros usuários que atuam mais ativamente no processo de anotação. Ressalta-se, entretanto, que são mantidos os niveis de interesse de cada usuário por meio das notas que foram atribuídas no passado por eles.

\subsubsection{Similaridade entre Usuários}

A medida de similaridade adotada neste trabalho para relacionar dois usuários é a correlação de Pearson [Resnick et al., 1994], definida no Capítulo 2, Subseção 2.4.2. Assume-se que $S_{u v}$ seja o conjunto de todos os itens avaliados por ambos usuários $u$ e $v$, i.e., $S_{u v}=\left\{s \in S \mid \delta_{u}(s) \neq \varnothing \quad \& \quad \delta_{v}(s) \neq \varnothing\right\}$. A função de similaridade $\operatorname{sim}(u, v)$ é definida como: 


$$
\operatorname{sim}(u, v)=\left(\frac{\left|S_{u v}\right|}{|S|}\right) \times\left(\frac{\sum_{s \in S_{u v}}\left(\delta_{u}(s)-\bar{\delta}_{u}\right)\left(\delta_{v}(s)-\bar{\delta}_{v}\right)}{\sqrt{\sum_{s \in S_{u v}}\left(\delta_{u}(s)-\bar{\delta}_{u}\right)^{2} \sum_{s \in S_{u v}}\left(\delta_{v}(s)-\bar{\delta}_{v}\right)^{2}}}\right),
$$

onde $\bar{\delta}_{u}$ é a média de valores das notas atribuídas pelo usuário $u$ para todos os itens, e $\bar{\delta}_{v}$ o mesmo para o usuário $v$. O motivo pelo qual foi adotada a função de similaridade definida na Equação 5.1 é porque ela considera o fato que muitos usuários podem avaliar itens usando uma escala de notas de maneira diferente. Ao contrário de se usar os valores absolutos das notas, consideram-se suas diferenças em relação à nota média do usuário correspondente [Adomavicius \& Tuzhilin, 2005]. Adicionalmente, a divisão $\left|S_{u v}\right| /|S|$ é usada para definir uma importância superior àqueles usuários que têm mais itens avaliados em comum (maior confidência).

\subsubsection{Representação}

A Listagem 5.2 apresenta um trecho de código de um perfil de usuário criado com base em sua interação com o conteúdo. Tal descrição segue o modelo de representação contextual definido por Goularte et al. [2006], que é baseado em XML Schema, e fornece uma biblioteca de contexto permitindo a sua extensão conforme a necessidade. Neste trabalho, estendeu-se o modelo por meio da criação do tipo preferencesType para descrição de preferências pessoais, estruturando as informações de acordo com o tipo de interação com o conteúdo.

Listagem 5.2: Perfil de um usuário utilizando o modelo de contexto proposto por Goularte et al. [2006].

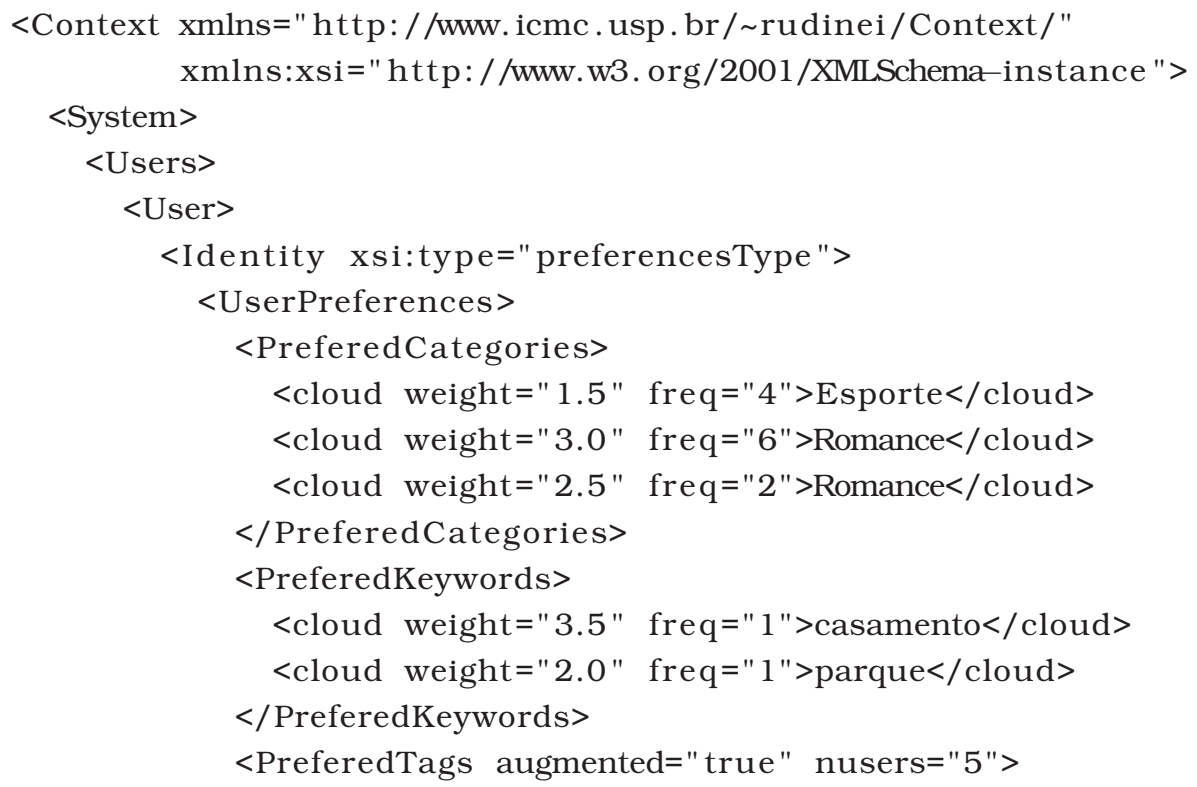


$<$ cloud weight $=" 5.0 "$ freq="2" $>$ muito bom $</$ cloud $>$

$<$ cloud weight $=" 4.5$ " freq $=" 3 ">$ muito bom $</$ cloud $>$

$<$ cloud weight $=" 3.5 "$ freq="1">visitando os pais $</$ cloud $>$

$<$ PreferedTags $>$

$<$ PreferedFaces augmented="true" nusers=" $5 ">$

$<$ cloud weight $=" 4.5 "$ freq="2" symbol="square" $>$ Teri_Polo $</$ cloud $>$

$<$ cloud weight $=" 4.5 "$ freq $=" 1 "$ symbol="cross" $>$ Ben_Stiller $</$ cloud $>$

$</$ PreferedFaces $>$

$<$ PreferedImages $>$

$<$ KeyFrame href="G:\program_23\program_23.xml\#id1" time="00:01:25" path="G:\users \user_a \frame_001.jpg" />

$</$ PreferedImages $>$

$<$ Ratings $>$

$<$ Rating href="G: \program_23\program_23.xml\#id5" $>3.0</$ Rating $>$

$<$ Rating href="G: pprogram_21\program_21.xml\#id 1 " >4.5</Rating>

$<$ Rating href="G:\program_9 \program_9.xml\#id8" >3.5</Rating $>$

$</$ Ratings $>$

$</$ UserPreferences $>$

$</$ Identity $>$

$<$ Identity xsi:type="userSimilarityType" $>$

$<$ UserSimilarity $>$

$<$ RelatedUser weight="0.86" href="G:\users \user_b.xml"/>

$<$ RelatedUser weight="0.76" href="G:\users\user_c $. x m l " />$

$<$ RelatedUser weight="0.64" href="G:\users\user_d.xml" />

$</$ UserSimilarity $>$

$</$ Identity $>$

$</$ User $>$

$</$ Users $>$

$</$ System $>$

$</$ Context $>$

O bloco definido pelas linhas 8-12 descreve a nuvem de gêneros, que contém as categorias de interesse associadas às notas inseridas anteriormente por meio de avaliação. As linhas 13-16 apresentam a descrição da nuvem de palavras-chave, que podem ser termos criados por descritores hierárquicos, ou palavras obtidas do closed-caption do vídeo. Nas linhas 17-21 lista-se a nuvem de etiquetas criadas pelo usuário, também associadas às notas e frequência de utilização. O bloco definido pelas linhas 22-25 apresenta os nomes das pessoas identificadas pelas faces anotadas pelo usuário; quando disponível, apresenta-se também o símbolo reconhecido pelo sistema.

Ainda na Listagem 5.2, uma lista dos quadros capturados é disponibilizada no bloco definido pelas linhas 26-29, incluindo uma referência para a descrição do vídeo (atributo href), o momento de captura do quadro (atributo time) e o caminho para a imagem que representa o quadro capturado (atributo path). Nas linhas 30-34 são apresentadas as avaliações realizadas pelo usuário, contendo a nota escolhida 
e uma referência para o vídeo ou cena avaliados. Tal distinção entre vídeo ou cena é realizada pelo atributo href, que além de apontar para o arquivo XML com a descrição do programa, também informa o identificador do objeto avaliado (id5, por exemplo). De acordo com a descrição no modelo MediaObject (vide Listagem 5.1, linhas 6 e 14), esse identificador pode ser todo o vídeo (escopo global) ou uma cena (escopo local).

Além do tipo preferencesType para descrição de preferências, também foi criado o tipo userSimilarityType, que é utilizado para especificar a lista de usuários com gostos similares. O bloco definido pelas linhas 38-42 apresenta três usuários similares ao atual, incluindo uma referência (atributo href) para o arquivo XML que armazena o perfil de cada indivíduo. O valor do atributo weight é calculado segundo a Equação 5.1.

\subsection{Considerações Finais}

Este capítulo apresentou a arquitetura de personalização proposta neste trabalho. Os módulos descrição hierárquica, extração de metadados, autoria/enriquecimento/anotação e perfil do usuário, que estão especificados na Figura 5.1, foram descritos em detalhes, incluindo seus relacionamentos que definem o processo de extração de dois tipos de informações que são essenciais para os serviços de personalização: metadados sobre o conteúdo e preferências do usuário.

O procedimento de descrição hierárquica indica uma peculiaridade importante do processo que é a possibilidade de se complementar as descrições com informações criadas colaborativamente pelos usuários. Mostrou-se que faces reconhecidas, anotações colaborativas e classificação de programas podem ser agregadas às descrições existentes, diminuindo os esforços necessários por profissionais para descrever conteúdo multimídia.

Adicionalmente, apresentou-se na Seção 5.2 o ambiente de interação M4Note, que foi adotado e estendido para fornecer capacidades de enriquecimento e anotações aos usuários. Vale ressaltar que outras aplicações de anotação podem ser utilizadas, uma vez que os tipos de anotação adotados neste trabalho já são utilizados por outras ferramentas disponíveis na literatura (vide Capítulo 4). Para isso, entretanto, é necessário que sejam adequadas as técnicas situadas no módulo extração de metadados da Figura 5.1(b) para que sejam obtidos os dados enriquecidos da apresentação multimídia customizada criada pelo usuário.

Por fim, este capítulo descreveu o processo de construção e representação de perfis. A atividade do usuário de enriquecimento de conteúdo é investigada para se capturar informações relevantes sobre suas preferências. A criação de perfis conta também com um procedimento de complementação, onde folksonomias de termos e faces são utilizadas para enriquecer a representação de interesses com informações 
semânticas. Essas folksonomias são construídas dinamicamente pela comunidade de usuários e não apresentam a limitação de restrição de domínio de dados, assim como é encontrado em estruturas baseadas em conhecimento existentes atualmente, como ontologias.

A partir da arquitetura de personalização proposta, melhores serviços de personalização podem ser desenvolvidos explorando as informações que são disponibilizadas a respeito do conteúdo e das preferências do usuário. Tais serviços de personalização, conforme explicado ao longo deste capítulo, diferem-se dos tradicionais, pois consideram informações semânticas sem depender do domínio de dados, delegando parte da tarefa de indexação aos usuários do sistema. Desse modo, o próximo capítulo descreve alguns desses serviços. Também são apresentadas análises que comprovam a melhoria dos resultados devido à adoção da estratégia proposta. 


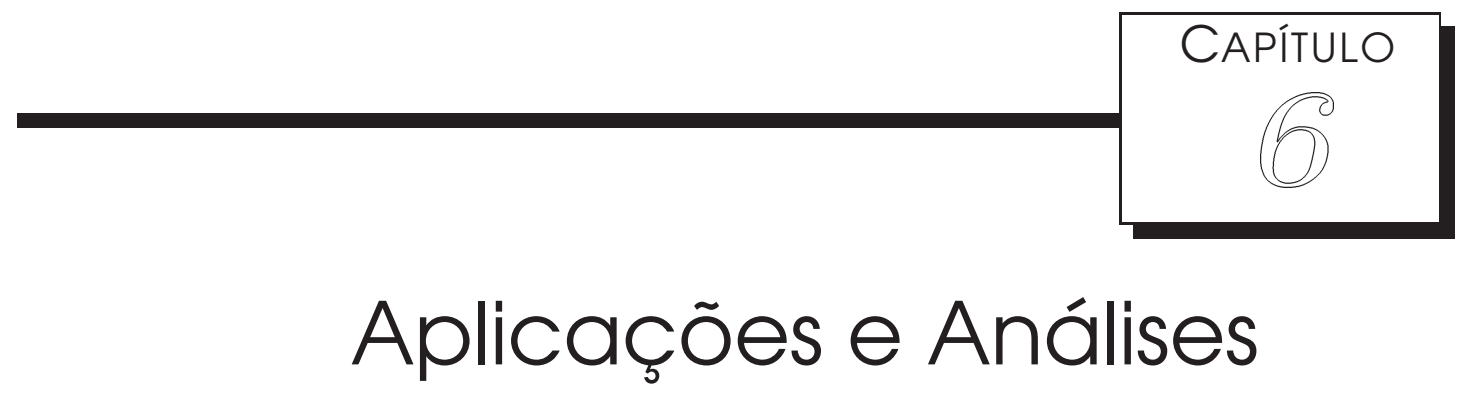

arquitetura de personalização apresentada no capítulo anterior fornece subsí-
dios para que aplicações diversas sejam desenvolvidas explorando metadados
semânticos que descrevem o conteúdo e os interesses dos usuários. Utilizando a proposta, algumas vantagens são disponibilizadas nesse contexto, sendo que a principal é a exploração de anotações criadas colaborativamente pelos indivíduos. Provedores de conteúdo podem reduzir os esforços na criação de metadados, uma vez que tal tarefa de indexação é delegada aos usuários finais. Outra vantagem é a obtenção mais precisa das preferências do usuário, que por meio de diferentes informações, fornece um perfil multimodal contendo uma representação dos interesses pessoais. Tal perfil é ainda complementado com metadados relacionados semanticamente, resultando em uma representação rica das preferências do indivíduo, podendo ser irrestrita ao domínio de dados. Para isso, utilizam-se dados provenientes de folksonomias que são criadas dinamicamente por comunidades de usuários.

Conforme apresentado no Capítulo 2, aplicações que implementam funcionalidades de personalização são geralmente desenvolvidas para prover serviços em três campos distintos, ou seja:

- seleção de conteúdo: serviços que oferecem busca de itens multimídia a partir de critérios definidos pelo usuário. Neste trabalho, a atividade de enriquecimento de conteúdo por meio de anotações é vista como um processo de customização ou personalização dos dados pelo próprio usuário. Assim, o mecanismo de seleção pode auxiliar essa atividade por meio do provimento de funcionalidades de recuperação de dados audiovisuais relacionados semanticamente às anotações produzidas durante o enriquecimento. Tais anotações, por sua vez, são usadas 
para se definir automaticamente os critérios usados durante a busca;

- recomendação: ao contrário da seleção de conteúdo, cujos dados de busca são inseridos manualmente pelo usuário, a recomendação consiste em selecionar automaticamente os itens de interesse, a partir do perfil de preferências;

- sumarização: criação de uma versão modificada do conteúdo, com base em uma agregação de unidades fundamentais que foram selecionadas automaticamente a partir de critérios definidos pelo usuário e seu perfil de interesses. Como exemplo, um telejornal pode ser modificado para conter apenas notícias sobre saúde ou educação, sendo que tais categorias são definidas no perfil do usuário como relevantes.

A arquitetura apresentada no Capítulo 5 é genérica o suficiente para suportar o desenvolvimento de quaisquer aplicações de personalização, referentes a qualquer um desses serviços. Nesse contexto, este capítulo propõe dois serviços distintos que foram implementados neste trabalho: a seleção de conteúdo e o sistema de recomendação. A seleção de conteúdo tem como diferencial a utilização de múltiplos critérios para busca multimídia. Ao contrário de se utilizar uma única técnica para recuperar informações, como algoritmos de busca baseados em texto ou imagem, adota-se uma abordagem multimodal, onde vários critérios são definidos automaticamente com base em anotações criadas durante o enriquecimento de conteúdo. A vantagem é a recuperação de itens mais relacionados semanticamente aos dados de busca, já que uma técnica é capaz de complementar as limitações de outra.

No caso do sistema de recomendação, como a arquitetura permite a estruturação do perfil do usuário considerando a carga semântica inerente ao processo de anotação, os algoritmos desenvolvidos são capazes de reduzir os problemas da sobre-especialização e do novo usuário. Consequentemente, os resultados da recomendação serão melhores, já que diferentes tipos de usuários serão contemplados: i) aqueles que adotam uma postura muito ativa ou que já estão utilizando o sistema há muito tempo; e ii) aqueles recém-cadastrados ou que não interagem com o conteúdo de modo frequente.

Este capítulo apresenta ambos sistemas desenvolvidos. Adicionalmente, descreve-se uma análise das melhorias obtidas com a arquitetura de personalização, quando comparada com os trabalhos atuais citados na literatura. Os resultados obtidos comprovam a eficácia da abordagem proposta. Em tempo, a penúltima seção deste capítulo apresenta uma discussão de como um sistema de sumarização pode ser construído; o desenvolvimento, entretanto, é deixado para trabalhos futuros. 


\subsection{Sistema de Seleção de Conteúdo}

Relacionada à arquitetura de personalização proposta no capítulo anterior, esta seção descreve uma das aplicações desenvolvidas: um sistema de seleção de conteúdo com base em múltiplos critérios [Manzato et al., 2011]. Tal sistema visa complementar a arquitetura por meio de um algoritmo de agregação, que combina os resultados de diferentes técnicas de recuperação de dados. Portanto, a multimodalidade das anotações produzidas é explorada pelo sistema de modo a prover uma busca baseada em conteúdo com resultados mais semanticamente relacionados aos interesses do usuário.

A Figura 6.1 ilustra o esquema geral do sistema. Usuários (Figura 6.1(a)) podem assistir a diferentes programas e noticiários, criando anotações ou enriquecendo o conteúdo (Figura 6.1(b)) com o objetivo de personalizar e compartilhar uma versão modificada da apresentação multimídia. Durante esse período de enriquecimento, o usuário pode enviar uma requisição ao provedor de conteúdo solicitando itens multimídia relacionados ao vídeo sendo acessado, a fim de serem usados em sua atividade de autoria, ou explorar informações extras sobre o tópico da cena sendo exibida. Portanto, dependendo do tipo de informação provida pelo usuário e da viabilidade de metadados sobre o conteúdo (Figura 6.1(e)), um conjunto de dados multimodais para busca é criado (Figura 6.1(c)), transformando o material enriquecido em critérios específicos para recuperação baseada em conteúdo (Figura 6.1(d)). Especificamente, tais critérios são definidos como:

- regiões de interesse (ROI): Delimitadas pelas coordenadas máximas e mínimas dos traços, símbolos ou notas escritas pelo usuário com caneta/tinta eletrônica. Essas regiões são áreas específicas de uma imagem, sendo usadas para pesquisar cenas compostas por quadros que apresentam regiões similares àquelas definidas. A princípio, neste trabalho, utilizam-se ROIs apenas para demarcar regiões ao redor de faces;

- faces de interesse: Após a definição da ROI, uma técnica de detecção de faces ${ }^{1}$ é aplicada na região, de modo a verificar se o usuário criou uma anotação relacionada a alguma face. Em caso positivo, o usuário pode informar o nome da pessoa anotada, possibilitando a busca por cenas contendo o indivíduo de interesse em um banco de dados multimídia com descrições hierárquicas;

- categorias/palavras-chave: Cenas classificadas em um subconjunto de categorias (como exemplo, clima, política, esporte, economia, entre outros) podem ser mais interessantes para um usuário e, portanto, com maior probabilidade

\footnotetext{
${ }^{1}$ Analogamente ao processo de indexação multimídia, utiliza-se a API em Java FAINT para tal procedimento.
} 
(b) Enriquecimento

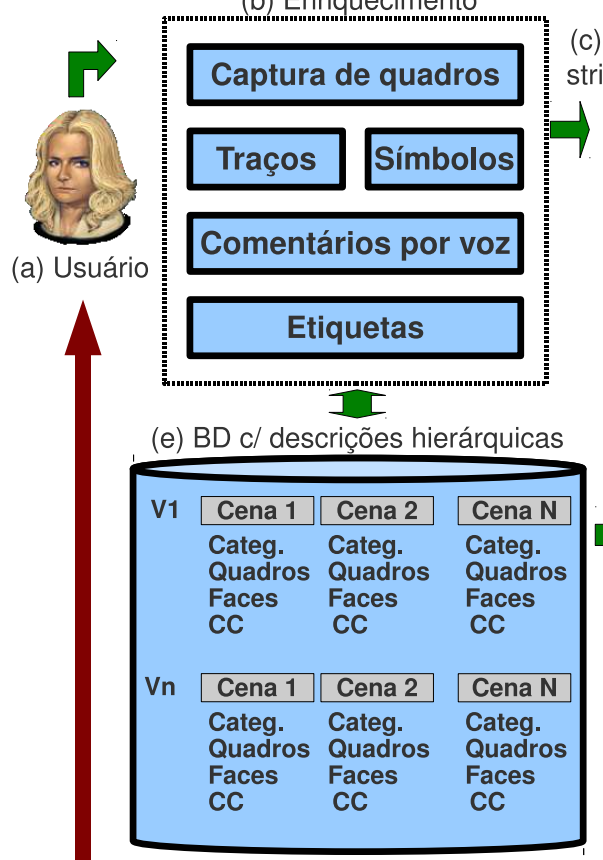

(d) Critérios de busca

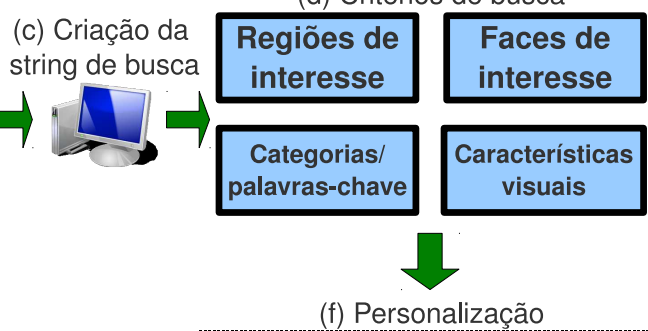

(f) Personalização

Seleção por imagem

Seleção por tópico

Seleção por face

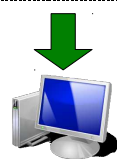

(g) Combinação de ranks

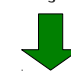

Rank de cenas similares

Figura 6.1: Esquema geral para o sistema de seleção de conteúdo. (a) representa o usuário envolvido em sua atividade de enriquecimento; (b) ilustra os tipos de anotação que podem ser realizados; (c) ilustra o processo de criação dos dados de busca; (d) lista os critérios de busca que podem ser usados; (e) apresenta o banco de dados com os metadados associados; (f) indica as técnicas de seleção de conteúdo; e (g) representa o processo de combinação de múltiplos rankings.

de serem apreciadas pelo indivíduo. Além disso, dentro de cada categoria, existem tópicos que diferem entre si e podem cativar o interesse do usuário em intensidades distintas. A utilização de palavras-chave provenientes do closed-caption e etiquetas fornecem os metadados necessários para se recuperar tais tópicos requisitados. Como exemplo, a partir de um conjunto de notícias sobre clima, o usuário pode ter maior interesse naquelas que informam a temperatura ontem em São Paulo;

- características visuais: Após a definição de uma imagem como amostra, algumas técnicas podem ser usadas para se extrair características visuais, que por sua vez, são utilizadas como dados de busca para pesquisar cenas que contêm quadros similares. Neste trabalho, utiliza-se a diferença de histogramas de cores locais entre quadros [Wang, 2001], que cria um vetor de características para se recuperar imagens similares. Particularmente, esse critério é importante quando certos conceitos devem ser considerados pelo usuário, como cenas que foram filmadas durante a noite e/ou outdoor, planos de fundo similares, entre outros. 
A partir dos diferentes tipos de informações, o sistema provê meios para se pesquisar cenas relacionadas semanticamente ao vídeo sendo enriquecido e às anotações do usuário, utilizando múltiplos critérios de busca simultaneamente (Figura 6.1(f)).

O último passo é responsável por combinar os resultados dos três critérios, de modo a gerar um único ranking de cenas relacionadas (Figura 6.1(g)). Esse procedimento é executado automaticamente pelo sistema, com base nas características das mídias, viabilidade de metadados e tipos de anotações. A Subseção 6.1.4 apresenta em detalhes como essa agregação de rankings é realizada neste trabalho. Inicialmente, porém, descreve-se nas próximas subseções cada um dos critérios de busca utilizados pelo sistema. A aplicação isolada e combinada dessas técnicas será descrita na Subseção 6.1.5.

Para todos os critérios de busca definidos, assume-se que eles geram um conjunto de pares ordenados que estão de acordo com as seguintes definições:

Definição 1 Considera-se $K=\left\{s_{1}, s_{2}, \ldots, s_{n}\right\}$ um conjunto de chaves, onde $s_{i}$ é um identificador para uma cena, com $i=1, \ldots, n \in \mathbb{N}$, e $n$ é o número total de cenas disponiveis. Considera-se também $V=\left\{v_{1}, v_{2}, \ldots, v_{n}\right\}$ um conjunto de valores, onde $v_{i}=\operatorname{rank}_{q|t| f \mid a}\left(s_{i}\right)$ é um número real positivo menor ou igual a 1, que é calculado, respectivamente, de acordo com os critérios baseados em imagem ( $\left.r a n k_{q}\right)$, tópico (rank $k_{t}$ ), face $\left(r a n k_{f}\right)$ ou a combinação deles (rank $\left.k_{a}\right)$. Define-se $R$ como um conjunto de pares chave-valor $\left(s_{i}, v_{i}\right)$, onde $s_{i} \in K$ e $v_{i} \in V$.

Definição 2 Dado o conjunto $R$ da Definição 1 , considera-se $R^{*}$ como o conjunto de pares chave-valor ordenados de $R$ em modo decrescente, de acordo com a relação ' $\geq$ ' se, dados quaisquer pares chave-valor $\left(s_{x}, v_{x}\right),\left(s_{y}, v_{y}\right) e\left(s_{z}, v_{z}\right)$, com $s_{x}, s_{y}, s_{z} \in K$ e $v_{x}, v_{y}, v_{z} \in V$, é sempre verdade que $\left(s_{x}, v_{x}\right) \geq\left(s_{y}, v_{y}\right)$ se as seguintes regras forem satisfeitas:
1. $v_{x} \geq v_{y}$
2. $v_{x} \geq v_{y}$ e $v_{y} \geq v_{z} \Rightarrow v_{x} \geq v_{z}$
3. $v_{x} \geq v_{y}$ e $v_{y} \geq v_{x} \Rightarrow v_{x}=v_{y}$

\subsubsection{Seleção de Conteúdo Baseada em Imagens}

Durante o acesso a um vídeo, certos conceitos visuais como uma paisagem ou cena de esporte podem cativar o interesse do usuário. Para que seja provido um mecanismo que permita a busca de cenas com base em características visuais, implementou-se uma técnica baseada na diferença de histogramas de cores locais 
que recupera imagens similares a partir de uma imagem de busca proveniente de sua captura no fluxo audiovisual acessado pelo usuário.

Geralmente, a diferença de histogramas locais pode ser usada de duas maneiras distintas para se recuperar imagens similares: i) calculando a diferença de histogramas locais entre duas imagens; e ii) calculando a diferença de histogramas globais entre duas imagens [Wang, 2001]. Adotou-se a primeira opção porque são consideradas informações relacionadas à distribuição de cores mantendo-se a localização de regiões na imagem, o que auxilia a exploração de algumas posições espaciais de objetos.

Histogramas locais utilizam o modelo de espaço de cores RGB (do Inglês, Red-Green-Blue - Vermelho-Verde-Azul). A diferença é calculada por meio da comparação de quadros-chave de cada cena com a imagem de busca. Os quadros-chave são extraídos conforme apresentado no Capítulo 5, Seção 5.3, e a imagem de busca é definida conforme sua captura pelo usuário durante a interação/anotação. Especificamente, a seleção baseada em imagens adota os seguintes passos:

1. redução da resolução da imagem para $2^{k}$ pixels em ambas dimensões (altura e largura);

2. segmentação da imagem de busca $q_{q}$ em blocos de $X \times X$ pixels e, em seguida, obtenção de um histograma de cores para cada bloco;

3. cálculo do conjunto de histogramas de um quadro candidato $u \mathrm{e}$, em seguida, cálculo da diferença de histogramas por meio da distância Euclideana conforme descrito a seguir:

$$
d_{L C H}\left(q_{q}, u_{s_{i}}^{p}\right)=\sum_{b=1}^{3} \sqrt{\sum_{g=1}^{G}\left(H_{q_{q}}^{b}[g]-H_{u_{s_{i}}^{p}}^{b}[g]\right)^{2}}
$$

onde $G$ é a quantidade de blocos $\left(G=\left[\left(2^{k}\right) / X\right]^{2}\right)$, $H_{q_{q}}^{b}[g]$ é o histograma local de cores do bloco $g$ da imagem de busca no canal de cor $b$ ( $b \in[R, G, B]$ ); e $H_{u_{s_{i}}^{p}}^{b}[g]$ é o histograma equivalente do $p$-ésimo quadro $u$ da cena $s_{i}$. Adotou-se a distância Euclideana devido aos bons resultados obtidos durante a experimentação e, também, porque a literatura reporta experiências que sugerem sua boa adequação em aplicações de recuperação de informações [Zhang \& Lu, 2003];

4. finalmente, cálculo do valor de ranking da cena $s_{i}, i=1, \ldots, n$, como descrito a seguir:

$$
\operatorname{rank}_{q}\left(s_{i}\right)=-\sum_{p=1}^{P_{s_{i}}} d_{L C H}\left(q_{q}, u_{s_{i}}^{p}\right)
$$


onde $\operatorname{rank}_{q}\left(s_{i}\right) \in V$, e $P_{s_{i}}$ é a quantidade de quadros-chave extraídos da cena $s_{i}$.

Após o cálculo dos valores $\operatorname{rank}_{q}\left(s_{i}\right)$ (e sua normalização para se adequar ao intervalo [0..1]), o conjunto chave-valor $R_{q}$ é ordenado em ordem decrescente de acordo com a Definição 2 , sendo os primeiros $m, m \leq n$, elementos de $R_{q}^{*}$ retornados para o usuário.

Embora a técnica de seleção baseada em imagens seja útil em alguns casos, existem certas situações em que os resultados podem se tornar insatisfatórios. $\mathrm{O}$ principal problema de se usar somente esse critério é que os itens selecionados são altamente dependentes da similaridade visual entre a imagem de busca e os quadros candidatos. Isso significa que a técnica irá retornar cenas com cores e plano de fundo similares, mas o conteúdo em si pode não estar relacionado semanticamente com as informações contidas no vídeo sendo visualizado no momento.

\subsubsection{Seleção de Conteúdo Baseada em Tópicos}

A seleção de conteúdo com base em tópicos consiste em recuperar vídeos cujo assunto tem um relacionamento semântico com aquele sendo acessado pelo usuário. Como exemplo, o telespectador pode estar assistindo a uma notícia sobre o degelo na Antártica, e após se interessar pelo tópico, decidir procurar notícias relacionadas, como aquecimento global, clima e vida selvagem naquele continente.

O sistema de seleção proposto utiliza procedimentos de análise textual, incluindo closed-caption, etiquetas, comentários por voz e categorias de cada cena ou vídeo. As categorias, em particular, informam a qual ou a quais domínios de dados uma cena pode estar relacionada. No contexto de noticiários, consideram-se as seguintes categorias: vinheta, comercial, clima, violência, esporte, economia, ciência, política, educação, saúde, cultura e cotidiano. O procedimento para obtenção de tais informações é reportado nos trabalhos de Manzato et al. [2009b] e Manzato \& Goularte [2008].

O motivo de se utilizar categorias em conjunto com closed-caption, etiquetas e comentários por voz é que pode-se reduzir alguns problemas que surgem ao lidar com análise textual, como polissemia e sinonímia. Um exemplo de polissemia é a palavra impedimento, que pode ter o significado de fora-de-jogo no domínio de futebol, ou dificuldade, barreira ou estorvo em outro contexto. Algumas técnicas de recuperação de informação, como a LSI (do Inglês, Latent Semantic Indexing - Indexação Semântica Latente), tentam reduzir esses problemas considerando a co-ocorrência de termos; entretanto, seus resultados são satisfatórios somente quando o conjunto de dados é composto por documentos extensos [Manzato et al., 2009b; Manzato \& Goularte, 2008]. Neste trabalho, o uso de closed-caption, etiquetas e comentários por voz não favorece o uso da LSI, já que algumas cenas não têm termos suficientes para suportar 
a análise semântica.

Por outro lado, desenvolveu-se um mecanismo de seleção de conteúdo baseado em Algoritmos Genéticos (AG) que é capaz de analisar em um único procedimento os termos de closed-caption, comentários e etiquetas em conjunto com as categorias pré-definidas de cada notícia. Consequentemente, os problemas de sinonímia e polissemia podem ser reduzidos: retornando ao exemplo anterior, usando categorias como esporte e comercial, pode-se delimitar implicitamente o significado da palavra impedimento.

A abordagem proposta consiste em retornar os $m, m \leq n$, documentos mais similares de todo conjunto de dados, utilizando, durante a busca, um conjunto de termos capturados do closed-caption, etiquetas criadas pelo usuário, comentários por voz inseridos e relacionados à cena e as categorias da notícia sendo assistida no momento. Essas informações são submetidas ao módulo AG, que executa todos os passos inerentes ao algoritmo. O método inicia com a construção da Matriz Termo-Documento (do Inglês, Term-Document Matrix - TDM), que gera uma tabela em duas dimensões contendo todos os termos e suas frequências por documento ${ }^{2}$. As linhas correspondem a termos distintos reduzidos ao seu radical, e as colunas representam os documentos. Cada item armazena um peso $w$ que indica a importância de um termo em cada documento. O valor de $w$, neste trabalho, é obtido usando a equação $T F \times I D F$, definida no Capítulo 2, Subseção 2.4.1, Equação 2.3.

O funcionamento básico de algoritmos genéticos pode ser encontrado no trabalho de Holland [1979]. No contexto da recuperação de cenas baseada em tópicos, a seleção de pais é realizada por meio da roda da roleta, a reprodução é feita por crossover mapeado parcialmente (do Inglês, Partially Mapped Crossover - PMX), e a inserção pela abordagem elitista [Holland, 1979; Goldberg, 1989].

Considera-se um cromossomo composto por $m$ genes, cada um apontando para uma cena candidata a ser retornada para o usuário. Portanto, a solução ótima consiste em um conjunto de $m$ cenas que são as mais relacionadas semanticamente aos dados de busca. Formalmente, um cromossomo $G$ é definido como um conjunto $G=\left\{g_{1}, g_{2}, \ldots, g_{m}\right\}$, onde $g_{i} \in K$ é uma cena candidata. O texto de busca $q_{t}$ é definido como $q_{t}=\left\{T_{q}, C_{q}\right\}$, onde $T_{q}$ é o conjunto de termos obtidos do closed-caption, comentários ou etiquetas da cena atual sendo visualizada, e $C_{q}$ é o conjunto de categorias previamente definidas da mesma cena.

A função de aptidão consiste em indicar o quão próxima uma solução candidata está da solução ótima. Tal função é definida como:

$$
f=\sum_{i=1}^{m} \operatorname{rank}_{t}\left(g_{i}\right)
$$

\footnotetext{
${ }^{2}$ Neste caso, cada documento representa o closed-caption ou legenda de uma única cena ou notícia.
} 
considerando que:

$$
\operatorname{rank}_{t}\left(g_{i}\right)=W\left(T\left(g_{i}\right), T_{q}\right) \cdot\left[\operatorname{sim}\left(C\left(g_{i}\right), C_{q}\right)+\operatorname{sim}\left(T\left(g_{i}\right), T_{q}\right)\right],
$$

onde $\operatorname{rank}_{t}\left(g_{i}\right) \in V, W\left(T\left(g_{i}\right), T_{q}\right)$ retorna a soma de todos os pesos $w$ obtidos da TDM, cujos termos se equivalem entre os termos de busca $T_{q}$ e o documento $T\left(g_{i}\right)$. Adicionalmente:

$$
\operatorname{sim}(A, B)=\frac{A \cap B}{A \cup B} .
$$

Conforme definido nas Equações 6.3 e 6.4 $\operatorname{sim}\left(C\left(g_{i}\right), C_{q}\right)$ retorna o coeficiente de Jaccard das categorias equivalentes entre os termos de busca $C_{q}$ e as categorias $C\left(g_{i}\right)$ do documento $g_{i} ; \operatorname{sim}\left(T\left(g_{i}\right), T_{q}\right)$ retorna o coeficiente de Jaccard dos termos equivalentes entre $T_{q}$ e $T\left(g_{i}\right)$ do documento $g_{i}$. Escolheu-se o coeficiente de Jaccard como medida de similaridade devido à sua simplicidade e aos bons resultados obtidos durante experimentação quando comparados a outras métricas, como similaridade por cosseno, distância Euclideana e correlação de Pearson. Portanto, a Equação 6.3 fornece maior importância àqueles documentos cujos termos e categorias têm mais equivalentes no texto de busca $q_{t}$. Ao mesmo tempo, considera-se a importância de cada termo quando comparados a todo conjunto de documentos, por meio do peso $w$ que é calculado durante a criação da TDM.

Após o cálculo de $\operatorname{rank}_{t}\left(g_{i}\right)$ (e sua normalização para se adequar ao intervalo [0..1]), o conjunto correspondente de chave-valor $R_{t}$ é ordenado em ordem decrescente de acordo com a Definição 2, sendo os primeiros $m$ elementos de $R_{t}^{*}$ retornados ao usuário.

Em geral, a seleção de conteúdo baseada em tópicos pode gerar bons resultados, mesmo com a existência de problemas conhecidos, como polissemia e sinonímia. Por outro lado, ao se trabalhar com dados multimídia, especialmente imagens e vídeo, essas técnicas baseadas em texto são altamente dependentes da viabilidade textual para serem consideradas. A seleção de cenas que não contêm closed-caption, palavras-chave ou qualquer outro tipo de informação textual é uma tarefa difícil de ser realizada. Portanto, a utilização e agregação de diferentes critérios de busca é importante para satisfazer tais cenários realísticos.

\subsubsection{Seleção de Conteúdo Baseada em Faces}

Em noticiários e programas de difusão, é comum pessoas conhecidas ao telespectador aparecerem frequentemente na mídia, tais como famosos, jornalistas, políticos, artistas, entre outras. O uso de uma técnica de detecção e reconhecimento de faces, juntamente com um conjunto de amostras dessas faces conhecidas, podem fornecer informações semânticas valiosas sobre o vídeo e, portanto, viabilizar procedimentos 
de busca avançada em bancos de dados multimídia. Um exemplo: um usuário está assistindo a uma notícia que trata da morte do cantor Michael Jackson, e decide obter mais cenas que mostram o artista. Se o closed-caption não está disponível, ou se a cena está mostrando uma de suas apresentações sem quaisquer informações textuais sobre seu nome, o uso de técnicas para análise intraquadro torna-se essencial para a recuperação de conteúdo relacionado.

Conforme apresentado no Capítulo 5, Seção 5.3, o processo de descrição hierárquica conta com uma fase de detecção e reconhecimento de faces. A detecção é realizada automaticamente, e o reconhecimento, por sua vez, pode ser executado de maneira automática ou manual. Uma vez disponíveis os metadados relacionados às faces presentes, torna-se trivial a criação de um ranking de cenas com base na aparência de faces conhecidas. Idealmente, selecionam-se as $m$ primeiras cenas cuja face desejada foi reconhecida. A face de busca $q_{f}$ contém o(s) nome(s) da(s) pessoa(s) a ser(em) pesquisada(s), e sua criação é realizada quando o usuário captura um quadro do fluxo audiovisual, e cria uma anotação manual usando caneta/tinta eletrônica. Nesse caso, assume-se que quando o indivíduo associa uma anotação a uma face presente no quadro capturado, ele definiu a pessoa que será pesquisada. Essa suposição é útil quando mais de uma face está presente na imagem, e deseja-se procurar por cenas contendo somente uma dessas pessoas.

Uma vez definido o valor de $q_{f}$, o valor de ranking da cena $s_{i}, i=1, \ldots, n$, é:

$$
\operatorname{rank}_{f}\left(s_{i}\right)=\left\{\begin{array}{ll}
1 & \text { se } \operatorname{match}\left(P\left(s_{i}\right), q_{f}\right)>0 \\
0 & \text { caso contrário }
\end{array},\right.
$$

onde $\operatorname{rank}_{f}\left(s_{i}\right) \in V, P\left(s_{i}\right)$ é o conjunto de todos os nomes das pessoas presentes na cena $s_{i}$, e match $\left(P\left(s_{i}\right), q_{f}\right)$ retorna a frequência em que a cena $s_{i}$ tem um nome especificado em $q_{f}$.

Após o cálculo de $\operatorname{rank}_{f}\left(s_{i}\right)$, o conjunto correspondente de chave-valor $R_{f}$ é ordenado em ordem decrescente de acordo com a Definição 2, sendo os primeiros $m, m \leq n$, elementos de $R_{f}^{*}$ retornados ao usuário.

O uso de faces durante a seleção pode melhorar significativamente a relação semântica entre os dados de busca e as cenas recuperadas. Entretanto, alguns problemas podem surgir quando técnicas de detecção e reconhecimento de faces devem ser executadas no banco de dados multimídia. Algumas cenas, de fato, não mostram claramente a face de certas pessoas, tornando-se difícil a detecção e reconhecimento de pessoas sem a utilização de outros tipos de metadados. 


\subsubsection{Algoritmo de Agregação}

Existem casos em que o usuário precisa utilizar vários critérios durante a seleção. Essas condições acontecem quando os resultados retornados não satisfazem os requisitos necessários, devido às limitações das técnicas, e também por causa das características do conteúdo. Como descrito nas subseções anteriores, os seguintes fatores sumarizam algumas situações que podem motivar o uso de mais de um critério. Em tempo, exemplos concretos serão apresentados na Subseção 6.1.5.

- quando não há closed-caption, etiquetas ou qualquer outra informação textual para alimentar a seleção de conteúdo baseada em tópicos. O uso de características visuais, nesse caso, é essencial;

- quando a técnica de detecção e reconhecimento de faces não tem amostras suficientes no banco de dados para suportar o reconhecimento automático. Algumas cenas, na verdade, não mostram claramente a face de uma pessoa conhecida, tornando impossivel a tarefa de detecção/reconhecimento. Portanto, a recuperação dessas cenas específicas deve ser realizada usando um critério diferente;

- quando a seleção de conteúdo baseada em imagens, por alguma razão, não gera resultados satisfatórios. Certas imagens usadas na busca podem ser complexas, contendo muitas informações em um único quadro; nesses casos, a qualidade das cenas retornadas será ruim.

Portanto, a proposta apresentada neste trabalho é que, combinando vários critérios de busca, pode-se reduzir os problemas inerentes a cada técnica e, também, às características dos vídeos. Existem várias possibilidades de se combinar rankings de diferentes fontes (Masthoff [2004] apresenta algumas delas). No contexto deste trabalho, alguns requisitos foram definidos com base em experimentação e, atualmente, consideram-se os seguintes fatores:

- a satisfação individual de um critério de seleção deve ser preferido ao invés dos resultados combinados de todo grupo de técnicas. Como alguns tipos de metadados podem não estar disponíveis, os métodos de seleção baseados nesses tipos de informação podem retornar cenas com baixa relação semântica. Por outro lado, quando uma quantidade razoável de metadados está presente no fluxo audiovisual, técnicas que usam essas informações podem gerar bons resultados na mesma busca;

- como consequência do item anterior, informações de contexto sobre cada cena devem ser exploradas para se decidir quais conjuntos de técnicas serão 
consideradas durante a agregação. Neste trabalho, assume-se que "informações de contexto" são dados referentes às características de cada cena, que formam a base das técnicas de seleção. Como exemplos, pode-se citar a presença ou ausência de faces reconhecidas, closed-caption, e o quanto um quadro é similar a uma imagem usada na busca;

- após a definição das técnicas que serão consideradas durante a agregação, a posição relativa de um item no ranking correspondente deve ser usada para ditar a importância de cada cena de acordo com o critério adotado. Primeiramente, os elementos iniciais de cada ranking são inferidos como os mais relevantes; e posteriormente, os valores de ranking de uma mesma cena em diferentes critérios são usados para definir a técnica que teve um melhor desempenho.

Dadas as considerações, a abordagem de agregação proposta neste trabalho é definida como:

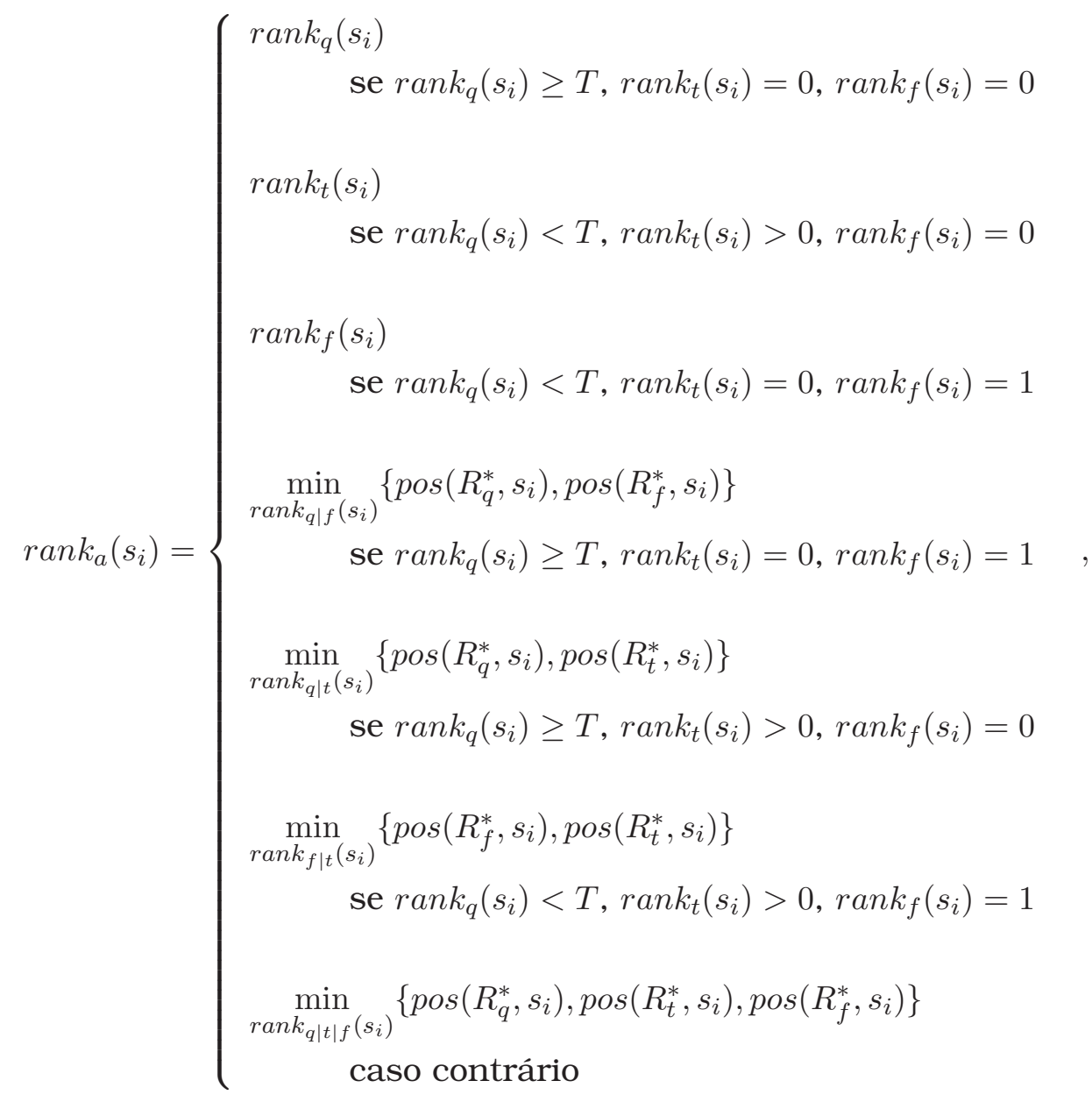

onde $\operatorname{rank}_{a}\left(s_{i}\right) \in V, \operatorname{com} i=1, \ldots, n ; \operatorname{pos}\left(R_{q|t| f}^{*}, s_{i}\right)$ retorna a posição relativa de $s_{i}$ no conjunto correspondente de pares; $T$ é um limiar pré-definido; e a função min procura 
pela menor posição relativa da cena $s_{i}$ entre os rankings considerados (imagem, tópico e/ou face), e retorna o valor de ranking desse elemento.

Após o cálculo de $\operatorname{rank}_{a}\left(s_{i}\right)$, as cenas selecionadas e retornadas para o usuário correspondem às primeiras $m, m \leq n$, cenas de $R_{a}^{*}$, obtidas de $R_{a}$ de acordo com a Definição 2.

\subsubsection{Avaliação}

Esta subseção descreve a avaliação realizada no sistema de seleção de conteúdo proposto neste trabalho. O objetivo é avaliar três experimentos distintos, onde os critérios de busca são formulados a partir da interação do usuário com o conteúdo. Neste estudo, restringiu-se o domínio de dados para seleção de notícias a fim de facilitar a análise dos resultados; entretanto, a arquitetura de personalização pode ser usada em outros gêneros, como filmes (vide Seção 6.2).

O banco de dados utilizado na avaliação corresponde a notícias segmentadas de um famoso programa jornalístico brasileiro. Ao longo do período de Junho de 2008 a Março de 2010, 25 programas foram gravados com closed-caption usando uma placa de captura de vídeo analógico. Suas descrições hierárquicas foram criadas conforme o procedimento apresentado no Capítulo 5, Seção 5.3. A Tabela 6.1 sumariza as informações existentes no banco de dados. Cada programa contém notícias em uma variedade de categorias, sendo que algumas dessas cenas estão associadas a mais de uma categoria. Nesses casos, o número de cenas, duração, quadros-chave e faces foram contados repetidamente (linha iniciando com "Soma" na Tabela 6.1). No total, 785 notícias distintas foram usadas na avaliação, correspondendo a cerca de 16,5 horas de vídeo.

Como reportado no procedimento de descrição hierárquica (Capítulo 5, Seção 5.3), para cada quadro-chave extraído das cenas, as faces existentes foram automaticamente detectadas; portanto, 11.672 quadros-chave foram extraídos dos programas e 3.604 faces foram detectadas. O reconhecimento, por sua vez, envolve a colaboração de usuários para identificar as faces de interesse. Como esta avaliação não contempla análises com usuários reais, limitando-se apenas ao estudo de performance das técnicas propostas, decidiu-se realizar o processo de reconhecimento de faces da seguinte maneira: i) automaticamente, quando um número suficiente de amostras estava disponível no banco de dados para suportar a técnica de reconhecimento automático $^{3}$; ii) semi-automaticamente, quando o nome da pessoa era exibido visualmente na imagem por meio de legenda ou closed-caption ${ }^{4}$; e iii) manualmente, quando faces detectadas eram bem conhecidas, como artistas e políticos, mas não

\footnotetext{
${ }^{3}$ Esse é o caso de pessoas-âncora, que são exibidas em quase todas as cenas.

${ }^{4} \mathrm{O}$ processo de assinalar o nome da pessoa detectada é executado manualmente neste trabalho, mas técnicas de reconhecimento ótico de símbolos (OCR) poderiam ser utilizadas.
} 
Tabela 6.1: Estrutura de noticiários e metadados.

\begin{tabular}{|c||c|c|c|c|}
\hline Categoria & Cenas & Duração & Quadros-chave & Faces \\
\hline \hline Vinheta & 135 & $04: 18: 29$ & 826 & $393 / 282$ \\
\hline Comercial & 89 & $07: 32: 23$ & 2.704 & $719 / 5$ \\
\hline Violência & 88 & $07: 02: 57$ & 1.360 & $389 / 225$ \\
\hline Política & 127 & $10: 40: 20$ & 1.463 & $650 / 396$ \\
\hline Economia & 93 & $04: 44: 09$ & 910 & $360 / 213$ \\
\hline Clima & 50 & $01: 43: 09$ & 531 & $97 / 49$ \\
\hline Saúde & 51 & $02: 50: 35$ & 836 & $298 / 154$ \\
\hline Cotidiano & 187 & $21: 26: 25$ & 2.860 & $816 / 425$ \\
\hline Esporte & 75 & $03: 40: 25$ & 1.096 & $257 / 162$ \\
\hline Ciência & 38 & $01: 39: 30$ & 739 & $198 / 85$ \\
\hline Educação & 13 & $00: 32: 16$ & 279 & $121 / 55$ \\
\hline Cultura & 34 & $01: 55: 08$ & 1.037 & $266 / 82$ \\
\hline \hline Soma & 980 & $68: 05: 46$ & 14.641 & $4.564 / 2.133$ \\
\hline \hline Cenas Únicas & 785 & $16: 31: 15$ & 11.672 & $3.604 / 1.617$ \\
\hline
\end{tabular}

possuíam amostras suficientes no banco de dados para suportar o reconhecimento automático ${ }^{5}$. Todas as outras faces e falsos positivos foram assinalados com o rótulo "desconhecido". De todas as 3.604 faces detectadas, 1.617 foram reconhecidas, sendo 372 distintas.

Os limiares das cenas e closed-caption correspondente foram usados para criar a matriz termo-documento. Optou-se por simular um cenário realístico onde nem todos os noticiários são acompanhados de closed-caption; portanto, de todos os 25 programas, 10 não apresentam quaisquer informações textuais (closed-caption, comentários e categorias). Consequentemente, das 785 notícias distintas usadas para avaliação, somente 499 contêm categorias e closed-caption, totalizando 5.433 termos distintos.

Após a descrição hierárquica, foram obtidos 25 documentos em XML, que seguem o modelo MediaObject para representação de metadados (vide Capítulo 5, Seção 5.3, Listagem 5.1), sendo que cada um corresponde a um programa gravado. Usando esses arquivos, é possível identificar a qual programa e cena um conjunto de metadados (quadros-chave, faces e texto) pertence.

Os parâmetros da técnica AG para seleção baseada em tópicos foram definidos a partir de análises experimentais. Utiliza-se uma população inicial de 200 cromossomos, que interagem entre si durante 60 gerações; as taxas de reprodução e mutação foram configuradas para 0,5 e 0,7, respectivamente. O limiar $T$ da Equação 6.6 foi configurado empiricamente para 0,6. Em relação à seleção baseada em imagens, o valor de $k$ foi definido como 7 , portanto, a resolução de cada imagem foi redefinida

\footnotetext{
${ }^{5} \mathrm{Na}$ verdade, na arquitetura proposta, essa tarefa é delegada aos usuários finais.
} 
para $128 \times 128$ pixels. O tamanho de um bloco $X$ foi configurado para 16 pixels, totalizando $G=64$ blocos por imagem.

Os experimentos exploram três procedimentos de busca que combinam diferentes critérios para recuperação de cenas relacionadas. Durante a análise, foram utilizados os critérios bem conhecidos revocação (do Inglês, recall) e precisão (do Inglês, precision) [Joachims, 1998], que são definidos como:

$$
\begin{aligned}
\text { revocação } & =\frac{\text { num. verdade positivos }}{\text { num. verdade positivos }+ \text { num. falso negativos }} \\
\text { precisã o } & =\frac{\text { num. verdade positivos }}{\text { num. verdade positivos }+ \text { num. falso positivos }}
\end{aligned}
$$

onde num. verdade positivos é o número de cenas relevantes que foram retornadas pela técnica; num. falso positivos é o número de cenas irrelevantes retornadas pela técnica; e num. falso negativos é o número de cenas relevantes que não foram retornadas pela técnica. A classificação de cada notícia como relevante ou irrelevante foi realizada manualmente para cada um dos experimentos.

Os gráficos do tipo revocação $\times$ precisão indicam a precisão para cada valor de revocação. Isso significa que é mostrada a performance da técnica incrementalmente para cada cena retornada. Idealmente, quanto mais a curva está próxima do canto superior direito do gráfico, melhor é o desempenho da técnica. As seguintes subseções descrevem a avaliação e resultados obtidos.

\section{Experimento 1: Previsão do Tempo}

O primeiro experimento supõe que um usuário está assistindo a um noticiário, e durante a previsão do tempo, ele decide procurar por outras cenas sobre o mesmo assunto. Após a captura de um quadro que exibe as temperaturas em diferentes regiões no mapa, o sistema utiliza essa imagem, juntamente com um trecho de closed-caption correspondente, para procurar por notícias relacionadas. A Figura 6.2 apresenta a ferramenta M4Note, que foi utilizada durante a interação. Adicionalmente, a Figura 6.2 exibe os dados utilizados pelo sistema para busca, de acordo com os diferentes critérios.

A Figura 6.3 apresenta os resultados para este experimento. Como o usuário não especificou nenhuma face, os resultados obtidos usando somente esse critério foram os piores. Conforme esperado, ao se utilizar somente a técnica baseada em tópicos, a performance do sistema é menor, uma vez que nem todas as cenas têm closed-caption e categorias para serem explorados. A relação semântica das cenas retornadas usando somente imagens foi satisfatória, já que notícias com quadros visualmente similares à imagem de busca têm uma ligação forte com o tópico sobre 


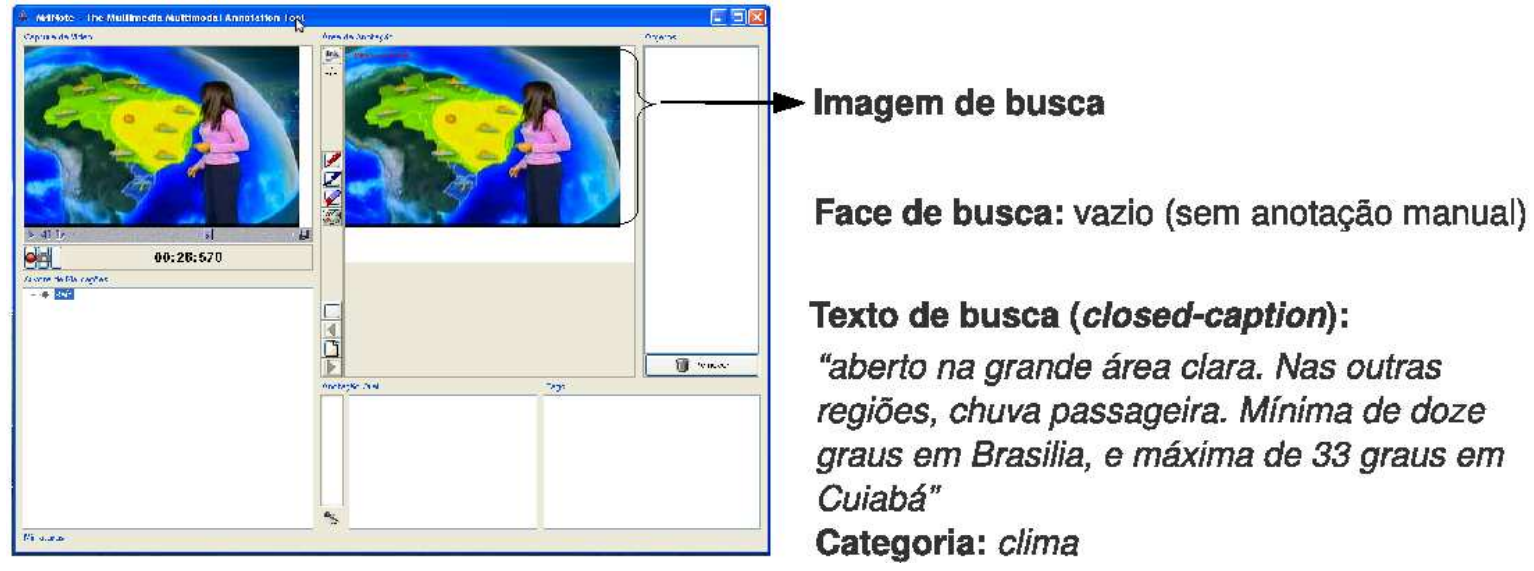

Figura 6.2: Experimento 1: O usuário está assistindo a uma notícia sobre clima, e usa o quadro capturado e um trecho da legenda para procurar por outras cenas relacionadas.

clima. Durante a agregação, por outro lado, a técnica proposta parece ter tido um desempenho inferior incrementalmente, mas no valor de 0,95 de revocação, a precisão foi a mesma $(0,9)$ quando comparada ao critério baseado em imagens.

\section{Experimento 2: Cotação da Bolsa e do Dólar}

O segundo experimento é similar ao primeiro, mas nesse caso, assume-se que o usuário está assistindo a uma cena onde o âncora apresenta a cotação da bolsa e do dólar do dia. Após a captura de um quadro contendo o âncora, o sistema utiliza essa imagem, juntamente com um trecho de closed-caption correspondente, para buscar por cenas relacionadas. A Figura 6.4 apresenta a ferramenta M4Note, que foi utilizada durante a interação, e os dados utilizados pelo sistema para busca, de acordo com os diferentes critérios.

A Figura 6.5 apresenta os resultados para este experimento. Novamente, o usuário não especificou nenhuma face para ser usada na busca; portanto, os resultados obtidos usando somente esse critério foram os piores. Em relação àquele baseado em imagens, a técnica foi capaz de recuperar cenas com quadros bastante similares visualmente, mas entre essas cenas, algumas não tratavam de notícias sobre economia e cotação. A razão é que o programa jornalístico considerado usa um modelo para plano de fundo composto por um quadro verde ao lado do âncora para exibição de estatísticas em geral, e não apenas para economia. Assim, nesse cenário, nota-se uma limitação de se usar somente o critério baseado em imagens, já que poucas informações semânticas são consideradas durante a busca. Por outro lado, a performance da técnica baseada em tópicos foi melhor pois os dados de busca contêm mais informações significativas sobre o assunto. 


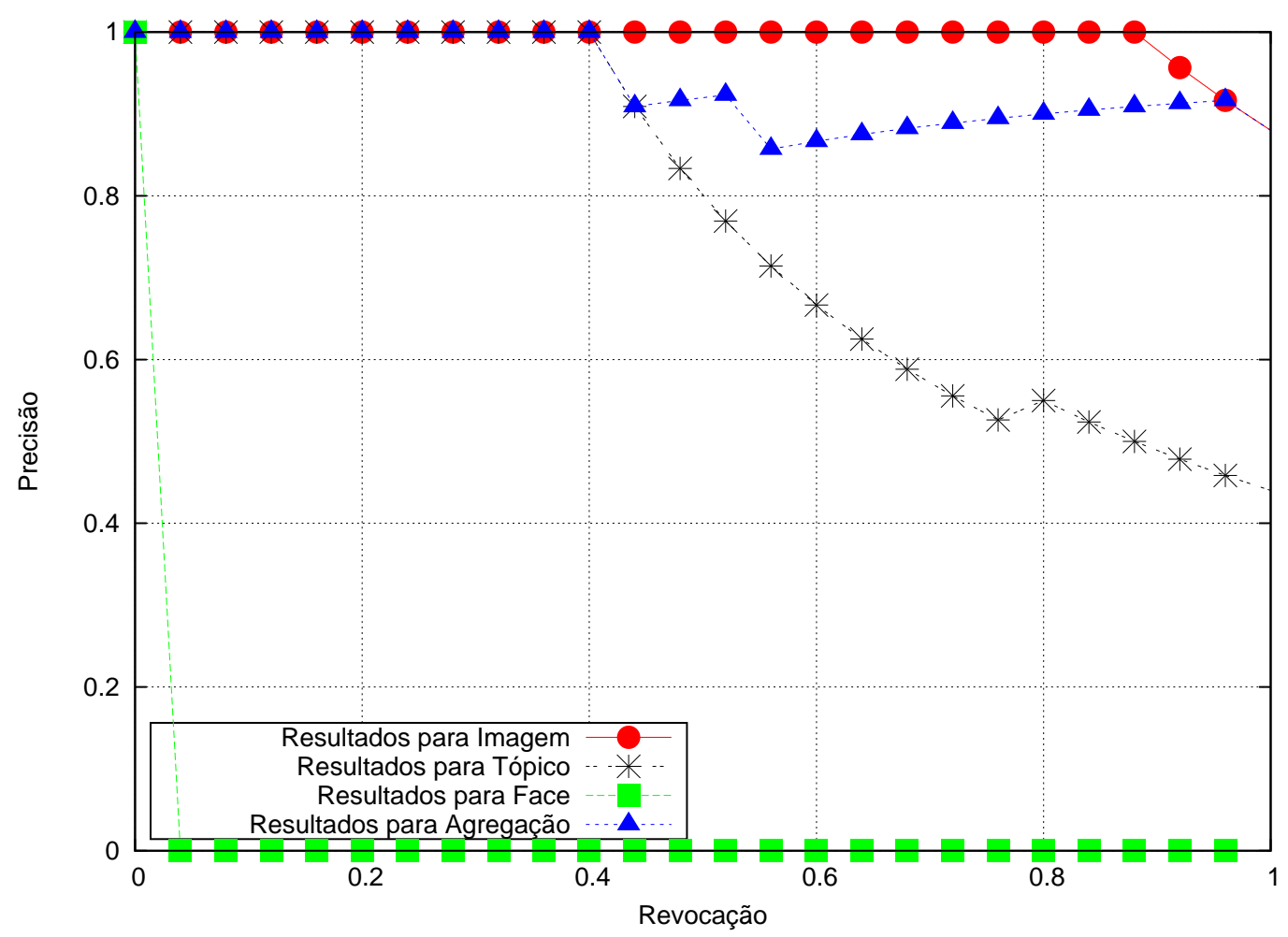

Figura 6.3: Resultados para experimento 1: $m=24$ cenas do banco de dados são relevantes para a busca formulada. As técnicas baseadas em imagens e a agregação foram capazes de retornar 22 cenas relevantes; consequentemente, no final, ambas atingiram o mesmo valor de precisão.

A abordagem de agregação, entretanto, obteve os melhores resultados quando comparada às técnicas isoladas. Tal fato é explicado pela estratégia de considerar os pontos fortes de cada critério. Em particular, a agregação foi melhor do que a técnica baseada em tópicos porque, para aquelas cenas que não têm closed-caption, o sistema considerou automaticamente algumas cenas relevantes retornadas pela abordagem baseada em imagem. Como consequência, a combinação de critérios foi capaz de retornar cenas mais relevantes semanticamente para o usuário, melhorando a precisão na maioria dos valores de revocação.

\section{Experimento 3: Presidente Brasileiro}

O último experimento supõe que o usuário quer recuperar cenas que falam do ex-presidente do Brasil. Durante uma notícia que fala do ex-presidente Lula, o usuário captura um quadro exibindo o político e realiza uma anotação manual usando tinta eletrônica ao redor de sua face. Adicionalmente, ao invés de usar um trecho do closed-caption, ele decide inserir algumas etiquetas para serem usadas como dados de busca. A Figura 6.6 apresenta a ferramenta M4Note, juntamente com os traços e 


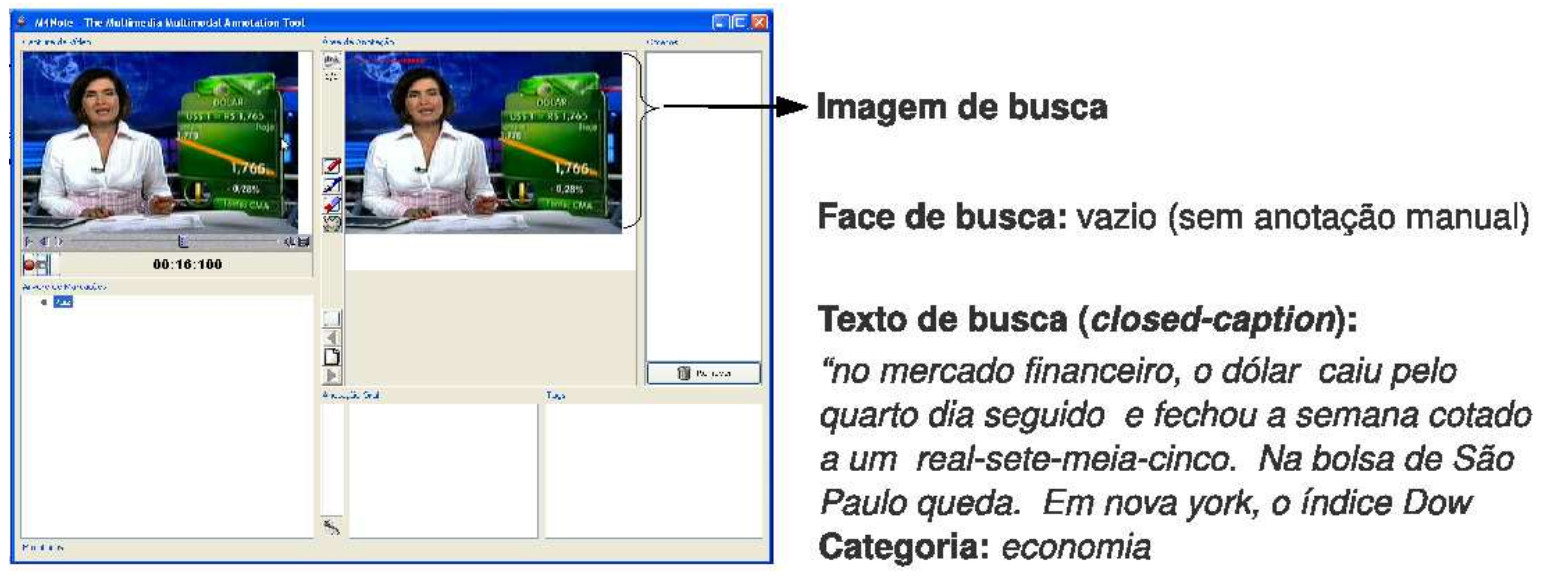

Figura 6.4: Experimento 2: O usuário está assistindo a uma notícia sobre cotação da bolsa e do dólar, e usa o quadro capturado e um trecho da legenda para procurar por outras cenas relacionadas.

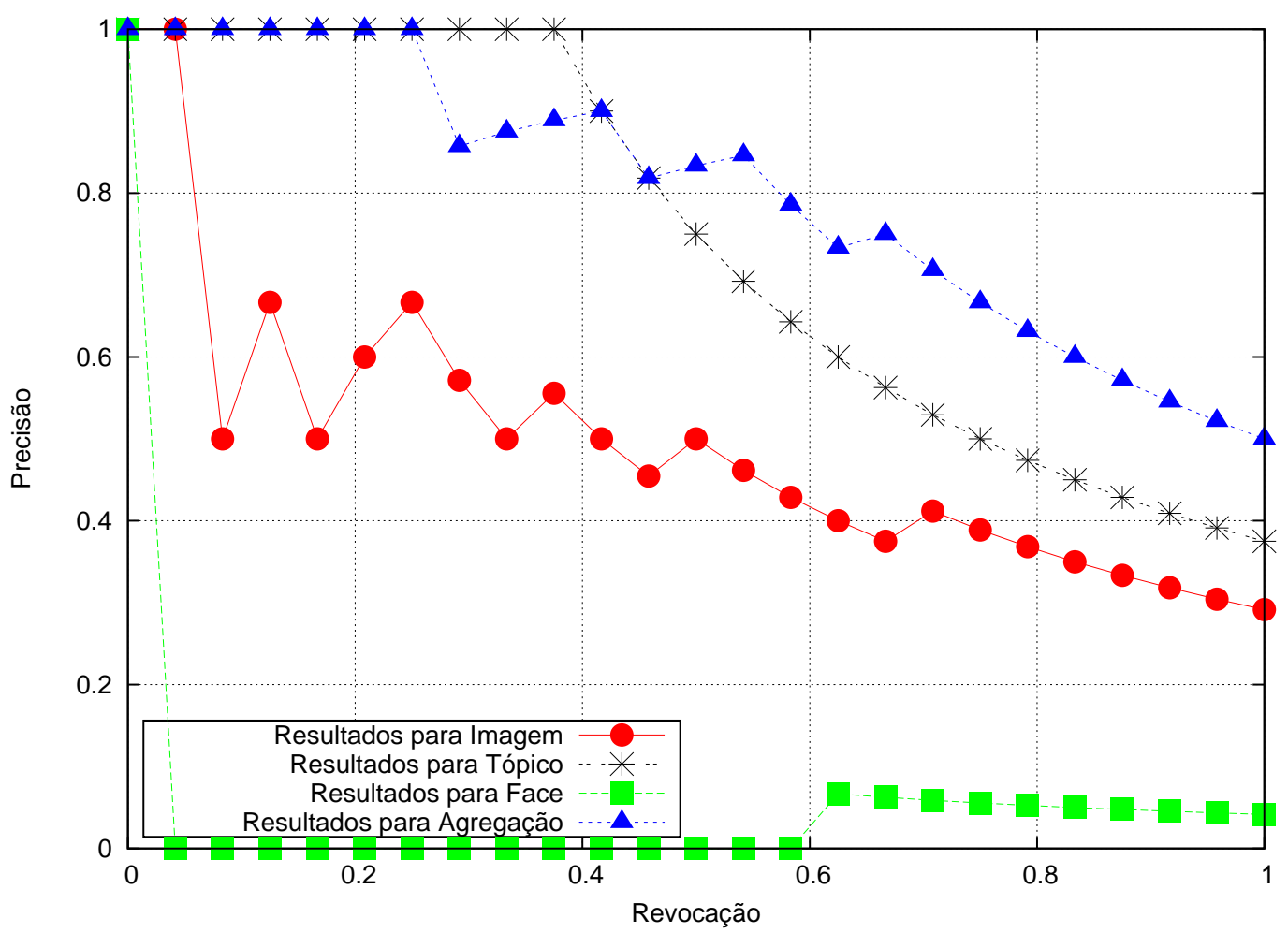

Figura 6.5: Resultados para experimento 2: $m=24$ cenas do banco de dados são relevantes para a busca formulada. A combinação de critérios foi capaz de atingir os melhores resultados, retornando 12 cenas relevantes para o usuário.

termos criados pelo usuário. Também são exibidos os dados de busca utilizados pelo sistema para recuperar cenas relacionadas.

A Figura 6.7 apresenta os resultados para este experimento. Ao contrário das 


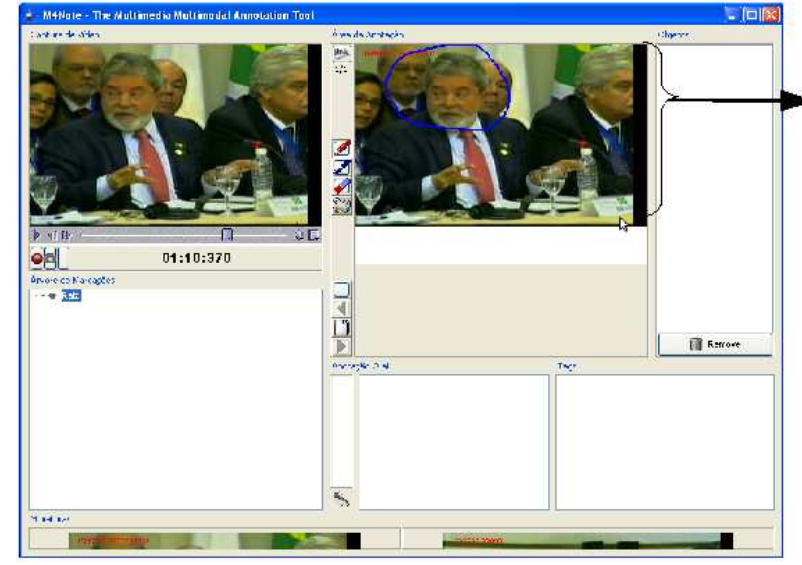

Imagem de busca

Face de busca:

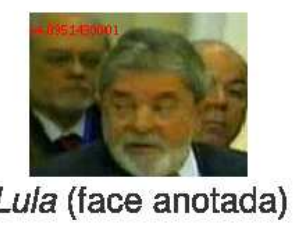

Texto de busca (etiquetas):

"Presidente Lula Brasil"

Categoria: política/economia

Figura 6.6: Experimento 3: O usuário está assistindo a uma notícia que exibe o ex-presidente Lula e usa sua face em conjunto com etiquetas para recuperar cenas que contêm o político.

análises anteriores, o critério baseado em imagens teve o pior desempenho, pois a imagem usada para busca não agrega qualquer informação semântica que possa ser extraída somente pela análise de características visuais de baixo nível. A abordagem baseada em tópicos teve uma pequena melhoria, mas com resultados ainda insatisfatórios. A razão é que, além da falta de closed-caption em algumas cenas, quase todas que citam a pessoa desejada referem-se a outros assuntos, em diferentes contextos, usando termos genéricos como "presidente" e "Brasil".

A técnica baseada em faces obteve melhores resultados, mas algumas cenas não puderam ser retornadas pois elas não exibiam a face do ex-presidente; na verdade, um número de faces não pôde ser detectado pela técnica devido à ocorrência de oclusões. Por outro lado, a abordagem de agregação, como mostrado na Figura 6.7, teve um desempenho melhor em quase todos os valores de revocação, quando comparada aos critérios isolados.

\subsection{Sistema de Recomendação}

Além do serviço de seleção de conteúdo, este trabalho contempla uma outra aplicação que também utiliza a arquitetura de personalização descrita no capítulo anterior. Propõe-se um sistema de recomendação de filmes que explora metadados relacionados ao conteúdo e interesses pessoais [Manzato \& Goularte, 2010]. Essas informações são provenientes de descrições hierárquicas, bem como das anotações produzidas colaborativamente por usuários finais. Tal mecanismo é inerente à arquitetura de personalização proposta, conforme pode ser visto no Capítulo 5, Seção 5.1. 


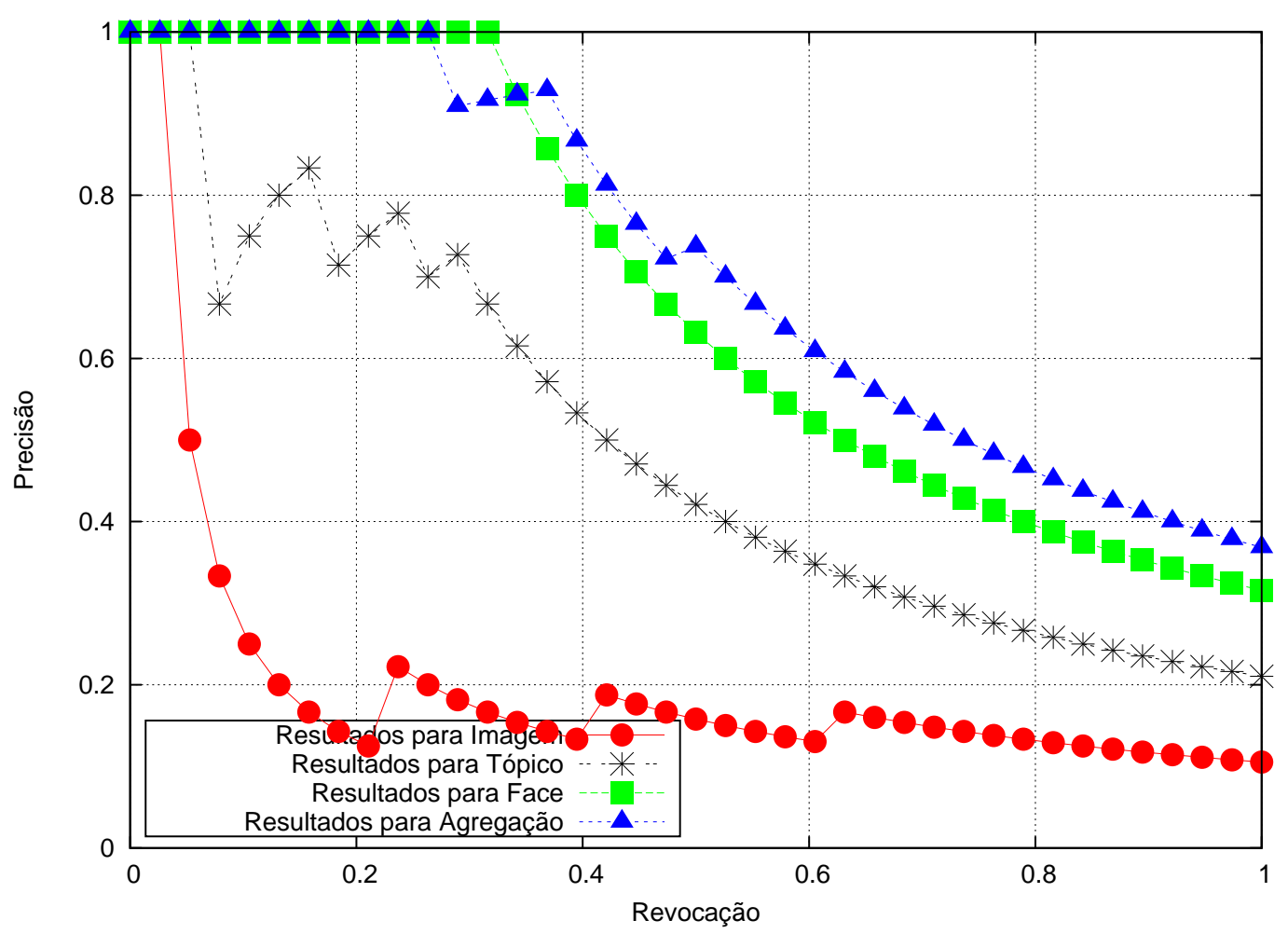

Figura 6.7: Resultados para experimento 3: $m=38$ cenas do banco de dados são relevantes para a busca formulada. A combinação de critérios foi capaz de atingir os melhores resultados, retornando 14 cenas revelantes para o usuário.

Esta seção apresenta em detalhes o sistema de recomendação desenvolvido. Nas próximas três subseções, descreve-se um conjunto de algoritmos de recomendação que foram propostos anteriormente na literatura. Essas abordagens serão usadas como referência na Subseção 6.2.5 durante a análise dos resultados, comparando-as à alternativa proposta, que é descrita na Subseção 6.2.4. Salienta-se que, nesta seção, adotou-se a nomenclatura previamente definida no Capítulo 5, Seção 5.4.

\subsubsection{Recomendação Baseada em Conteúdo}

Szomszor et al. [2007] propuseram uma abordagem para filtragem baseada em conteúdo que utiliza palavras-chave para predizer notas que um usuário daria para filmes. A partir dessa predição, recomendam-se aqueles itens que obtiveram as maiores notas preditas. O algoritmo proposto foi chamado pelos autores de Comparação Ponderada de Nuvens de Palavras-chave (do Inglês, Weighted Keyword Cloud Comparison) ${ }^{6}$ e sua definição é baseada em uma medida de similaridade entre

\footnotetext{
${ }^{6} \mathrm{Na}$ verdade, o nome original definido pelos autores é Comparação Ponderada de Nuvens de Etiquetas (do Inglês, Weighted Tag Cloud Comparison); entretanto, eles utilizam palavras-chave como base para a técnica de recomendação. Neste trabalho, uma vez que se explora a notação de nuvens de etiquetas
} 
nuvens de palavras-chave, que considera os pesos existentes nos metadados do conteúdo e na nuvem de palavras-chave existente no perfil do usuário.

Dado um filme não-avaliado $s$, a técnica considera o conjunto de palavras-chave $K_{s}$ e calcula sua similaridade com a nuvem $\operatorname{cloud}_{k}(u, r)$ da seguinte maneira:

$$
\sigma_{k}(u, s, r)=\sum_{\left\{\left(k, n_{k, u, r}\right) \in \text { cloud }_{k}(u, r) \mid k \in K_{s}\right\}} \frac{n_{k, u, r}}{\log \left(N_{k}\right)} .
$$

Tal equação soma todas as palavras-chave que $K_{s}$ e $\operatorname{cloud}_{k}(u, r)$ têm em comum, calculando os pesos de cada palavra-chave $k$ proporcionalmente à sua frequência $n_{k, u, r}$ na nuvem, e inversamente proporcional ao logaritmo de sua frequência global $N_{k}$. Portanto, a nota média ponderada $\lambda_{k}(u, s)$ de palavras-chave é definida como:

$$
\lambda_{k}(u, s)=\frac{\sum_{r \in R} \sigma_{k}(u, s, r) r}{\sum_{r \in R} \sigma_{k}(u, s, r)},
$$

que é utilizada em conjunto com a nota média $\bar{\delta}(s)$ do filme $s$ :

$$
\bar{\delta}(s)=\frac{1}{U_{s}} \sum_{v \in U_{s}} \delta_{v}(s)
$$

para predizer a nota $\delta_{u}(s)$ do usuário $u$ em relação ao filme $s$ :

$$
\delta_{u}(s)=(1-\gamma) \bar{\delta}(s)+\gamma \lambda_{k}(u, s)
$$

onde $0<\gamma<1$ é um fator de ponderação entre as duas estimativas. Analogamente aos autores, configurou-se essa variável neste trabalho como $\gamma=1 / 2$, sendo que a nota predita $r$ para o filme $s$ é o valor mais próximo em $R$ de acordo com $\delta_{u}(s)$.

\subsubsection{Recomendação Colaborativa}

Algoritmos de filtragem colaborativa predizem a nota $\delta_{u}(s)$ que um usuário $u$ daria para o filme $s$ com base em sua coleção de notas atribuídas anteriormente pelos $Q$ usuários com preferências mais similares. Considera-se $\hat{U}$ o conjunto de $Q$ usuários que são mais similares a $u$ e que avaliaram o item $s$. Define-se uma função de agregação como [Adomavicius \& Tuzhilin, 2005]:

como aqueles termos criados pelos usuários, a nomenclatura utilizada pelos autores foi alterada com o objetivo de diferenciar ambas abordagens. 


$$
\delta_{u}(s)=\bar{\delta}_{u}+\frac{\sum_{v \in \hat{U}} \operatorname{sim}(u, v)\left(\delta_{v}(s)-\bar{\delta}_{v}\right)}{\sum_{v \in \hat{U}}|\operatorname{sim}(u, v)|} .
$$

sendo que:

$$
\operatorname{sim}(u, v)=\left(\frac{\left|S_{u v}\right|}{|S|}\right) \times\left(\frac{\sum_{s \in S_{u v}}\left(\delta_{u}(s)-\bar{\delta}_{u}\right)\left(\delta_{v}(s)-\bar{\delta}_{v}\right)}{\sqrt{\sum_{s \in S_{u v}}\left(\delta_{u}(s)-\bar{\delta}_{u}\right)^{2} \sum_{s \in S_{u v}}\left(\delta_{v}(s)-\bar{\delta}_{v}\right)^{2}}}\right),
$$

Na Equação 6.13, utilizam-se os desvios dos valores de notas em relação à nota média do usuário correspondente com o objetivo de reduzir o problema de haver diferentes escalas de notas adotadas por cada usuário.

\subsubsection{Recomendação Híbrida}

Um sistema de recomendação híbrida combina os métodos baseados em conteúdo e colaborativos, procurando reduzir as limitações inerentes a ambas abordagens. $\mathrm{O}$ Capítulo 2, Seção 2.4 apresentou uma discussão sobre algumas dessas limitações, juntamente com a descrição de vários meios de se combinar essas técnicas em uma abordagem única e híbrida. Neste trabalho, devido à simplicidade de implementação, realiza-se uma combinação linear estendendo a técnica de recomendação baseada em conteúdo apresentada na Subseção 6.2.1. Especificamente, a Equação 6.12 é modificada para substituir a média de notas $\bar{\delta}(s)$ do filme $s$ pela predição calculada na filtragem colaborativa definida na Subseção 6.2.2. Portanto:

$$
\delta_{u}(s)=(1-\gamma) \text { Collaborative }_{u}(s)+\gamma \lambda_{k}(u, s)
$$

onde Collaborative $_{u}(s)$ é equivalente à Equação 6.13 e $\gamma=1 / 2$.

\subsubsection{Recomendação Baseada em Anotações}

Esta subseção apresenta o algoritmo de recomendação baseado em anotações proposto neste trabalho. Considera-se $\operatorname{match}_{e}(u, s)$ como o conjunto de pares $\left(e, n_{e, u, r}\right) \in \operatorname{cloud}_{e}^{*}(u, r)$ onde $e \in E_{s} \cap E_{u}$; e $\operatorname{match}_{f}(u, s)$ como o conjunto de pares $\left(f, n_{f, u, r}\right) \in \operatorname{cloud}_{f}^{*}(u, r)$ onde $f \in F_{s} \cap F_{u}$. Com base nesses conjuntos, definem-se as médias ponderadas de notas em faces e etiquetas, respectivamente, como: 


$$
\lambda_{e}(u, s)=\sum_{\operatorname{match}_{e}(u, s)} \frac{\sum_{r \in R} n_{e, u, r} r}{\sum_{r \in R} n_{e, u, r}}, \quad \lambda_{f}(u, s)=\sum_{\operatorname{match}_{f}(u, s)} \frac{\sum_{r \in R} n_{f, u, r} r}{\sum_{r \in R} n_{f, u, r}} .
$$

Em seguida, ambos os valores de médias são combinados para que uma nota baseada apenas em anotações seja predita, como segue:

$$
\lambda_{e f}(u, s)=\frac{\lambda_{e}(u, s)+\lambda_{f}(u, s)}{\left|\operatorname{match}_{e}(u, s)\right|+\left|\operatorname{match}_{f}(u, s)\right|} .
$$

Entretanto, a utilização de $\lambda_{e f}(u, s)$ isoladamente provoca sérios problemas na recomendação quando o usuário não cria anotações durante a interação. Nesse caso, o divisor da fração da Equação 6.17 será zero. Para evitar esse problema, combina-se $\lambda_{e f}(u, s)$ com o algoritmo de filtragem baseada em conteúdo definido anteriormente, ou seja:

$$
\delta_{u}(s)=(1-\gamma) \text { Content }_{u}(s)+\gamma \lambda_{e f}(u, s)
$$

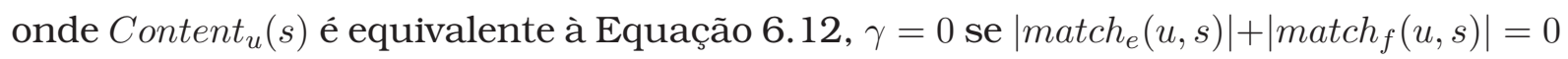
e $\gamma=1 / 2$ caso contrário.

Será mostrado na Subseção 6.2.5 que a Equação 6.18 já é capaz de melhorar os resultados usando apenas a filtragem baseada em conteúdo. Antes disso, porém, apresenta-se uma versão melhorada da recomendação híbrida, que combina o algoritmo de recomendação baseada em anotações com a filtragem colaborativa. Tal versão é definida como:

$\delta_{u}(s)= \begin{cases}\text { Collaborative }_{u}(s) & \text { se }\left|K_{s}\right|<\alpha \text { e }\left|E_{s}\right|<\alpha \\ \text { Annotation }_{u}(s) & \text { se } \delta_{v}(s)=\varnothing \text { ou }\left|S_{u v}\right| /|S|<\beta \\ (1-\gamma) \text { Collaborative }_{u}(s)+\gamma \text { Annotation }_{u}(s) & \text { caso contrário, }\end{cases}$

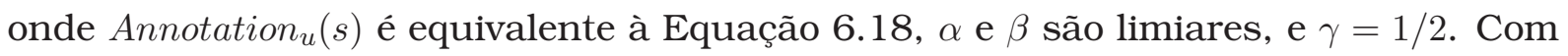
base na análise da quantidade de metadados para cada filme $s$, e nos parâmetros de similaridade entre usuários $u$ e $v \in \hat{U}$, a nota predita de $s$ é calculada por meio da seleção de valor da melhor abordagem conforme algoritmo definido na Equação 6.19.

As técnicas de recomendação propostas até o momento podem ser aperfeiçoadas se forem considerados outros metadados disponíveis em cada filme. Gêneros, por exemplo, melhoram significativamente os algoritmos de recomendação. Define-se match $_{g}(u, s)$ como o conjunto de pares $\left(g, n_{g, u, r}\right) \in \operatorname{cloud}_{g}(u, r)$, onde $g \in G_{s} \cap G_{u}$. Com base nesse conjunto, propõe-se a nota média ponderada em gêneros como: 


$$
\lambda_{g}(u, s)=\sum_{\text {match }_{g}(u, s)} \frac{\sum_{r \in R} n_{g, u, r} r}{\sum_{r \in R} n_{g, u, r}},
$$

que é combinada com a abordagem híbrida melhorada para prover melhores predições. Assim:

$$
\delta_{u}(s)=(1-\gamma) \operatorname{Hybrid}_{u}(s)+\gamma \lambda_{g}(u, s),
$$

onde $\operatorname{Hybrid}_{u}(s)$ é equivalente à Equação 6.19, e $\gamma=1 / 2$.

\subsubsection{Avaliação}

Após a definição dos algoritmos de recomendação, esta seção descreve a análise de resultados da filtragem baseada em anotações proposta neste trabalho. O estudo consiste em comparar a performance de todos os algoritmos descritos nas subseções anteriores, usando a Raiz do Erro Quadrático Médio (do Inglês, Root Mean Squared Error - RMSE) [Anderson \& Woessner, 1992]. Nessa métrica, assume-se que quanto menor o valor de erro calculado, mais preciso será o conjunto de predições. Dado o conjunto de $N$ notas preditas $\left\{r_{i}\right\}$ e o conjunto correspondente de notas reais $\left\{r_{i}^{*}\right\}$, a RMSE é definida como:

$$
\operatorname{RMSE}\left(\left\{r_{i}\right\},\left\{r_{i}^{*}\right\}\right)=\sqrt{\frac{1}{N} \sum_{i}\left(r_{i}-r_{i}^{*}\right)^{2}}
$$

As amostras que foram usadas como dados para avaliação correspondem a um subconjunto da base de dados MovieLens ${ }^{7}$, que inclui notas de filmes de vários usuários reais, juntamente com etiquetas atribuídas por eles a uma variedade de filmes. Na base de dados original, existem cerca de 70.000 usuários, que criaram etiquetas e notas para um conjunto de 65.133 filmes diferentes, totalizando 95.580 etiquetas e 10.000.054 notas. Entretanto, como o cálculo das predições para todos esses usuários seria uma tarefa exaustiva necessitando de considerável tempo de processamento, 500 usuários foram aleatoriamente selecionados para serem utilizados na avaliação, o que reduziu o conjunto de notas para 197.211 atribuições.

Decidiu-se adotar a base de dados MovieLens ao invés de avaliar a performance da técnica com o uso da ferramenta M4Note. Tal decisão foi fundamentada no principal objetivo deste estudo que é verificar o quanto o algoritmo proposto pode melhorar os resultados. Assim, para validar a análise, seria necessário um conjunto de usuários reais em larga escala, o que se tornou inviável durante o desenvolvimento

\footnotetext{
${ }^{7}$ http://www.grouplens.org/node/12, último acesso em 10 de Novembro de 2010.
} 
do projeto. Portanto, embora sejam considerados usuários reais provenientes da base de dados MovieLens, na prática esses indivíduos não interagiram com a ferramenta M4Note para assistir, anotar e avaliar cada filme. Por outro lado, várias anotações que poderiam ser criadas com a ferramenta são simuladas nesta avaliação conforme descrito a seguir.

As descrições hierárquicas de cada filme foram exploradas conforme explicado no Capítulo 5, Seção 5.3. Especificamente, os algoritmos de recomendação utilizaram palavras-chave e gêneros provenientes das descrições disponiveis na base de dados IMDB. Para isso, porém, foi necessário que cada um dos 65.133 filmes da base MovieLens fosse relacionado ao seu correspondente na base IMDB $^{8}$. Esse mapeamento foi realizado automaticamente por meio de uma comparação do título e ano de produção. Como resultado, os 65.133 filmes da base MovieLens foram associados às suas descrições hierárquicas correspondentes disponiveis na base IMDB.

Além de gêneros e palavras-chave, que são metadados provenientes de descrições hierárquicas, consideram-se também as anotações produzidas por todos os 500 usuários selecionados para compor o conjunto utilizado na análise. Etiquetas e faces detectadas/reconhecidas são exploradas, mas no segundo caso, como a base MovieLens não possui informações sobre faces, a ação de anotar, detectar e reconhecer uma face é simulada por meio de uma análise do conteúdo de cada etiqueta. Utilizando a lista de atores proveniente da base IMDB, nomes conhecidos foram procurados na lista de etiquetas, sendo que quando um nome foi reconhecido, tal etiqueta foi julgada como uma face anotada pelo usuário. No total, 12.758 faces foram consideradas na avaliação.

O conjunto de 197.211 notas foi dividido em conjuntos de treinamento e teste. Portanto, assumiu-se que o conjunto de treinamento corresponde a itens que já foram visitados pelo usuário, o que torna possível a criação de perfis de interesse para cada indivíduo. O conjunto de teste, por sua vez, é usado para testar as predições das técnicas de recomendação, comparando os resultados com as notas reais. Essa divisão do conjunto em treinamento e teste foi feita de modo a disponibilizar exatamente 10 notas para cada usuário no conjunto de teste. Consequentemente, esses conjuntos contêm, respectivamente, 192.211 e 5.000 notas atribuídas.

Além dos valores de parâmetros definidos até o momento, as outras variáveis foram configuradas como segue: durante o enriquecimento das nuvens de etiquetas e faces, $P=5$ (vide Capítulo 5, Seção 5.4); na filtragem colaborativa, $Q=|\hat{U}|=10$ (vide Equação 6.13); e na filtragem híbrida melhorada, $\alpha=5$ e $\beta=0.02$ (vide Equação 6.19). Todos esses valores foram definidos de maneira empírica, ou seja, diferentes configurações foram analisadas, de modo a ser possível criar um relacionamento entre os resultados obtidos com: i) a quantidade de dados em cada

\footnotetext{
${ }^{8}$ http://www.imdb.com/interfaces, último acesso em 10 de Novembro de 2010.
} 
nuvem de dados, ii) a viabilidade de metadados sobre o conteúdo, e iii) o número de filmes em comum.

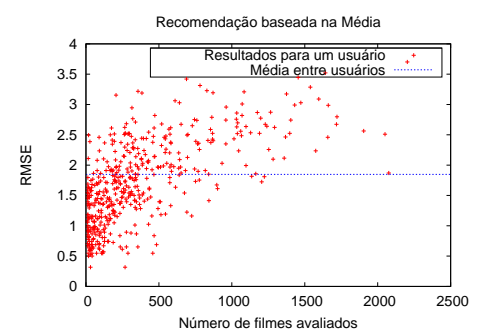

(a)

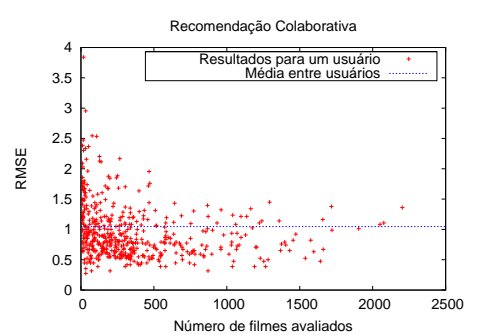

(d)

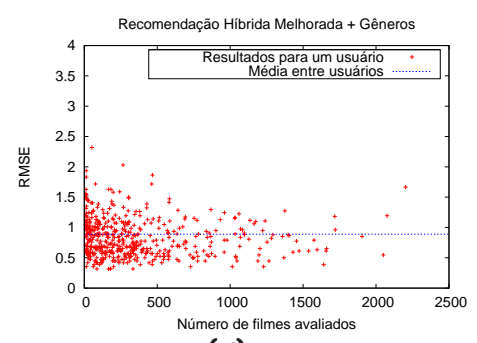

(g)

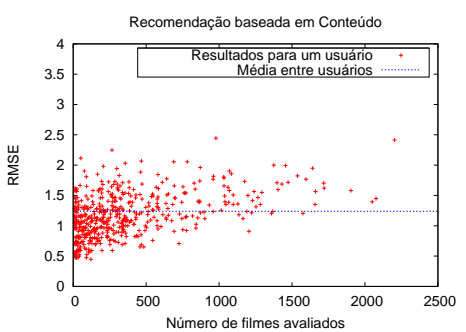

(b)

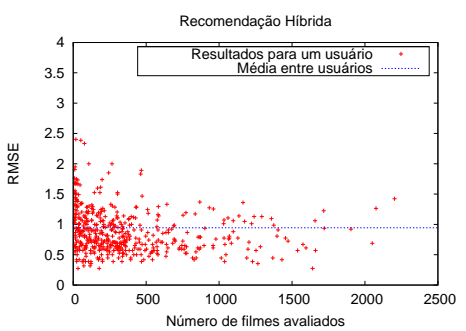

(e)

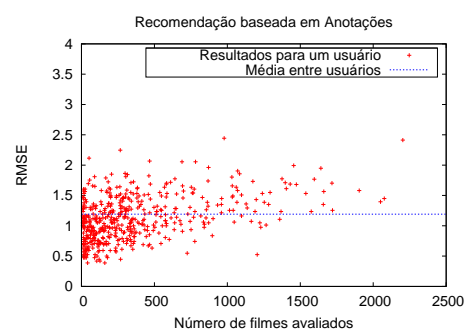

(c)

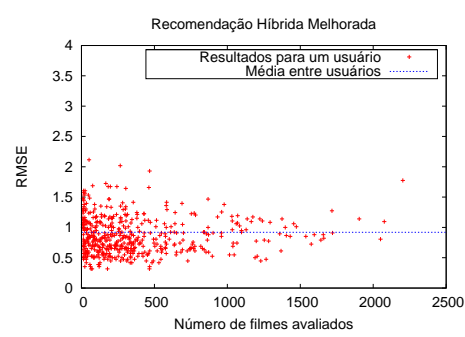

(f)

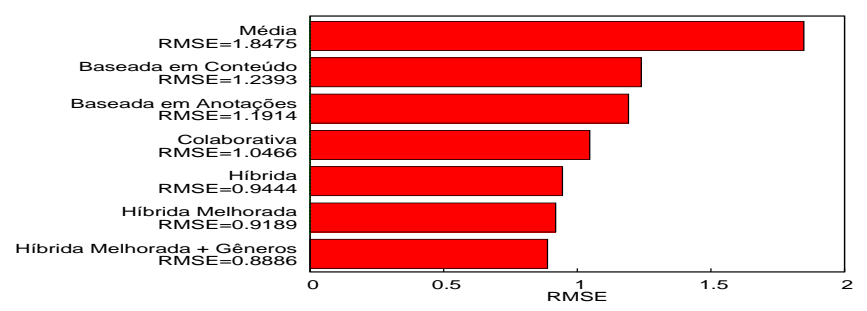

(h)

Figura 6.8: Resultados para todos os algoritmos de recomendação. Os gráficos de (a) a (g) exibem a RMSE para todos os usuários juntamente com a quantidade de notas atribuídas: (a) é a predição usando a média de notas do filme (Equação 6.11); (b) é a predição baseada em conteúdo (Equação 6.12); (c) é a predição baseada em anotações (Equação 6.18); (d) é a predição colaborativa (Equação 6.13); (e) é a predição híbrida (Equação 6.15); (f) é a predição híbrida melhorada (Equação 6.19); e (g) é a predição híbrida melhorada mais gêneros (Equação 6.21). O gráfico (h) exibe a média de RMSE para cada abordagem.

Todos os algoritmos de recomendação descritos nesta seção utilizam o mesmo conjunto de dados. A Figura 6.8 apresenta os resultados obtidos. Os gráficos de (a) a (g) exibem a distribuição de usuários de acordo com o número de notas atribuídas por eles (coordenada $x$ ), indicando a RMSE correspondente (coordenada $y$ ). Portanto, os pontos que mais se aproximam da linha $(x, 0)$ são aqueles usuários que receberam melhores recomendações (com base em seus perfis de interesse).

Para aqueles algoritmos que lidam com a filtragem colaborativa (gráficos (d)-(g)), é possível visualizar uma tendência para melhores resultados à medida que mais 
notas são atribuídas por cada indivíduo. Isso acontece devido à relacionalidade entre usuários, que torna-se mais forte quando mais notas estão disponíveis para serem usadas pela métrica de similaridade.

Ao avaliar os resultados para usuários isolados nas abordagens baseadas em conteúdo e colaborativa (gráficos (b) e (d)), notam-se alguns casos onde a sobre-especialização e o problema do novo usuário são evidentes. Verificando o gráfico (b), o usuário que avaliou cerca de 2.250 filmes obteve uma predição ruim, com cerca de 2,4 de RMSE na técnica baseada em conteúdo. Isso sugere que seu perfil contém muitas informações (palavras-chave/notas), mas não implicando bons resultados. Embora o mesmo usuário tenha obtido cerca de 1,4 de RMSE com a recomendação colaborativa (gráfico (d)), nessa mesma abordagem houve outros usuários que avaliaram poucos filmes (cerca de 10) e obtiveram predições muito ruins (cerca de 3,8 de RMSE no pior caso), o que evidencia a ocorrência do problema do novo usuário.

A abordagem híbrida (gráfico (e)) foi capaz de balancear os resultados de ambas as técnicas. Entretanto, os mesmos novos usuários obtiveram cerca de 2,4 de RMSE, o que é pior do que a abordagem híbrida melhorada (gráfico (f)), cujos mesmos usuários obtiveram cercam de 2,1 de RMSE no pior caso. Isso pode ser explicado pelo enriquecimento de perfil, que provê conceitos mais ricos semanticamente às nuvens de etiquetas e faces, mesmo com poucas anotações e notas produzidas por eles.

A Figura 6.8(h) apresenta a média de RMSE para cada abordagem. Pode-se visualizar que a filtragem baseada em anotações foi melhor do que a baseada em conteúdo, melhorando sua RMSE em cerca de 3,9\%. A técnica híbrida melhorada, que também considera anotações, foi capaz de melhorar a abordagem tradicional híbrida em cerca de 2,7\%. O melhor algoritmo, entretanto, foi a combinação da técnica híbrida melhorada com os gêneros disponíveis em cada filme, obtendo um valor de RMSE de 0,8886 e aperfeiçoando a técnica híbrida melhorada em cerca de $3,3 \%$.

A partir desta análise, verificou-se que quanto mais informações estão disponíveis sobre usuários e conteúdo, melhores serão os resultados das recomendações baseadas em diferentes critérios. Notou-se que anotações são importantes para obter as preferências e interesses do usuário, mas elas dependem de metadados hierárquicos disponíveis para tornarem-se úteis. Essa afirmativa é suportada pelo fato de que nem todos os usuários irão prover etiquetas e faces como anotações, sendo necessário, nesse caso, o uso de outras metodologias, como a filtragem colaborativa ou baseada em conteúdo. Por outro lado, quando essas anotações estão disponíveis, é possível combiná-las com medidas de relacionalidade para enriquecer as nuvens de dados e, consequentemente, prover melhores recomendações com alto nível semântico. 


\subsection{Sistema de Sumarização Temporal: Discussão}

Conforme apresentado no Capítulo 2, Seção 2.3, a sumarização pode ser efetuada em nível de quadros, onde regiões espaciais de uma imagem são eliminadas de modo a serem apresentadas somente informações de interesse para o usuário. Adicionalmente, pode-se realizar uma sumarização temporal ou em nível de cenas, onde se cria um conteúdo novo a partir de algum já existente contendo apenas eventos relevantes para o indivíduo [Magalhães \& Pereira, 2004]. Tais dados espaciais e temporais são selecionados automaticamente por meio de algum critério semântico adotado, normalmente presente no perfil de interesses do usuário.

Com base na arquitetura de personalização proposta neste trabalho, torna-se viável o desenvolvimento de aplicações de sumarização temporal, já que os dados necessários para a sustentação da técnica são disponibilizados pelo sistema. De modo geral, um sistema de sumarização requer metadados semânticos que descrevem as unidades fundamentais (cenas, tomadas ou quadros) que serão combinadas e compostas para gerar o novo conteúdo. Além disso, são necessárias informações sobre os interesses do usuário, incluindo suas preferências gerais e intenções em um determinado momento. Salienta-se, entretanto, que a arquitetura de personalização provê suporte apenas à sumarização temporal. No caso da espacial, é inevitável a utilização de técnicas de segmentação de objetos, o que está fora do escopo deste trabalho.

Ao longo desta tese, foram discutidas algumas limitações inerentes ao processo de desenvolvimento de serviços de personalização. Entre esses problemas, destaca-se a necessidade de se obter metadados semânticos sobre o conteúdo audiovisual. Além disso, as aplicações requerem dados que indiquem as preferências reais do usuário, e tais informações são extraídas do indivíduo de maneira limitada pelas abordagens encontradas atualmente na literatura. Destarte, a utilização da arquitetura proposta para suportar serviços de sumarização apresenta as seguintes vantagens:

- maior exatidão no perfil do usuário em relação às suas preferências, já que são explorados outros mecanismos de interação com o conteúdo, resultando em uma representação multimodal. Tal melhoria na construção do perfil é comprovada na avaliação realizada no sistema de recomendação, apresentada na Subseção 6.2.5 deste capítulo;

- realização de buscas de conteúdo multimídia com maior nível semântico, uma vez que é viabilizada a possibilidade de se utilizar consultas em múltiplas modalidades simultaneamente. Essa funcionalidade foi descrita em detalhes na Seção 6.1, juntamente com uma avaliação e análise dos resultados;

- enriquecimento e complementação de informações na descrição hierárquica de 
conteúdo audiovisual, reduzindo os esforços de profissionais para criação de metadados utilizáveis em sistemas de personalização.

Uma peculiaridade dos sistemas de sumarização é que o conteúdo modificado é composto por unidades fundamentais que são recuperadas a partir de uma combinação de informações presentes no perfil de preferências do usuário e as consultas produzidas pelo indivíduo durante a interação com o conteúdo. Assim, a busca por cenas, tomadas ou quadros será customizada de acordo com os interesses pessoais, resultando em uma versão resumida do vídeo, que contém apenas eventos relevantes de acordo com suas intenções e preferências.

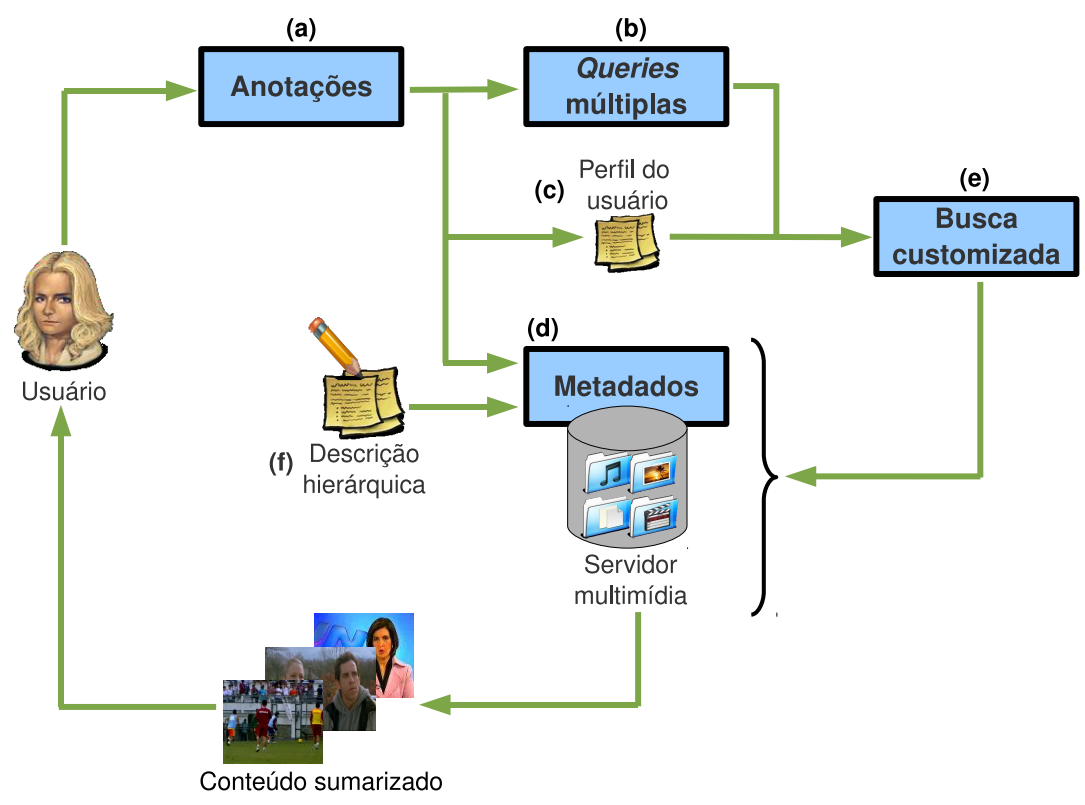

Figura 6.9: Sumarização baseada em anotações de usuários. (a) indica o módulo de anotações e enriquecimento pelo usuário; (b) representa os dados de busca formulados a partir das anotações; (c) exibe o perfil enriquecido do usuário com as anotações; (d) mostra os metadados relacionados ao conteúdo; (e) ilustra o processo de busca customizada de acordo com o perfil do usuário; e (f) representa o processo de indexação multimídia.

A Figura 6.9 ilustra um esquema para o desenvolvimento da técnica de sumarização que explora as capacidades de interação entre usuário e conteúdo. As anotações (Figura 6.9(a)) são produzidas pelo indivíduo no momento do enriquecimento dos dados, acarretando em informações que podem ser classificadas em consultas (Figura 6.9(b)), dados sobre as preferências (Figura 6.9(c)), ou metadados que descrevem o vídeo imparcialmente (Figura 6.9(d)). Esse processo de classificação de anotações pode ser executado da seguinte maneira:

1. anotações provenientes de diferentes usuários, produzidas colaborativamente 
sobre um mesmo conteúdo, podem ser usadas para enriquecer os metadados provenientes de descrições hierárquicas. Uma vez que vários usuários criaram anotações parecidas, pode-se inferir que essas informações apresentam um caráter imparcial, que não indicam ideias pessoais de um indivíduo. Um exemplo de tal metodologia, explorada neste trabalho, é o uso de anotações armazenadas no banco de dados IMDB, onde diversos usuários produzem metadados relacionados a uma variedade de filmes, seriados e programas;

2. anotações originadas de um único usuário são suscetíveis de apresentarem um caráter pessoal, indicando pensamentos e ideias relacionados apenas aos interesses do indivíduo. Portanto, essas informações são passíveis de serem incluídas no perfil de preferências do mesmo. Para isso, algumas técnicas apresentadas neste trabalho são usadas: reconhecimento de fala, símbolos e faces, associação de etiquetas e usuários, e avaliações por meio de notas. O Capítulo 5, Seção 5.4 descreveu em mais detalhes o processo de construção de perfil;

3. considerando o ambiente de interação do usuário, que pode fazer uso de diferentes métodos para criar anotações (captura de quadros, manuscritos, comentários por voz, entre outros), é possível fornecer a possibilidade de se buscar conteúdo relacionado utilizando as anotações criadas anteriormente. Esses dados irão constituir um conjunto de dados de busca em diferentes modalidades (imagens, texto, faces, entre outras), resultando na recuperação de unidades fundamentais com um alto nível semântico associado. Descreveu-se essa funcionalidade em mais detalhes na Seção 6.1.

A partir das consultas em diferentes modalidades e do perfil de interesses, o sistema pode iniciar uma busca por dados multimídia de maneira customizada, agregando maior importância para mídias que satisfazem os critérios definidos para a busca, e que apresentam uma ligação com conceitos presentes no perfil do usuário (Figura 6.9(e)). Consequentemente, os itens retornados terão uma maior relevância para o usuário, podendo ser combinados para compor o conteúdo sumarizado. Uma vez que as mídias são acompanhadas de suas respectivas descrições hierárquicas (Figura 6.9(f)), é possível criar vídeos que satisfazem certos parâmetros definidos pelo usuário, como tempo máximo de duração, assunto e presença de pessoas.

\subsection{Considerações Finais}

Este capítulo apresentou duas aplicações que foram desenvolvidas utilizando a arquitetura de personalização proposta neste trabalho. Tais serviços apresentam 
uma característica em comum: a estratégia de considerar anotações dos usuários para melhorar os serviços de customização. Por meio de anotações colaborativas, as descrições hierárquicas sobre o conteúdo são enriquecidas com metadados semânticos criados pelos usuários. Adicionalmente, dados provenientes da atividade de enriquecimento de conteúdo são utilizados para complementar o perfil de interesses do indivíduo com informações que agregam alta carga semântica relacionada às suas preferências.

As aplicações descritas nas seções anteriores apresentam uma análise das técnicas desenvolvidas, que indica bons resultados na seleção de conteúdo e recomendação multimídia. A seção que descreve a técnica de seleção de conteúdo apresentou a estratégia de se utilizar múltiplos critérios para busca de dados audiovisuais. Esses critérios são definidos pelo usuário durante a atividade de enriquecimento, sendo que o sistema realiza automaticamente a combinação dos rankings das técnicas envolvidas, gerando melhores resultados do que a utilização de um único critério. Uma vez que cada mecanismo (seleção baseada em face, imagem e tópico) apresenta limitações próprias, a abordagem multimodal proposta combina os métodos existentes de modo a possibilitar que uma técnica compense as limitações de outra. Como resultado, recuperam-se cenas relacionadas semanticamente aos dados de busca, mesmo em casos onde há total falta de metadados, como closed-caption e/ou categorias. De fato, a avaliação realizada contempla três experimentos diversos, indicando em todos eles a melhoria dos resultados quando é utilizada a abordagem multimodal para seleção de conteúdo. Portanto, comprova-se a eficácia da arquitetura proposta, que viabiliza tal serviço de personalização juntamente com as funcionalidades de enriquecimento de conteúdo, complementação de metadados e de perfil.

A seção que descreve o sistema de recomendação apresentou a técnica de filtragem baseada em anotações, que utiliza um perfil de interesses multimodal enriquecido para representar os conceitos preferidos pelo usuário. A análise foi baseada em uma comparação da técnica proposta com abordagens clássicas existentes na literatura, como a filtragem baseada em conteúdo e a colaborativa, sendo que tais métodos também estão especificados nas subseções correspondentes. Durante a execução das técnicas na avaliação, utilizou-se o banco de dados MovieLens, que contém usuários reais, incluindo suas avaliações e anotações. Os resultados obtidos mostraram que, ao contrário dos algoritmos existentes, a abordagem proposta foi capaz de reduzir os problemas de sobre-especialização e do novo usuário em alguns indivíduos considerados na análise. Adicionalmente, o problema da análise limitada de conteúdo (descrita no Capítulo 2, Subseção 2.4.1) é reduzido, já que disponibilizam-se metadados sobre o conteúdo criados colaborativamente pelos usuários.

Nota-se, portanto, que a arquitetura de personalização é capaz de prover melhores serviços de personalização. Tal melhoria é obtida em razão de se considerar as 
informações semânticas sobre o conteúdo, que são extraídas com base nas anotações colaborativas dos usuários. O problema da restrição de domínio de dados na indexação semântica é inexistente na estratégia proposta, visto que as anotações são realizadas por comunidades de usuários de maneira colaborativa. De fato, a arquitetura apresentada é explorada neste capítulo durante o desenvolvimento de dois serviços de personalização que consideram domínios de dados distintos: o sistema de seleção de conteúdo em telejornais e o sistema de recomendação de filmes. Salienta-se ainda que embora o tipo de conteúdo considerado seja vídeo, é possível estender a arquitetura para outros itens de mídia, como áudio e imagens.

Na penúltima seção deste capítulo, por fim, apresentou-se uma discussão de como um sistema de sumarização pode ser desenvolvido com base na arquitetura proposta. Tal estudo será usado em trabalhos futuros para desenvolver uma ferramenta capaz de criar versões resumidas do conteúdo a partir das preferências de cada indivíduo. Pretende-se realizar uma avaliação no sistema, apontando suas vantagens e desvantagens, assim como foi feito nas aplicações desenvolvidas. 


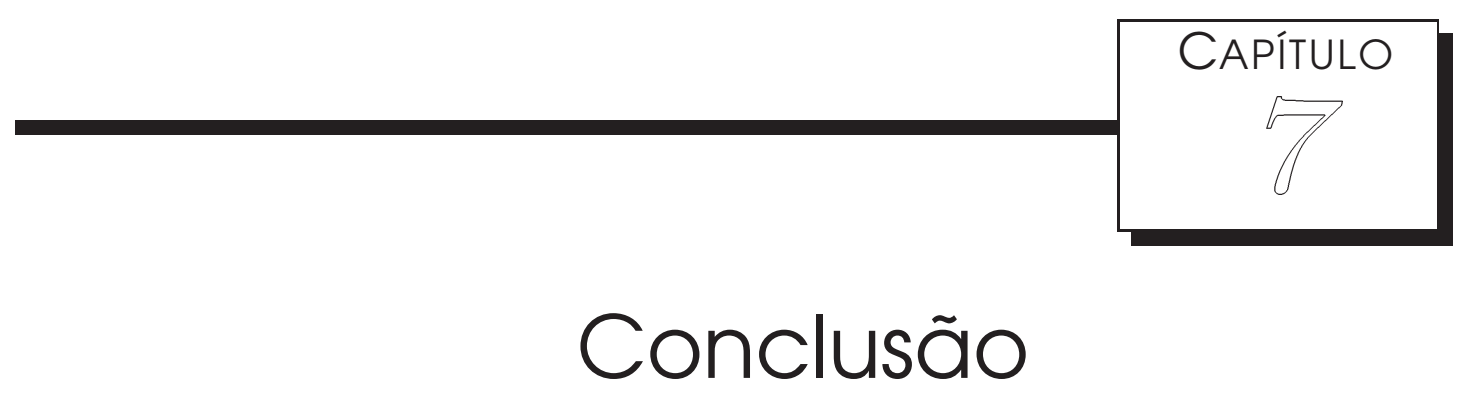

$\mathrm{E}$ ste trabalho apresentou uma arquitetura de personalização de conteúdo que utiliza as informações provenientes da interação entre usuário e conteúdo para fornecer o suporte necessário aos serviços relacionados. As anotações e novos dados inseridos pelo usuário são considerados na arquitetura, gerando metadados sobre o conteúdo e sobre suas preferências pessoais. Como resultado, obtém-se um processo de personalização mais preciso e eficaz do que abordagens tradicionais reportadas na literatura, conforme apresentado nas avaliações descritas no Capítulo 6, Subseções 6.1.5 e 6.2.5.

A partir da arquitetura proposta, duas aplicações foram desenvolvidas, as quais estão relacionadas aos serviços de seleção de conteúdo e recomendação multimídia. A seleção considera múltiplos critérios criados pelo usuário no momento da interação para busca baseada em conteúdo, sendo que os itens retornados apresentam forte relação semântica com os dados de busca definidos. A recomendação, por sua vez, explora o perfil do usuário construído a partir de suas atividades realizadas no passado, incluindo as etiquetas, faces reconhecidas, avaliações e notas que foram associadas em itens visitados anteriormente. Além disso, o perfil passa por um procedimento de complementação, onde folksonomias de termos e faces são utilizadas para enriquecê-lo com informações semânticas. Essas folksonomias são construídas dinamicamente pela comunidade de usuários e não apresentam a limitação de restrição de domínio de dados, assim como é encontrado em estruturas baseadas em conhecimento existentes atualmente, como ontologias. Em consequência, o documento XML que contém informações sobre as preferências do indivíduo é representado de modo a conter informações em diferentes modalidades, resultando 
em uma descrição com alta carga semântica sobre seus interesses.

As próximas seções deste capítulo estão estruturadas da seguinte maneira. A Seção 7.1 descreve as contribuições deste trabalho; na Seção 7.2 as limitações do mesmo são discutidas; a Seção 7.3 apresenta os trabalhos decorrentes desta pesquisa; e por fim, na Seção 7.4 algumas sugestões para trabalhos futuros são listadas.

\subsection{Contribuições}

A principal contribuição deste trabalho é a arquitetura de personalização, que considera uma variedade de possibilidades de interação com o conteúdo para prover informações semânticas que atuam como subsídios aos serviços agregados. Tal arquitetura apresenta as seguintes características, que não são exploradas pelos trabalhos relacionados:

- redução dos esforços para descrição multimídia, pois parte dessa atividade é delegada aos usuários, que por meio de um processo colaborativo, contribuem com a geração de metadados semânticos sobre o conteúdo;

- independência de domínio do conteúdo, ou seja, possibilidade de se utilizar a arquitetura de personalização em conteúdos diversos, como programas esportivos, filmes, noticiários, entre outros, desde que ocorram as atividades de enriquecimento e criação de anotações pelos usuários;

- representação mais precisa das preferências do usuário, que considera dados multimodais e conceitos relacionados semanticamente durante a construção do perfil do indivíduo;

- recuperação de cenas com maior similaridade semântica por meio da utilização de informações multimodais durante a construção dos dados de busca para seleção de conteúdo. A partir de múltiplos critérios que são definidos pelo usuário, os dados multimodais são comparados com descrições sobre os vídeos existentes na base de dados, sendo que esses metadados são criados por profissionais e técnicas automáticas no provedor de conteúdo, e enriquecidos pelos usuários durante a interação.

Conforme discutido no Capítulo 4, uma das características das anotações de usuários é que elas podem ser realizadas de diferentes maneiras, não seguindo um vocabulário restrito, e permitindo que exista plena liberdade de expressão do autor. Portanto, uma contribuição adicional deste trabalho é o procedimento de extração de metadados multimodais, que é composto por técnicas específicas que exploram os 
diferentes tipos de anotações para criar informações úteis que podem ser agregadas às descrições hierárquicas. Essas técnicas referem-se a métodos de reconhecimento de símbolos, extração de regiões de interesse, detecção e reconhecimento de faces, conversão de fala em texto, entre outras. Os dados produzidos por essas técnicas são utilizados para complementar o conjunto de descrições hierárquicas, provendo informações semânticas sobre o conteúdo, e reduzindo os problemas relacionados à indexação multimídia automática e manual. Como contribuição adicional, este trabalho estendeu o modelo MediaObject [Goularte et al., 2006] para representação de metadados, o que permite estruturá-los em diferentes modalidades para serem acessados pelos módulos da arquitetura de personalização [Manzato et al., 2009a].

Em relação às aplicações desenvolvidas, uma outra contribuição deste trabalho é o procedimento de agregação de múltiplos rankings provenientes das técnicas de seleção de conteúdo [Manzato et al., 2011]. Essa combinação considera algumas informações contextuais das cenas disponíveis, como presença de dados textuais e faces detectadas, além do nível de complexidade dos quadros para serem usados como imagens de busca. O algoritmo de combinação foi analisado em três experimentos distintos, e os resultados obtidos mostram um melhor desempenho quando comparado às abordagens isoladas.

No serviço de recomendação de filmes, a principal contribuição refere-se aos procedimentos de enriquecimento de perfil e descrição hierárquica, que utilizam anotações de usuários para fomentar a extração de informações semânticas sobre as preferências pessoais e sobre o conteúdo [Manzato \& Goularte, 2010; 2009]. No primeiro caso, utiliza-se um procedimento de co-ocorrência de etiquetas e faces, a fim de relacionar semanticamente as anotações individualizadas produzidas pelo usuário com termos existentes em folksonomias. O conjunto de termos interligados é adicionado ao perfil do usuário, resultando em uma descrição semântica mais rica e detalhada dos conceitos de interesse. No segundo caso, são acopladas às descrições hierárquicas existentes as faces reconhecidas pelos usuários, além de metadados criados e disponibilizados colaborativamente em serviços situados na Web 2.0, como a base de dados IMDB. Como resultado do processo de enriquecimento, propõe-se um novo algoritmo de recomendação multimídia baseado em anotações, que quando comparado aos métodos existentes (i.e., filtragem baseada em conteúdo, colaborativa e híbrida), apresenta melhor desempenho conforme mostrado na avaliação com usuários reais.

De fato, os resultados mostrados no Capítulo 6 indicam que a arquitetura proposta é capaz de reduzir problemas conhecidos da área de personalização e adaptação de conteúdo. Em particular, os problemas da sobre-especialização e do novo usuário são sobrepostos devido ao procedimento de enriquecimento de perfil. No primeiro caso, termos mais ricos semanticamente são adicionados à lista 
de preferências, possibilitando a recuperação de itens multimídia variados, porém relacionados significativamente. No segundo caso, usuários que não adotam uma postura ativa de anotação também são beneficiados pela complementação de perfil, já que diferentes termos são envolvidos em sua lista a partir de poucas anotações adicionadas anteriormente. De modo geral, a estratégia de considerar anotações de enriquecimento traz vantagens ao sistema, uma vez que tal atividade interativa agrega alta carga semântica relacionada aos interesses do usuário.

A multimodalidade também contribui para reduzir alguns dos problemas existentes em P\&A. A análise limitada de conteúdo, em especial, é reduzida com a arquitetura proposta já que utilizam-se diferentes informações para extrair os metadados. Assim, os problemas de uma técnica específica são compensados por outras, as quais exploram outros tipos de mídia relacionados ao conteúdo. Adicionalmente, anotações colaborativas também ajudam a sobrepor tal problema, fazendo com que a indexação multimídia seja realizada, neste trabalho, de modo irrestrito ao domínio de dados e sem despender grandes esforços para anotação de conteúdo.

\subsection{Limitações}

Uma limitação do trabalho realizado é que as anotações dos usuários podem conter ruídos ou informações não relacionadas que podem interferir no processo de geração de metadados e preferências. No caso da etiquetação, por exemplo, muitos termos não apresentam qualquer informação agregada, sendo impossivel inferir conceitos a partir dessas etiquetas específicas. Para resolver esse problema, seria necessário desenvolver um módulo de avaliação de anotações, com o objetivo de filtrar aqueles termos esporádicos que podem influenciar o funcionamento do sistema.

Apesar de o problema do novo usuário poder ser reduzido com o procedimento de complementação de perfil, conforme mostrado no Capítulo 6, Subseção 6.2.5, itens adicionados recentemente ao sistema necessitam de um tempo mínimo para que sejam acessados e anotados pelos usuários. Desse modo, novo conteúdo irá conter poucas informações semânticas agregadas até que vários usuários tenham dedicado esforços colaborativos para anotar e/ou enriquecer aqueles dados.

Outra limitação existente é que o processo de segmentação temporal de cenas durante a descrição hierárquica é realizado manualmente neste trabalho. Uma vez que o conceito de cenas depende do domínio de dados considerado, é difícil prover uma técnica automática que realize uma agregação de unidades fundamentais relacionadas semanticamente, de modo a se obter os limiares de cada cena.

Por fim, alguns dos algoritmos propostos apresentam a limitação de utilizarem parâmetros constantes para tomada de decisão. Como exemplo, o processo de agregação de rankings, descrito no Capítulo 6, Subseção 6.1.4, Equação 6.6 utiliza o parâmetro 
$T$ como limiar para decidir entre utilizar ou não o ranking baseado em imagens. Uma vez que as características do conteúdo podem variar, seria necessário desenvolver um método que não fosse dependente de constantes pré-definidas, ou alternativamente, implementar um mecanismo de definição automática dos parâmetros a partir de análises do conteúdo.

\subsection{Trabalhos Decorrentes desta Pesquisa}

Dois direcionamentos de pesquisa foram decorrentes das investigações realizadas neste trabalho. Um deles, em nível de iniciação científica, tem como objetivo estudar uma heurística de extração de quadros-chave com o objetivo de otimizar o tempo de processamento gasto pela técnica de detecção de faces. Ao término desse estudo, a heurística desenvolvida deverá ser acoplada ao procedimento de descrição hierárquica da arquitetura de personalização.

O outro trabalho, em nível de mestrado, tem como objetivo propor um sistema de segmentação de cenas multimodal para telejornais. O sistema deverá utilizar características visuais, auditivas e textuais para criar relacionamentos semânticos entre as tomadas, objetivando a formação de cenas. Do mesmo modo, ao término desse estudo, a técnica desenvolvida deverá ser acoplada ao procedimento de descrição hierárquica da arquitetura, possibilitando, na descrição de telejornais, que a segmentação de cenas seja feita automaticamente.

\subsection{Trabalhos Futuros}

Esta seção apresenta algumas sugestões de trabalhos futuros que variam desde simples implementações até tópicos de pesquisa com potencial para mestrado e doutorado. Trabalhos com pequeno grau de dificuldade são:

- integrar os módulos da arquitetura a fim de automatizar todo o processo de personalização;

- estender a arquitetura para que outras aplicações de anotação possam ser utilizadas na autoria, enriquecimento e compartilhamento de anotações;

- gerar representações de metadados e de perfil usando especificações padronizadas, como TV-Anytime e MPEG-7, a fim de possibilitar o compartilhamento dessas informações entre diferentes sistemas.

Trabalhos mais elaborados, que exigem esforços investigatórios, são: 
- desenvolver um mecanismo de avaliação de anotações. Tal procedimento poderia ser utilizado para filtrar as informações irrelevantes geradas pelos usuários que seriam integradas nas descrições hierárquicas;

- desenvolver um processo de classificação de anotações para inferir indicações positivas ou negativas das preferências do usuário a partir de comentários, etiquetas e outros dados criados por ele. Tal processo viabilizaria a criação do perfil de interesses contendo tópicos relevantes e irrelevantes sem necessitar das notas de avaliação providas diretamente pelo usuário;

- avaliar a interface de interação com usuários reais, verificando quais tipos de anotações são de fato utilizados;

- avaliar a atividade de interação com usuário reais, com o objetivo de se mapear em quais situações, motivos e cenários os indivíduos realmente realizam anotações;

- desenvolver o sistema de sumarização de conteúdo utilizando a arquitetura de personalização;

- integrar as anotações produzidas pelos usuários com objetos de mídia intraquadro. Tal procedimento requer a utilização de técnicas de segmentação de objetos, assim como padrões de codificação baseada em objetos, como o MPEG-4;

- explorar outros tipos de anotações para criar metadados relacionados ao conteúdo. Em particular, investigar como regiões de interesse, juntamente com outras anotações, como comentários e etiquetas, podem ser usadas para auxiliar um processo de segmentação espacial e posterior identificação de objetos;

- desenvolver uma técnica de segmentação temporal de cenas independente de domínio de dados, que considera as informações semânticas produzidas pelas anotações dos usuários;

- desenvolver novos critérios de seleção de conteúdo baseados em anotações produzidas pelo usuário. 


\section{Referências Bibliográficas}

Abate, A. F., Nappi, M., Riccio, D., e Sabatino, G. (2007). 2D and 3D Face Recognition: A Survey. Pattern Recognition Letters, 28(14):1885-1906.

Abney, S. (1996). Part-of-Speech Tagging and Partial Parsing. In Corpus-Based Methods in Language and Speech, pp. 118-136. Kluwer Academic Publishers.

Abowd, G. D., Gauger, M., e Lachenmann, A. (2003). The Family Video Archive: An Annotation and Browsing Environment for Home Movies. In Proceedings of the 5th. ACM SIGMM International Workshop on Multimedia Information Retrieval, pp. 1-8, Berkeley, California. ACM Press.

Abowd, G. D. e Mynatt, E. D. (2000). Charting Past, Present, and Future Research in Ubiquitous Computing. ACM Transactions on Computer-Human Interaction, $7(1): 29-58$.

Adomavicius, G. e Tuzhilin, A. (2005). Toward the Next Generation of Recommender Systems: A Survey of the State-of-the-Art and Possible Extensions. IEEE Transactions on Knowledge and Data Engineering, 17(6):734-749.

Ahmad, I., Wei, X., Sun, Y., e Zhang, Y. Q. (2005). Video Transcoding. IEEE Transactions on Multimedia, 7(5):793-804.

Aleem, T. A. (1998). A Taxonomy of Multimedia Interactivity. PhD thesis, The Union Institute, USA.

Anderson, M. P. e Woessner, W. W. (1992). Applied Groundwater Modeling: Simulation of Flow and Advective Transport. Academic Press, 2nd. edition ed.

Ansari, A., Essegaier, S., e Kohli, R. (2000). Internet Recommendations Systems. Journal of Marketing Research, 37(3):363-375. 
Babaguchi, N., Kawai, Y., e Kitahashi, T. (2002). Event Based Indexing of Broadcasted Sports Video by Intermodal Collaboration. IEEE Transactions on Multimedia, 4(1):68-75.

Baeza-Yates, R. A. e Ribeiro-Neto, B. (1999). Modern Information Retrieval. Addison-Wesley, New York, USA.

Balabanovic, M. e Shoham, Y. (1997). Fab: Content-Based, Collaborative Recommendation. Commications of ACM, 40(3):66-72.

Barrett, R., Maglio, P. P., e Kellem, D. C. (1997). How to Personalize the Web. In Proceedings of the SIGCHI Conference on Human Factors in Computing Systems, pp. 75-82, Atlanta, Georgia. ACM Press.

Barrios, V. M. G., Mödritscher, F., e Gütl, C. (2005). Personalization versus Adaptation? A User-centred Model Approach and its Application. In Proceedings of the 5th International Conference on Knowledge Management, pp. 120-127, Graz, Australia.

Bell, R. M. e Koren, Y. (2007). Lessons from the Netflix Prize Challenge. ACM SIGKDD Explorations Newsletter, 9(2):75-79.

Bertini, M., Cucchuara, R., Bimbo, A. D., e Prati, A. (2006). Semantic Adaptation of Sport Videos With User-Centred Performance Analysis. IEEE Transactions on Multimedia, 8(3):433-443.

Bertini, M., Del Bimbo, A., e Pala, P. (2001). Content-based Indexing and Retrieval of TV News. Pattern Recognition Letters, 22(5):503-516.

Bi, S., Shao, B., Liang, D., e Shen, X. (2008). Human Body Segmentation based on Adaptive Feature Selection in Complex Situations. v. 6813, San Jose, CA, USA. SPIE.

Bieber, G. e Giersich, M. (2001). Personal Mobile Navigation Systems - Design Considerations and Experiences. Computers \& Graphics, 25(4):563-570.

Bikel, D. M., Schwartz, R., e Weischedel, R. M. (1999). An Algorithm that Learns What's in a Name. Machine Learning, 34(1-3):211-231.

Billsus, D. e Pazzani, M. J. (1998). Learning Collaborative Information Filters. In Proceedings of the Fifteenth International Conference on Machine Learning, pp. 46-54, San Francisco, CA, USA. Morgan Kaufmann Publishers Inc.

Billsus, D. e Pazzani, M. J. (2000). User Modeling for Adaptive News Access. User Modeling and User-Adapted Interaction, 10(2-3):147-180. 
Bloedorn, E., Mani, I., e Macmillan, T. R. (1996). Machine Learning of User Profiles: Representational Issues. In Proceedings of the Thirteenth National Conference on Artificial Intelligence, pp. 433-438, Portland, Oregon. AAAI/MIT Press.

Boggs, J. M. e Petrie, D. W. (2000). The Art of Watching Films. Mayfield, Mountain View, CA, 5th. ed.

Boll, S., Krosche, J., e Scherp, A. (2004). Personalized Mobile Multimedia meets Location-Based Services.

Breese, J. S., Heckerman, D., e Kadie, C. (1998). Empirical Analysis of Predictive Algorithms for Collaborative Filtering. In Proceedings of the 14th. Conference on Uncertainty in Artificial Intelligence, pp. 43-52, Madison, Wisconsin, USA.

Brettel, H. e Vienot, F. (2001). Color Display for Color-Blind Users. In Eschbach, R. e Marcu, G. G., editores, Color Imaging: Device-Independent Color, Color Hardcopy, and Applications, v. 4663 of SPIE, pp. 199-207.

Brezeale, D. (2006). Using Closed Captions and Visual Features to Classify Movies by Genre. In Poster session of the Seventh International Workshop on Multimedia Data Mining, pp. 1-5, Philadelphia, PA, USA.

Brezeale, D. e Cook, D. J. (2007). Automatic Video Classification: A Survey of the Literature. IEEE Transactions on Systems, Man, and Cybernetics, 38(3):416-430.

Brin, S. e Page, L. (1998). The Anatomy of a Large-Scale Hypertextual Web Search Engine. Computer Networks and ISDN Systems, 30(1-7):107-117.

Brunelli, R., Mich, O., e Modena, C. M. (1999). A Survey on the Automatic Indexing of Video Data. Journal of Visual Communication and Image Representation, 10(2):78-112.

Bulterman, D. C. A. (2003). Using SMIL to Encode Interactive, Peer-Level Multimedia Annotations. In Proceedings of the 2003 ACM Symposium on Document Engineering, pp. 32-41, Grenoble, France. ACM Press.

Bulterman, D. C. A. (2004). Animating Peer-Level Annotations Within Web-Based Multimedia. In 7th Eurographics Workshop on Multimedia, pp. 49-57, Nanjing, China.

Burke, R. (2000). Knowledge-Based Recommender Systems, v. 69. Marcel Dekker. Supplement 32.

Cattelan, R. G., Teixeira, C., Goularte, R., e Pimentel, M. D. G. C. (2008). Watch-and-Comment as a Paradigm Toward Ubiquitous Interactive Video Editing. 
ACM Transactions on Multimedia Computing, Communications and Applications, $4(4): 1-24$.

Cattuto, C., Benz, D., Hotho, A., e Stumme, G. (2008). Semantic Grounding of Tag Relatedness in Social Bookmarking Systems. In Sheth, A. P., Staab, S., Dean, M., Paolucci, M., Maynard, D., Finin, T. W., e Thirunarayan, K., editores, The Semantic Web - ISWC 2008, v. 5318 of Lecture Notes in Computer Science, pp. 615-631, Berlin/Heidelberg. Springer.

Cavallaro, A., Steiger, O., e Ebrahimi, T. (2005). Semantic Video Analysis for Adaptive Content Delivery and Automatic Description. IEEE Transactions on Circuits and Systems for Video Technology, 15(10):1200-1209.

Cernekova, Z., Pitas, I., e Nikou, C. (2006). Information Theory-Based Shot Cut/Fade Detection and Video Summarization. IEEE Transactions on Circuits and Systems for Video Technology, 16(1):82-91.

Cesar, P., Bulterman, D. C., e Jansen, A. J. (2008). Usages of the Secondary Screen in an Interactive Television Environment: Control, Enrich, Share, and Transfer Television Content. In Proceedings of the 6th. European Conference on Changing Television Environments, pp. 168-177, Salzburg, Austria. Springer-Verlag.

Cesar, P., Bulterman, D. C. A., e Jansen, A. J. (2006). An Architecture for End-User TV Content Enrichment. Journal of Virtual Reality and Broadcasting, 3(9).

Cesar, P., Bulterman, D. C. A., Jansen, J., Geerts, D., Knoche, H., e Seager, W. (2009). Fragment, Tag, Enrich, and Send: Enhancing Social Sharing of Video. ACM Transactions on Multimedia Computing, Communications, and Applications, 5(3): $1-27$.

Cesario, E., Folino, F., Locane, A., Manco, G., e Ortale, R. (2008). Boosting Text Segmentation via Progressive Classification. Knowledge and Information Systems, 15(3):285-320.

Chang, S. F., Chen, W., e Sundaram, H. (1998). Semantic Visual Templates: Linking Visual Features to Semantic. International Conference on Image Processing, Workshop on Content Based Video Search and Retrieval, 3(1):531-534.

Chen, C. C., Chen, M. C., e Sun, Y. (2001). PVA: A Self-Adaptive Personal View Agent System. In Proceedings of the Seventh ACM SIGKDD International Conference on Knowledge Discovery and Data Mining, pp. 257-262, San Francisco, California. ACM Press. 
Chen, D., Odobez, J. M., e Bourlard, H. (2004). Text Detection and Recognition in Images and Video Frames. Pattern Recognition, 37(3):595-608.

Chen, L. e Sycara, K. (1998). WebMate: A Personal Agent for Browsing and Searching. In Proceedings of the Second International Conference on Autonomous Agents, pp. 132-139, Minneapolis, Minnesota, USA. ACM Press.

Cheng, C. C. e Hsu, C. T. (2006). Fusion of Audio and Motion Information on HMM-based Highlight Extraction for Baseball Games. IEEE Transactions on Multimedia, 8(3):585-599.

Cheverst, K., Mitchell, N., Friday, A., e Efstratiou, C. (2000). Developing a Context-Aware Electronic Tourist Guide: Some Issues and Experiences. In Proceedings of the CHI 2000 Conference, pp. 17-24, The Hague, The Netherlands. ACM Press.

Christel, M. G., Olligschlaeger, A. M., e Huang, C. (2000). Interactive Maps for a Digital Video Library. IEEE Multimedia, 7(1):60-67.

Chávez, E., Ide, R., e Kirste, T. (1999). Interactive Applications of Personal Situation-Aware Assistants. Computers \& Graphics, 23(6):903-915.

Claypool, M., Gokhale, A., Miranda, T., Murnikov, P., Netes, D., e Sartin, M. (1999). Combining Content-Based and Collaborative Filters in an Online Newspaper. In Proceedings of the ACM SIGIR'99 Workshop Recommender Systems: Algorithms and Evaluation, Berkeley, California, USA.

Condliff, M. K., Lewis, D. D., e Madigan, D. (1999). Bayesian Mixed-Effects Models for Recommender Systems. In Proceedings of ACM SIGIR '99 Workshop on Recommender Systems: Algorithms and Evaluation, Berkeley, California, USA.

Conklin, G. J., Greenbaum, G. S., Lillevold, K. O., Lippman, A. F., e Reznik, Y. A. (2001). Video Coding for Streaming Media Delivery on the Internet. IEEE Transactions on Circuits and Systems for Video Technology, 11(3):269-281.

Costa, R. M. R., Moreno, M. F., Rodrigues, R. F., e Soares, L. F. G. (2006). Live Editing of Hypermedia Documents. In Proceedings of the 2006 ACM Symposium on Document Engineering, pp. 165-172, Amsterdam, The Netherlands. ACM Press.

Cour, T., Jordan, C., Miltsakaki, E., e Taskar, B. (2008). Movie/Script: Alignment and Parsing of Video and Text Transcription. In Proceedings of the 10th European Conference on Computer Vision, pp. 158-171, Marseille, France. Springer-Verlag.

Cucchiara, R., Grana, C., e Prati, A. (2003). Semantic Video Transcoding using Classes of Relevance. International Journal in Image Graphics, 3(1):145-169. 
Daoud, M., Tamine, L., e Boughanem, M. (2010). A Personalized Graph-Based Document Ranking Model Using a Semantic User Profile. In Bra, P. D., Kobsa, A., e Chin, D., editores, User Modeling, Adaptation, and Personalization, v. 6075 of Lecture Notes in Computer Science, pp. 171-182.

Das, R. e Geetha, M. K. (2010). Video Classification Using Spatio Temporal Features. Assam University Journal of Science and Technology, 5(2):182-185.

de Wachter, M., Matton, M., Demuynck, K., Wambacq, P., Cools, R., e Compernolle, D. V. (2007). Template-Based Continuous Speech Recognition. IEEE Transactions on Audio, Speech and Language Processing, 15(4):1377-1390.

Dimitrova, N., Agnihotri, L., e Wei, G. (2000). Video Classification Based On HMM Using Text And Faces. In Proceedings of the European Signal Processing Conference, Tampere, Finland.

Dogan, S., Eminsoy, S., Sadka, A. H., e Kondoz, A. M. (2004). Video Content Adaptation Using Transcoding for Enabling UMA over UMTS. 5th International Workshop on Image Analysis for Multimedia Interactive Services.

Dumais, S., Cutrell, E., Cadiz, J., Jancke, G., Sarin, R., e Robbins, D. C. (2003). Stuff I've Seen: A System for Personal Information Retrieval and Re-use. In Proceedings of the 26th Annual International ACM SIGIR Conference on Research and Development in Informaion Retrieval, pp. 72-79, Toronto, Canada. ACM Press.

Eickeler, S. e Muller, S. (1999). Content-based Video Indexing of TV Broadcast News using Hidden Markov Models. In Proceedings of the Acoustics, Speech, and Signal Processing, pp. 2997-3000, Washington, DC, USA. IEEE Computer Society.

Fano, A. E. (1998). Shopper's Eye: Using Location-based Diltering for a Shopping Agent in the Physical World. In Autonomous Agents '98, Minneapolis, USA.

Fendri, E., Ben-Abdallah, H., e Hamadou, A. B. (2010). A Novel Approach for Soccer Video Summarization. International Conference on Multimedia and Information Technology, 2:138-141.

Fortune, S. (1995). Voronoi Diagrams and Delaunay Triangulation. World Scientific, London.

Gales, M. e Young, S. (2008). The Application of Hidden Markov Models in Speech Recognition. Foundations and Trends in Signal Processing, 1(3):195-304.

Gauch, S., Speretta, M., Chandramouli, A., e Micarelli, A. (2007). User Profiles for Personalized Information Access. In Brusilovsky, P., Kobsa, A., e Nejdl, W., editores, The Adaptive Web, v. 4321 of Lecture Notes in Computer Science, pp. 54-89. 
Gemmis, M. D., Lops, P., Semeraro, G., e Basile, P. (2008). Integrating Tags in a Semantic Content-based Recommender. In Proceedings of the 2008 ACM Conference on Recommender Systems, pp. 163-170, Lausanne, Switzerland.

Gentili, G., Micarelli, A., e Sciarrone, F. (2003). Infoweb: An Adaptive Information Filtering System for the Cultural Heritage Domain. Applied Artificial Intelligence, 17(8-9):715-744.

Ghosal, A., Chakraborty, R., Chakraborty, R., Haty, S., Dhara, B. C., e Saha, S. K. (2009). Speech/Music Classification Using Occurrence Pattern of ZCR and STE. In Third International Symposium on Intelligent Information Technology Application, v. 3, pp. 435-438, Nanchang, China. IEEE Computer Society.

Goldberg, D. E. (1989). Genetic Algorithms in Search, Optimization, and Machine Learning. Addison-Wesley.

Goldberg, K., Roeder, T., Gupta, D., e Perkins, C. (2001). Eigentaste: A Constant Time Collaborative Filtering Algorithm. Information Retrieval, 4(2):133-151.

Golder, S. A. e Huberman, B. A. (2005). The Structure of Collaborative Tagging Systems. The Computing Research Repository (CoRR), abs/cs/0508082.

Goularte, R., Camacho-Guerrero, J. A., Inacio Jr., V. R., Cattelan, R. G., e Pimentel, M. d. G. C. (2004). M4Note: A Multimodal Tool for Multimedia Annotations. In Proceedings of the WebMedia \& LA-Web 2004 Joint Conference 10th Brazilian Symposium on Multimedia and the Web 2nd Latin American Web Congress, pp. 142-149, Ribeirão Preto, SP, Brazil. IEEE Computer Society.

Goularte, R., Cattelan, R. G., Camacho-Guerrero, J. A., Inácio, Jr., V. R., e da Graça C. Pimentel, M. (2004). Interactive multimedia annotations: enriching and extending content. In Proceedings of the 2004 ACM Symposium on Document Engineering, pp. 84-86, Milwaukee, Wisconsin, USA. ACM Press.

Goularte, R., Pimentel, M., e Moreira, E. (2006). Context-Aware Support in Structured Documents for Interactive-TV. Multimedia Systems, 11(4):367-382.

Gould, S., Gao, T., e Koller, D. (2009). Region-based Segmentation and Object Detection. In 23rd. Annual Conference on Neural Information Processing Systems, pp. 1-9, Vancouver, B.C., Canada.

Governor, J., Hinchcliffe, D., e Nickull, D. (2009). Web 2.0 Architectures. O'Reilly Media/Adobe Dev Library.

Guarino, N., Masolo, C., e Vetere, G. (1999). OntoSeek: Content-based Access to the Web. IEEE Intelligent Systems and Their Applications, 14(3):70-80. 
Guha, R., McCool, R., e Miller, E. (2003). Semantic Search. In Proceedings of the 12th international conference on World Wide Web, pp. 700-709, Budapest, Hungary. ACM Press.

Gupta, L., Pathangay, V., Patra, A., Dyana, A., e Das, S. (2007). Indoor versus Outdoor Scene Classification using Probabilistic Neural Network. EURASIP Journal on Applied Signal Processing, 2007(1):123-123.

Haering, N., Qian, R. J., Sezan, M. I., e Member, S. (2000). A Semantic Event-Detection Approach and Its Application to Detecting Hunts in Wildlife Video. IEEE Transactions on Circuits and Systems for Video Technology, 10(1):857-868.

Halavati, R., Shourakia, S. B., e Zadeh, S. H. (2007). Recognition of Human Speech Phonemes Using a Novel Fuzzy Approach. Applied Soft Computing, 7(3):828-839.

Halsall, F. (2001). Multimedia Communications. Addison-Wesley, Pearson Education, England.

Hammond, T., Hannay, T., Lund, B., e Scott, J. (2005). Social Bookmarking Tools (I): A General Review. D-Lib Magazine, 11(4).

Hampapur, A., Weymouth, T. E., e Jain, R. (1995). Feature Based Digital Video Indexing. In Proceedings of the Third IFIP WG2.6 Working Conference on Visual Database Systems 3, pp. 115-141, London, UK. Chapman \& Hall, Ltd.

Hanjalic, A. (2002). Shot-Boundary Detection: Unraveled and Resolved? IEEE Transactions on Circuits and Systems for Video Technology, 12(2):90-105.

Hauptmann, A. G. e Witbrock, M. J. (1998). Story Segmentation and Detection of Commercials in Broadcast News Video. In Proceedings of the Advances in Digital Libraries Conference, page 168, Washington, DC, USA. IEEE Computer Society.

Heigold, G., Zweig, G., Li, X., e Nguyen, P. (2009). A Flat Direct Model for Speech Recognition. pp. 3861-3864, Taipei, Taiwan. IEEE Computer Society.

Hill, W., Stead, L., Rosenstein, M., e Furnas, G. (1995). Recommending and Evaluating Choices in a Virtual Community of Use. In Proceedings of the SIGCHI Conference on Human Factors in Computing Systems, pp. 194-201, New York, NY, USA. ACM Press/Addison-Wesley.

Hoashi, K., Matsumoto, K., Inoue, N., e Hashimoto, K. (2000). Document Filtering Method using Non-Relevant Information Profile. In Proceedings of the 23rd Annual International ACM SIGIR Conference on Research and Development in Information Retrieval, pp. 176-183, Athens, Greece. ACM Press. 
Hofmann, T. (1999). Probabilistic Latent Semantic Analysis. In Proceedings of Uncertainty in Artificial Intelligence, Stockholm, Sweden.

Holland, J. H. (1979). Adaptation in Natural and Artificial Systems. MIT Press, Michigan.

Horn, U. e Girod, B. (1997). Scalable Video Transmission for the Internet. Computer Networks and ISDN Systems, 29(15):1833-1842.

Hotho, A., Jäschke, R., Schmitz, C., e Stumme, G. (2006). Information Retrieval in Folksonomies: Search and Ranking. In Sure, Y. e Domingue, J., editores, The Semantic Web: Research and Applications, v. 4011 of Lecture Notes in Computer Science, pp. 411-426.

Jain, A. K., Duin, R. P., e Mao, J. (2000). Statistical Pattern Recognition: A Review. IEEE Transactions on Pattern Analysis and Machine Intelligence, 22:4-37.

Jain, R. e Hampapur, A. (1994). Metadata in Video Databases. ACM Special Interest Group on Management of Data, 23(4):27-33.

Javed, O., Rasheed, Z., e Shah, M. (2001). A Framework for Segmentation of Talk \& Game Shows. v. 2, pp. 532 - 537, Vancouver, BC, Canada. IEEE Computer Society.

Joachims, T. (1998). Text Categorization with Support Vector Machines: Learning with Many Relevant Features. In Proceedings of ECML-98, 10th European Conference on Machine Learning, pp. 137-142, Chemnitz, Germany.

Joyce, R. A. e Bede, L. (2006). Temporal Segmentation of Video using Frame and Histogram Space. IEEE Transactions on Multimedia, 8(1):130-140.

Kelly, D. e Teevan, J. (2003). Implicit Feedback for Inferring User Preference: A Bibliography. ACM SIGIR Forum, 37(2):18-28.

Kim, H.-R. e Chan, P. K. (2008). Learning Implicit User Interest Hierarchy for Context in Personalization. Applied Intelligence, 28(2):153-166.

Kim, J. S., Kim, S. H., Yang, H. J., Son, H. J., e Kim, W. P. (2007). Text Extraction for Spam-Mail Image Filtering Using a Text Color Estimation Technique. In Okuno, H. G. e Ali, M., editores, New Trends in Applied Artificial Intelligence, v. 4570 of Lecture Notes in Computer Science, pp. 105-114.

Klasnja Milicevic, A., Nanopoulos, A., e Ivanovic, M. (2010). Social Tagging in Recommender Systems: A Survey of the State-of-the-Art and Possible Extensions. Artificial Intelligence Review, 33(3):187-209. 
Kohli, P., Rihan, J., Bray, M., e Torr, P. (2008). Simultaneous Segmentation and Pose Estimation of Humans Using Dynamic Graph Cuts. International Journal of Computer Vision, 79(3):285-298.

Konstan, J. A., Miller, B. N., Maltz, D., Herlocker, J. L., Gordon, L. R., e Riedl, J. (1997). GroupLens: Applying Collaborative Filtering to Usenet News. Communications of the ACM, 40(3):77-87.

Koprinska, I. e Carrato, S. (2001). Temporal Video Segmentation: A Survey. Signal Processing: Image Communication, 16(5):477-500.

Koren, Y., Bell, R., e Volinsky, C. (2009). Matrix Factorization Techniques for Recommender Systems. IEEE Computer, 42(8):30-37.

Kovacs, G., Kucsera, I., Abraham, G., e Wenzel, K. (2001). Enhancing Color Representation for Anomalous Trichromats on CRT Monitors. Color Research \& Application, 26(1):273-276.

Kuhmunch, C. (1997). On the Detection and Recognition of Television Commercials. In Proceedings of the 1997 International Conference on Multimedia Computing and Systems, page 509, Washington, DC, USA. IEEE Computer Society.

Kyperountas, M., Kotropoulos, C., e Pitas, I. (2007). Enhanced Eigen-Audioframes for Audiovisual Scene Change Detection. IEEE Transactions on Multimedia, 9(4):785-797.

La Cascia, M., Sethi, S., e Sclaroff, S. (1998). Combining Textual and Visual Cues for Content-based Image Retrieval on the World Wide Web. In Proceedings of the IEEE Workshop on Content-Based Access of Image and Video Libraries, Santa Barbara, CA, USA.

Labrou, Y. e Finin, T. (1999). Yahoo! as an Ontology: Using Yahoo! Categories to Describe Documents. In Proceedings of the eighth international conference on Information and knowledge management, pp. 180-187, Kansas City, Missouri, USA. ACM Press.

Lee, C.-H., Shih, J.-L., Yu, K.-M., e Lin, H.-S. (2009). Automatic Music Genre Classification based on Modulation Spectral Analysis of Spectral and Cepstral Features. IEEE Transactions on Multimedia, 11(4):670-682.

Lee, W., Kim, H., Kang, H., Lee, J., Kim, Y., e Jeon, S. (2005). Video Cataloging System for Real-Time Scene Change Detection of News Video. In Klette, R. e Zunic, J., editores, Combinatorial Image Analysis, Lecture Notes in Computer Science, pp. 705-715. 
Lei, Z. e Georganas, N. (2002). H.263 Video Transcoding for Spatial Resolution Downscaling. In Proceedings of the International Conference on Information Technology: Coding and Computing, pp. 425-430, Las Vegas, Nevada, USA.

Leibe, B., Leonardis, A., e Schiele, B. (2008). Robust Object Detection with Interleaved Categorization and Segmentation. International Journal of Computer Vision, 77(1-3):259-289.

Li, D., Sethi, I. K., Dimitrova, N., e McGee, T. (2001). Classification of General Audio Data for Content-based Retrieval. Pattern Recognition Letters, 22(5):533-544.

Li, W. (2001). Overview of Fine Granularity Scalability in MPEG-4 Video Standard. IEEE Transactions on Circuits Systems Video Technology, 11(3):301-317.

Liang, H., Xu, Y., Li, Y., e Nayak, R. (2008). Collaborative Filtering Recommender Systems Using Tag Information. In Proceedings of the 2008 IEEE/WIC/ACM International Conference on Web Intelligence and Intelligent Agent Technology, pp. 59-62, Sydney, NSW, Austrália. IEEE Computer Society.

Lienhart, R. e Wernicke, A. (2002). Localizing and Segmenting Text in Images and Videos. IEEE Transactions on Circuits and Systems for Video Technology, 12(4):256-268.

Lippman, A. (1999). Video Coding for Multiple Target Audiences. In Proceedings of the IS and T/SPIE Conference on Visual Communications and Image Processing, pp. 780-784, San Jose.

Liu, F., Yu, C., e Meng, W. (2002). Personalized Web Search by Mapping User Queries to Categories. In Proceedings of the Eleventh International Conference on Information and Knowledge Management, pp. 558-565, McLean, Virginia, USA. ACM Press.

Liu, Y., Shriberg, E., Stolcke, A., Hillard, D., Ostendorf, M., e Harper, M. (2006). Enriching Speech Recognition with Automatic Detection of Sentence Boundaries and Disfluencies. IEEE Transactions on Audio, Speech, and Language Processing, 14(5):1526-1540.

Liu, Y., Zhang, D., Lu, G., e Ma, W. Y. (2007). A Survey of Content-based Image Retrieval with High-level Semantics. Pattern Recognition, 40(1):262-282.

Livshin, A. e Rodet, X. (2009). Purging Musical Instrument Sample Databases Using Automatic Musical Instrument Recognition Methods. IEEE Transactions on Audio, Speech \& Language Processing, 17(5):1046-1051.

Lum, W. Y. e Lau, F. C. M. (2002). A Context-Aware Decision Engine for Context Adaptation. IEEE Pervasive Computing, 1(3):41-49. 
Magalhães, J. e Pereira, F. (2003). MPEG-7 Based Color Temperature Customization. In Proceedings of the ConfTele 2003, pp. 481-484, Aveiro, Portugal.

Magalhães, J. e Pereira, F. (2004). Using MPEG Standards for Multimedia Customization. Signal Processing: Image Communication, 19:437-456.

Manning, C. D. e Schütze, H. (1999). Foundations of Statistical Natural Language Processing. MIT Press, Cambridge, MA.

Manzato, M. G., Coimbra, D. B., e Goularte, R. (2009). Multimedia Content Personalization Based on Peer-level Annotation. In Proceedings of the 7th. European Conference on Interactive TV, pp. 57-66, Leuven, Belgium. ACM Press.

Manzato, M. G., Coimbra, D. B., e Goularte, R. (2011). An Enhanced Content Selection Mechanism for Personalization of Video News Programmes. Multimedia Systems Journal, 17(1):19-34.

Manzato, M. G. e Goularte, R. (2007). Shot Boundary Detection Based on Intelligent Systems. In Proceedings of the 13rd. Brazilian Symposium on Multimedia and the Web, pp. 190-197, Gramado-RS, Brazil. ACM Press.

Manzato, M. G. e Goularte, R. (2008). Video News Classification for Automatic Content Personalization: A Genetic Algorithm Based Approach. In Proceedings of 14th. Brazilian Symposium on Multimedia and the Web, pp. 36-43, Vila Velha-ES, Brazil. ACM Press.

Manzato, M. G. e Goularte, R. (2009). Supporting Multimedia Recommender Systems with Peer-level Annotations. In Proceedings of the 15th. Brazilian Symposium on Multimedia and the Web, pp. 202-209, Fortaleza, CE, Brazil.

Manzato, M. G. e Goularte, R. (2010). Peersommender: A Peer-Level Annotation-Based Approach for Multimedia Recommendation. Journal of Information and Data Management, 1(2):277-292.

Manzato, M. G., Macedo, A. A., e Goularte, R. (2009). Evaluation of Video News Classification Techniques for Automatic Content Personalization. International Journal of Advanced Media and Communication, 3(4):383-403.

Marais, H. e Bharat, K. (1997). Supporting Cooperative and Personal Surfing with a Desktop Assistant. In Proceedings of the 10th annual ACM symposium on User interface software and technology, pp. 129-138, Banff, Alberta, Canada. ACM Press.

Marlow, C., Naaman, M., Boyd, D., e Davis, M. (2006). Ht06, tagging paper, taxonomy, flickr, academic article, to read. In Proceedings of the 17th. Conference on Hypertext and Hypermedia, pp. 31-40, Odense, Denmark. ACM Press. 
Masthoff, J. (2004). Group Modeling: Selecting a Sequence of Television Items to Suit a Group of Viewers. User Modeling and User-Adapted Interaction, 14:37-85.

Micarelli, A. e Sciarrone, F. (2004). Anatomy and Empirical Evaluation of an Adaptive Web-Based Information Filtering System. User Modeling and User-Adapted Interaction, 14(2-3):159-200.

Mika, P. (2007). Ontologies Are Us: A Unified Model of Social Networks and Semantics. Web Semantics: Science, Services and Agents on the World Wide Web, 5(1):5-15.

Mohan, C. K. e Yegnanarayana, B. (2010). Classification of Sport Videos using Edge-based Features and Autoassociative Neural Network Models. Signal, Image and Video Processing, 4(1):61-73.

Moncrieff, S., Dorai, C., e Venkatesh, S. (2001). Detecting Indexical Signs in Film Audio for Scene Interpretation. In IEEE International Conference on Multimedia \& Expo, pp. 1192-1195, Tokyo, Japan.

Montagnuolo, M. e Messina, A. (2009). Parallel Neural Networks for Multimodal Video Genre Classification. Multimedia Tools and Applications, 41(1):125-159.

Mooney, R. J., Bennett, P. N., e Roy, L. (1998). Book Recommending Using Text Categorization with Extracted Information. In Proceedings of Recommender Systems Papers from 1998 Workshop, Technical Report, pp. 49-54.

Mori, S., Nishida, H., e Yamada, H. (1999). Optical Character Recognition. John Wiley \& Sons, Inc.

Mukhopadhyay, A., Chakraborty, S., Choudhury, M., Lahiri, A., Dey, S., e Basu, A. (2006). Shruti: an Embedded Text-to-Speech System for Indian languages. 153(2):75-79.

Mundur, P., Rao, Y., e Yesha, Y. (2006). Keyframe-Based Video Summarization using Delaunay Clustering. International Journal on Digital Libraries, 6(2):219-232.

Nam, J., Alghoniemy, M., e Tewfik, A. H. (1998). Audio-Visual Content-Based Violent Scene Characterization. In IEEE International Conference on Image Processing, pp. 353-357, Chicago, USA.

Nam, J., Ro, Y. M., Huh, Y., e Kim, M. (2005). Visual Content Adaptation According to User Perception Characteristics. IEEE Transactions on Multimedia, 7(3):435-445.

Nascimento, G., Manzato, M. G., e Goularte, R. (2010). Extração de Quadros-Chave Como Subsídio Para Personalização em Vídeos Digitais. In Proceedings of the 16th. 
Brazilian Symposium on Multimedia and the Web, pp. 105-107, Belo Horizonte-MG, Brazil. ACM Press.

Nguyen, H. T., Worring, M., e Boomgaard, R. V. D. (2003). Watersnakes: Energy-Driven Watershed Segmentation. IEEE Transactions on Pattern Analysis and Machine Intelligence, 25(3):330-342.

Oliveira, L. M. V. V. C. (1996). Sintese de Fala a Partir de Texto. PhD thesis, Universidade Técnica de Lisboa, Lisboa.

Otsuka, I., Radhakrishnan, R., Siracusa, M., Divakaran, A., e Mishima, H. (2006). An Enhanced Video Summarization System using Audio Features for a Personal Video Recorder. IEEE Transactions on Consumer Electronics, 52(1):168-172.

Papin, C. e Luo, J. (2007). Key Frame Extraction from Unstructured Consumer Video Clips. In Chen, C. W., Schonfeld, D., e Luo, J., editores, Proceedings of Visual Communications and Image Processing, v. 6508 of SPIE.

Patel, N. e Sethi, I. (1996). Audio Characterization for Video Indexing. In Sethi, I. K. e Jain, R. C., editores, Storage and Retrieval for Still Image and Video Databases, v. 2670 of SPIE, pp. 373-384.

Pavlov, D. Y. e Pennock, D. M. (2002). A Maximum Entropy Approach To Collaborative Filtering in Dynamic, Sparse, High-Dimensional Domains. In Proceedings of Neural Information Processing Systems, pp. 1441-1448, Vancouver, BC, Canada. MIT Press.

Pazzani, M. (1999). A Framework for Collaborative, Content-Based, and Demographic Filtering. Artificial Intelligence Review, 13(5-6):393-408.

Pazzani, M. e Billsus, D. (1997). Learning and Revising User Profiles: The Identification of Interesting Web Sites. Machine Learning, 27(3):313-331.

Pazzani, M., Muramatsu, J., e Billsus, D. (1998). Syskill \& Webert: Identifying Interesting Web Sites. In Proceedings of 13th National Conference on Artificial Intelligence, pp. 54-61.

Pentland, A., Moghaddam, B., e Starner, T. (1994). View-Based and Modular Eigenspaces for Face Recognition. In IEEE International Conference on Computer Vision \& Pattern Recognition, pp. 84-91, Seattle, WA, USA.

Peter N. Belhumeur, João P. Hespanha, D. J. K. (1997). Eigenfaces vs. Fisherfaces: Recognition Using Class Specific Linear Projection. IEEE Transactions on Pattern Analysis and Machine Intelligence, 19(7):711-720. 
Pfeiffer, S., Lienhart, R., e Efflsberg, W. (2001). Scene Determination Based on Video and Audio Features. Multimedia Tools and Applications, 15(1):59-81.

Pimentel, M. G., Goularte, R., Cattelan, R. G., Santos, F. S., e Teixeira, C. (2007). Enhancing Multimodal Annotations with Pen-Based Information. In Proceedings of the Ninth IEEE International Symposium on Multimedia Workshops, pp. 207-213, Washington, DC, USA. IEEE Computer Society.

Pitrelli, J. F., Bakis, R., Eide, E. M., Fernandez, R., Hamza, W., e Picheny, M. A. (2006). The IBM Expressive Text-to-Speech Synthesis System for American English. IEEE Transactions on Audio, Speech and Language Processing, 14(4):1099-1108.

Popescul, A., Popescul, R., Ungar, L. H., Pennock, D. M., e Lawrence, S. (2001). Probabilistic Models for Unified Collaborative and Content-Based Recommendation in Sparse-Data Environments. In Proceedings of the Seventeenth Conference on Uncertainty in Artificial Intelligence, pp. 437-444, Seattle, Washington, USA.

Pretschner, A. e Gauch, S. (1999). Ontology Based Personalized Search. In Proceedings of the 11th IEEE International Conference on Tools with Artificial Intelligence, page 391, Washington, DC, USA. IEEE Computer Society.

Price, M. N., Schilit, B. N., e Golovchinsky, G. (1998). Xlibris: the active reading machine. In CHI 98 Conference Summary on Human Factors in Computing Systems, pp. 22-23, Los Angeles, California, USA. ACM.

Quattoni, A. e Torralba, A. (2009). Recognizing Indoor Scenes. In IEEE Conference on Computer Vision and Pattern Recognition, Miami Beach, Florida, USA.

Quiroga, L. M. e Mostafa, J. (1999). Empirical Evaluation of Explicit versus Implicit Acquisition of User Profiles in Information Filtering Systems. In Proceedings of the Fourth ACM Conference on Digital libraries, pp. 238-239, Berkeley, California, USA. ACM Press.

Ramos, G. e Balakrishnan, R. (2003). Fluid Interaction Techniques for the Control and Annotation of Digital Video. In Proceedings of the 16th. Annual ACM Symposium on User Interface Software and Technology, pp. 105-114, Vancouver, Canada. ACM Press.

Rashid, A. M., Albert, I., Cosley, D., Lam, S. K., Mcnee, S. M., Konstan, J. A., e Riedl, J. (2002). Getting to Know You: Learning New User Preferences in Recommender Systems. In Proceedings of the 7th International Conference on Intelligent User Interfaces, pp. 127-134, San Francisco, California, USA. ACM Press. 
Resnick, P., Iacovou, N., Suchak, M., Bergstrom, P., e Riedl, J. (1994). GroupLens: An Open Architecture for Collaborative Filtering of Netnews. In Proceedings of the 1994 ACM Conference on Computer Supported Cooperative Work, pp. 175-186, Chapel Hill, North Carolina, USA.

Rigden, C. (1999). The Eye of the Beholder Designing for Color-Blind Users. British Telecommunications Engineering, 17(1):291-295.

Rui, Y., Gupta, A., e Acero, A. (2000). Automatically Extracting Highlights for TV Baseball Programs. In Proceedings of the Eighth ACM International Conference on Multimedia, pp. 105-115, Marina del Rey, California, USA. ACM Press.

Salton, G. (1989). Automatic Text Processing. Addison-Wesley, New York, USA.

Santos, C. A. S. e Neto, A. N. R. (2004). Uma abordagem para anotação em vídeos digitais com aplicações em telemedicina. In Proceedings of the 4th. Workshop on Medical Informatics, Brasilia, Brazil.

Santos, C. A. S., Neto, A. N. R., e Tavares, T. A. (2005). Using cannot framework to generate video-based applications. In Proceedings of the 3rd. Latin American Web Congress, pp. 191-194, Buenos Aires, Argentina. IEEE Computer Society.

Sappa, A. D. e Dornaika, F. (2006). An Edge-Based Approach to Motion Detection. In Alexandrov, V. N., van Albada, G. D., Sloot, P. M., e Dongarra, J., editores, Computational Science - ICCS 2006, v. 3991 of Lecture Notes in Computer Science, pp. 563-570.

Saraceno, C. e Leonardi, R. (1998). Identification of Story Units in Audio-Visual Sequences by Joint Audio and Video Processing. In 1998 International Conference on Image Processing, v. 1, pp. 363-367, Chicago, IL, USA. IEEE Computer Society.

Sarwar, B. M., Karypis, G., Konstan, J. A., e Riedl, J. T. (2000). Application of Dimensionality Reduction in Recommender System - A Case Study. In Proceedings of ACM SIGKDD Conference on Knowledge Discovery in Databases, Boston, MA, USA.

Satoh, S., Nakamura, Y., e Kanade, T. (1999). Name-It: Naming and Detecting Faces in News Videos. IEEE MultiMedia, 6:22-35.

Schein, A. I., Popescul, A., Ungar, L. H., e Pennock, D. M. (2002). Methods and Metrics for Cold-Start Recommendations. In Proceedings of the 25th Annual International ACM SIGIR Conference on Research and Development in Information Retrieval, pp. 253-260, Tampere, Finland. ACM Press. 
Sen, S., Vig, J., e Riedl, J. (2009). Tagommenders: Connecting Users to Items through Tags. In International World Wide Web Conference, Madrid, Spain. ACM Press, ACM Press.

Shardanand, U. e Maes, P. (1995). Social Information Filtering: Algorithms for Automating "Word of Mouth". In Proceedings of the ACM SIGCHI Conference on Human Factors in Computing Systems, pp. 210-217, New York, NY, USA. ACM Press/Addison-Wesley.

Shearer, K., Dorai, C., e Venkatesh, S. (2000). Incorporating Domain Knowledge with Video and Voice Data Analysis in News Broadcasts. In ACM International Conference on Knowledge Discovery and Data Mining, pp. 46-53, Boston, USA.

Sheth, B. e Maes, P. (1993). Evolving Agents for Personalized Information Filtering. In Proceedings of the 9th IEEE Conference on Artificial Intelligence for Applications, pp. 345-352, Orlando, Florida, USA.

Shevade, B. e Sundaram, H. (2003). Vidya: an experiential annotation system. In Proceedings of the 2003 ACM SIGMM Workshop on Experiential Telepresence, pp. 91-98, Berkeley, California. ACM.

Smeaton, A. F. (2007). Techniques Used and Open Challenges to the Analysis, Indexing and Retrieval of Digital Video. Information Systems, 32(4):545-559.

Smeulders, A. W. M., Worring, M., Santini, S., Gupta, A., e Jain, R. (2000). Content-Based Image Retrieval at the End of the Early Years. IEEE Transactions on Pattern Analysis and Machine Intelligence, 22(12):1349-1380.

Smith, J. R., Mohan, R., e Chung-Sheng, L. (1998). Transcoding Internet Content for Heterogeneous Client Devices. In Proceedings of the 1998 IEEE International Symposium on Circuits and Systems, Mounterey, USA.

Smith, V. C. e Pokorny, J. (1975). Spectral Sensitivity of the Fovea Cone Pigments Between 400 and 700 nm. Vision Research, 15(2):161-171.

Snoek, C. G. e Worring, M. (2005). Multimodal Video Indexing: A Review of the State-of-the-art. Multimedia Tools and Applications, 25(1):5-35.

Soboroff, I. e Nicholas, C. (1999). Combining Content and Collaboration in Text Filtering. In Proceedings of the IJCAI-99 Workshop on Machine Learning for Information Filtering, pp. 86-91, Stockholm, Sweden.

Solana-Cipres, C., Fernandez-Escribano, G., Rodriguez-Benitez, L., Moreno-Garcia, J., e Jimenez-Linares, L. (2009). Real-Time Moving Object Segmentation in H.264 
Compressed Domain based on Approximate Reasoning. International Journal of Approximate Reasoning, 51(1):99-114.

Specia, L. e Motta, E. (2007). Integrating Folksonomies with the Semantic Web. In Proceedings of the 4th European Conference on The Semantic Web, pp. 624-639, Innsbruck, Austria. Springer-Verlag.

Speretta, M. e Gauch, S. (2005). Personalized Search Based on User Search Histories. In Proceedings of the 2005 IEEE/WIC/ACM International Conference on Web Intelligence, pp. 622-628, Washington, DC, USA. IEEE Computer Society.

Stefani, A. e Strappavara, C. (1998). Personalizing Access to Web Sites: The SiteIF Project. In Proceedings of the 2nd. Workshop on Adaptive Hypertext and Hypermedia HYPER-TEXT'98, Pittsburgh, Pennsylvania, USA.

Szomszor, M., Cattuto, C., Alani, H., O’Hara, K., Baldassarri, A., Loreto, V., e Servedio, V. D. (2007). Folksonomies, the Semantic Web, and Movie Recommendation. In 4th. European Semantic Web Conference, Bridging the Gap between Semantic Web and Web 2.0, pp. 71-84, Innsbruck, Austria.

Teevan, J., Dumais, S. T., e Horvitz, E. (2005). Personalizing Search via Automated Analysis of Interests and Activities. In Proceedings of the 28th Annual International ACM SIGIR Conference on Research and Development in Information Retrieval, pp. 449-456, Salvador, Brazil. ACM Press.

Terveen, L., Hill, W., Amento, B., Mcdonald, D., e Creter, J. (1997). PHOAKS: A System for Sharing Recommendations. Communications of the ACM, 40(3):59-62.

Thang, T. C., Jung, Y. J., e Ro, Y. M. (2005). Modality Conversion for QoS Management in Universal Multimedia Access. IEE Proceedings on Vision, Image and Signal Processing, 152(3):374-384.

Toutanova, K. e Cherry, C. (2009). A Global Model for Joint Lemmatization and Part-of-Speech Prediction. In Proceedings of the Joint Conference of the 47th Annual Meeting of the ACL and the 4th International Joint Conference on Natural Language Processing of the AFNLP, pp. 486-494, Suntec, Singapore. Association for Computational Linguistics.

Trajkova, J. e Gauch, S. (2004). Improving Ontology-Based User Profiles. In Proceedings of RIAO 2004, pp. 380-389, Avignon, France.

Truong, B. T. e Venkatesh, S. (2001). Determining Dramatic Intensification via Flashing Lights in Movies. IEEE International Conference on Multimedia and Expo, page 16. 
Truong, B. T., Venkatesh, S., e Dorai, C. (2000). Automatic Genre Identification for Content-Based Video Categorization. In Proceedings of the International Conference on Pattern Recognition, page 4230, Washington, DC, USA. IEEE Computer Society.

Tsekeridou, S. e Pitas, I. (2001). Content-based Video Parsing and Indexing based on Audio-Visual Interaction. 11(4):522-535.

Tseng, B. L., Lin, C. Y., e Smith, J. R. (2004). Using MPEG-7 and MPEG-21 for Personalizing Video. IEEE Transactions on Multimedia, 11(1):42-52.

Tso-Sutter, K. H. L., Marinho, L. B., e Schmidt-Thieme, L. (2008). Tag-aware Recommender Systems by Fusion of Collaborative Filtering Algorithms. In Proceedings of the 2008 ACM Symposium on Applied Computing, pp. 1995-1999, Fortaleza, CE, Brazil.

Ueda, H., Tsukamoto, M., e Nishio, S. (2000). W-MAIL: An Electronic Mail System for Wearable Computing Environments. In Proceedings of the 6th Annual Conference on Mobile Computing and Networking, pp. 284-291.

Ursu, M. F., Cook, J. J., Zsombori, V., Zimmer, R., Kegel, I., Williams, D., Thomas, M., Wyver, J., e Mayer, H. (2007). Conceiving ShapeShifting TV: A Computational Language for Truly-Interactive TV. In Proceedings of the 5th. European Conference on Interactive TV, pp. 96-106, Amsterdam, The Netherlands. Springer-Verlag.

Vasconselos, N. (2003). The Design of End-to-end Optimal Image Retrieval Systems. In Proceedings of the International Conference on ANN, pp. 1-4, Istanbul, Turkey.

Vasconselos, N. (2004). On the Efficient Evaluation of Probabilistic Similarity Functions for Image Retrieval. IEEE Transactions on Information Theory, 50(7):1482-1496.

Vendrig, J. e Worring, M. (2002). Systematic Evaluation of Logical Story Unit Segmentation. IEEE Transactions on Multimedia, 4(4):492-499.

Vetro, A., Christopoulos, C., e Sun, H. (2003). Video Transcoding Architectures and Techniques. IEEE Signal Processing Magazine, 20(2):18-29.

Vetro, A., Haga, T., Sumi, K., e Sun, H. (2003). Object-based Coding for Long-Term Archive of Surveillance Video. In Proceedings of the IEEE Iternational Conference on Multimedia \& Expo, pp. 417-420, Baltimore, MD, USA.

Wang, H. L., Huang, J., Liu, Z., Wang, Y., Chen, Y., e Wong, E. K. (1999). Integration Of Multimodal Features For Video Scene Classification Based On HMM. In Proceedings of the IEEE Workshop on Multimedia Signal Processing, pp. 53-58, Copenhagen, Denmark. 
Wang, S. (2001). A Robust CBIR Approach Using Local Color Histograms. Technical Report TR 01-13, University of Alberta.

Wang, Y., Aroyo, L. M., Stash, N., e Rutledge, L. (2007). Interactive User Modeling for Personalized Access to Museum Collections: The Rijksmuseum Case Study. In Proceedings of the 11th International Conference on User Modeling, pp. 385-389, Corfu, Greece. Springer-Verlag.

Weiser, M. (1991). The Computer of the 21st Century. Scientific American, 265(3):94-104.

Weiß, D., Scheuerer, J., Wenleder, M., Erk, A., Gülbahar, M., e Linnhoff-Popien, C. (2008). A User Profile-based Personalization System for Digital Multimedia Content. In Proceedings of the 3rd International Conference on Digital Interactive Media in Entertainment and Arts, pp. 281-288, Athens, Greece. ACM Press.

White, R. W., Jose, J. M., e Ruthven, I. (2001). Comparing Explicit and Implicit Feedback Techniques for Web Retrieval: TREC-10 Interactive Track Report. In Proceedings of the Tenth Text Retrieval Conference, pp. 1-5.

Wold, E., Blum, T., Keislar, D., e Wheaton, J. (1996). Content-Based Classification, Search, and Retrieval of Audio. IEEE Multimedia, 3(3):27-36.

Wu, X., Zhang, L., e Yu, Y. (2006). Exploring Social Annotations for the Semantic Web. In Proceedings of the 15th International Conference on World Wide Web, pp. 417-426, Edinburgh, Scotland. ACM Press.

Xiao, J., Zhuang, Y., Yang, T., e Wu, F. (2006). An Efficient Keyframe Extraction from Motion Capture Data. In Nishita, T., Peng, Q., e Seidel, H.-P., editores, Advances in Computer Graphics, v. 4035 of Lecture Notes in Computer Science, pp. 494-501.

Xin, J., Lin, C. W., e Sun, M. T. (2005). Digital Video Transcoding. Proceedings of the IEEE, 93(1):84-97.

Xiong, Z. (2006). Audio-Visual Sports Highlights Extraction using Coupled Hidden Markov Models. Pattern Analysis \& Applications, 8(1-2):62-71.

Xiong, Z., Zhou, X. S., Tian, Q., Rui, Y., e Huangm, T. S. (2006). Semantic Retrieval of Video - Review of Research on Video Retrieval in Meetings, Movies and Broadcast News, and Sports. IEEE Signal Processing Magazine, 23(2):18-27.

Xu, P., Xie, L., e fu Chang, S. (2001). Algorithms And System For Segmentation And Structure Analysis In Soccer Video. In Proceedings of IEEE International Conference on Multimedia and Expo, pp. 928-931, Tokyo, Japan. 
Yan, L., Du, J., Huang, Q., e Jiang, S. (2007). Story Unit Segmentation with Friendly Acoustic Perception. In Proceedings of the 2007 international conference on Multimedia content analysis and mining, pp. 223-231, Weihai, China. Springer-Verlag.

Yang, M.-H., Kriegman, D. J., e Ahuja, N. (2002). Detecting Faces in Images: A Survey. IEEE Transactions on Pattern Analysis and Machine Intelligence, 24(1):34-58.

Yeung, C. M. A., Gibbins, N., e Shadbolt, N. (2007). Understanding the Semantics of Ambiguous Tags in Folksonomies. In The International Workshop on Emergent Semantics and Ontology Evolution, pp. 108-121, Busan, South Korea.

Yokoyama, T., Iwasaki, T., e Watanabe, T. (2009). Motion Vector Based Moving Object Detection and Tracking in the MPEG Compressed Domain. In Proceedings of the 2009 Seventh International Workshop on Content-Based Multimedia Indexing, pp. 201-206, Washington, DC, USA. IEEE Computer Society.

Yu, F., Chang, E., Xu, Y., e Shum, H.-Y. (2001). Emotion Detection from Speech to Enrich Multimedia Content. In Proceedings of the Second IEEE Pacific Rim Conference on Multimedia, pp. 550-557, London, UK. Springer-Verlag.

Yu, K., Schwaighofer, A., Tresp, V., Xu, X., e Kriegel, H.-P. (2004). Probabilistic Memory-Based Collaborative Filtering. Transactions on Knowledge and Data Engineering, 16(1):56-69.

Zanardi, V. e Capra, L. (2008). Social Ranking: Uncovering Relevant Content Using Tag-based Recommender Systems. In Proceedings of the 2008 ACM Conference on Recommender Systems, pp. 51-58, Lausanne, Switzerland.

Zeng, W., Du, J., Gao, W., e Huang, Q. (2005). Robust Moving Object Segmentation on H.264/AVC Compressed Video using the Block-based MRF Model. Real-Time Imaging, 11(4):290-299.

Zhang, B., Chen, W., Dou, W., Zhang, Y., e Chen, L. (2007). Content-based Table Tennis Games Highlight Detection Utilizing Audiovisual Clues. In Proceedings of the 4th. International Conference on Image and Graphics, pp. 833-838, Chengdu, Sichuan, China.

Zhang, D. e Lu, G. (2003). Evaluation of Similarity Measurement for Image Retrieval. In Proceedings of the 2003 International Conference on Neural Networks and Signal Processing, v. 2, pp. 928-931.

Zhang, K., Koung, J., Qiu, M., e Song, G. L. (2005). Multimedia Layout Adaptation through Grammatical Specifications. Multimedia Systems, 10(3):245-260. 
Zhang, T. e Kuo, C.-C. J. (1999). Hierarchical Classification of Audio Data for Archiving and Retrieving. In Proceedings of the Acoustics, Speech, and Signal Processing, 1999. on 1999 IEEE International Conference, pp. 3001-3004, Washington, DC, USA. IEEE Computer Society.

Zhang, Y., Callan, J., e Minka, T. (2002). Novelty and Redundancy Detection in Adaptive Filtering. In Proceedings of the 25th Annual International ACM SIGIR Conference on Research and Development in Information Retrieval, pp. 81-88, Tampere, Finland. ACM Press.

Zhang, Y.-F., Xu, C., Lu, H., e Huang, Y.-M. (2009). Character Identification in Feature-Length Films using Global Face-Name Matching. IEEE Transactions on Multimedia, 11(7):1276-1288.

Zhong, D. e Chang, S.-F. (2001). Structure Analysis of Sports Video Using Domain Models. In IEEE International Conference on Multimedia \& Expo, pp. 920-923, Tokyo, Japan.

Zhou, W., Vellaikal, A., e Kuo, C. C. J. (2000). Rule-based Video Classification System for Basketball Video iIndexing. In Proceedings of the 2000 ACM workshops on Multimedia, pp. 213-216, Los Angeles, California, USA. ACM Press.

Zhu, H., Zhong, J., Li, J., e Yu, Y. (2002). An Approach for Semantic Search by Matching RDF Graphs. In Proceedings of the Fifteenth International Florida Artificial Intelligence Research Society Conference, pp. 450-454, Pensacola Beach, Florida, USA. AAAI Press.

Zhuang, Y., Liu, X., e Pan, Y. (1999). Apply Semantic Template to Support Content-based Image Retrieval. In Yeung, M. M., Yeo, B.-L., e Bouman, C. A., editores, Storage and Retrieval for Media Databases, v. 3972 of SPIE, pp. 442-449. 


\section{Apêndice A: Publicações}

A seguir é apresentada a lista de publicações originadas a partir deste trabalho:

\section{Artigos completos em periódicos internacionais:}

1. Manzato, M. G., Coimbra, D. B., e Goularte, R. (2011). An Enhanced Content Selection Mechanism for Personalization of Video News Programmes. Multimedia Systems Journal, 17(1):19-34.

Abstract. In this paper, we propose a content selection framework that improves the users' experience when they are enriching or authoring pieces of news. This framework combines a variety of techniques to retrieve semantically related videos, based on a set of criteria which are specified automatically depending on the media's constraints. The combination of different content selection mechanisms can improve the quality of the retrieved scenes, because each technique's limitations are minimized by other techniques' strengths. We present an evaluation based on a number of experiments, which show that the retrieved results are better when all criteria are used at time.

2. Manzato, M. G., e Goularte, R. (2010). Peersommender: A Peer-Level Annotation-Based Approach for Multimedia Recommendation. Journal of Information and Data Management, 1(2):277-292.

Abstract. In this article, we propose the Peersommender architecture, which is the set of applications that provide personalized content to users according to their annotations produced when watching multimedia items. As opposite to hierarchical authoring, which is metadata created by experts to describe content in an organized, structured and impartial manner, peer-level annotations are highly personal because they are created by consumers, and this feature can be used to infer relevant content that is of interest to the user. Particularly, we 
propose a movie recommender system that explores a user profile with automatic augmentation, which is based on annotations produced by the user in the past. By combining tags, faces of interest and ratings with usual hierarchical metadata, we are able to predict ratings for new movies based on an enhanced hybrid approach for content filtering. Our evaluation was executed over a large scale dataset containing real users, and it shows good results when compared to other techniques.

3. Manzato, M. G., Macedo, A. A., e Goularte, R. (2009). Evaluation of Video News Classification Techniques for Automatic Content Personalization. International Journal of Advanced Media and Communication, 3(4):383-403.

Abstract. With the development of content-based multimedia services, the personalization task has become increasingly important. There is a need for semantic information knowledge, extracted from multimedia streams, in order to achieve the benefits of automatic matching user preferences with multimedia content meaning. Text-based classification techniques may be used in closed-captions captured from news programs, which can define the subject of each piece of news. Latent Semantic Indexing (LSI)-based systems are widely used for information retrieval purposes, and may be adapted to classification tasks; however, some drawbacks of the technique may impose limitations, mainly when considering multiple collections. In this paper, we compare an LSI implementation with a Genetic Algorithm (GA)-based system which was designed with the same objective. The classification is made based on high level semantic information extracted from the news video streams. We show that the GA alternative achieves better results when used to automatically classify pieces of news video programs.

\section{Artigos completos em conferências internacionais:}

4. Manzato, M. G., Coimbra, D. B., e Goularte, R. (2009). Multimedia Content Personalization Based on Peer-Level Annotation. In Proceedings of the 7th. European Conference on Interactive TV, pp. 57-66, Leuven, Belgium. ACM Press. Abstract. In this paper, we propose an architecture which supports metadata extraction by exploring interaction mechanisms among users and content. The interaction activity addressed in this work is related to peer-level annotation, where any user acts as author, being able to enrich the content by making annotations, using, for instance, pen-based devices. Peer-level annotation makes users comfortable when taking digital notes, as they do in every day life. This is an advantage over hierarchical authoring, which is a time-consuming task usually employed by content providers. The set of metadata extracted 
by peer-level annotation is used in this paper to generate a user's profile, which contains preferences about the content, and may be further explored by personalization services.

\section{Artigos completos em conferências nacionais:}

5. Manzato, M. G., e Goularte, R. (2009). Supporting Multimedia Recommender Systems with Peer-Level Annotations. In Proceedings of the 15th. Brazilian Symposium on Multimedia and the Web, pp. 202-209, Fortaleza-CE, Brazil. ACM Press.

Abstract. Peer-level annotation stands for the enrichment of content by any user, who acts as author, being able to make annotations, using, for instance, handwriting or speech recognition capabilities. This type of annotation makes users comfortable when taking digital notes, as they do in every day life. This is an advantage over hierarchical authoring, which is a time-consuming task usually employed by content providers. This paper proposes a content-based recommender architecture which explores information that is available at the time users enhance content. This feature enables our architecture to reach a certain level of semantic information from the content and from user's preferences, which is essential for recommender systems applications.

6. Manzato, M. G., e Goularte, R. (2008). Video News Classification for Automatic Content Personalization: A Genetic Algorithm Based Approach. In Proceedings of the 14th. Brazilian Symposium on Multimedia and the Web, pp. 36-43, Vila Velha-ES, Brazil. ACM Press.

Abstract. With the development of content-based multimedia services, the personalization task has become increasingly important. There is a need for semantic information knowledge, extracted from multimedia streams, in order to achieve the benefits of automatic matching user preferences with multimedia content meaning. Text-based classification techniques may be used in closed-captions captured from news programs, which can define the subject of each piece of news. Latent Semantic Indexing (LSI)-based systems are widely used for classification tasks; however, some drawbacks of the technique may impose limitations, mainly when considering multiple collections. In this paper, we compare an LSI implementation with a Genetic Algorithm (GA)-based system which was designed with the same objective. The classification is made based on high level semantic information extracted from the news video streams. We show that the GA alternative achieves better results when used to automatically classify pieces of news video programs.

7. Manzato, M. G., e Goularte, R. (2007). Shot Boundary Detection Based 
on Intelligent Systems. In Proceedings of the 13rd. Brazilian Symposium on Multimedia and the Web, pp. 190-197, Gramado-RS, Brazil. ACM Press.

Abstract. With the development of content-based multimedia services, the temporal segmentation of video streams has become crucial once it is not addressed by the codec standards. Although lots of works have explored the field, the utilization of intelligent systems for its purpose has not been fully explored yet. In this paper we preset two techniques based on genetic algorithms and artificial neural networks to temporally segment video streams. By comparing the techniques, we show that both schemes have advantages and drawbacks which must be considered when designing content-based application scenarios.

\section{Artigos resumidos em conferências nacionais:}

8. Nascimento, G., Manzato, M. G., e Goularte, R. (2010). Extração de Quadros-Chave Como Subsídio Para Personalização em Vídeos Digitais. In Proceedings of the 16th. Brazilian Symposium on Multimedia and the Web, pp. 105-107, Belo Horizonte-MG, Brazil. SBC.

Resumo. Este trabalho apresenta uma análise de técnicas de extração de quadros-chave em vídeos digitais no contexto de adaptação e personalização de conteúdo, com o propósito de facilitar a obtenção de informações semânticas de vídeos mediante detecção de faces. Isso implica em minimizar o custo computacional necessário, sem comprometer a eficiência da obtenção dessas informações através da detecção facial.

9. Manzato, M. G., Junqueira, D. C., e Goularte, R. (2008). Interactive News Documents for Digital Television. In Proceedings of the 14th. Brazilian Symposium on Multimedia and the Web, pp. 1-4, Vila Velha-ES, Brazil. ACM Press.

Abstract. As different technologies emerge each day in the context of digital television, interaction functionalities are becoming crucial once users are already familiarized with the interaction on the web. Although digital television standards provide ways to interact with the content, more complex manipulations can be accomplished using the MPEG-J specification, which is part of the MPEG-4 standard. In this paper, we present a technique that aims at the generation of dynamic and interactive content from interactive sources like the web, enabling users, despite their limited interactivity with the content of TV, have access to fresh dynamic content that is generated in real time during the video's compilation. Although we have not explored the full potential of MPEG-J, we think that this work is the first step for more contributions in the area of digital and interactive television. 


\section{Relatórios técnicos:}

10. Manzato, M. G., Fortes, R. P. M., e Goularte, R. (2007). Técnicas e Métodos para Segmentação de Vídeo: Um Estudo Sistemático. In Relatórios Técnicos do ICMC-USP, 293, ICMC-USP, São Carlos-SP, Brasil. 57 páginas.

Resumo. Com o desenvolvimento do vídeo digital e a popularidade da WWW, a demanda por interatividade em sistemas com transmissão de televisão e videoconferência têm aumentado. Tal demanda frequentemente aparece como funcionalidades adicionais para os usuários, entre elas serviços avançados com interatividade baseada em conteúdo multimídia, personalização de conteúdo, busca e recuperação de informações audiovisuais e navegação. Uma vez que esses serviços estão centrados no conteúdo multimídia, torna-se necessário que o sistema esteja ciente da estrutura e composição do conteúdo que está sendo utilizado. Padrões como o MPEG-4 oferecem meios de se codificar, transmitir e armazenar dados visuais baseados em objetos de vídeo; porém não especifica meios de como segmentar o conteúdo em tais objetos. Este relatório técnico tem como objetivo fornecer subsídios para realização de uma revisão sistemática sobre segmentação de vídeo. A partir deste trabalho, a fase de extração das informações dos estudos selecionados poderá ser realizada, o que será facilitada pelo conhecimento a priori sobre o tema, o qual se encontra relatado neste relatório por meio de uma descrição das principais técnicas existentes. 


\section{Glossário}

Adaptação - Procedimento que procura decidir a versão de conteúdo ideal para apresentação, e a melhor estratégia para gerar essa versão.

AG - Algoritmo Genético. Técnica de busca utilizada para encontrar soluções aproximadas em problemas de otimização e busca. É uma classe particular de algoritmos evolutivos que usa técnicas inspiradas pela biologia evolutiva como hereditariedade, mutação, seleção natural e recombinação.

Anotação - Neste trabalho, a anotação pode se referir ao processo de criação de metadados relacionados ao conteúdo, como também à atividade de enriquecimento de apresentações pelo usuário.

Árvore de Decisão - Trata-se de uma maneira alternativa de se expressar regras, as quais são representadas sob a forma de uma árvore.

Bloco - Estrutura utilizada em compressão de imagens e vídeo. É formada por um conjunto de oito linhas, onde cada linha contém oito pixels, totalizando 64 pixels.

Blog - Serviço Web que permite a atualização rápida a partir de acréscimos de artigos criados por um número variável de pessoas, de acordo com a política do blog.

Classificador Bayesiano - Classe de algoritmos classificatórios que tem como objetivo calcular a probabilidade de uma amostra desconhecida pertencer a cada uma das classes possiveis, ou seja, predizer a classe mais provável. 
Closed-Caption - Sistema de transmissão de legendas que tem como objetivo permitir que os deficientes auditivos possam acompanhar os programas transmitidos. Descreve além das falas dos atores ou apresentadores qualquer outro som presente na cena, como palmas, passos, trovões, música, risos, etc.

Clusterização por Lógica Difusa - É uma extensão da lógica booleana que admite valores lógicos intermediários, como "talvez". Isso significa que um valor lógico difuso é um valor qualquer no intervalo de valores entre 0 e 1 .

Codificação - Em processamento digital de sinais, codificação significa a modificação de características de um sinal para torná-lo mais apropriado para uma aplicação específica, como por exemplo, transmissão ou armazenamento de dados.

Decodificação - Decodificação é o processo contrário da codificação, ou seja, as características modificadas de um sinal são transformadas em seu formato original.

Detecção de Bordas - Técnica de processamento de imagem e visão computacional para determinar pontos de uma imagem digital em que a intensidade luminosa muda repentinamente.

Dicromacia - Caracterizada pela falta completa de um dos pigmentos dos cones do olho humano. Consequentemente, as cores do espectro visível são percebidas a partir de duas cores monocromáticas.

Dominio de Aplicação - Refere-se ao tipo de aplicação que será considerado para provimento dos serviços de personalização. Exemplos são: turismo, vendas, telemedicina, guias de programação, entre outros.

Domínio de Dados/Conteúdo - Refere-se ao gênero ou subgênero do conteúdo. Exemplos são: telejornais, filmes, comerciais, reportagens, documentários, desenhos, entre outros.

Enriquecimento - Atividade realizada pelo usuário que consiste em customizar uma apresentação multimídia adicionando diferentes artefatos, como anotações em caneta/tinta eletrônica, comentários por texto e/ou voz, mídias relacionadas semanticamente, etc. 
Espectrograma - Nome dado à decomposição da luz, em suas cores constituintes, através de um sistema ótico, sendo possivel analisar a luz emitida por uma determinada fonte.

Etiqueta - Termo associado com uma informação que a descreve e permite uma classificação baseada em palavras-chave.

Folksonomia - São taxonomias criadas colaborativamente pelos usuários de um sistema.

GPS - Sistema de Posicionamento Global (do Inglês, Global Positioning System). É um sistema de informação eletrônico que fornece a um aparelho receptor móvel via rádio a posição do mesmo com referência às coordenadas geográficas terrestres.

Histograma - Representação gráfica da distribuição de frequências de uma massa de medições, normalmente um gráfico de barras verticais.

HMM - Modelo Escondido de Markov (do Inglês, Hidden Markov Model). Modelo estatístico em que o sistema modelado é assumido como um processo de Markov com parâmetros desconhecidos, e o desafio é determinar os parâmetros ocultos a partir dos parâmetros observáveis. Os parâmetros extraídos do modelo podem então ser usados para realizar novas análises, por exemplo para aplicações de reconhecimento de padrões.

Inteligência Coletiva - Agrupamento e organização dinâmica de usuários, de maneira automática, fazendo reuso de conteúdo, atualizações fracionárias, e contribuições para trabalhos coletivos. Como resultado, os serviços tornam-se mais valiosos e poderosos à medida que mais usuários participam ativamente das atividades.

Lacuna Semântica - A falta de coincidência entre as informações que se pode extrair do fluxo audiovisual e a interpretação que os mesmos dados geram para um determinado usuário em dada situação.

Largura de Banda - Intervalo do espectro de frequências disponível ou necessário para transmitir dados (imagens, áudio, pacotes digitais) sobre um meio, tal como cabo ou ar, ou sobre um dispositivo elétrico. Guanto maior é a largura de banda disponivel, maior é a quantidade de dados que pode ser transmitida por segundo. 
LPC - Coeficiente de Predição Linear (do Inglês, Linear Prediction Coefficient). Predição linear é uma operação matemática onde os valores futuros de um sinal discreto temporalmente são estimados como a função linear de amostras precedentes.

LSI - Indexação Semântica Latente (do Inglês, Latent Semantic Indexing). É um método de indexação e busca que usa a SVD para identificar padrões nos relacionamentos entre os termos e conceitos contidos em uma coleção não-estruturada textual.

MAP - Maximum-a-Posteriori. É utilizado para se obter uma estimativa de pontos de uma amostra não observada na base de dados empíricos. Emprega uma otimização objetiva que incorpora uma pré-distribuição dos dados a serem estimados.

MLE - Estimativa de Máxima Verossimilhança (do Inglês, Maximum-Likelihood Estimation). Método usado para se definir um modelo estatístico para os dados considerados.

Metadado - Informações que descrevem um conteúdo, podendo criar uma indexação para uso em procedimentos de recuperação de informações.

MFCC - Coeficiente Cepstral nas Frequências de Mel (do Inglês, Mel-Frequency Cepstral Coefficient). É uma respresentação em curto-prazo do espectro de um som, baseada em uma transformação linear do cosseno do espectro em longo-prazo da escala de Mel não-linear.

Multimídia - É a utilização simultânea de vários tipos de mídia (texto, sons, imagens, gráficos, vídeos e animações).

NCL - Linguagem de Contexto Aninhado (do Inglês, Nested Context Language). Linguagem declarativa adotada pelo Sistema Brasileiro de TV Digital para sincronização de mídias e estruturação de programas interativos.

OCR - Reconhecimento Ótico de Símbolos (do Inglês, Optical Character Recognition). Tecnologia criada para reconhecer caracteres a partir de um arquivo de imagem.

Ontologia - Uma especificação formal de como representar objetos, conceitos e entidades em alguma área de interesse e os relacionamentos entre eles. 
P2P - Ponto-a-ponto (do Inglês, Peer-to-Peer). Arquitetura de sistemas distribuídos caracterizada pela decentralização das funções na rede, onde cada nó realiza tanto funções de servidor quanto de cliente.

Perfil - O perfil é constituído por todas as informações que estão disponíveis sobre um usuário, podendo ser usadas para personalizar informações ou serviços.

Personalização - É o processo no qual um sistema se adapta a fim de satisfazer os requisitos de determinado usuário.

Personomia - É uma folksonomia que contém termos criados apenas por um usuário.

Polissemia - Ocorre quando um termo apresenta múltiplos significados.

Provedor de Conteúdo - É uma entidade que age como o agente para o conteúdo. Por exemplo, uma editora poder ser considerada um provedor do conteúdo.

Quadro-chave - Também conhecido como intraquadro no contexto de compressão de vídeo, um quadro-chave contém informações completas sobre a imagem para posterior decodificação. Consequentemente, ele não depende de outros quadros como referência para reconstrução, e geralmente, apresenta melhor qualidade na imagem decodificada.

Redes Neurais Artificiais - Técnicas computacionais que apresentam um modelo matemático inspirado na estrutura neural de organismos inteligentes e que adquirem conhecimento através da experiência.

Relação Sintagmática - Conceito que define relações semânticas entre palavras se elas ocorrem na mesma região do texto.

Resolução Espacial - Define o tamanho de um quadro de um vídeo, normalmente expressa em pixels.

Resolução Temporal - Define a taxa de quadros de um vídeo, normalmente expressa em quadros/s. 
Segmentação - É o processo de identificar porções distintas de um documento, tais como cabeçalho, seções, parágrafos e figuras. Em multimídia, porções podem ser sequências, cenas e quadros, por exemplo.

Sinonimia - Ocorre quando palavras diferentes apresentem significados iguais.

SMIL - Linguagem de Integração Multimídia Sincronizada (do Inglês, Synchronized Multimedia Integration Language). Linguagem de marcação recomendada pela W3C para descrição de programas multimídia.

SNR - Razão Sinal-Ruído (do Inglês, Signal-to-Noise Ratio). Utilizada para medir o quanto de "ruído" (imagem granulada) uma imagem de vídeo contém, normalmente expressa em decibéis (dB). Essa medição é calculada por meio do valor da voltagem máxima atingida pelo sinal dividido pelo valor residual da voltagem que permanece quando o sinal é removido - ou seja, a quantidade de ruído no mesmo.

Stopwords - São termos que não carregam informações importantes sobre o conteúdo. Geralmente são formadas por preposições, artigos, advérbios e pronomes.

SubRip - Formato aberto para definição e representação de legendas em vídeo digital.

SVD - Decomposição de Valor Singular (do Inglês, Singular Value Decomposition). Processo matemático de fatorização de matrizes, podendo ser usado em processamento de sinais e estatística.

SVM - Máquina de Vetor de Suporte (do Inglês, Support Vector Machine). É definido como um conjunto de métodos de aprendizagem supervisionados usados para classificação e regressão. Uma propriedade especial de SVMs é que eles simultaneamente minimizam o erro de classificação empírica e maximizam a margem geométrica.

Taxonomia - Esquema classificatório e hierárquico usado para categorizar objetos.

TDM - Matriz Termo-Documento (do Inglês, Term-Document Matrix). Matriz que contém as frequências de todos os termos de uma coleção de acordo com cada documento. 
Tomada - Nas modalidades visual e auditiva, representa uma gravação contínua ou não-interrupta de uma câmera ou microfone. Na modalidade textual, representa uma expressão textual contínua ou não-interrupta que pode estar em um nível de palavras ou sentenças.

Triangulação de Delaunay - Triangulação cuja principal característica é maximizar o ângulo mínimo de todos os ângulos dos triângulos do esquema.

Tricomacia Anômala - Também conhecida como Daltonismo, caracteriza-se pela modificação de uma das três classes de pigmentos dos cones do olho humano, resultando em distorções nas cores originais.

URI - Identificador de Recurso Uniforme (do Inglês, Uniform Resource Identifier). Cadeia de caracteres compacta usada para identificar ou denominar um recurso na Internet.

URL - Localizador Padrão de Recursos (do Inglês, Uniform Resource Locator). Define o endereço global de documentos e outros recursos na Internet. A primeira parte do endereço indica qual protocolo utilizar, a segunda parte especifica o endereço IP ou o domínio onde o recurso está localizado.

Vetor de Movimento - Termo utilizado em compressão de vídeo. Indica a translação espacial de um bloco para outro em quadros distintos, sendo que essa translação é especificada pela aplicação da técnica estimativa de movimento.

XML - Linguagem de Marcação Extensiva (do Inglês, Extensible Markup Language). É uma especificação desenvolvida pela W3C utilizada em documentos da Web. Permite que projetistas criem suas próprias etiquetas, disponibilizando a definição, transmissão, validação e interpretação de dados entre aplicações e organizações. 
